\title{
Small fiber neuropathy
}

Citation for published version (APA):

de Greef, B. T. A. (2019). Small fiber neuropathy: from underlying conditions to treatment. [Doctoral Thesis, Maastricht University]. ProefschriftMaken Maastricht. https://doi.org/10.26481/dis.20190315bg

Document status and date:

Published: 01/01/2019

DOI:

$10.26481 /$ dis.20190315bg

Document Version:

Publisher's PDF, also known as Version of record

\section{Please check the document version of this publication:}

- A submitted manuscript is the version of the article upon submission and before peer-review. There can be important differences between the submitted version and the official published version of record.

People interested in the research are advised to contact the author for the final version of the publication, or visit the DOI to the publisher's website.

- The final author version and the galley proof are versions of the publication after peer review.

- The final published version features the final layout of the paper including the volume, issue and page numbers.

Link to publication

\footnotetext{
General rights rights.

- You may freely distribute the URL identifying the publication in the public portal. please follow below link for the End User Agreement:

www.umlib.nl/taverne-license

Take down policy

If you believe that this document breaches copyright please contact us at:

repository@maastrichtuniversity.nl

providing details and we will investigate your claim.
}

Copyright and moral rights for the publications made accessible in the public portal are retained by the authors and/or other copyright owners and it is a condition of accessing publications that users recognise and abide by the legal requirements associated with these

- Users may download and print one copy of any publication from the public portal for the purpose of private study or research.

- You may not further distribute the material or use it for any profit-making activity or commercial gain

If the publication is distributed under the terms of Article $25 \mathrm{fa}$ of the Dutch Copyright Act, indicated by the "Taverne" license above, 



\section{Small fiber neuropathy: from underlying conditions to treatment}

Bianca T.A. de Greef 
(C) B.T.A. de Greef, Maastricht 2019

Lay-out: Nicky Bertens

Cover design: Jessy van Tiel - van der Velden

Picture on cover: Moovel Lab

Production: ProefschriftMaken || proefschriftmaken.nl

ISBN: 9789463802123

The research described in this thesis was performed at the Department of Neurology, Maastricht University Medical Center+ (Maastricht UMC+), and within the School of Mental Health and Neuroscience (MHeNs) and was funded by the Prinses Beatrix Spierfonds.

The printing of this thesis was financially supported by Lamepro, Pfizer, Grünenthal, and Maastricht University. 


\title{
Small fiber neuropathy: from underlying conditions to treatment
}

\begin{abstract}
PROEFSCHRIFT
ter verkrijging van de graad van doctor aan de Universiteit Maastricht, op gezag van de Rector Magnificus, Prof. dr. Rianne M. Letschert, volgens het besluit van het College van Decanen,

in het openbaar te verdedigen op vrijdag 15 maart 2019 om 14.00u.
\end{abstract}

door

Bianca Theodora Andrea de Greef 
Promotor:

Prof. dr. C.G. Faber

\section{Copromotoren:}

Dr. I.S.J. Merkies

Dr. J.G.J. Hoeijmakers

\section{Beoordelingscommissie:}

Prof. dr. C.D. Dirksen, voorzitter

Dr. M. Bakkers (Sint Jans Gasthuis, Weert)

Prof. dr. W.H. Mess

Dr. C. Verhamme (Academisch Medisch Centrum, Amsterdam)

Prof. dr. R.J. Vermeulen 
Aan Kiki Frencken en Giuseppe Melpignano

Noi non potemo avere perfetta vita senza amici (Dante). Non vi dimenticherò mai e sarete sempre nel mio cuore. 



\section{Table of contents}

$\begin{array}{ll}\text { Abbreviations } & 9\end{array}$

Part I Introduction

Chapter 1.1 General introduction $\quad 15$

Chapter 1.2 Outline of this thesis 29

Part II Associated conditions in small fiber neuropathy

Chapter 2 No Fabry disease in patients presenting with isolated small fiber neuropathy 35

Chapter 3 Associated conditions in small fiber neuropathy-a large cohort study $\quad 47$ and review of the literature

Part III Treatment of neuropathic pain in small fiber neuropathy

Chapter 4 Neuropathic pain due to small fiber neuropathy in aging:

current management and future prospects

Chapter 5 Efficacy, safety, and tolerability of lacosamide in patients with gain-of-function $\mathrm{Na}_{v} 1.7$ mutation-related small fiber neuropathy: study protocol of a randomized controlled trial - the LENSS study

Chapter 6 Lacosamide in patients with $\mathrm{Na}_{\mathrm{v}} 1.7$ mutations-related small fiber neuropathy: a randomized controlled trial

Chapter 7 Intravenous immunoglobulin therapy for small fiber neuropathy: study protocol for a randomized controlled trial

Part IV Summary

Chapter 8 Summary, general discussion, and future perspectives 143

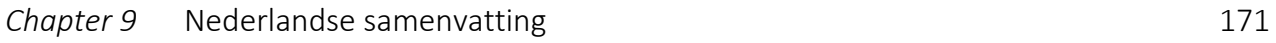

Chapter 10 Valorization addendum 181

$\begin{array}{ll}\text { Dankwoord } & 187\end{array}$

$\begin{array}{ll}\text { Curriculum vitae } & 197\end{array}$

List of publications 201 



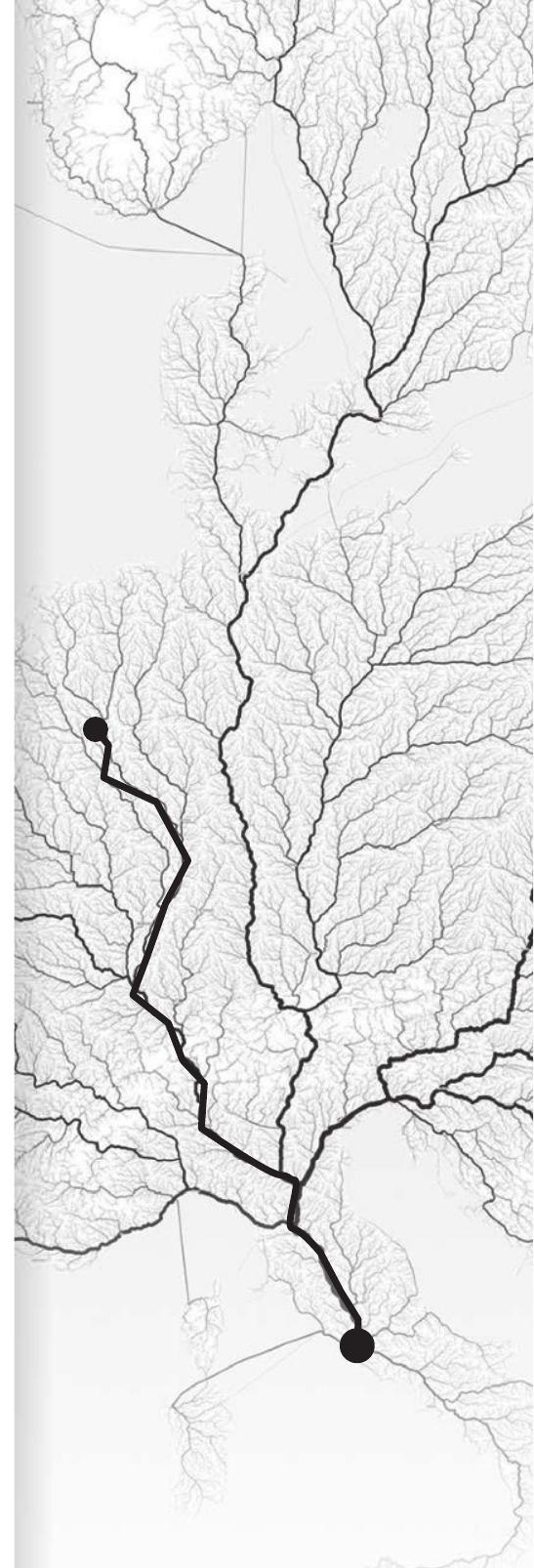





\begin{tabular}{|c|c|}
\hline$\alpha-G a l A$ & Alpha-Galactosidase A \\
\hline$A E$ & Adverse event \\
\hline ALN & Alcohol-related peripheral neuropathy \\
\hline BID & Bis in die (two times a day) \\
\hline CCM & Corneal confocal microscopy \\
\hline $\mathrm{CIP}$ & Congenital insensitivity to pain \\
\hline CIPN & Chemotherapy-induced peripheral neuropathy \\
\hline DM & Diabetes Mellitus \\
\hline DSIS & Daily sleep interference scale \\
\hline DRG & Dorsal root ganglion \\
\hline ECG & Electrocardiogram \\
\hline FD & Fabry disease \\
\hline HIV & Human immunodeficiency virus \\
\hline IEM & Inherited erythromelalgia \\
\hline IENFD & Intraepidermal nerve fiber density \\
\hline I-SFN & Idiopathic small fiber neuropathy \\
\hline IVIg & Intravenous immunoglobulin \\
\hline LENSS-study & Lacosamide-Efficacy-'N'-Safety in SFN \\
\hline Lyso-GB3 & Globotriaosylceramide \\
\hline $\mathrm{MCID}$ & Minimum clinically important difference \\
\hline MGUS & Monoclonal gammopathy of undetermined significance \\
\hline $\mathrm{Na}_{v} 1.3$ & Voltage-gated sodium channel 1.3 \\
\hline $\mathrm{Na}_{v} 1.7$ & Voltage-gated sodium channel 1.7 \\
\hline $\mathrm{Na}_{\vee} 1.8$ & Voltage-gated sodium channel 1.8 \\
\hline Nav1.9 & Voltage-gated sodium channel 1.9 \\
\hline NCS & Nerve conduction studies \\
\hline NNT & Number needed to treat \\
\hline NPS & Neuropathic pain scale \\
\hline PEPD & Paroxysmal extreme pain disorder \\
\hline PGIC & Patients' Global Impression of Change \\
\hline PI-NRS & Pain intensity numerical rating scale \\
\hline QST & Quantitative sensory testing \\
\hline SAE & Serious adverse event \\
\hline SCN9A & Sodium channel, voltage-gated, type IX, alpha subunit \\
\hline SCN10A & Sodium channel, voltage-gated, type $X$, alpha subunit \\
\hline SCN11A & Sodium channel, voltage-gated, type $\mathrm{XI}$, alpha subunit \\
\hline SF-36 & Generic short-form SF-36 health survey \\
\hline SFN & Small fiber neuropathy \\
\hline SFN-SIQ & SFN Symptom Inventory Questionnaire \\
\hline SNRI & Serotonin-Noradrenalin reuptake inhibitors \\
\hline TCA & Tricylic antidepressants \\
\hline VAS & Visual Analogue Pain Scale \\
\hline VGSC & Voltage-gated sodium channel \\
\hline
\end{tabular}








\section{Small fiber neuropathy}

\section{Anatomy}

Small fiber neuropathy (SFN) is a condition in which the small peripheral nerve fibers are affected. The peripheral nervous system includes the somatic and autonomic nervous system, which both consist of myelinated and unmyelinated nerve fibers with a variation in diameter, each having their own function. In SFN the thinly myelinated $\mathrm{A} \delta$ - and unmyelinated C-fibers are damaged. These fibers serve as noci- and thermoceptors in the skin. After activation, signals are conducted via the dorsal root ganglion (DRG) neurons to the central nervous system. ${ }^{1}$ In the autonomic nervous system the $\mathrm{A} \delta$-fibers have a preganglionic, and the $\mathrm{C}$-fibers a postganglionic sympathetic and parasympathetic function. ${ }^{2,3}$

In peripheral nerves, voltage-gated sodium channels (VGSC) are essential for the generation and conduction of action potentials. VGSCs Nav1.7, $\mathrm{Na}_{v} 1.8$, and $\mathrm{Na}_{v} 1.9$, respectively encoded by SCN9A, SCN10A, and SCN11A, are preferentially expressed in the small diameter DRGs and axons. Besides, $\mathrm{Na}_{v} 1.7$ is also present in sympathetic ganglion neurons (SGN), and along with $\mathrm{Na}_{\vee} 1.9$ in trigeminal ganglion neurons. ${ }^{4}$

\section{Large nerve fiber-versus small fiber neuropathy}

In general, polyneuropathy is considered as a condition of axonal degeneration of the large diameter peripheral nerves, with diabetic neuropathy being most prevalent. However, demyelinating neuropathies, such as the immune-mediated Guillain-Barré syndrome and various types of the hereditary Charcot-Marie Tooth neuropathy, are also forms of polyneuropathy. All these conditions have in common that patients may have muscle weakness, sensory disturbances (e.g. diminished vibration sense) and reduced tendon reflexes at neurological examination. The diagnosis can be supported by abnormalities in nerve conduction studies (NCS). ${ }^{5}$ In some conditions, such as diabetic neuropathy, the clinical picture can show additional symptoms like spontaneous neuropathic pain and autonomic dysfunction, which cannot solely be explained by large nerve fiber damage. Four decades ago, the first pathological studies that investigated the role of other nerve fibers, showed additional myelinated and unmyelinated small nerve fiber degeneration of sural nerves and post mortem removed splanchnic nerves. ${ }^{6,7}$ However, isolated damage to small nerve fibers can also occur. This condition is called pure SFN.

\section{Pure small fiber neuropathy}

One of the main symptoms of pure SFN is excruciating neuropathic pain, which is most often described as burning, shooting and/or prickling. Other sensory symptoms include an altered pain sensation and thermal perception. Autonomic symptoms may also be present, like hot flashes, palpitations, orthostatic dizziness, dry eyes or mouth, accommodation problems, micturation and bowel disturbances, sexual dysfunction, and hyper- or hypohidrosis. ${ }^{8,9}$ The clinical picture is suspect for having SFN when a patient reports two or more of these SFNspecific symptoms, which can be assessed by using the validated SFN-Symptom Inventory Questionnaire (SFN-SIQ). ${ }^{10}$ Sensory symptoms usually start distally in the feet and hands because the nerve endings are the most vulnerable. ${ }^{8}$ This is called a length-dependent pattern. 
The complaints can expand to proximal over time. Also, a patchier or non-length dependent pattern of complaints is described in patients with SFN. ${ }^{11,12}$ In SFN, neurological examination does not generally show any abnormalities in motor and large sensory nerve fiber functions (muscle strength, vibration sensation). Hyperalgesia and/or allodynia, as well as reduced pinprick and temperature sensation can be found. ${ }^{13}$

\section{Diagnostics}

One of the most applied and studied methods to examine small nerve fiber function is temperature threshold testing (TTT). This is a non-invasive test that measures warm and cold sensation in hands and feet. The values obtained by the method of levels are compared to ageand gender specific normative values. ${ }^{14,}{ }^{15}$ Besides this qualitative test, small nerve fibers in the epidermis can be determined quantitatively in a skin biopsy, which is taken from the lower leg. In skin biopsy, the intra-epidermal nerve fiber density (IENFD) is determined as a measure of small nerve fiber degeneration. Worldwide normative values are available to evaluate the IENFD. ${ }^{16}$ Unfortunately, TTT has a low specificity and depends on the degree of collaboration of the patient. On the other hand, skin biopsy has a high specificity and a moderate sensitivity, and is an invasive time-consuming method. ${ }^{16,17}$ Therefore, in the absence of a golden standard, at the moment the diagnosis of pure SFN is based on typical symptoms in combination with an abnormal TTT and/or abnormal IENFD in skin biopsy, without signs of involvement of the large nerve fibers (neurological examination and NCS). ${ }^{8,18}$

\section{Epidemiology}

SFN is not a rare condition, with an incidence of at least 12 per 100,000 persons per year and a prevalence of at least 53 per 100,000 persons in the southern part of the Netherlands. ${ }^{19}$ This is probably an underestimation, because of the unfamiliarity of the condition in patients, general practitioners, and even medical specialists, including neurologists.

\section{Impact}

SFN causes a significantly reduction of the quality of life, ${ }^{20}$ even substantially lower compared to patient populations like patients after myocardial infarction.

The prognosis of SFN is not very well known. In one study, the complaints of SFN remained stable over time in almost half of the patients, were progressive in about $30 \%$, and improved in $10 \%$, whereas in $13 \%$ the disease progressed to the involvement of large nerve fibers. ${ }^{21}$ Progression of SFN can lead to worsening of pain or to extension of the complaints to other parts of the body. The severe reduction in quality of life and the long-term prognosis urge the need for development of more effective treatments. ${ }^{20}$ 
Figure 1. The pathophysiology of SFN and development of (targeted) treatment

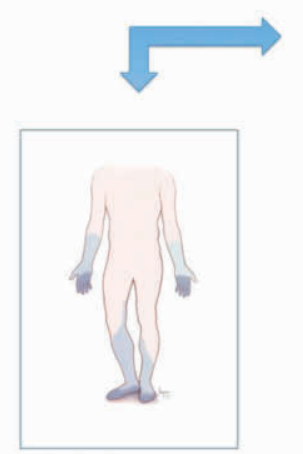

Clinical symptoms

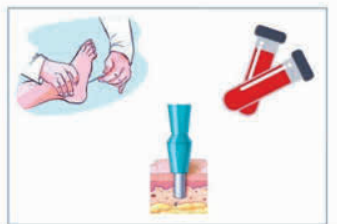

Additional diagnostics

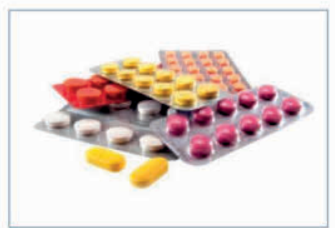

(Specific) treatment

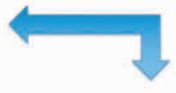

Legend to figure 1. The figure represents diagnostic testing for possible associated conditions in patients with SFN. If the diagnosis SFN is made in a patient, several diagnostic tests are usually performed to search for underlying conditions. Further scientific research may provide new insights into pathophysiology. This may eventually result in the development of more targeted treatments.

\section{Associated conditions}

The pathophysiology of SFN is still largely unsolved. In literature, various conditions are mentioned to contribute to the development of SFN. However, a clear causal relationship is often not proven. Moreover, many conditions are only reported in case reports, and large prevalence studies are lacking. It is important to gain knowledge about the conditions that are associated with SFN, as some of these are treatable, and adequate treatment might slow down the course of SFN, or may even lead to regeneration of nerve fibers. ${ }^{22,} 23$ Besides, it can contribute to a better understanding of the pathophysiology of SFN, which is necessary to develop targeted treatments (Figure 1).

The different associated conditions can be classified in the following groups: metabolic diseases (e.g. diabetes mellitus ${ }^{18}$ or kidney failure ${ }^{24}$ ), neurotoxic exposure (e.g. chemotherapy ${ }^{25}$ or alcohol abuse ${ }^{26}$ ), vitamin deficiencies or intoxications (e.g. vitamin B12 deficiency ${ }^{27}$ or vitamin B6 toxicity ${ }^{28}$ ), infectious diseases (e.g. HIV ${ }^{29}$ or Lyme's disease ${ }^{30}$ ), immunological diseases (e.g. sarcoidosis ${ }^{31}$ or coeliac disease ${ }^{32}$ ), and hereditary causes (e.g. sodium channel gene mutations ${ }^{33-35}$ or haemochromatosis $\left.{ }^{36}\right) .{ }^{8,17}$ Despite thorough workup, no associated conditions can be found in $30-50 \%$ of patients with SFN. This is called idiopathic SFN. ${ }^{19,} 20,37$

One of the most studied diseases in SFN is diabetes mellitus. ${ }^{18}$ It is thought that this metabolic disease causes damage to the nerve fibers in various ways, for example by the enhanced polyol 
pathway activity caused by hyperglycemia or because of vascular ischemia. ${ }^{38,39}$ However, it remains unclear why some patients develop neuropathy, while others do not, and why only a subset of patients with diabetic neuropathy develop pain. ${ }^{40}$ Recently, a genetic link has been found in some patients with SFN and pathogenic sodium channel variants. ${ }^{40}$

\section{Voltage-gated sodium channel mutations}

Gain-of-function SCN9A-mutations were first found in patients with primary erythromelalgia (IEM), a condition characterized by recurrent burning pain and redness of the extremities, induced by warm temperature and exercise. ${ }^{41,}{ }^{42}$ Subsequently, these mutations were also found in paroxysmal extreme pain disorder (PEPD), in which patients suffer from sudden attacks of severe pain in the mandibular, ocular and rectal areas, accompanied by erythematous color changes (flushes). ${ }^{43,44}$ Loss-of-function SCN9A-mutations were found in patients with pain insensitivity and autonomic deficits, called congenital insensitivity to pain (CIP). ${ }^{45,46}$ Gain-of-function mutations can cause a shift in hyperpolarization, whereby the channels are activated by smaller depolarization than in wild-type channels. Besides, the channels can show impaired deactivation. ${ }^{47}$ Both these changes may lead to increased firing of the neurons, called hyperexcitability, which in turn might lead to axonal degeneration. ${ }^{48}$ Because the clinical picture of IEM and PEPD shows similarities with SFN, this triggered the interest to investigate the role of SCN9A-muations in SFN. In a cohort of 28 biopsy-confirmed SFN patients gain-of-function mutations of the SCN9A-gene were found in $28 \%$ of the patients. ${ }^{33}$ After this discovery mutations in the SCN10A- and SCN11A-gene were also found to be present in SFN patients. ${ }^{34}, 35$ These findings have driven the search for targeted treatments. ${ }^{49}$

\section{Treatment}

When an underlying condition is found, treatment will start with specific therapy for this condition. However, a large proportion of patients suffer from idiopathic SFN, or patients will still require neuropathic pain treatment even though the underlying condition is treated well. ${ }^{50}$ At the moment, SFN is not a curable condition, where current treatment possibilities can only diminish the complaints, instead of recovering the nerve fiber degeneration. Current treatment of SFN consists of different classes of neuropathic pain medication, including antidepressants, anticonvulsants, opioids, and topical agents, as shown in table 1. ${ }^{51-53}$

In general, the efficacy of neuropathic pain treatment is disappointing, with only $50 \%$ pain reduction in around $50 \%$ of the patients. ${ }^{51,52,54}$ Furthermore, Table 1 shows that current drugs frequently produce bothersome side effects, partly because the medication is not specifically acting on peripheral nerves. Consequently, there is significant interest in the development of targeted treatments, like selective sodium channel blockers. Selective sodium channel blockers might not only be effective in patients with a gain-of-function sodium channel gene mutation, but also in other patients with chronic neuropathic pain, because the sodium channels play an important role in the generation of action potentials, leading to pain perception. Moreover, chronic pain states may also result in a higher expression of sodium channels. ${ }^{55}$ Selective sodium channel blockers can block the hyperexcitable channels and thereby may reduce the 
excessive firing of the neurons, as shown in figure 2. The advantage of these selective sodium channel blockers is that they are expected to cause fewer side effects.

Furthermore, it is conceivable that immunological mechanisms play a role in a subset of patients with SFN, since several immune-mediated diseases, such as sarcoidosis, Sjogren's disease and systemic lupus erythematosis may cause SFN. ${ }^{56-61}$ Besides, auto-antibodies, ${ }^{62-64}$ inflammatory changes in nerves, ${ }^{65,66}$ and elevated pro-inflammatory cytokines ${ }^{67}$ have been found in patients in SFN. In other immune-mediated neuropathies, such as chronic inflammatory demyelinating polyneuropathy ${ }^{68,69}$ and Guillain-Barré syndrome ${ }^{70}$ treatment with intravenous immunoglobulin (IVIg) has proven to be efficacious. Moreover, some case studies in patients with SFN and chronic pain have also reported effect of immunomodulating therapy. ${ }^{57,}$ 59, 71-73 Pain reduction with IVIg treatment has also been summarized recently. ${ }^{72}$ Therefore, treatment with IVIg in patients with SFN is hypothesized to be effective.

Figure 2. Schematic display of the mechanism of action of sodium channel blockers.

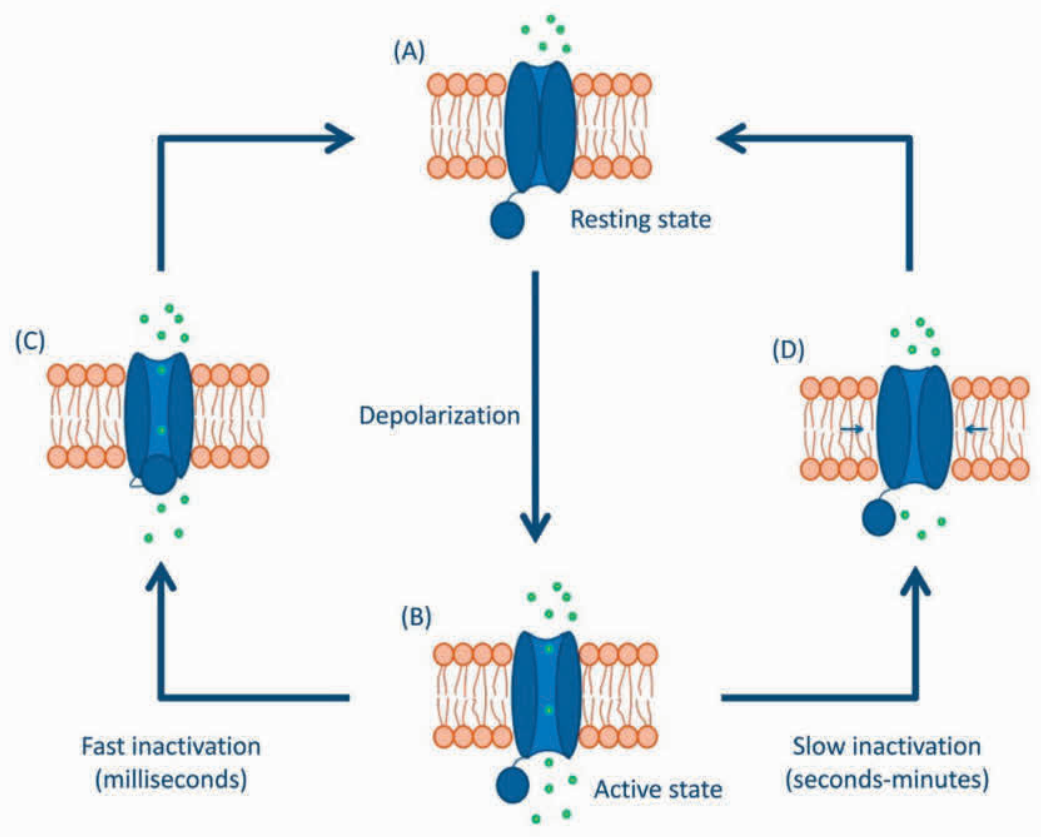

Legend to figure 2. This figure shows the voltage-gated sodium channel (VGSC): the VGSC in resting state (A), will open upon depolarization, caused by an external stimulus (B). After depolarization there are two mechanisms for closure: fast inactivation (C), which will take only milliseconds. A second way of closing is the slow inactivation (D), which can take seconds to minutes. Finally, the sodium channel will enter the resting state again (A) (Figure adapted from, Janneke G.J. Hoeijmakers. Small fiber neuropathy and sodium channel gene mutations - a paradigm shift. Thesis Maastricht University 2014). 


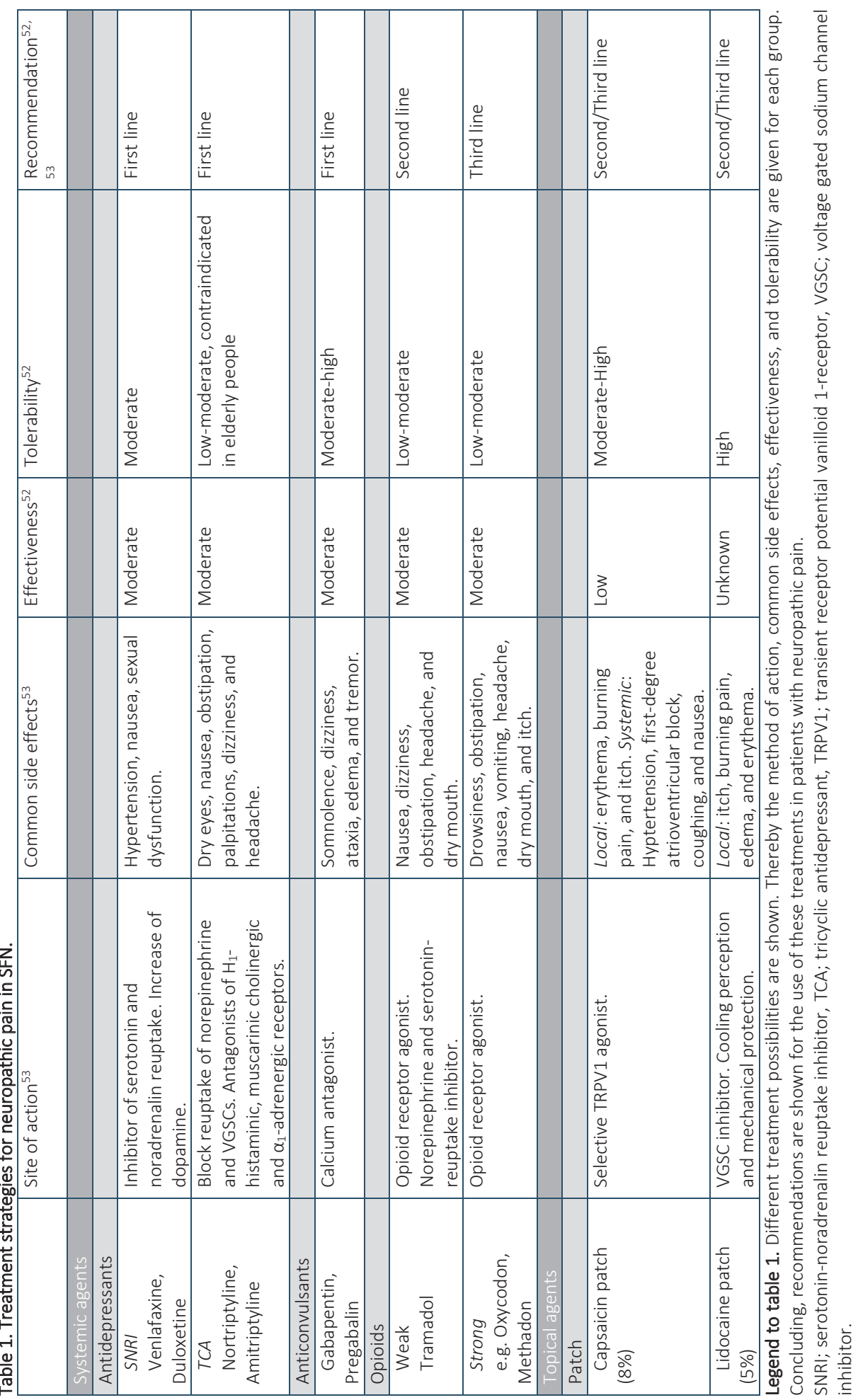




\section{General aim of this thesis.}

The general aim of this thesis is to investigate the prevalence of associated conditions in SFN and to evaluate the efficacy, safety and tolerability of specific neuropathic pain treatment options in patients with SFN. 


\section{References.}

1. Darian-Smith I, Johnson KO, LaMotte C, Shigenaga $Y$, Kenins $P$, Champness P. Warm fibers innervating palmar and digital skin of the monkey: responses to thermal stimuli. J Neurophysiol. 1979;42(5):1297315.

2. Grant G. The 1932 and 1944 Nobel Prizes in physiology or medicine: rewards for ground-breaking studies in neurophysiology. J Hist Neurosci. 2006;15(4):341-57.

3. McGlone F, Reilly D. The cutaneous sensory system. Neurosci Biobehav Rev. 2010;34(2):148-59.

4. Catterall WA, Goldin AL, Waxman SG. International Union of Pharmacology. XLVII. Nomenclature and structure-function relationships of voltage-gated sodium channels. Pharmacol Rev. 2005;57(4):397-409.

5. Gentile S, Turco S, Corigliano G, Marmo R. Simplified diagnostic criteria for diabetic distal polyneuropathy. Preliminary data of a multicentre study in the Campania region. S.I.M.S.D.N. Group. Acta Diabetol. 1995;32(1):7-12.

6. Dyck PJ, Lambert EH, O'Brien PC. Pain in peripheral neuropathy related to rate and kind of fiber degeneration. Neurology. 1976;26(5):466-71.

7. Lauria G. Innervation of the human epidermis. A historical review. Ital J Neurol Sci. 1999;20(1):63-70.

8. Hoeijmakers JG, Faber CG, Lauria G, Merkies IS, Waxman SG. Small-fibre neuropathies-advances in diagnosis, pathophysiology and management. Nat Rev Neurol. 2012;8(7):369-79.

9. Cazzato D, Lauria G. Small fibre neuropathy. Curr Opin Neurol. 2017;30(5):490-9.

10. Brouwer BA, Bakkers M, Hoeijmakers JG, Faber CG, Merkies IS. Improving assessment in small fiber neuropathy. J Peripher Nerv Syst. 2015;20(3):333-40.

11. Gorson KC, Herrmann DN, Thiagarajan R, et al. Non-length dependent small fibre neuropathy/ganglionopathy. J Neurol Neurosurg Psychiatry. 2008;79(2):163-9.

12. Khoshnoodi MA, Truelove S, Burakgazi A, Hoke A, Mammen AL, Polydefkis M. Longitudinal Assessment of Small Fiber Neuropathy: Evidence of a Non-Length-Dependent Distal Axonopathy. JAMA Neurol. 2016;73(6):684-90.

13. Blackmore D, Siddiqi ZA. Pinprick Testing in Small Fiber Neuropathy: Accuracy and Pitfalls. J Clin Neuromuscul Dis. 2016;17(4):181-6.

14. Bakkers M, Faber CG, Reulen JP, Hoeijmakers JG, Vanhoutte EK, Merkies IS. Optimizing temperature threshold testing in small-fiber neuropathy. Muscle Nerve. 2015;51(6):870-6.

15. Yarnitsky D, Sprecher E. Thermal testing: normative data and repeatability for various test algorithms. $J$ Neurol Sci. 1994;125(1):39-45.

16. Lauria G, Bakkers M, Schmitz C, et al. Intraepidermal nerve fiber density at the distal leg: a worldwide normative reference study. J Peripher Nerv Syst. 2010;15(3):202-7.

17. Terkelsen AJ, Karlsson P, Lauria G, Freeman R, Finnerup NB, Jensen TS. The diagnostic challenge of small fibre neuropathy: clinical presentations, evaluations, and causes. Lancet Neurol. 2017;16(11):934-44.

18. Tesfaye S, Boulton AJ, Dyck PJ, et al. Diabetic neuropathies: update on definitions, diagnostic criteria, estimation of severity, and treatments. Diabetes Care. 2010;33(10):2285-93.

19. Peters MJ, Bakkers M, Merkies IS, Hoeijmakers JG, van Raak EP, Faber CG. Incidence and prevalence of small-fiber neuropathy: a survey in the Netherlands. Neurology. 2013;81(15):1356-60.

20. Bakkers M, Faber CG, Hoeijmakers JG, Lauria G, Merkies IS. Small fibers, large impact: quality of life in small-fiber neuropathy. Muscle Nerve. 2014;49(3):329-36.

21. Devigili G, Tugnoli V, Penza P, et al. The diagnostic criteria for small fibre neuropathy: from symptoms to neuropathology. Brain. 2008;131(Pt 7):1912-25.

22. Lauria G, McArthur JC, Hauer PE, Griffin JW, Cornblath DR. Neuropathological alterations in diabetic truncal neuropathy: evaluation by skin biopsy. J Neurol Neurosurg Psychiatry. 1998;65(5):762-6.

23. Tavakoli M, Mitu-Pretorian M, Petropoulos IN, et al. Corneal confocal microscopy detects early nerve regeneration in diabetic neuropathy after simultaneous pancreas and kidney transplantation. Diabetes. 2013;62(1):254-60.

24. Chao CC, Wu VC, Tan CH, et al. Skin denervation and its clinical significance in late-stage chronic kidney disease. Arch Neurol. 2011;68(2):200-6.

25. Argyriou AA, Kyritsis AP, Makatsoris T, Kalofonos HP. Chemotherapy-induced peripheral neuropathy in adults: a comprehensive update of the literature. Cancer Manag Res. 2014;6:135-47. 
26. Zambelis T, Karandreas N, Tzavellas E, Kokotis P, Liappas J. Large and small fiber neuropathy in chronic alcohol-dependent subjects. J Peripher Nerv Syst. 2005;10(4):375-81.

27. Huang CR, Chang WN, Tsai NW, Lu CH. Serial nerve conduction studies in vitamin B12 deficiencyassociated polyneuropathy. Neurol Sci. 2011;32(1):183-6.

28. Bernstein AL. Vitamin B6 in clinical neurology. Ann N Y Acad Sci. 1990;585:250-60.

29. Polydefkis M, Yiannoutsos CT, Cohen BA, et al. Reduced intraepidermal nerve fiber density in HIVassociated sensory neuropathy. Neurology. 2002;58(1):115-9.

30. Younger DS, Orsher S. Lyme Neuroborreliosis: Preliminary Results from an Urban Referral Center Employing Strict CDC Criteria for Case Selection. Neurol Res Int. 2010;2010:525206.

31. Hoitsma E. Small fiber neuropathy. A novel finding in sarcoidosis. Maastricht: Thesis, ISBN 90-90188681, University of Maastricht; 2005.

32. Brannagan TH, 3rd, Hays AP, Chin SS, et al. Small-fiber neuropathy/neuronopathy associated with celiac disease: skin biopsy findings. Arch Neurol. 2005;62(10):1574-8.

33. Faber CG, Hoeijmakers JG, Ahn HS, et al. Gain of function Nav1.7 mutations in idiopathic small fiber neuropathy. Ann Neurol. 2012;71(1):26-39.

34. Faber CG, Lauria G, Merkies IS, et al. Gain-of-function Nav1.8 mutations in painful neuropathy. Proc Natl Acad Sci U S A. 2012;109(47):19444-9.

35. Huang J, Han C, Estacion M, et al. Gain-of-function mutations in sodium channel Na(v)1.9 in painful neuropathy. Brain. 2014;137(Pt 6):1627-42.

36. Wouthuis SF, van Deursen CT, te Lintelo MP, Rozeman CA, Beekman R. Neuromuscular manifestations in hereditary haemochromatosis. J Neurol. 2010;257(9):1465-72.

37. Farhad K, Traub R, Ruzhansky KM, Brannagan TH, 3rd. Causes of neuropathy in patients referred as "idiopathic neuropathy". Muscle Nerve. 2016;53(6):856-61.

38. Schreiber AK, Nones CF, Reis RC, Chichorro JG, Cunha JM. Diabetic neuropathic pain: Physiopathology and treatment. World J Diabetes. 2015;6(3):432-44.

39. Parry GJ, Brown MJ. Selective fiber vulnerability in acute ischemic neuropathy. Ann Neurol. 1982;11(2):147-54.

40. Hoeijmakers JG, Faber CG, Merkies IS, Waxman SG. Channelopathies, painful neuropathy, and diabetes: which way does the causal arrow point? Trends Mol Med. 2014;20(10):544-50.

41. Yang Y, Wang Y, Li S, et al. Mutations in SCN9A, encoding a sodium channel alpha subunit, in patients with primary erythermalgia. J Med Genet. 2004;41(3):171-4.

42. Tang Z, Chen Z, Tang B, Jiang H. Primary erythromelalgia: a review. Orphanet J Rare Dis. 2015;10:127.

43. Fertleman CR, Ferrie CD, Aicardi J, et al. Paroxysmal extreme pain disorder (previously familial rectal pain syndrome). Neurology. 2007;69(6):586-95.

44. Fertleman CR, Baker MD, Parker KA, et al. SCN9A mutations in paroxysmal extreme pain disorder: allelic variants underlie distinct channel defects and phenotypes. Neuron. 2006;52(5):767-74.

45. Nagasako EM, Oaklander AL, Dworkin RH. Congenital insensitivity to pain: an update. Pain. 2003;101(3):213-9.

46. Cox JJ, Reimann F, Nicholas AK, et al. An SCN9A channelopathy causes congenital inability to experience pain. Nature. 2006;444(7121):894-8.

47. Drenth JP, Waxman SG. Mutations in sodium-channel gene SCN9A cause a spectrum of human genetic pain disorders. J Clin Invest. 2007;117(12):3603-9.

48. Persson AK, Liu S, Faber CG, Merkies IS, Black JA, Waxman SG. Neuropathy-associated Nav1.7 variant I228M impairs integrity of dorsal root ganglion neuron axons. Ann Neurol. 2013;73(1):140-5.

49. Emery EC, Luiz AP, Wood JN. Nav1.7 and other voltage-gated sodium channels as drug targets for pain relief. Expert Opin Ther Targets. 2016;20(8):975-83.

50. Hovaguimian A, Gibbons $\mathrm{CH}$. Diagnosis and treatment of pain in small-fiber neuropathy. Curr Pain Headache Rep. 2011;15(3):193-200.

51. Attal N, Cruccu G, Baron R, et al. EFNS guidelines on the pharmacological treatment of neuropathic pain: 2010 revision. Eur J Neurol. 2010;17(9):1113-e88.

52. Finnerup NB, Attal N, Haroutounian S, et al. Pharmacotherapy for neuropathic pain in adults: a systematic review and meta-analysis. Lancet Neurol. 2015;14(2):162-73. 
53. Brouwer BA, de Greef BT, Hoeijmakers JG, et al. Neuropathic Pain due to Small Fiber Neuropathy in Aging: Current Management and Future Prospects. Drugs Aging. 2015;32(8):611-21.

54. Themistocleous AC, Ramirez JD, Serra J, Bennett DL. The clinical approach to small fibre neuropathy and painful channelopathy. Pract Neurol. 2014;14(6):368-79.

55. Levinson SR, Luo S, Henry MA. The role of sodium channels in chronic pain. Muscle Nerve. 2012;46(2):155-65.

56. Hoitsma E, Marziniak M, Faber CG, et al. Small fibre neuropathy in sarcoidosis. Lancet. 2002;359(9323):2085-6.

57. Parambil JG, Tavee JO, Zhou L, Pearson KS, Culver DA. Efficacy of intravenous immunoglobulin for small fiber neuropathy associated with sarcoidosis. Respir Med. 2011;105(1):101-5.

58. Bakkers M, Merkies IS, Lauria G, et al. Intraepidermal nerve fiber density and its application in sarcoidosis. Neurology. 2009;73(14):1142-8.

59. Wakasugi D, Kato T, Gono T, et al. Extreme efficacy of intravenous immunoglobulin therapy for severe burning pain in a patient with small fiber neuropathy associated with primary Sjogren's syndrome. Mod Rheumatol. 2009;19(4):437-40.

60. Goransson LG, Herigstad A, Tjensvoll AB, Harboe E, Mellgren SI, Omdal R. Peripheral neuropathy in primary sjogren syndrome: a population-based study. Arch Neurol. 2006;63(11):1612-5.

61. Goransson LG, Tjensvoll AB, Herigstad A, Mellgren SI, Omdal R. Small-diameter nerve fiber neuropathy in systemic lupus erythematosus. Arch Neurol. 2006;63(3):401-4.

62. Chamberlain JL, Pittock SJ, Oprescu AM, et al. Peripherin-lgG association with neurologic and endocrine autoimmunity. J Autoimmun. 2010;34(4):469-77.

63. Ferrari S, Morbin M, Nobile-Orazio E, et al. Antisulfatide polyneuropathy: antibody-mediated complement attack on peripheral myelin. Acta Neuropathol. 1998;96(6):569-74.

64. Dabby R, Weimer LH, Hays AP, Olarte M, Latov N. Antisulfatide antibodies in neuropathy: clinical and electrophysiologic correlates. Neurology. 2000;54(7):1448-52.

65. Zafrir B, Zimmerman M, Fellig Y, Naparstek Y, Reichman N, Flatau E. Small fiber neuropathy due to isolated vasculitis of the peripheral nervous system. Isr Med Assoc J. 2004;6(3):183-4.

66. Kelkar P, McDermott WR, Parry GJ. Sensory-predominant, painful, idiopathic neuropathy: inflammatory changes in sural nerves. Muscle Nerve. 2002;26(3):413-6.

67. Uceyler N, Kafke W, Riediger N, et al. Elevated proinflammatory cytokine expression in affected skin in small fiber neuropathy. Neurology. 2010;74(22):1806-13.

68. Hughes RA, Donofrio P, Bril V, et al. Intravenous immune globulin (10\% caprylate-chromatography purified) for the treatment of chronic inflammatory demyelinating polyradiculoneuropathy (ICE study): a randomised placebo-controlled trial. Lancet Neurol. 2008;7(2):136-44.

69. European Federation of Neurological Societies/Peripheral Nerve Society Guideline on management of multifocal motor neuropathy. Report of a joint task force of the European Federation of Neurological Societies and the Peripheral Nerve Society. J Peripher Nerv Syst. 2006;11(1):1-8.

70. van Doorn PA, Kuitwaard K, Walgaard C, van Koningsveld R, Ruts L, Jacobs BC. IVIG treatment and prognosis in Guillain-Barre syndrome. J Clin Immunol. 2010;30 Suppl 1:S74-8.

71. Dabby R, Gilad R, Sadeh M, Lampl Y, Watemberg N. Acute steroid responsive small-fiber sensory neuropathy: a new entity? J Peripher Nerv Syst. 2006;11(1):47-52.

72. Goebel A. Immunoglobulin responsive chronic pain. J Clin Immunol. 2010;30 Suppl 1:S103-8.

73. Souayah N, Chin RL, Brannagan TH, et al. Effect of intravenous immunoglobulin on cerebellar ataxia and neuropathic pain associated with celiac disease. Eur J Neurol. 2008;15(12):1300-3. 




\section{CHAPTER 1.2 OUTLINE OF THIS THESIS}



In literature it has been described that SFN could be the first symptom of a metabolic disorder, called Fabry disease. Chapter 2 shows the prevalence of Fabry disease in patients with SFN without other Fabry specific symptoms.

Based on the results of the previous chapter, chapter 3 describes the prevalence of other associated conditions in SFN that are mentioned earlier in literature. Also recommendations for diagnostics profile will be made.

The treatment of neuropathic pain in patients with SFN is challenging. In chapter 4 the different therapeutic options currently used, are discussed and possible pitfalls are highlighted, with special interest for the elder patients. Eventually, a therapeutic algorithm is provided.

In chapter 5 the protocol of the Lacosamide-Efficacy-' $N$ '-Safety in Small fiber neuropathy (LENSS) study is described. In this randomized, double-blinded, placebo-controlled, crossover study Lacosamide is compared to placebo in a group of patients with an SCN9A-associated SFN.

Chapter 6 shows the results of the LENSS study that is extensively described in the previous chapter. It discusses the efficacy, safety, and tolerability of lacosamide compared to placebo.

In a large proportion of the patients with SFN, no underlying condition can be found, which makes targeted treatment difficult. An immunological cause is suspected in at least part of the patients. The study protocol of a randomized, double-blinded study with intravenous immunoglobulin, as a new and different treatment possibility will be discussed in chapter 7 .

For the overview, in chapter 8 and 9 the findings of this thesis are summarized and the future perspectives will be discussed.

Finally, chapter 10 will discuss the importance, influence, and practical implementation of the findings of this thesis. 



\section{PART II}

\section{ASSOCIATED}

CONDITIONS IN SMALL FIBER NEUROPATHY 



\section{CHAPTER 2 NO FABRY DISEASE IN PATIENTS PRESENTING WITH ISOLATED SMALL FIBER NEUROPATHY}

Bianca T.A. de Greef ${ }^{1}$, Janneke G.J. Hoeijmakers ${ }^{1}$, Emma E. Wolters ${ }^{1}$, Hubertus J.M. Smeets ${ }^{2}$, Arthur van den Wijngaard ${ }^{2}$, Ingemar S.J. Merkies ${ }^{1,3}$, Catharina G. Faber ${ }^{1}$, Monique M. Gerrits' ${ }^{2}$.

${ }^{1}$ Department of Neurology, School of Mental Health and Neuroscience, Maastricht University Medical Center, Maastricht, The Netherlands.

${ }^{2}$ Department of Clinical Genetics, Maastricht University Medical Center Maastricht, The Netherlands. ${ }^{3}$ Department of Neurology, Spaarne hospital, Hoofddorp, The Netherlands. 


\section{Abstract}

Objective: Screening for Fabry disease in patients with small fiber neuropathy has been suggested, especially since Fabry disease is potentially treatable. However, the diagnostic yield of testing for Fabry disease in small fiber neuropathy patients has never been systematically investigated. Our aim is to determine the presence of Fabry disease in patients with small fiber neuropathy.

Methods: Patients referred to our institute, who met the criteria for isolated small fiber neuropathy were tested for Fabry disease by measurement of alpha-Galactosidase A activity in blood, lysosomal globotriaosylsphingosine in urine and analysis on possible GLA gene mutations.

Results: 725 patients diagnosed with small fiber neuropathy were screened for Fabry disease. No skin abnormalities were seen except for redness of the hands or feet in $30.9 \%$ of the patients. Alfa-Galactosidase A activity was tested in all 725 patients and showed diminished activity in eight patients. Lysosomal globotriaosylsphingosine was examined in 509 patients and was normal in all tested individuals. Screening of GLA for mutations was performed for 440 patients, including those with diminished $\alpha$-Galactosidase A activity. Thirteen patients showed a GLA gene variant. One likely pathogenic variant was found in a female patient. The diagnosis Fabry disease could not be confirmed over time in this patient. Eventually none of the patients were diagnosed with Fabry disease.

Conclusions: In patients with isolated small fiber neuropathy, and no other signs compatible with Fabry disease, the diagnostic yield of testing for Fabry disease is extremely low. Testing for Fabry disease should be considered only in cases with additional characteristics, such as childhood onset, cardiovascular disease, renal failure or typical skin lesions. 


\section{Introduction}

Small fiber neuropathy (SFN) is a disorder of the thinly myelinated A $\delta$-fibers and unmyelinated $\mathrm{C}$-fibers. These fibers are responsible for the sensation of temperature and pain and regulate a great deal of the autonomic nervous system. As a result, SFN is clinically characterized by neuropathic pain and autonomic symptoms. ${ }^{1}{ }^{2}$ Patients with SFN experience different types of pain mainly described as a burning sensation, itching, prickling, or shooting pains. These symptoms usually occur in a symmetrical length-dependent pattern, ${ }^{3}$ but non-length dependent patterns have been described. ${ }^{4} \mathrm{SFN}$ is not a rare condition; a recent study showed a minimum prevalence of 53/100.000. ${ }^{5}$ Many diseases can underlie small nerve fiber damage, such as diabetes or impaired glucose tolerance, HIV infection, immune-mediated disorders (e.g. Sjögren syndrome and sarcoidosis), ${ }^{2}$ and hereditary disorders (e.g. sodium channel gene mutations). ${ }^{6-8}$ Diabetes mellitus is considered one of the most common causes of SFN. Despite thorough investigations, an underlying cause cannot be identified in $38-48 \%$ of the patients. ${ }^{5}$, 9

One of the possible causes of SFN is Fabry disease (FD). ${ }^{10-12}$ FD is an X-linked glycolipid storage disease due to a mutation in the GLA gene. This causes an absent or diminished activity of the lysosomal enzyme alpha-Galactosidase A ( $\alpha$-Gal A), leading to accumulation of globotriaosylceramide (lyso-GB3) in different cell types and subsequently to severe multisystem disease. ${ }^{13}, 14$ The involvement of different cell types leads to various clinical manifestations, such as cardiovascular disease, renal failure, and skin lesions. The accumulation of lyso-GB3 also occurs in neurons, which causes neurological symptoms. The symptoms may develop in different periods of the patient's life. Shooting pain and discomfort in the hands and feet, which are triggered by heat, exercise, and stress, are considered the most common symptoms that patient experience in early childhood and adolescence. About $70 \%$ of children and adolescents with classical FD develop pain in hands and feet. ${ }^{15}$ These neuropathic pain symptoms can become more generalized over time. ${ }^{16}$ However, it is not clear how often FD is the underlying cause in patients presenting with SFN.

The relationship between FD and small nerve fiber dysfunction has been described before. ${ }^{10-}$ ${ }^{14}$ The prevalence of SFN cases that are caused by FD is not well known. However, it is important to identify patients with FD, because it is a treatable disorder. Treatment with enzyme replacement therapy (ERT) may improve the quality of life and prevent serious and potential life-threatening complications. ${ }^{17-20}$ Early ERT has been suggested to improve small nerve fiber function, ${ }^{14,21,22}$ although these findings could be not validated by others. ${ }^{23}$

The aim of our study is to investigate the prevalence of FD in a well-defined cohort of patients diagnosed with SFN and related costs to this diagnostic testing.

\section{Methods}

\section{Patients}

We included all consecutive patients referred for possible SFN to the Maastricht University Medical Center (Maastricht UMC+) between August 2006 and April 2015. The diagnosis SFN was made if patients fulfilled the criteria for SFN as described earlier. ${ }^{2,24}$ These criteria include the presence of $\geq 2$ typical symptoms for SFN not otherwise explained, no signs of large fiber 
involvement, and reduced intraepidermal nerve fiber density ${ }^{25}$ and/or abnormal temperature thresholds in quantitative sensory testing. ${ }^{26,27}$ Screening for FD was performed in all patients with SFN as described in the following.

\section{Biochemical assessments and DNA analysis for FD}

Presence of FD was examined through measurement of $\alpha$-Gal A activity in leukocytes, ${ }^{28}$ IysoGB3 excretion in urine, ${ }^{29}$ and screening of the GLA gene for mutations. $\alpha-G a l$ A enzyme activity is considered normal between 30 and $180 \mathrm{mmol} / \mathrm{L}$ and diminished $<30 \mathrm{mmol} / \mathrm{L}$.

Lyso-GB3 excretion is considered abnormal $>0 \mathrm{nmol} / \mathrm{mmol}$ creatinine. ${ }^{29}$ The measurement of lyso-GB3 excretion in urine was incorporated in our workflow for SFN patients from April 2012. Variants in the coding and intermediate flanking regions of the GLA gene were classified according to the Practice Guidelines for the Evaluation of Pathogenicity and the Reporting of Sequence Variant in clinical Molecular Genetics. ${ }^{30}$ Class 1 and 2 variants are considered nonpathogenic. Class 3 variants have an uncertain pathogenicity. Class 4 variants are likely to be pathogenic and class 5 variants are certain pathogenic. ${ }^{30}$

In men, a normal $\alpha$-Gal A activity and lyso-GB3 excretion excludes FD. ${ }^{14}$ However, if the enzyme activity is reduced or the lyso-GB3 is increased, screening of the GLA gene for mutations is required to confirm FD (Figure $1 \mathrm{~A}$ ). ${ }^{14}{ }^{31}$ In women, a normal $\alpha$-Gal $A$ enzyme activity ${ }^{15}$ and normal lyso-GB3 excretion does not rule out FD. Due to skewed X-inactivation, ${ }^{32}$ it is known that the clinical manifestations in heterozygous females may range from asymptomatic to severely affected subjects. As GLA is the only gene in which mutations are known to cause FD, ${ }^{33}$ screening of the GLA gene for mutations is the most reliable method of diagnosing the carrier state in females. Biochemical findings of $\alpha-G a l A$ and lyso-GB3 could serve as biomarkers of disease severity. ${ }^{29}$ Therefore, $\alpha$-Gal A activity, lyso-GB3 excretion, screening of the GLA gene for mutations were performed simultaneously in women (Figure 1B). ${ }^{14,34}$

\section{Standard protocol approvals, registrations, and patient consents}

The Maastricht UMC's Medical Ethics Committee and Board of Directors approved this study. According to the Code of Conduct for the use of data in Health Research, ${ }^{35}$ for this type of retrospective study, informed consent does not need to be obtained if the data are used anonymously and patients are given the opportunity to object against the use of their medical and personal data for research (which is the case in the Maastricht UMC+). All data were obtained from medical records. Patient records were anonymized and de-identified prior to analysis. The individuals described in this manuscript have given written informed consent for publication of their case details. 
Figure 1. Diagnostic algorithm for confirming Fabry disease in SFN patients.

A

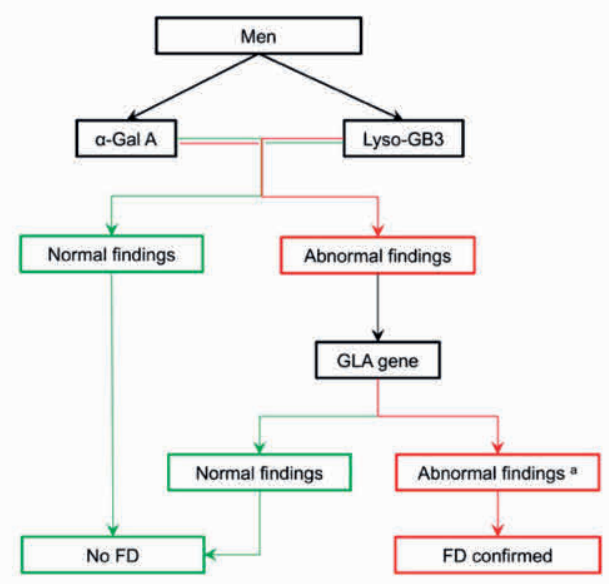

B

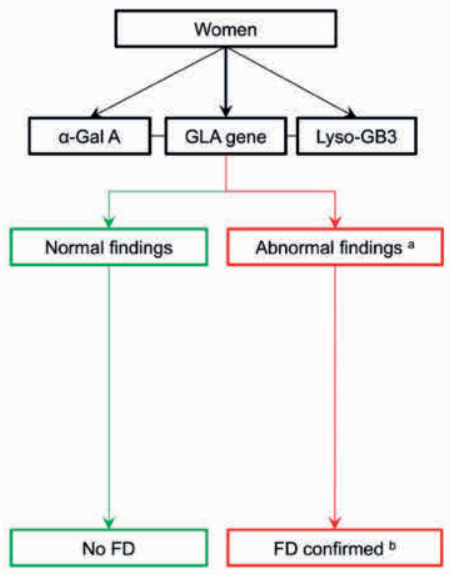

Legend to figure 1: (A) Diagnostic algorithm for men. (B) Diagnostic algorithm for women. $\alpha$-Gal A: $\alpha$-galactosidase A, FD: Fabry disease, Lyso-GB3: lysosomal globotriaosylceramide.

a Abnormal findings of the GLA gene include class 3 variants (uncertain to be pathogenic), class 4 variants (likely to be pathogenic), and class 5 variants (certain pathogenic).

${ }^{b}$ The diagnosis FD is confirmed in women when the abnormal findings of the GLA gene complemented with abnormal findings in the biochemical assessment ( $\alpha$-Gal $A$ and Lyso-GB3).

\section{Results}

\section{Patient selection and general characteristics}

A total of 1040 patients were referred to the Maastricht UMC+ for possible SFN. In 771 patients (74\%) the diagnosis SFN was confirmed. Forty-six patients with SFN were excluded from the study based on non-available or incomplete FD diagnostic data. Eventually, a total of 725 patients with SFN were screened for FD (305 (42.1\%) men, 420 (57.9\%) women). All patients except seven were adults (99\%). The median age of onset of the complaints was 47 , with a standard deviation of 14.3 .

Possible underlying causes in our patient cohort were diabetes mellitus ( $n=35 ; 4.8 \%$; 4 type 1 diabetes (0.6\%), 31 type 2 diabetes (4.3\%)), sarcoidosis ( $n=23 ; 3.2 \%)$, morbus Sjögren ( $n=11$, $1.5 \%)$, monoclonal gammopathy of undetermined significance ( $n=5 ; 0.7 \%)$, and hypothyreoidism ( $n=3 ; 0.4 \%)$.

Besides redness of the hands or feet in $30.9 \%$ of the 725 patients, no other skin abnormalities were seen. None of the patients had a history of cardiomyopathy of renal failure.

\section{Diagnostics for Fabry disease}

The three tests for FD, $\alpha$-Gal A activity in blood, lyso-GB3 excretion in urine, and GLA gene sequencing, were applied to the study population as presented in Figure 2. 
Figure 2. Small fiber neuropathy patients analyzed for Fabry disease (FD) in the Maastricht University Medical Center.

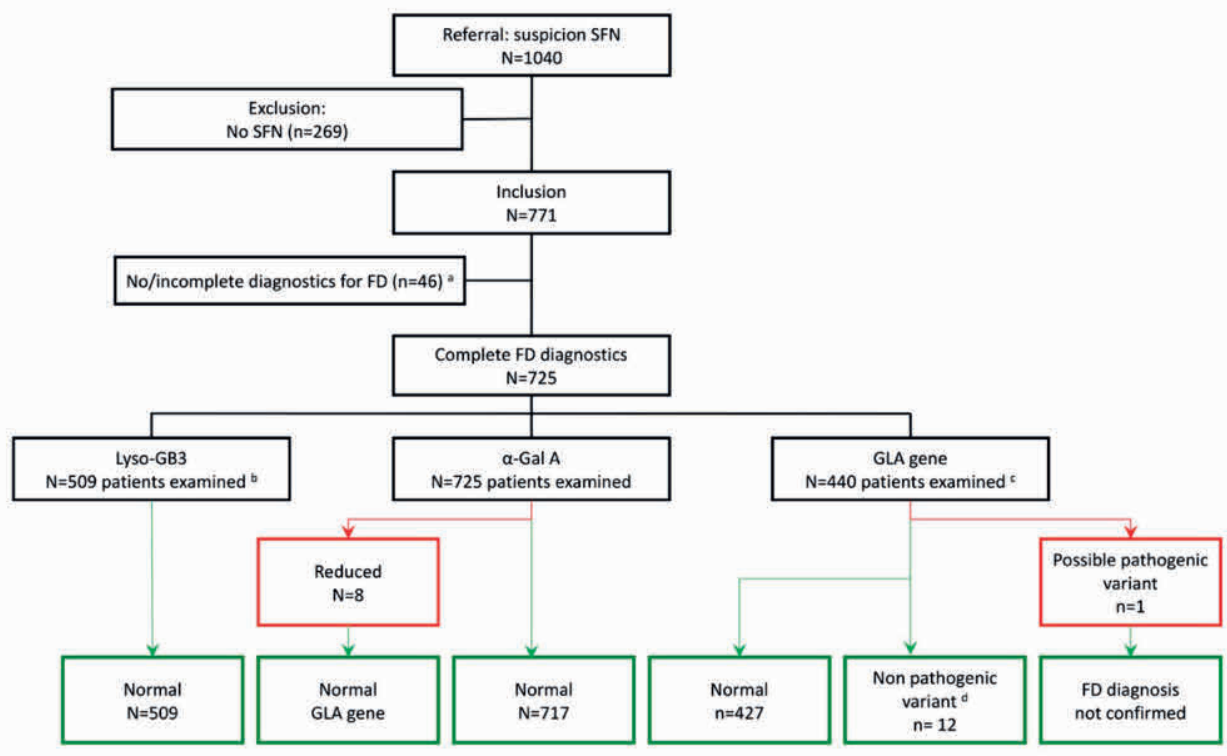

Legend to figure 2: Illustration of the outcome of investigations to confirm the diagnosis of Fabry disease. $\alpha$-Gal A: $\alpha$-galactosidase A, Lyso-GB3: Iysosomal globotriaosylceramide, FD: Fabry disease, SFN: small fiber neuropathy.

${ }^{\text {a }}$ Missing data.

${ }^{b}$ The measurement of lyso-GB3 excretion in urine was incorporated in our workflow for SFN patients from April 2012.

${ }^{\mathrm{C}} \mathrm{GLA}$ gene sequencing was performed in all women, and in males in case of reduced $\alpha$-Gal A enzyme activity.

${ }^{d}$ These includes the class 2 variants (unlikely to be pathogenic) and the class 3 variants (uncertain to be pathogenic).

\section{$\alpha$-Gal A enzyme activity}

$\alpha$-Gal A enzyme activity was determined in leukocytes of all 725 eligible patients. In eight patients (1.1\%) a reduced $\alpha$-Gal A enzyme activity was found, ranging from 2.8 to $26.9 \mathrm{mmol} / \mathrm{L}$. The $\alpha$-Gal A enzyme activity was normal in the other 718 patients (30.3-191.9 (mean 81.2) $\mathrm{mmol} / \mathrm{L})$.

\section{Lyso-GB3 excretion in the urine}

Five hundred nine of the 725 SFN patients were tested for lyso-GB3 excretion in the urine. All results were normal (100\%). Five of these 509 patients with a normal lyso-GB3 excretion had a diminished $\alpha$-Gal A enzyme activity (7.1-26.9 $\mathrm{mmol} / \mathrm{L})$.

\section{GLA gene screening for possible mutations}

A total of 440 patients underwent screening of the GLA gene for mutations. Thirteen SFN patients (3.0\%) carried a variant in the GLA gene (Table 1). 
Table 1: GLA gene variants and results of biochemical testing in a population of SFN patients ( $n=725$ ).

\begin{tabular}{|c|c|c|c|c|c|}
\hline Patient & c.position variant & $\begin{array}{l}\text { p.position } \\
\text { variant }\end{array}$ & Class & $\begin{array}{l}\alpha-\mathrm{Gal} A \\
(\mathrm{mmol} / \mathrm{L})\end{array}$ & $\begin{array}{l}\text { Lyso-GB3 } \\
\text { (nmol/mmol } \\
\text { creatinine) }\end{array}$ \\
\hline $1 \mathrm{~F}$ & c. $-40 G>C$ & - & 2 & 57.4 & NA \\
\hline $2 \mathrm{~F}$ & c. $-8 C>G$ & - & 2 & 68.8 & NA \\
\hline $3 \mathrm{~F}$ & c. $48 \mathrm{~T}>\mathrm{G}$ & p.Leu16Leu & 2 & 69.7 & NA \\
\hline $4 \mathrm{~F}$ & c. $123 C>T$ & p.Thr41Thr & 2 & 72.9 & NA \\
\hline $5 \mathrm{~F}$ & c. $352 C>T$ & p.Arg118Cys & 4 & 59.2 & 0 \\
\hline $6 \mathrm{~F}$ & c. $376 A>G$ & p.Ser126Gly & 2 & 52.6 & 0 \\
\hline $7 F$ & c. $801+21 T>C$ & - & 2 & 43.2 & 0 \\
\hline $8 \mathrm{~F}$ & c.937G >T & p.Asp313Tyr & 3 & 62.4 & NA \\
\hline $9 \mathrm{~F}$ & c.937G $>T$ & p.Asp313Tyr & 3 & 60.6 & NA \\
\hline $10 \mathrm{M}$ & c. $937 \mathrm{G}>\mathrm{T}$ & p.Asp313Tyr & 3 & 30.3 & 0 \\
\hline $11 \mathrm{~F}$ & c. $937 \mathrm{G}>\mathrm{T}$ & p.Asp313Tyr & 3 & 51.5 & 0 \\
\hline $12 \mathrm{~F}$ & c.937G >T & p.Asp313Tyr & 3 & 62.5 & 0 \\
\hline $13 \mathrm{~F}$ & c.999+11_12ins11+999+16_20del5 & - & 2 & 78.9 & NA \\
\hline
\end{tabular}

Legend to table 1: $\alpha$-Gal A: $\alpha$-galactosidase A enzyme activity, $F$ : female, Lyso-GB3: lysosomal globotriaosylceramide, M: male, NA: not available.

Of the nine variants identified [c.-40G>C; c.-8C>G; c.48T>G (p.Leu16Leu); c.123C>T (p.Thr41Thr); c.352C>T (p.Arg118Cys); c.376A>G (p.Ser126Gly); c.801+21T>C; c.937G>T (p.Asp313Tyr) ( $n=5) ; \quad c .999+11 \_12$ ins11+999+16_20del5], only one variant (c.352C>T (p.Arg118Cys) was classified as a likely pathogenic. The other eight variants were classified as a class 2 or class 3 variant. The eight patients with a reduced $\alpha-G a l$ A enzyme activity were also part of this cohort and showed no abnormalities.

The patient carrying the c.352C>T variant heterozygous was a 33-year old female. Her $\alpha$-Gal A enzyme activity was normal $(59.2 \mathrm{mmol} / \mathrm{L})$. The patient was referred to a tertiary referral and treatment center for FD in the Netherlands, where a detailed work-up of potential FDpathologies and biomarkers was performed. The $\alpha$-Gal A enzyme activity was retested and normal $(53.0 \mathrm{mmol} / \mathrm{L})$. For this patient no excretion of lyso-GB3 was detected in urine. During three years of follow-up, the patient did not develop symptoms or signs of FD (skin lesions, cornea verticillata, cardiac or renal involvement). Therefore the diagnosis of FD could not be confirmed. All patients with a class 2 or 3 variant had a $\alpha$-Gal A enzyme activity $>30 \mathrm{mmol} / \mathrm{L}$, and if tested, normal lyso-GB3.

In total, 725 patients underwent testing for FD, and the diagnosis FD was not confirmed in any of these patients.

\section{Diagnostics for FD costs}

In our center, the costs per person for testing $\alpha$-Gal A enzyme activity in leukocytes are $\$ 1,186$, for Lyso-GB3 in urine $\$ 883$, and for GLA gene sequencing $\$ 1,017$, which is a total of $\$ 2,069$ (for men) and $\$ 3,086$ (for women) per patient. In this cohort of 725 patients the costs for FD diagnostics were $\$ 1,756,777$. 


\section{Discussion}

In a large cohort of patients diagnosed with isolated SFN who were tested for FD ( $n=725)$, we did not find any patients with FD. In only one patient a possible pathogenic variant was identified, but after thorough investigations and years of follow-up, the diagnosis FD could not be established. Because FD is a treatable disease, early diagnosis can prevent further complications of the disease and may improve the quality of life. ${ }^{17-20}$ However, little is known about the prevalence of SFN as first symptom of FD. Previously, only two small cohort studies examined the presence of GLA gene mutations in idiopathic SFN. The first study identified one GLA gene mutation in a cohort of 24 patients diagnosed with idiopathic SFN. ${ }^{36}$ In a second study, in one out of 29 patients with idiopathic SFN, a variant of the GLA gene was shown. As in our study, the diagnosis FD could not be made in any of these patients. ${ }^{37}$ However, our study is the first that systematically examined the prevalence of FD in a large clinically well-defined cohort of patients diagnosed with isolated SFN.

Our results show isolated SFN not being the first and certainly not the only symptom of FD. Patients with FD probably also have other symptoms, like skin lesions or hearing loss, cardiac or renal involvement leading to the diagnosis of FD. ${ }^{17}$ These symptoms could be accompanied with neuropathic pain, but the neuropathic pain alone does not seem typical for adult FD patients. A previous study showed that only 12 patients, out of a cohort of 366 patients with $\mathrm{FD}$, had neurological signs or symptoms, without the involvement of any other organs. ${ }^{15}$ The general view at our center is that patients with potential SFN related complaints are being referred and examined, often without an underlying etiology. Possible referral bias is conceivable in cases having other symptoms indicative for FD being referred to a tertiary center for FD.

Neuropathic pain has been addressed as one of the first symptoms of FD in some cases. ${ }^{11-13,16}$ However, most of these studies concerned children, adolescents and young adults. ${ }^{17,38}$ These observations were not confirmed by the current study in adults with SFN. In contrast with literature, ${ }^{13,15}$ none of the children in our study cohort were diagnosed having FD. However, some caution is warranted since only 7 children were part of the study population.

From the current results, it is clear that the suspicion of FD is extremely low, if not absent in adult patients presenting with SFN without concomitant symptoms or signs compatible with FD (skin lesions, hearing loss, cardiac or renal involvement). In addition, genetic and biochemical testing for FD is expensive, more than 1.7 million US dollars in the cohort $(n=725)$ examined in the current study with no patient being diagnosed having FD. Therefore, in adult patients with isolated SFN, routine screening for FD does not seem warranted.

In case testing for FD is warranted, we would recommend to start with the GLA gene sequencing as the first test. ${ }^{14,39,40}$ If this test turned out to be normal, the patient is diagnosed not having FD. Whenever a variant of the GLA gene is found, the diagnostics could be complemented with the $\alpha$-Gal A enzyme activity, and other biochemical assessments necessary, to confirm the diagnosis FD. This strategy would largely reduce the costs of diagnostic testing for FD. 


\section{References}

1. Stewart JD, Low PA, Fealey RD. Distal small fiber neuropathy: results of tests of sweating and autonomic cardiovascular reflexes. Muscle Nerve. 1992;15(6):661-5.

2. Hoeijmakers JG, Faber CG, Lauria G, Merkies IS, Waxman SG. Small-fibre neuropathies-advances in diagnosis, pathophysiology and management. Nat Rev Neurol. 2012;8(7):369-79.

3. Gorson KC, Ropper AH. Idiopathic distal small fiber neuropathy. Acta Neurol Scand. 1995;92(5):376-82.

4. Gorson KC, Herrmann DN, Thiagarajan R, et al. Non-length dependent small fibre neuropathy/ganglionopathy. J Neurol Neurosurg Psychiatry. 2008;79(2):163-9.

5. Peters MJ, Bakkers M, Merkies IS, Hoeijmakers JG, van Raak EP, Faber CG. Incidence and prevalence of small-fiber neuropathy: a survey in the Netherlands. Neurology. 2013;81(15):1356-60.

6. Faber CG, Hoeijmakers JG, Ahn HS, et al. Gain of function Nav1.7 mutations in idiopathic small fiber neuropathy. Ann Neurol. 2012;71(1):26-39.

7. Faber CG, Lauria G, Merkies IS, et al. Gain-of-function Nav1.8 mutations in painful neuropathy. Proc NatI Acad Sci U S A. 2012;109(47):19444-9.

8. Huang J, Han C, Estacion M, et al. Gain-of-function mutations in sodium channel Na(v)1.9 in painful neuropathy. Brain. 2014;137(Pt 6):1627-42.

9. Bakkers M, Faber CG, Hoeijmakers JG, Lauria G, Merkies IS. Small fibers, large impact: quality of life in small-fiber neuropathy. Muscle Nerve. 2014;49(3):329-36.

10. Bertelsen AK, Tondel C, Krohn J, et al. Small fibre neuropathy in Fabry disease. J Neurol. 2013;260(3):9179.

11. Biegstraaten M, Binder A, Maag R, Hollak CE, Baron R, van Schaik IN. The relation between small nerve fibre function, age, disease severity and pain in Fabry disease. Eur J Pain. 2011;15(8):822-9.

12. Biegstraaten M, Hollak CE, Bakkers M, Faber CG, Aerts JM, van Schaik IN. Small fiber neuropathy in Fabry disease. Mol Genet Metab. 2012;106(2):135-41.

13. Biegstraaten M, Linthorst GE, van Schaik IN, Hollak CE. Fabry disease: a rare cause of neuropathic pain. Curr Pain Headache Rep. 2013;17(10):365.

14. El-Abassi R, Singhal D, England JD. Fabry's disease. J Neurol Sci. 2014;344(1-2):5-19.

15. Mehta A, Ricci R, Widmer U, et al. Fabry disease defined: baseline clinical manifestations of 366 patients in the Fabry Outcome Survey. Eur J Clin Invest. 2004;34(3):236-42.

16. Zarate YA, Hopkin RJ. Fabry's disease. Lancet. 2008;372(9647):1427-35.

17. Burlina AP, Sims KB, Politei JM, et al. Early diagnosis of peripheral nervous system involvement in Fabry disease and treatment of neuropathic pain: the report of an expert panel. BMC Neurol. 2011;11:61.

18. Germain DP, Waldek S, Banikazemi M, et al. Sustained, long-term renal stabilization after 54 months of agalsidase beta therapy in patients with Fabry disease. J Am Soc Nephrol. 2007;18(5):1547-57.

19. Banikazemi M, Bultas J, Waldek S, et al. Agalsidase-beta therapy for advanced Fabry disease: a randomized trial. Ann Intern Med. 2007;146(2):77-86.

20. Weidemann F, Niemann M, Breunig F, et al. Long-term effects of enzyme replacement therapy on fabry cardiomyopathy: evidence for a better outcome with early treatment. Circulation. 2009;119(4):524-9.

21. Hilz MJ, Brys M, Marthol H, Stemper B, Dutsch M. Enzyme replacement therapy improves function of C, Adelta-, and Abeta-nerve fibers in Fabry neuropathy. Neurology. 2004;62(7):1066-72.

22. Uceyler N, He L, Schonfeld D, et al. Small fibers in Fabry disease: baseline and follow-up data under enzyme replacement therapy. J Peripher Nerv Syst. 2011;16(4):304-14.

23. Schiffmann R, Hauer P, Freeman B, et al. Enzyme replacement therapy and intraepidermal innervation density in Fabry disease. Muscle Nerve. 2006;34(1):53-6.

24. Tesfaye S, Boulton AJ, Dyck PJ, et al. Diabetic neuropathies: update on definitions, diagnostic criteria, estimation of severity, and treatments. Diabetes Care. 2010;33(10):2285-93.

25. Lauria G, Bakkers M, Schmitz C, et al. Intraepidermal nerve fiber density at the distal leg: a worldwide normative reference study. J Peripher Nerv Syst. 2010;15(3):202-7.

26. Yarnitsky D, Sprecher E. Thermal testing: normative data and repeatability for various test algorithms. J Neurol Sci. 1994;125(1):39-45.

27. Bakkers M, Faber CG, Reulen JP, Hoeijmakers JG, Vanhoutte EK, Merkies IS. Optimizing temperature threshold testing in small-fiber neuropathy. Muscle Nerve. 2015;51(6):870-6. 
28. Desnick RJ, Allen KY, Desnick SJ, Raman MK, Bernlohr RW, Krivit W. Fabry's disease: enzymatic diagnosis of hemizygotes and heterozygotes. Alpha-galactosidase activities in plasma, serum, urine, and leukocytes. J Lab Clin Med. 1973;81(2):157-71.

29. Auray-Blais C, Ntwari A, Clarke JT, et al. How well does urinary lyso-Gb3 function as a biomarker in Fabry disease? Clin Chim Acta. 2010;411(23-24):1906-14.

30. Wallis Y, Payne S, McAnulty C, et al. Practical Guidelines for the Evaluation of Pathogenicity and the Reporting of Sequence Variants in Clinical Molecular Genetics. Association for Clinical Genetic Science (ACGS). 2013:1-16.

31. Desnick R, loannou CS, Eng CM. Alpha-Galactosidase A deficiency: Fabry disease. In: Metabolic and Molecular Bases of Inherited Disease Edited by: Scriver, CR, Beaudet, AL, Sly, WS, Valle, D. 2001; New York: McGraw-Hill:3733-74.

32. Sharp A, Robinson D, Jacobs P. Age- and tissue-specific variation of X chromosome inactivation ratios in normal women. Hum Genet. 2000;107(4):343-9.

33. Mehta A, Hughes D. Fabry Disease. In: Pagon RA, Adam MP, Ardinger HH, editors. GeneReviews. Seattle (WA): University of Washington, Seattle; 1993-2014, 2002 aug 05 [updated 2013 Oct 17].

34. Salviati A, Burlina AP, Borsini W. Nervous system and Fabry disease, from symptoms to diagnosis: damage evaluation and follow-up in adult patients, enzyme replacement, and support therapy. Neurol Sci. 2010;31(3):299-306.

35. Federa. Available at: www.federa.org/codes-conduct. Accessed February 13, 2013.

36. Tanislav C, Kaps M, Rolfs A, et al. Frequency of Fabry disease in patients with small-fibre neuropathy of unknown aetiology: a pilot study. Eur J Neurol. 2011;18(4):631-6.

37. Samuelsson K, Kostulas K, Vrethem M, Rolfs A, Press R. Idiopathic small fiber neuropathy: phenotype, etiologies, and the search for fabry disease. J Clin Neurol. 2014;10(2):108-18.

38. MacDermot J, MacDermot KD. Neuropathic pain in Anderson-Fabry disease: pathology and therapeutic options. Eur J Pharmacol. 2001;429(1-3):121-5.

39. van der Tol L, Smid BE, Poorthuis BJ, et al. A systematic review on screening for Fabry disease: prevalence of individuals with genetic variants of unknown significance. J Med Genet. 2014;51(1):1-9.

40. Gal A, Hughes DA, Winchester B. Toward a consensus in the laboratory diagnostics of Fabry disease recommendations of a European expert group. J Inherit Metab Dis. 2011;34(2):509-14. 




\section{CHAPTER 3 ASSOCIATED CONDITIONS IN SMALL FIBER NEUROPATHY a large cohort study and review of the literature}

Bianca T.A. de Greef 1 , MD, Janneke G.J. Hoeijmakers', MD, PhD, Carla M.L. Gorissen-Brouwers ${ }^{1}$, MSc, Margot Geerts ${ }^{1}$, MSc, Catharina G. Faber ${ }^{1}$, MD, PhD, Ingemar S.J. Merkies ${ }^{1,2}, M D, P h D$.

${ }^{1}$ Department of Neurology, School of Mental Health and Neuroscience, Maastricht University Medical Center+, Maastricht, The Netherlands. ${ }^{2}$ Department of Neurology, St. Elisabeth Hospital, Willemstad, Curaçao. 


\section{Abstract}

Background and purpose: Small fiber neuropathy (SFN) is a common disorder, leading to neuropathic pain and autonomic symptoms. The objective of this study was to investigate associated conditions in a large cohort of SFN patients and compare the prevalence to healthy individuals.

Methods :A total of 921 patients with pure SFN were screened according to a standardized comprehensive diagnostic algorithm and compared with literature findings.

Results: No associated condition could be found in $53 \%$ of the patients. Autoimmune diseases, sodium channel gene mutations, diabetes mellitus including glucose intolerance, and vitamin B12 deficiencies were more prevalent than reported literature findings, followed by alcohol abuse, chemotherapy, monoclonal gammopathy of undetermined significance, and haemochromatosis. In patients who were already known with a possible underlying condition at screening, additional underlying conditions were still found in another $26.7 \%$ of patients.

Conclusions: Based on these results, it is recommended that patients with pure SFN are screened at least for autoimmune diseases, sodium channel gene mutations, diabetes mellitus including glucose intolerance, and vitamin B12 deficiency, even when they already have a potential underlying condition at referral. 


\section{Introduction}

Small fiber neuropathy (SFN) affects the thinly myelinated A $\delta$-fibers and the unmyelinated Cfibers and leads to excruciating neuropathic pain and autonomic symptoms ${ }^{1}$ with a negative impact on quality of life expectations. ${ }^{2}$ The diagnosis of pure SFN is based on typical complaints, combined with abnormal intraepidermal nerve fiber density in skin biopsy and/or abnormal temperature threshold testing levels, without signs of large nerve fiber involvement. ${ }^{1,3}$ SFN has been described in several conditions, such as diabetes mellitus and sodium channel gene mutations. ${ }^{1,4}$ Management is mostly based on symptomatic treatment. Knowing which conditions are associated with SFN is important, since some conditions are potentially treatable. Most patients diagnosed with SFN undergo many diagnostic tests to find an underlying cause, leading to high burden for patients and high health-related costs. ${ }^{5}$ Illustratively, it was shown that Fabry disease was not found in 725 patients with isolated SFN, even though it has been mentioned in the literature as a potential underlying illness. ${ }^{6}$ This may also apply to other conditions. A better selection of associated conditions may result in a more targeted diagnostic work-up with lower costs.

The aims of this study were to investigate associated conditions in a large cohort of patients with pure SFN and to compare the prevalence with literature reports on these conditions in healthy persons. Finally, recommendations are provided for a more targeted diagnostic workup in patients with pure SFN.

\section{Methods}

\section{Patients}

From January 2010 to December 2015, all consecutive patients fulfilling the diagnosis criteria for SFN at our SFN Center, Maastricht University Medical Center+ (Maastricht UMC+), were included in this study. Maastricht UMC+ serves as a tertiary referral center for SFN in the Netherlands. Records on complaints and medical history were collected in a standardized fashion as described earlier. ${ }^{7}$ To confirm the diagnosis of SFN, patients needed to have the typical complaints of SFN combined with a reduced intraepidermal nerve fiber density in skin biopsy $^{8}$ and/or abnormal temperature threshold testing ${ }^{9}$ without large nerve fiber involvement based on neurological examination (normal muscle strength, vibration sense, and tendon reflexes) and nerve conduction studies.

To find possible underlying conditions, blood and urine analyses, and a chest X-ray were performed (table 1). The selection of these additional investigations was based on literature review ${ }^{1,10-12}$ and on corresponding diagnostic guidelines (see below).

\section{Underlying conditions}

The following underlying conditions were screened for: alcohol abuse, diabetes mellitus including glucose intolerance, haemochromatosis, autoimmune diseases, monoclonal gammopathy of undetermined significance, sodium channel gene mutations, and vitamin B12 deficiency. The definitions of these underlying conditions are summarized in the supporting information 1. 
Table 1: Diagnostic tests performed in patients referred to the SFN Center

\begin{tabular}{lll}
\hline Kind of test & & Disease investigated \\
X-ray & Chest X-ray & Sarcoidosis \\
\hline Blood samples & Glucose & Diabetes Mellitus
\end{tabular}

\section{Abnormal values}

Sarcoidosis

\begin{tabular}{ll} 
Glucose tolerance test & Impaired glucose tolerance \\
\hline Cholesterol & Hypercholesterolemia
\end{tabular}

Two sober plasma levels of $\geq$

$7.0 \mathrm{mmol} / \mathrm{l}$ or the combination of a sober plasma glucose level of $\geq 7.0$ $\mathrm{mmol} / \mathrm{l}$, a random plasma glucose level of $\geq 11.1 \mathrm{mmol} / \mathrm{l}$ with complaints of hyperglycemia, or a level of $\geq$ $11.1 \mathrm{mmol} / \mathrm{l}$ after $120 \mathrm{~min}$ Sober level of $<7.0 \mathrm{mmol} / \mathrm{l}$ and a level of $\geq 7.8$ and $<11.1$ $\mathrm{mmol} / \mathrm{l}$ after $120 \mathrm{~min}$ Low density lipoprotein value above $3.1 \mathrm{mmol} / \mathrm{l}$, high density lipoprotein value lower than $0.9 \mathrm{mmol} / \mathrm{l}$, and triglyceride value above 2.1 $\mathrm{mmol} / \mathrm{l}$

\begin{tabular}{|c|c|c|}
\hline Liver function & Hepatic impairment & Increased liver functions \\
\hline Kidney function & Renal insufficiency & Glomerular filtration rate $<30$ \\
\hline Thyroid function & $\begin{array}{l}\text { Hypothyroid or } \\
\text { hyperthyroid function }\end{array}$ & $\begin{array}{l}\text { Increased or decreased } \\
\text { thyroid stimulating hormone / } \\
\text { thyroxin }\end{array}$ \\
\hline Vitamin B1 & Vitamin B1 deficiency & $<100 \mathrm{nmol} / \mathrm{l}$ \\
\hline Vitamin B6 & Vitamin B6 toxicity & $>200 \mathrm{nmol} / \mathrm{l}$ \\
\hline Vitamin B12 & Vitamin B12 deficiency & $<148 \mathrm{pmol} / \mathrm{l}$ \\
\hline Anti-tissue transglutaminase & Coeliac disease & Present \\
\hline $\begin{array}{l}\text { Anti extractable nuclear } \\
\text { antigen antibodies }\end{array}$ & Sjogren's disease & Present \\
\hline $\begin{array}{l}\text { Antinuclear antibodies, anti- } \\
\text { neutrophil cytoplasmic } \\
\text { antibodies, and soluble } \\
\text { Interleukin-2 receptor }\end{array}$ & $\begin{array}{l}\text { Other auto-immune } \\
\text { diseases }\end{array}$ & $\begin{array}{l}\text { Present or soluble IL-2 } \\
\text { receptor above } 700 \mathrm{U} / \mathrm{I}\end{array}$ \\
\hline Monoclonal gammopathy & $\begin{array}{l}\text { Monoclonal gammopathy } \\
\text { of undetermined } \\
\text { significance }\end{array}$ & Present \\
\hline $\begin{array}{l}\text { Borrelia burgdorferi } \\
\text { (immunoglobulin I and M) }\end{array}$ & Lyme's disease & Present \\
\hline $\begin{array}{l}\text { Anti-human } \\
\text { immunodeficiency virus } 1 \\
\text { and } 2\end{array}$ & $\begin{array}{l}\text { Human immunodeficiency } \\
\text { virus }\end{array}$ & Present \\
\hline $\begin{array}{l}\text { Alfa-galactosidase A activity } \\
\text { and alpha-galactosidase A } \\
\text { gene }\end{array}$ & Fabry disease & $\begin{array}{l}<30 \mathrm{mmol} / \mathrm{l} \text { and variants class } \\
3,4 \text { or } 5 \text {. }\end{array}$ \\
\hline $\begin{array}{l}\text { SCN9A-, SCN10A-, and } \\
\text { SCN11A-gene }\end{array}$ & $\begin{array}{l}\text { Sodium channel gene } \\
\text { mutations }\end{array}$ & $\begin{array}{l}\text { Variants with uncertain } \\
\text { clinical significance, possibly } \\
\text { pathogenic, probably } \\
\text { pathogenic or pathogenic } \\
\text { variants }\end{array}$ \\
\hline $\begin{array}{l}\text { lysosomal } \\
\text { globotriaosylceramide }\end{array}$ & Fabry disease & $>0 \mathrm{nmol} / \mathrm{mmol}$ creatinine \\
\hline
\end{tabular}

Legend to table 1: SCN, sodium voltage-gated channels. 
Supporting information 1. Definitions of underlying conditions.

\section{Underlying conditions}

Alcohol abuse was defined as an alcohol consumption of $>5$ international unit (IU) per day. ${ }^{1}$ The diagnosis DM was based on two fasting plasma glucose levels of $\geq 7.0 \mathrm{mmol} / \mathrm{l}$ (measured on two different days), the combination of a fasting plasma glucose level of $\geq 7.0 \mathrm{mmol} / \mathrm{l}$, a random plasma glucose level of $\geq 11.1 \mathrm{mmol} / \mathrm{I}$ with complaints of hyperglycemia or a level of $\geq 11.1 \mathrm{mmol} / \mathrm{l}$ after 120 minutes at the glucose tolerance test. ${ }^{2}$ Impaired glucose tolerance was defined as a glucose level of $\geq 7.8$ and $<11.1 \mathrm{mmol} / \mathrm{l}$ after 120 minutes at a sober level of $<7.0 \mathrm{mmol} / \mathrm{I}^{2}$

Haemochromatosis was suspected when there was an increase in the transferrin saturation and the serum ferritin. If there was a high level of iron, the blood was tested for a mutation in the HFE gene (High iron Fe). ${ }^{3}$ An experienced internal medicine physician confirmed the diagnosis of hemochromatosis.

Patients were referred to an immunologist for additional investigations, when an underlying immunological disease was suspected, such as sarcoidosis (e.g. abnormalities on chest X-ray), ${ }^{4}$ Sjogren's disease (positive anti-ENA antibodies, antinuclear antibodies (ANA)), ${ }^{5}$ or increased soluble Interleukin-2 receptor, a non-specific marker for autoimmune diseases. Coeliac disease was suspected when anti-tissue transglutaminase (anti-TTG) was found; ${ }^{6}$ these patients were referred to a gastroenterologist. Potential treatments in these cases were led to the interpretation of these experts to execute.

Monoclonal gammopathy of undetermined significance (MGUS) was diagnosed when monoclonal gammopathy was present without evidence for malignancies as a cause after investigation by a hematologist. ${ }^{7}$

Variants in the coding and intermediate flanking regions of the sodium channel genes SCN9A, SCN1OA and SCN11A were interpreted in the context of functional assessment, or family segregation analysis of phenotype and genotype. ${ }^{8}$

Vitamin B12 deficiency was defined as a serum concentration of vitamin B12 lower than 148 $\mathrm{pmol} / \mathrm{I}^{9}$

1. Koike H, Mori K, Misu K, et al. Painful alcoholic polyneuropathy with predominant small-fiber loss and normal thiamine status. Neurology. 2001;56(12):1727-32.

2. Dutch College of General Practitioners - standard Diabetes Mellitus type 2 2013. Available from: https://www.nhg.org/standaarden/volledig/nhg-standaard-diabetes-mellitus-type-2.

3. Sood R, Bakashi R, Hegade VS, Kelly SM. Diagnosis and management of hereditary haemochromatosis. $\mathrm{Br} J$ Gen Pract. 2013;63(611):331-2.

4. National Heart LaBi. Sarcoidosis. How is Sarcoidosis diagnosed? 2013. Available from: https://www.nhlbi.nih.gov/health/health-topics/topics/sarc/diagnosis.

\section{Literature comparison}

Literature research on potential conditions related to SFN was performed in PubMed database using the following keywords "small fiber neuropathy", "small fibre neuropathy", "neuropathy", "painful neuropathy", "etiology", in combination with the different known conditions. Also Dutch guidelines were searched for prevalence of the conditions in healthy controls. 


\section{Statistics}

Patients' characteristics were expressed as mean with standard deviation, when data were normally distributed. When not normally distributed, the median and the interquartile range were calculated. Frequencies between two groups were compared by using the chi-squared test. A stepwise approach was conducted: the prevalence of conditions potentially related to SFN was measured and subsequently compared with reported prevalence in healthy controls. Analyses were performed using SPSS (Version 23.0, SPSS Inc., Chicago, IL, USA).

\section{Standard protocol approvals, registrations, and patient consents}

The Maastricht UMC+'s Medical Ethics Committee and Board of Directors approved this study. According to the Code of Conduct for the use of data in Health Research, ${ }^{13}$ for this type of retrospective study, informed consent does not need to be obtained if the data are used anonymously and patients are given the opportunity to object against the use of their medical and personal data for research (which is the case in the Maastricht UMC+).

\section{Results}

Of 1275 patients screened, the diagnosis pure SFN could be established in $72 \%$ ( $n=921$; figure 1). The characteristics of SFN patients included in the study are shown in table 2. After the diagnostic workup, no underlying condition was found in 488 patients (53\%).

Results of the total cohort of patients with pure SFN.

In the total cohort, 696 patients (75.6\%) did not have known SFN-related comorbidities before the diagnostic workup.

The diagnostic workup ( $n=921$ ) showed immunological conditions in 175 patients (19\%), including sarcoidosis (3.0\%), Sjogren's disease (1.3\%), coeliac disease $(0.5 \%)$, other autoimmune diseases (8.8\%) and non-specific abnormal immunological laboratory findings (6.1\%). Eight patients had two or more of these conditions. The other most frequently found associated conditions with available prevalence numbers in the general population were variants in SCN9A (8.5\%), SCN1OA (4.8\%), and SCN11A (3.4\%), diabetes mellitus (7.7\%), vitamin B12 deficiency (4.7\%), alcohol abuse (3.0\%), chemotherapy (2.2\%), monoclonal gammopathy of undetermined significance (MGUS) (1.4\%) and haemochromatosis (0.3\%) (figure 2). The MGUS subtypes included IgG-MGUS (62\%), IgM-MGUS (15\%), IgA-MGUS (15\%), and a biclonalMGUS (8\%, IgG and IgA). The glucose intolerance test was performed in 493 of these patients. In total, 48 patients were found with glucose intolerance (9.7\%). The prevalence of the other conditions screened for are shown in supporting information 2. In 488 patients (53\%), no underlying conditions were found despite extensive laboratory testing (idiopathic SFN). Of the above-mentioned conditions, only variants in the SCN9A-gene were found significantly more often in patients with a non-length-dependent pattern of SFN compared to patients with length-dependent complaints (12.4\% versus 6.9\%, p-value: 0.014), whereas all other conditions showed no differences. 
Figure 1 Flowchart of inclusion/exclusion

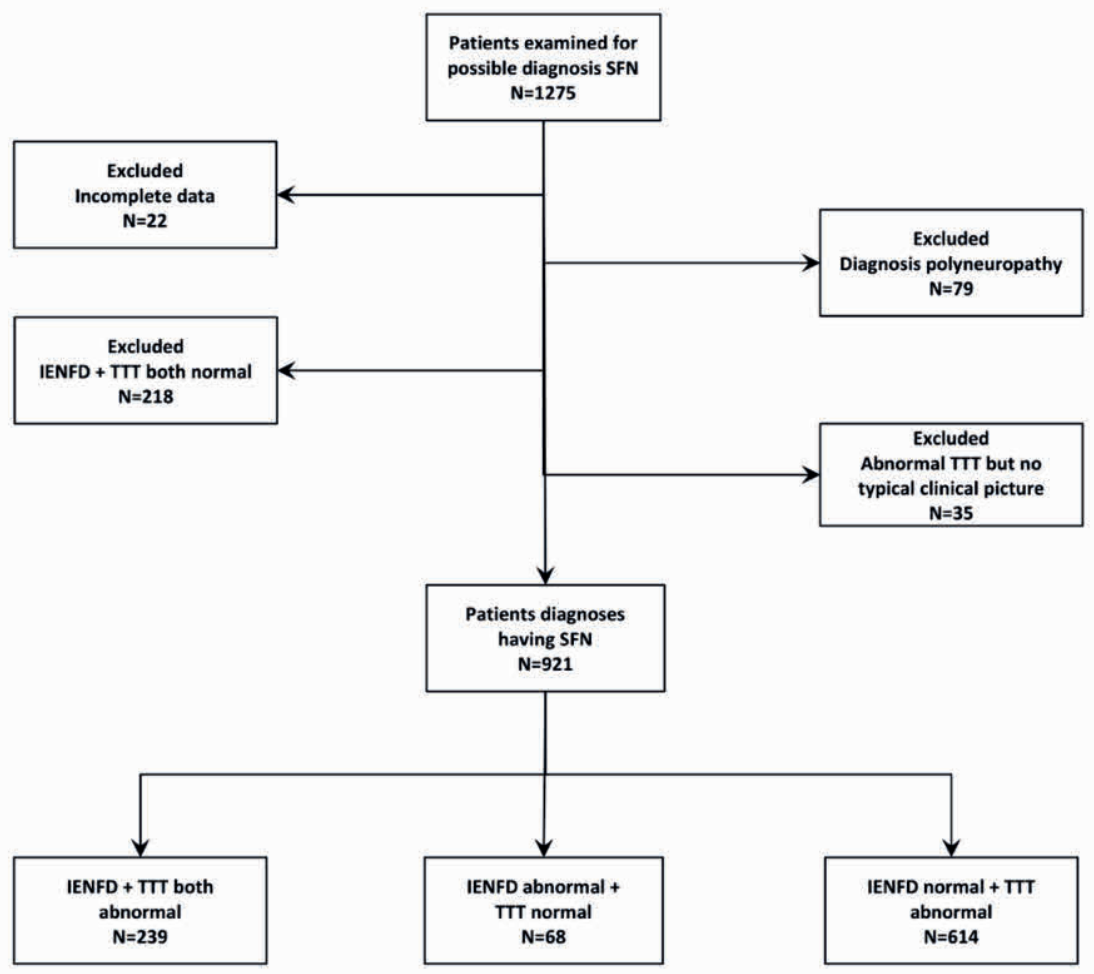

Legend to figure 1: IENFD, intraepidermal nerve fiber density; SFN, small fiber neuropathy; TTT, temperature threshold testing.

Table 2: Characteristics of patients with confirmed diagnosis of SFN

\begin{tabular}{ll|}
\hline Female (\%) & Total, $\mathrm{n}=921$ \\
\hline Age at visit, median (IQR) & $532(57.8)$ \\
\hline Age at onset, median (IQR) & $53(44-61.5)$ \\
\hline Duration of complaints, median (IQR) & $47(38-57)$ \\
\hline Diagnosis SFN & $3(2-7)$ \\
\hline Abnormal TTT (\%) & $614(66.7)$ \\
\hline Abnormal Skin biopsy (\%) & $68(7.4)$ \\
\hline Abnormal TTT \& Skin biopsy (\%) & $239(26)$ \\
\hline Legend to table 2: IQR, interquartile range; SFN, small fiber neuropathy; TTT, temperature threshold testing.
\end{tabular}


Supporting information 2. Prevalence of other conditions.

\begin{tabular}{|c|c|c|c|c|}
\hline \multicolumn{2}{|l|}{$\begin{array}{l}\text { Kind of } \\
\text { test }\end{array}$} & Disease investigated & Abnormal values & $\begin{array}{l}\text { Results in study } \\
\text { population }\end{array}$ \\
\hline & Kidney function & Renal insufficiency & $\begin{array}{l}\text { Glomerular filtration } \\
\text { rate }<30\end{array}$ & $\begin{array}{l}\text { Prior to screening: } \\
n=4(0.4 \%) \\
\text { New cases: } n=0(0 \%)\end{array}$ \\
\hline & Vitamin B1 & $\begin{array}{l}\text { Vitamin B1 } \\
\text { deficiency }\end{array}$ & $<100 \mathrm{nmol} / \mathrm{l}$ & $\begin{array}{l}\text { Prior to screening: } \\
n=0(0 \%) \\
\text { New cases: } n=22 \\
(2.4 \%)\end{array}$ \\
\hline & Vitamin B6 & Vitamin B6 toxicity & $>200 \mathrm{nmol} / \mathrm{l}$ & $\begin{array}{l}\text { Prior to screening: } \\
n=1(0.1 \%) \\
\text { New cases: } n=47 \\
(5.1 \%)\end{array}$ \\
\hline & $\begin{array}{l}\text { Anti-human } \\
\text { immunodeficiency } \\
\text { virus } 1 \text { and } 2\end{array}$ & $\begin{array}{l}\text { human } \\
\text { immunodeficiency } \\
\text { virus }\end{array}$ & Present & $\begin{array}{l}\text { Prior to screening: } \\
n=0(0 \%) \\
\text { New cases: } n=0(0 \%)\end{array}$ \\
\hline & $\begin{array}{l}\text { Alfa-galactosidase A } \\
\text { activity and alpha- } \\
\text { galactosidase A gene }\end{array}$ & Fabry disease & $\begin{array}{l}<30 \mathrm{mmol} / \mathrm{l} \text { and } \\
\text { variants class 3, 4, or } 5 .\end{array}$ & $\begin{array}{l}\text { Prior to screening: } \\
n=0(0 \%) \\
\text { New cases: } n=0(0 \%)\end{array}$ \\
\hline $\begin{array}{l}\text { Urine } \\
\text { sample }\end{array}$ & $\begin{array}{l}\text { Lysosomal } \\
\text { globotriaosylceramide }\end{array}$ & Fabry disease & $\begin{array}{l}>0 \mathrm{nmol} / \mathrm{mmol} \\
\text { creatinine }\end{array}$ & $\begin{array}{l}\text { Prior to screening: } \\
n=0(0 \%) \\
\text { New cases: } n=0(0 \%)\end{array}$ \\
\hline
\end{tabular}

Legend to supporting information 2: Results of different laboratory tests in study population, which are not mentioned in the manuscript.

Results for the group of SFN patients without known associated conditions at presentation.

Of the patients without comorbidity at presentation ( $n=696$ ), abnormal immunological laboratory findings were present in 5.9\%, variants in SCN9A in 9.6\%, SCN1OA in 4.5\%, SCN11A in 3.4\%, diabetes mellitus in 3\%, vitamin B12 deficiency in $0.75 \%$, and MGUS in $0.6 \%$. In 379 of these patients, glucose intolerance was tested and this was diagnosed in 35 patients (9.2\%). In total, associated conditions were found in 208 of these patients $(29.9 \%)$ with additional diagnostic tests.

Results for the group with known comorbidities at presentation.

In the group of patients that were already known to have one or more comorbidities $(n=225)$ at presentation, also new abnormalities were found: abnormal immunological laboratory findings (5.8\%), variants in SCN9A (4.9\%), SCN1OA (5.8\%), and SCN11A (3.1\%), and diabetes mellitus (2.7\%). In 114 of these patients, glucose intolerance was tested and was diagnosed in 13 patients (11.4\%). In total, additional associated conditions were found in 60 patients $(26.7 \%)$ with our diagnostic panel. 
Figure 2. Prevalence of possible underlying causes in patients with SFN ( $n=921)$.

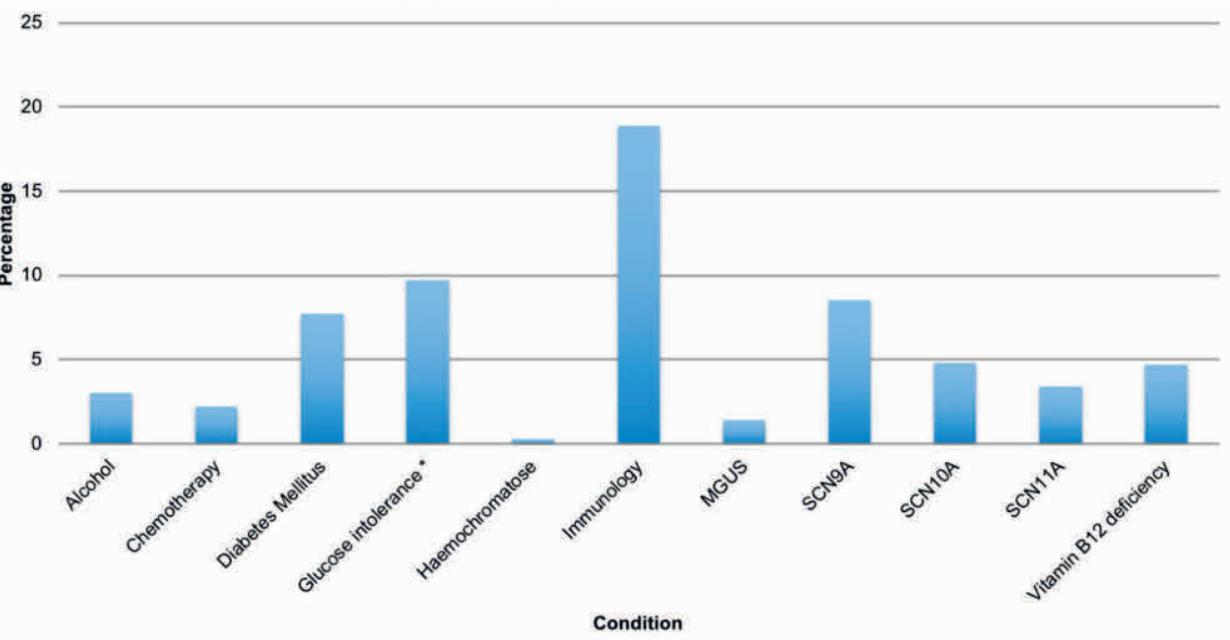

Legend to figure 2: * Glucose intolerance was only tested in 493 patients instead of 921.

Immunology; Sarcoidosis, Sjogren's disease, coeliac disease, other autoimmune diseases, and abnormal immunological laboratory findings (antinuclear antibodies, anti-neutrophil cytoplasmic antibodies, monoclonal gammopathy, soluble interleukin-2 receptor, anti-tissue transglutaminase, and anti-extractable nuclear antigen antibodies), MGUS; monoclonal gammopathy of undetermined significance, SCN; sodium voltage-gated channels.

\section{Discussion}

In our cohort of 921 patients with pure SFN, an underlying condition was found in 433 patients (47\%). The most prevalent conditions were immunological conditions, sodium channel gene mutations, diabetes mellitus including glucose intolerance, and vitamin B12 deficiency and at least these entities are suggested to be tested in the diagnostic workup of potential SFN. Even if comorbidity was present at presentation, still other associated conditions were found in 26.7\% after diagnostic testing. After thorough workup, 53\% of patients had no underlying cause (idiopathic pure SFN), which is in conformity with literature. ${ }^{11,14} \mathrm{~A}$ recent study also described high prevalence of immunological abnormalities, but no association with diabetes mellitus or vitamin B12 deficiency, possibly due to smaller sample size and different criteria for diagnosis of SFN. ${ }^{15}$

\section{Immunological abnormalities}

Immunological conditions may affect nerve fibers, ${ }^{16}$ and were found in $12.9 \%$ ( $\left.n=119\right)$ of patients, whereas another $6.1 \%$ of patients had one or more abnormal immunological laboratory findings. The overall prevalence of autoimmune diseases in the Netherlands is around $3 \%-6 \%,{ }^{17}$ which is much lower than in our cohort.

Also the prevalence of sarcoidosis is higher in our cohort than in the general European population (3.0\% versus $0.005 \%-0.03 \%$ ). ${ }^{18}$ However, the prevalence of sarcoidosis in our cohort might be an overestimation, because until 5 years ago Maastricht UMC+ was a tertiary referral center for patients with sarcoidosis.

Sjogren's disease was present in $1.3 \%$ of our SFN patients compared to a prevalence in the general population of $0.1 \%-4.8 \%$, thus within the reported limits in the general population. ${ }^{19}$ 
Of our patients, $0.5 \%$ had coeliac disease, with a prevalence of recognized coeliac disease of $0.016 \%$ and non-recognized coeliac disease around $0.35 \%$ in the Netherlands. ${ }^{20}$

\section{Sodium channel gene mutations}

In $16.7 \%$ of SFN patients a sodium channel gene variant was found. The sodium channels Nav1.7, Nav1.8, and Nav1.9, coded by SCN9A, SCN10A, and SCN11A respectively, are all preferentially expressed in peripheral nerves. ${ }^{21}$ Mutations in the SCN9A-, SCN10A-, and SCN11A-gene, showing electrophysiological changes in the corresponding channel, have been described by others and us in patients with SFN. ${ }^{7,22,23}$ Although the exact mechanism for axonal degeneration is not completely clear, it is plausible that DRG neuron hyperexcitability results in neuropathic pain. ${ }^{24}$ The results in this cohort are comparable to the results that are published earlier in a smaller cohort $(n=393),{ }^{4}$ although prevalence is lower than the results of SCN9A-variants in a small cohort of patients with biopsy-confirmed idiopathic SFN. ${ }^{7}$ SCN9Avariants were more frequently found in the patients with a non-length dependent pattern; which is in line with the description of different clinical patterns in patients with SCN9Amutations and SFN. ${ }^{25}$

\section{Diabetes mellitus}

Diabetes mellitus was found in $7.7 \%$, of which most (90.1\%) were type 2 diabetes. Peripheral neuropathy is the most common complication of diabetes mellitus with lifetime prevalence up to $50 \% .{ }^{26}$ The prevalence of diabetes is around $6 \%$ in the Netherlands. ${ }^{27}$ Our proportion found in SFN (7.7\%) is higher than the prevalence of patients in the Netherlands. The prevalence in our cohort probably is an underestimation, as most patients with painful diabetic neuropathy will not be referred to our center, because painful neuropathy is a well-known complication of diabetes mellitus.

In addition, as has been suggested by literature, the glucose tolerance test was also abnormal in $9.7 \%$ of the patients, adding to the underlying conditions of SFN. ${ }^{28,29}$

\section{Vitamin B12 deficiency}

Vitamin B12 deficiency was present in $4.7 \%$ of SFN patients. The prevalence of vitamin B12 deficiency is less than $3 \%$ in the general population aged between 20 and 39 years, and increases gradually up to $10 \%$ or higher in people of 70 years or older. The prevalence of vitamin B12 deficiency in our SFN population was higher than in the general population. According to general guidelines, vitamin B12 deficiency was diagnosed when serum vitamin B12 was below $148 \mathrm{pmol} / \mathrm{l}$ or when there was a history of vitamin B12 deficiency for which patients were treated. Homocystein or methylmalonic acid was not assessed, which may have led to underestimation of functional vitamin B12 in patients with serum vitamin B12 of 148$258 \mathrm{pmol} / \mathrm{l}$.

\section{Alcohol abuse}

In our cohort $3.0 \%$ of the patients $(n=28)$ reported an alcohol consumption of $>5$ IU/day. As people tend to underreport their alcohol intake, this may be an underestimation as well. ${ }^{30}$ The 
typical presentation of alcohol-related peripheral neuropathy is a painful, burning neuropathy and autonomic instability. ${ }^{31}$ In the Netherlands, the estimated prevalence of alcohol abuse is $0.75 \%$ of adults between 18 and 65 years old. ${ }^{30}$ The prevalence of alcohol abuse is higher in our cohort of patients with pure SFN suggesting an association.

\section{Chemotherapy}

Chemotherapy-induced peripheral neuropathy is a well-known adverse event of several chemotherapeutic agents, and was present in $2.2 \%(n=20)$ of our patients with pure SFN. Different prevalence are mentioned, between $17 \%$ and $88 \%$, for different ages, different grades of neuropathies and different agents. ${ }^{32}$ The prevalence of chemotherapy found in our cohort is probably underestimated, as these patients are usually not referred because the neuropathy is considered an expected adverse event of the treatment.

\section{Monoclonal gammopathy of undetermined significance}

In our cohort, $1.4 \%$ patients were known with MGUS. The etiology of MGUS in peripheral neuropathy is not very well understood. ${ }^{33}$ In healthy subjects (above $45-50$ years old) the prevalence of MGUS is found in 3.2\%-3.5\%. ${ }^{34,35}$ The prevalence of monoclonal gammopathy increases with age. ${ }^{36}$ The prevalence of MGUS in our population is lower than the prevalence found in the general population. However, the overall prevalence is based on subjects between 45 and 50 years old, and in our population we have patients ranging from 11 to 85 years.

\section{Haemochromatosis}

Three patients (0.3\%) had haemochromatosis. In north-European countries, $0.4 \%$ of the people are homozygote for the $\mathrm{C} 282 \mathrm{Y}$ allele. ${ }^{37}$ This means that the prevalence in the whole population is equal to the prevalence in patients with SFN, which makes the association between SFN and haemochromatosis less likely.

\section{Patients with associated conditions at presentation}

Despite having an associated condition at presentation, additional associated conditions were found in $26.7 \%$ in our SFN cohort. Finding other diseases might lead to new treatment possibilities for these patients, and possibly relieve of complaints or prevention of disease progression.

\section{Pathophysiology}

This study shows that some of the associated conditions are more prevalent in patients with pure SFN compared to healthy persons. However, the underlying pathophysiology is still unclear in most of these conditions. It would be of interest to investigate these specific conditions in detail in animal models, to search for underlying mechanisms. This knowledge would also stimulate the development of targeted therapy. Better treatments would lead to reduction of pain, and therefore to lower health costs. ${ }^{5}$ 


\section{Conclusion.}

Autoimmune diseases, sodium channel gene mutations, diabetes mellitus including glucose intolerance, and vitamin B12 deficiency are the most common underlying conditions in patients with pure SFN; despite a thorough workup no underlying condition could be found in $53 \%$ of the SFN patients. The prevalence of alcohol abuse, autoimmune diseases, diabetes mellitus including glucose intolerance, and vitamin B12 deficiencies seems higher in our population of patients with pure SFN than found in the general population. Moreover, the prevalence of SFN is much higher in patients which received chemotherapy compared to the prevalence of SFN in the Netherlands. For these conditions a causal relationship with small nerve fiber damage is suspected. Further research is needed to explore the exact pathophysiological mechanisms. Although some patients are already known with an underlying condition at presentation, it is still recommended that all patients with pure SFN are tested for diabetes mellitus including glucose intolerance, autoimmune diseases, sodium channel gene mutations, and vitamin B12 deficiency. Testing for rarer underlying conditions can be considered in SFN, based on specific signs or symptoms. 


\section{References.}

1. Hoeijmakers JG, Faber CG, Lauria G, Merkies IS, Waxman SG. Small-fibre neuropathies-advances in diagnosis, pathophysiology and management. Nat Rev Neurol. 2012;8(7):369-79.

2. Bakkers M, Faber CG, Hoeijmakers JG, Lauria G, Merkies IS. Small fibers, large impact: quality of life in small-fiber neuropathy. Muscle Nerve. 2014;49(3):329-36.

3. Tesfaye S, Boulton AJ, Dyck PJ, et al. Diabetic neuropathies: update on definitions, diagnostic criteria, estimation of severity, and treatments. Diabetes Care. 2010;33(10):2285-93.

4. Brouwer BA, Merkies IS, Gerrits MM, Waxman SG, Hoeijmakers JG, Faber CG. Painful neuropathies: the emerging role of sodium channelopathies. J Peripher Nerv Syst. 2014;19(2):53-65.

5. Schaefer C, Mann R, Sadosky A, et al. Health status, function, productivity, and costs among individuals with idiopathic painful peripheral neuropathy with small fiber involvement in the United States: results from a retrospective chart review and cross-sectional survey. J Med Econ. 2014;17(6):394-407.

6. de Greef BT, Hoeijmakers JG, Wolters EE, et al. No Fabry Disease in Patients Presenting with Isolated Small Fiber Neuropathy. PLoS One. 2016;11(2):e0148316.

7. Faber CG, Hoeijmakers JG, Ahn HS, et al. Gain of function Nav1.7 mutations in idiopathic small fiber neuropathy. Ann Neurol. 2012;71(1):26-39.

8. Lauria G, Bakkers M, Schmitz C, et al. Intraepidermal nerve fiber density at the distal leg: a worldwide normative reference study. J Peripher Nerv Syst. 2010;15(3):202-7.

9. Bakkers M, Faber CG, Reulen JP, Hoeijmakers JG, Vanhoutte EK, Merkies IS. Optimizing temperature threshold testing in small-fiber neuropathy. Muscle Nerve. 2015;51(6):870-6.

10. Hovaguimian A, Gibbons $\mathrm{CH}$. Diagnosis and treatment of pain in small-fiber neuropathy. Curr Pain Headache Rep. 2011;15(3):193-200.

11. Devigili G, Tugnoli V, Penza P, et al. The diagnostic criteria for small fibre neuropathy: from symptoms to neuropathology. Brain. 2008;131(Pt 7):1912-25.

12. Lauria G. Small fibre neuropathies. Curr Opin Neurol. 2005;18(5):591-7.

13. Federa. Available at: www.federa.org/codes-conduct. Accessed February 13, 2013.

14. Peters MJ, Bakkers M, Merkies IS, Hoeijmakers JG, van Raak EP, Faber CG. Incidence and prevalence of small-fiber neuropathy: a survey in the Netherlands. Neurology. 2013;81(15):1356-60.

15. Lang M, Treister R, Oaklander AL. Diagnostic value of blood tests for occult causes of initially idiopathic small-fiber polyneuropathy. J Neurol. 2016;263(12):2515-27.

16. Lehmann HC, Meyer Zu Horste G, Kieseier BC, Hartung HP. Pathogenesis and treatment of immunemediated neuropathies. Ther Adv Neurol Disord. 2009;2(4):261-81.

17. Rijkers GT, Batstra MR, Allebes W, Janssens PMW. Auto-immuunziekten. Ned Tijdschr Klin Chem Labgeneesk. 2006(31):246-8.

18. Mekkes JR. Sarcoidosis 2014. Available from: http://www.huidziekten.nl/zakboek/dermatosen/stxt/ Sarcoidose.htm.

19. Tincani A, Andreoli L, Cavazzana I, et al. Novel aspects of Sjogren's syndrome in 2012. BMC Med. 2013;11:93.

20. Maag-Darm-Leverartsen NVv. Guideline coeliac disease and dermatitis herpetiformis. 2008.

21. Dib-Hajj SD, Tyrrell L, Black JA, Waxman SG. NaN, a novel voltage-gated Na channel, is expressed preferentially in peripheral sensory neurons and down-regulated after axotomy. Proc Natl Acad Sci U S A. 1998;95(15):8963-8.

22. Faber CG, Lauria G, Merkies IS, et al. Gain-of-function Nav1.8 mutations in painful neuropathy. Proc Nat/ Acad Sci U S A. 2012;109(47):19444-9.

23. Huang J, Han C, Estacion M, et al. Gain-of-function mutations in sodium channel Na(v)1.9 in painful neuropathy. Brain. 2014;137(Pt 6):1627-42.

24. Hoeijmakers JG, Faber CG, Merkies IS, Waxman SG. Painful peripheral neuropathy and sodium channel mutations. Neurosci Lett. 2015;596:51-9.

25. Estacion M, Han C, Choi JS, et al. Intra- and interfamily phenotypic diversity in pain syndromes associated with a gain-of-function variant of NaV1.7. Mol Pain. 2011;7:92.

26. Boulton AJ, Vinik Al, Arezzo JC, et al. Diabetic neuropathies: a statement by the American Diabetes Association. Diabetes Care. 2005;28(4):956-62. 
27. National Public Health Compass - Diabetes Mellitus 2014. Available from: http://www.nationaalkompas.nl/gezondheid-en-ziekte/ziekten-en-aandoeningen/endocrienevoedings-en-stofwisselingsziekten-en-immuniteitsstoornissen/diabetes-mellitus/.

28. Singleton JR, Smith AG, Bromberg MB. Increased prevalence of impaired glucose tolerance in patients with painful sensory neuropathy. Diabetes Care. 2001;24(8):1448-53.

29. Singleton JR, Smith AG, Bromberg MB. Painful sensory polyneuropathy associated with impaired glucose tolerance. Muscle Nerve. 2001;24(9):1225-8.

30. National Public Health Compass - Alcohol dependence 2010. Available from: http://www.nationaalkompas.nl/gezondheid-en-ziekte/ziekten-en-aandoeningen/psychischestoornissen/afhankelijkheid-van-alcohol-drugs-of-andere-middelen/afhankelijkheid-van-alcohol/.

31. Mellion ML, Silbermann E, Gilchrist JM, Machan JT, Leggio L, de la Monte S. Small-fiber degeneration in alcohol-related peripheral neuropathy. Alcohol Clin Exp Res. 2014;38(7):1965-72.

32. Brewer JR, Morrison G, Dolan ME, Fleming GF. Chemotherapy-induced peripheral neuropathy: Current status and progress. Gynecol Oncol. 2016;140(1):176-83.

33. Ramchandren S, Lewis RA. An update on monoclonal gammopathy and neuropathy. Curr Neurol Neurosci Rep. 2012;12(1):102-10.

34. Eisele L, Durig J, Huttmann A, et al. Prevalence and progression of monoclonal gammopathy of undetermined significance and light-chain MGUS in Germany. Ann Hematol. 2012;91(2):243-8.

35. Kyle RA, Therneau TM, Rajkumar SV, et al. Prevalence of monoclonal gammopathy of undetermined significance. N Engl J Med. 2006;354(13):1362-9.

36. Crawford J, Eye MK, Cohen HJ. Evaluation of monoclonal gammopathies in the "well" elderly. Am J Med. 1987;82(1):39-45.

37. European Association For The Study Of The L. EASL clinical practice guidelines for HFE hemochromatosis. J Hepatol. 2010;53(1):3-22. 




\section{PART III}

TREATMENT OF NEUROPATHIC PAIN IN SMALL FIBER NEUROPATHY 



\section{CHAPTER 4 NEUROPATHIC PAIN DUE TO SMALL FIBER NEUROPATHY IN AGING current management and future prospects}

Brigitte A. Brouwer ${ }^{1}, M D$, Bianca T.A. de Greef ${ }^{2}, M D$, Janneke G.J. Hoeijmakers $^{2}, M D, P h D$, Margot Geerts ${ }^{2}, M S c$, Maarten van Kleef ${ }^{1}, M D, P h D$, Ingemar S.J. Merkies ${ }^{2,3}, \mathrm{MD}, \mathrm{PhD}$, Catharina G. Faber $\mathrm{CG}^{2}, \mathrm{MD}, \mathrm{PhD}$.

${ }^{1}$ Department of Anesthesiology and Pain Medicine, Maastricht University Medical Center, 6202 AZ Maastricht, the Netherlands ${ }^{2}$ Department of Neurology, Maastricht University Medical Center, 6202 AZ Maastricht, the Netherlands

${ }^{3}$ Department of Neurology, Spaarne Hospital, 2130 AT Hoofddorp, The Netherlands 


\section{Abstract}

Over the last 10 years, the diagnosis small fiber neuropathy (SFN) has gained recognition worldwide. Patients often suffer from severe neuropathic pain that may be difficult to treat. A substantial subset of patients with SFN is aged 65 years or older, and these patients often exhibit comorbidities and usage of multiple drugs, making neuropathic pain treatment more challenging. In this review, we highlight relevant pathophysiological aspects and discuss currently used therapeutic strategies for neuropathic pain. Possible pitfalls in neuropathic pain treatment in the elderly will be underlined. 


\section{Introduction}

Small fiber neuropathy (SFN) is a peripheral neuropathy in which predominantly the unmyelinated C-fibers and thinly myelinated A $\delta$-fibers are affected. ${ }^{1}$ The diagnosis is based on clinical symptoms, reduced intra-epidermal nerve fiber density in skin biopsy, and/or abnormal temperature threshold tests, ${ }^{2-4}$ and no large nerve fiber involvement at physical examination or nerve conduction tests. The prevalence is at least 53 cases per 100,000 inhabitants, and the rates are higher in elderly patients. ${ }^{5}$ Many conditions have been associated with small fiber neuropathy, such as diabetes mellitus, hyperlipidemia, amyloidosis, Fabry syndrome, celiac disease, sarcoidosis and other systemic illnesses, human immunodeficiency virus (HIV) infection, and hereditary sensory and autonomic neuropathies. ${ }^{3}$ Recently, also pathogenic mutations in sodium channels ( $\mathrm{Na}_{v} 1.7, \mathrm{Na}_{v} 1.8$ and $\left.\mathrm{Na}_{v} 1.9\right)$ were reported in patients with painful neuropathy. ${ }^{6}$ Despite a comprehensive work-up of patients with SFN, in a substantial proportion (ranging from $24 \%$ to $93 \%$ in different series) no underlying cause can be identified. $^{3}$

SFN patients often suffer from devastating pain, and have a severely reduced quality of life. ${ }^{7}$ In addition to the typical SFN-related complaints (neuropathic pain and autonomic symptoms such as dry mouth, dry eyes, micturation problems or bowel dysfunction), anxiety, depression, sleeping problems and fatigue may also influence quality-of-life expectations. ${ }^{8-10}$ Pain severity is associated with a high use of medication, frequent physician consultations and substantial health care costs. ${ }^{10}$

For the symptomatic treatment of neuropathic pain in SFN, mostly general guidelines are used. ${ }^{11-15}$ Pharmacological treatment options mainly are antidepressants, ${ }^{16}$ anticonvulsants, ${ }^{17}$ and opioids ${ }^{18}$ with generally disappointing results. ${ }^{14}$

\section{Pathways in neuropathic pain}

Understanding pathways and mechanisms involved in the development of neuropathic pain is important to define possible therapeutic targets. Pain is defined as an unpleasant sensory and emotional experience associated with actual or potential tissue damage. ${ }^{19}$ As the definition suggests, pain is a subjective phenomenon, and is difficult to catch in an objective outcome measure. ${ }^{20-23}$ In humans, pain represents a final integrative package, consisting of neurophysiological processes as well as contextual, psychological, and sociocultural factors.

Neuropathic pain is caused by a lesion or disease that affects the somatosensory nervous system. ${ }^{19}$ The thinly myelinated A $\delta$-fibers and unmyelinated C-fibers, predominantly involved in SFN, ${ }^{1-3}$ arise in the skin where they serve for the detection of cold, heat and, as nociceptors, for detection of painful stimuli. ${ }^{24-26}$ In addition, they fulfill an efferent function as part of the peripheral autonomic nervous system. ${ }^{3,27}$ Generally, nociceptors are electrically silent; after activation by noxious stimuli an action potential is initiated and transported via peripheral axons to the cell bodies located in the trigeminal ganglia and in the dorsal root ganglia alongside the spinal column and medulla oblongata. ${ }^{6}$ Via central axons, the signal is transmitted onward to synapse on second order neurons in the central nervous system. 24,26 Voltage-gated sodium, potassium and calcium channels, transient receptor potential channels and acid-sensing ion channels all contribute to the regulation of nociceptor excitability. ${ }^{24,26,28-}$ 
${ }^{30}$ Recently, painful peripheral neuropathy has been linked to three different types of voltagegated sodium channel (VGSC) mutations. 6 , 31-34

Animal models and human studies have shown that nerve damage, such as in painful peripheral neuropathy, can result in pathologic sensitization and ectopic impulse generation in primary afferent nociceptors with subsequent secondary changes in central processing. ${ }^{35}$ Central sensitization is largely mediated by the $\mathrm{N}$-methyl-D-aspartate (NMDA) receptor. ${ }^{36}$ Activation of descending pathways (spinal norepinephrine pathway and the descending spinal serotonergic (5-HT) pathway) in the periaqueductal grey-rostral ventromedial medulla oblongata may also reduce pain transmission. ${ }^{37}$ However, the system may also facilitate pain transmission, thereby contributing to chronic pain states. ${ }^{38-40}$

\section{Small fiber neuropathy in the elderly}

A substantial number of patients with SFN is 65 years or older. In our cohort of 598 patients diagnosed with SFN, diagnosed according to international criteria, at the Maastricht University Medical Centert, 2, 3 19\% was 65 years or older ( $n=117)$. Most of these elderly patients had several comorbidities at first presentation (Figure $1 A)$. Only $11 \%(n=13)$ had no comorbidity (compared to $46 \%$ in patients $<65$ years ( $X^{2}$ test: $\left.p<0.001\right)$. The most frequent concomitant disorders were hypertension (60\%), cardiovascular disease (44\%), immune-mediated diseases (20\%), malignancy (16\%) and diabetes mellitus (9\%). As a consequence, most patients used several drugs, on average four (Figure $1 \mathrm{~B}$ ). Only $6 \%$ did not use any medication (compared to $26 \%$ in patients $<65$ years ( $X^{2}$ test: $\left.p<0.001\right)$.

The most frequently prescribed pain drugs in this group of elderly patients were anticonvulsants (pregabalin, gabapentine, carbamazepine; 16\%), antidepressants (amitriptyline, duloxetine, nortriptyline, venlafaxine; 14\%), opioids (weak and strong opioids; $14 \%)$, cyclooxygenase (COX) inhibitors (11\%) and acetaminophen (12\%).

The presence of comorbidity, polypharmacy and physiological changes (e.g. increased body fat, reduced muscle mass, reduction body's fluid balance, decrease in renal and hepatic function) in older people increases the risk of side effects and poses a challenge on symptomatic drug treatment of neuropathic pain. ${ }^{41,42}$

\section{Pharmacological management of neuropathic pain}

Several therapeutic strategies are commonly used for the treatment of neuropathic pain. Most pharmacological treatment regimens exist in three groups: antidepressants, anticonvulsants and opioids. However, less than $50 \%$ of patients achieve $50 \%$ of pain relief with currently available drugs. ${ }^{12,}{ }^{14}$ Most of the available analgesics act at different levels (e.g. sodium channels, noradrenergic system, opioidergic system) and are prescribed without any selection in terms of pathogenesis and etiology. Unfortunately, none of the new drugs have proven to be more effective than amitriptyline, ${ }^{12}$ an old antidepressant. Additional treatment strategies are topical treatments, such as capsaicin and lidocaine, ${ }^{14,41}$ and transcutaneous electrical nerve stimulation (TENS). ${ }^{43}$ 
Figure 1. Comorbidities and use of drugs in the elderly.
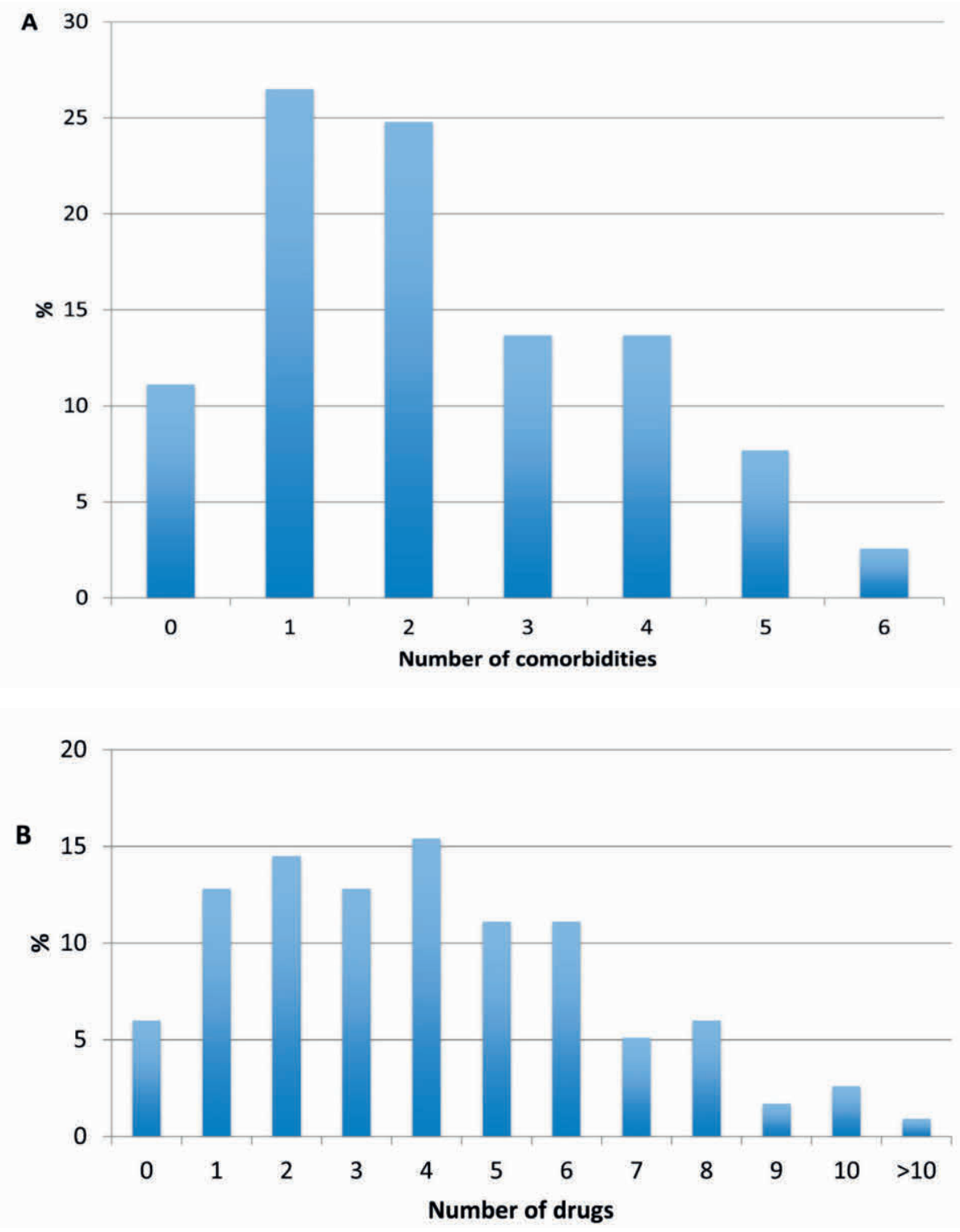

Legend to figure 1: A) Number of comorbidities at initial presentation. B) Number of drugs used at initial presentation in patients with SFN aged 65 years or older $(n=117)$. Concomitant disorders were hypertension (60\%), cardiovascular disease (44\%), immune-mediated diseases (20\%), malignancy (16\%) and diabetes mellitus (9\%). SFN: small fiber neuropathy 


\section{Antidepressants}

Since the 1960s antidepressants have been used for pain relief, ${ }^{44}$ and nowadays mainly for neuropathic pain treatment. Tricyclic antidepressants (TCAs) and serotonin-noradrenalin reuptake inhibitor (SNRIS) are generally considered first-line treatments for neuropathic pain. ${ }^{12,14,15}$

Tricyclic antidepressants (TCAs)

TCAs were initially synthesized as antipsychotic drugs, but appeared to have an antidepressive trait. ${ }^{45,46}$ They are widely used for neuropathic pain and have a number needed to treat (NNT) of 3.6. ${ }^{14}$ TCAs are also known as dirty drugs because of their actions on multiple neurotransmitter receptors: they block reuptake of norepinephrine, VGSCc, and are antagonists of $\mathrm{H}_{1}$-histaminic, muscarinic cholinergic and $\alpha_{1}$-adrenergic receptors. Some TCAs inhibit serotonin reuptake or are antagonists of serotonin $2 \mathrm{~A}$ and $2 \mathrm{C}$ receptors. ${ }^{47-53}$ Other presumed effects are anti-inflammatory, increasing and decreasing cytokine production, and potentiation of opioid analgesia. ${ }^{54-56}$ TCAs may improve sleep disturbances and in higher dose have an antidepressive effect. The choice of a specific TCA is often influenced by the side effect profile. Secondary amine TCAs (nortriptyline and desipramine) are preferred because they are better tolerated than tertiary amine TCAs (amitriptyline and imipramine) with comparable analgesic efficacy. ${ }^{15,}, 57,58$

\section{Serotonin-Noradrenalin reuptake inhibitors (SNRIS)}

As the name already suggests, SNRIs have a dual monoamine mechanism that should lead to better efficacy, however for neuropathic pain SNRIs have an NNT of 6.4. ${ }^{14}$ SNRIs indirectly also lead to an increase of dopamine in the prefrontal cortex by blocking the norepinephrine transporters, which may modulate pain. ${ }^{59,60}$ Venlafaxine and duloxetine are well-studied drugs for neuropathic pain. ${ }^{14}$ Duloxetine has a lower incidence of side effects than venlafaxine (such as hypertension, nausea and sexual dysfunction). ${ }^{15,} 61$ Precautions are needed in liver dysfunction, severe kidney dysfunction, uncontrolled hypertension, and with venlafaxine in significant cardiac disease. Simultaneous use of other antidepressants and tramadol should be avoided.

\section{Antidepressants and elderly}

Age-associated morbidity can complicate the treatment with antidepressants. Antidepressants are metabolized more slowly in elderly, which can lead to a higher plasma drug level. The American Geriatrics Society (AGS) strongly recommends that TCAs should be avoided in older adults, because of the risk of adverse events, such as cardiac arrhythmia, somnolence, hypotension with increased risk of falls and injury, cognitive impairment, and anticholinergic side-effects. ${ }^{62}$ TCAs should certainly be dosed below $75 \mathrm{mg} /$ day in adults aged 65 years. ${ }^{14}$ 


\section{Anticonvulsants}

Anticonvulsant drugs have been used since the 1960s for pain management. They exhibit different mechanisms of action. Gabapentin and pregabalin are considered first-line treatment for neuropathic pain. ${ }^{12,14,15}$

\section{Gabapentin and pregabalin}

Gabapentin was initially designed in 1994 as an analogue of GABA (as an anti-epileptic drug), which could penetrate the blood-brain-barrier. In 1996, it became clear that Gabapentin had a therapeutic effect on pain. Pregabalin, a chemically related amino-acid drug, was developed a few years later.

Though gabapentin initially was assumed to have a GABA-mimetic effect, it turned out that gabapentin does not interact with GABA-A or B-receptors and does not influence GABA uptake. ${ }^{63}$ Gabapentin and pregabalin both bind to voltage gated $\alpha_{2} \delta$-calcium channel of $\mathrm{N}$-type and $\mathrm{P} / \mathrm{Q}$ type in the dorsal horn, but also on the level of the thalamus, periaqueductal gray and cortex. ${ }^{64}$ These presynaptic voltage-sensitive calcium channels are involved in regulation of neurotransmitter release by firing synaptic vesicles into the synapse. Binding gabapentin or pregabalin blocks calcium influx and influences the release of presynaptic neurotransmitters, such as GABA, glutamate, acetylcholine, substance $P$ and monoamines. ${ }^{65-68}$

Gabapentin has a NNT of 7.2 for neuropathic pain and pregabalin of 7.7.14 Gabapentin and pregabalin both have no clinically important drug-drug interactions. Gabapentin dose titration may take several weeks, whereas the starting dose of pregabalin of $75 \mathrm{mg}$ is already efficacious. ${ }^{15}$ The potential for twice daily dosing and the linear pharmacokinetics leading to a predictable dose-response relationship of pregabalin may be an advantage in the ease of use of pregabalin.

Side effects of gabapentin and pregabalin are somnolence, dizziness, ataxia, edema and tremor. Pregabalin increases slow wave sleep and total sleep duration in patients with pain, ${ }^{69}$ and can also be used for generalized anxiety disorders. Both drugs require dosage reduction in patients with renal impairment. ${ }^{70}$

\section{Other antiepileptic drugs}

Several other anti-epileptic drugs, such as topiramate, zonisamide, and oxcarbazepine or carbamazepine, have been studied for neuropathic pain, though most studies were negative, ${ }^{14}$ and therefore these drugs are not recommended as first-line treatment.

\section{Anticonvulsants and elderly}

Gabapentin or pregabalin are usually well tolerated if titrated appropriately. Treatment should start with the lowest possible dose and be increased very slowly based on response and side effects, such as somnolence, dizziness, ataxia and peripheral edema. ${ }^{71}$ Gabapentin can cause or exacerbate cognitive or gait impairment. Dose reduction in patients with renal dysfunction is needed. ${ }^{70}$ Furthermore, antiepileptic drugs may lead to an increased risk of falling. ${ }^{71}$ 


\section{Opioids}

Opioids refer to all substances that produce morphine-like effects that are blocked by antagonists such as naloxone, and can be produced synthetically or endogenous. Opioids have a well-defined role in the treatment of cancer pain, however, their role in the long-term treatment of non-malignant pain is controversial due to concerns about tolerability, the development of tolerance to the analgesic effect, and addiction. ${ }^{72}$ Furthermore, side effects occurred in about $50 \%$ of patients treated for chronic non-malignant pain, and more than $20 \%$ discontinued treatment because of adverse events. ${ }^{73,74}$ Opioids can be effective in neuropathic pain with numbers NNT of 4.7 for tramadol and 4.3 for strong opioids, ${ }^{14,75}$ and are considered second- and third-line treatments. ${ }^{12,14,15}$

Opioids produce analgesia by acting on opioid receptors in peripheral afferent neurons, dorsal horn of the spinal cord, brainstem and the brain. The opioid receptors are G-protein coupled receptors (GPCRs) and are classified as mu (MOP), delta (DOP) and kappa (KOP) and a fourth non-classical opioid receptor for nociception/orhanin GQ (NOP). ${ }^{76}$, 77 The receptor pharmacology is complex; the cellular response is not only depending on the ligand and the type of receptor, but also on the cellular environment of the receptor ${ }^{78,79}$ After activation of the receptor, a portion of the G-protein is released, and leads to inhibition of cyclic AMP, with consequently alteration of protein phosphorylation. Cyclic AMP acts as a second messenger within the cell resulting in the activation of protein kinases (short term effects) and gene transcription proteins and/or gene transcription (long term effects). ${ }^{80}$ Opioid receptors located on the presynaptic terminals of the nociceptive $\mathrm{C}$ - and A- fibers can be activated by an opioid agonist, which will indirectly inhibit voltage-gated calcium channels, decreasing cAMP levels and blocking the release of pain neurotransmitters such as glutamate, substance $P$, and calcitonin gene-related peptide. ${ }^{80}$ Furthermore, opioids activate presynaptic receptors on GABA neurons, which inhibit the release of GABA in the ventral tegmental area, indirectly leading to an increase in dopamine. The latter plays a role in the development of addiction. One of the most common side effects is constipation, which requires prophylaxis. ${ }^{72}$ Other side effects are pruritus, dizziness, nausea and vomiting, sedation, impaired concentration, and ataxia. The risk of respiratory depression should be weighed in patients with underlying pulmonary condition or receiving concomitant central nervous system drugs associated with hypoventilation. Not all opioids show equal effects on respiratory depression. Long-term use of opioids can lead to hypogonadism and immunological changes. Prolonged opioid use may lead to tolerance (the need to increase the dose to maintain pain relief) and opioid-induced hyperalgesia. ${ }^{81,82}$ Rotation from one strong opioid to another can restore not only analgesia, but also cause other side effects. ${ }^{83,84}$

One of the biggest concerns is addiction due to prolonged opioid use, with high health and economic costs and potential fatal consequences. ${ }^{85,86}$

Increasing opioid doses are strongly related to large increases in risk of overdose morbidity and mortality, with a substantially increased risk associated with doses at or above 100-120 mg morphine equivalent dose per day. ${ }^{86}$ Moreover, disordered breathing during non-REM sleep increases with dose. Therefore opioid therapy should be part of a multifaceted approach to pain management, ${ }^{86}$ and clinicians should be alert for behavior suggestive of addiction, such as frequent change of doctors, non-compliance, and reports of lost prescriptions. ${ }^{85}$ 


\section{Weak opioids}

\section{Tramadol}

Tramadol, a second line treatment, is a weak opioid receptor agonist and a norepinephrine(NE) and serotonin (5HT)-reuptake inhibitor and has a number needed to treat of 4.7. ${ }^{14}$ Special precautions should be taken with patients with asthma, epilepsy, and severe liver and renal impairment. It has interactions with most antidepressant drugs.

\section{Strong opioids}

Strong opioids are considered third-line treatment, and have a NNT of 4.3. ${ }^{14}$

\section{Transdermal Buprenorphine}

Buprenorphine is a semisynthetic non-selective mixed opioid agonist-antagonist and can bind to the three classical and the non-classical opioid receptors. The anti-nociceptive effect is primarily exerted via the mu-receptor and is attenuated by the nociception receptor. No specific adjustments have to be made in kidney impairment. Excretion is mainly by the liver, and liver impairment can prolong the half-life, however without clinical relevance because of low activity metabolites. Precautions should be taken in patients with asthma or COPD. When rotating from a pure agonist, withdrawal symptoms can occur because Buprenorphine is a partial Mu-agonist. ${ }^{87}$

\section{Oxycodone sustained-release}

Oxycodone is an agonist for the mu- and kappa-receptor. Oxycodone has similar efficacy to morphine and is usually well tolerated. It frequently causes constipation. Oxycodone has multiple active metabolites that may accumulate in renal dysfunction. ${ }^{87}$

\section{Fentanyl patch}

Fentanyl is an opioid agonist. The vast majority of the metabolites-around 75\%-are eliminated in the urine. In cases of renal impairment, the clearance of fentanyl is reduced and the terminal half-life of the drug is prolonged. The clinical significance of this is not known. ${ }^{87}$ In liver impairment, adjustment of dose may be required, though no specific guideline is available.

\section{Methadone}

Methadone is a synthetic opioid (mu agonist) a weak NMDA receptor antagonist and a serotonin-reuptake inhibitor. No adjustments have to be made in kidney impairment. In serious liver failure, the use of methadone is contraindicated. Methadone can have a long and variable half-life time. Variation of half-life is $8-80$ hours, with a risk of accumulation. It has potential interactions with multiple drugs. Furthermore, it may cause prolongation of the QTtime interval, ${ }^{88}$ and ECG screening or monitoring may be considered. 


\section{Opioids and elderly}

Although older people tend to require lower doses than younger individuals, opioid effects do not appear to vary with age. ${ }^{89}$ Though short-term efficacy of opioid use ( $\leq 12$ weeks) among older adults has been established, almost half of the patients discontinued the medication, mostly because of intolerable side effects. ${ }^{90}$ There is limited evidence in support of long-term opioid treatment. ${ }^{86,91}$ In the elderly, the half-life time of the active drug and its metabolites is increased, but not in buprenorphine making it a relative safe choice in elderly. ${ }^{87}$ Furthermore, buprenorphine does not have a dose-dependent decrease in respiration. ${ }^{92,} 93$ In elderly patients with impaired hepatic and renal function, there is the risk of accumulation of metabolites from certain opioids, such as morphine.

Given the established risks associated with opioid use, such as hospital admission, mortality and fractures, ${ }^{94}$ the potential negative effects must be carefully weighed and be used as part of an integrated treatment program, including functional and psychosocial modalities. ${ }^{87,} 94$ Methadone should only be prescribed by clinicians who have considerable experience with the drug, or in closely monitored settings because of difficulty in titration. ${ }^{62}$

\section{Topical analgesic agents}

Topical administration may be better tolerated than other routes of administration. However, the efficacy of topical lidocaine and capsaicin in the management of localized neuropathic pain is limited, and therefore these drugs are considered second-line treatment. ${ }^{14,41}$

\section{Capsaicin}

Capsaicin is the primary component in hot peppers that gives the highly strong spicy flavor. Topical capsaicin is available in cream with low concentrations capsaicin (0.025-0.075\%) and transdermal patches with high concentration capsaicin (8\%). Capsaicin can only be used when the skin is intact and has no interaction with other medication. There are minimal systemic side effects (hypertension, first degree atrioventricular block, coughing, nausea). Local side effects are erythema, burning pain and itch. Topical treatment with capsaicin can cause reversible degeneration of epidermal nerve fibers. The long-term safety of repeated applications of highconcentration capsaicin patches, particularly with respect to this epidermal nerve fiber degeneration is unknown. ${ }^{14}$

\section{Lidocaine $5 \%$ medicated plaster}

Topical lidocaine has been used for both acute and chronic pain treatments. The effect of the lidocaine plaster is based on two actions. The plaster itself provides a cooling perception and mechanical protection. ${ }^{95-97}$ Additionally, lidocaine is a VGSC inhibitor, which stabilizes the neuronal membrane potential of $\mathrm{A} \delta$ - and C-fibers. This pharmacological action results in a reduction of pain and allodynia. ${ }^{98}$ The $5 \%$ lidocaine-medicated plaster has minimal systemic absorption of the active substance, ${ }^{99}$ with low risk of toxicity and lack of drug-drug interactions. ${ }^{100}$ Although the absorption of the skin is extremely low, caution is needed in patients with class 1 antiarrhythmic drugs or other local anesthetics. 
Topical agents and elderly

Lidocaine patch and high-concentration capsaicin patches are considered second-line treatment because of low effect sizes. However, lidocaine patches may be considered as firstline drug in case of side-effects or safety of other first-line treatments, particularly in elderly patients. ${ }^{14}$

\section{Complementary therapies}

Transcutaneous electrical nerve stimulation (TENS)

TENS is the application of electrical stimulation of varying frequency, intensity and pulse duration to the skin for pain relief. ${ }^{101}$ TENS is generally believed to be a safe non-invasive intervention. However, the effectiveness of TENS in chronic pain has not been established with certainty. ${ }^{43}$

\section{TENS and elderly}

Age does not have a significant impact on pain or TENS comfort, though age-related changes might limit the use of TENS among the older population. ${ }^{41,102}$

Table 1. Practical tips for the best treatment strategy of small fiber neuropathy in the elderly

Practical tips for the clinician

Always make the best choice considering safety and tolerability, strive for tailored made therapy and individualization of care in clinical practice

\begin{tabular}{ll}
\hline Local treatment & In case of focal pain distribution or systemic contra-indications \\
\hline Medication & Take a careful medication history \\
& Ask for previous adverse effects, inadequate effects, inadequate dose \\
& Check for comorbidity such as liver and kidney impairment \\
& Check potential interactions with other drugs, herbs, caffeine, smoking, grapefruit \\
& Adjust dose if necessary \\
& Consider genetic testing in patients with a history of many side effects \\
& Make patient also responsibility for medication history by handing out a form for \\
& medication \\
\hline Opioids & Avoid instant release opioids \\
& Start strong opioids only as third line treatment \\
& Be aware of the potential risks \\
Social context & Ask for impact on sleep, work, daily functioning, relationship, anxiety and treat when \\
possible
\end{tabular}

\section{Multifaceted neuropathic pain management in elderly}

Managing neuropathic pain in elderly is often complex due to its multifactorial facets. The neurobiology of aging, its relation to pain, changes in pharmacokinetics, drug metabolism, and body composition, polypharmacy and cognitive and affective factors may influence pain expression and pain management in elderly. ${ }^{103}$ 
Individual drugs have $50 \%$ of pain relief with a NNT of 4-10, meaning that the outcome of drug treatment is, at best, moderate. ${ }^{14,104}$ Multifaceted therapy is often needed to address the various pain conditions, whereas older people may be particularly susceptible to side effects and drug interactions. A practical approach is presented in table 1, and figure 2 and 3.

In general, medication should be started in a low dose and titrated slowly. TCAs should be avoided in elderly if possible, or at least not be prescribed above $75 \mathrm{mg} /$ day. A therapeutic trial should be of adequate length to assess efficacy, and the dose needs to be adjusted if side effects become burdensome, with a slower titration curve to attain therapeutic levels if needed. ${ }^{62,103}$ It is important to optimize one regimen first, and then gradually add agents, if needed. Therapies which have overlapping pharmacodynamics or that may have an adverse pharmacokinetic interaction, such as metabolic inhibitors, should not be combined. Especially in older patients, attention is needed in agents acting within the central nervous system. Therapy should be tapered down over time, if possible, to attain the lowest effective maintenance dose.

Figure 2. Treatment Algorithm for SFN in the elderly

\section{Treatment Algorithm for SFN in elderly}

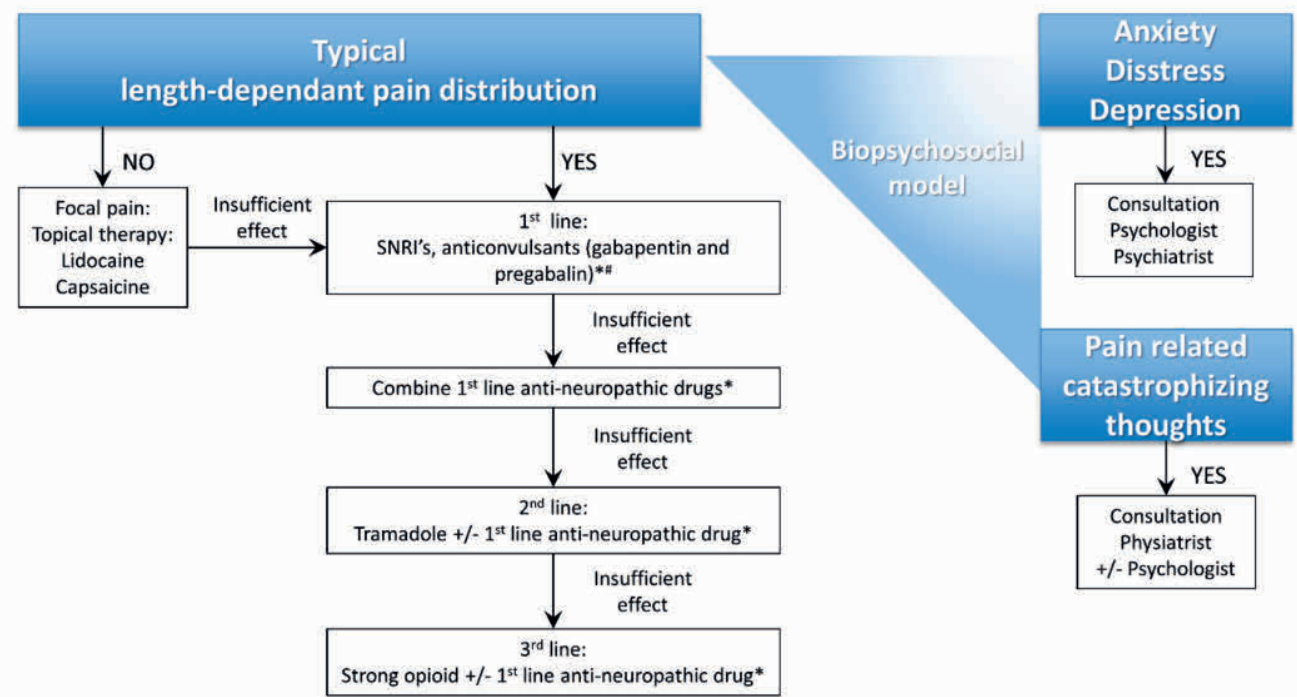

Legend to figure 2 In addition to physical factors, psychological, neurophysiological, socio-economic and cultural aspects may influence the experience and maintain pain; a multidisciplinary approach in line with the biopsychosocial model is required in optimizing treatment for the individual patient. ${ }^{41}$ * see also Figure 3 (contraindication algorithm for drugs prescription) and Table 1 (Practical tips for the best treatment strategy of SFN in elderly), "in contrast with first line neuropathic pain treatment in adults $<65$ years, TCAs should be avoided in older adults, because of the risk of adverse events, such as cardiac arrhythmia, somnolence, hypotension with increased risk of falls and injury, cognitive impairment, and anticholinergic side-effects. ${ }^{62}$ SFN: small fiber neuropathy, SNRI: serotonin-noradrenalin reuptake inhibitor, TCA: tricyclic antidepressant. 
Figure 3 Contra-indication algorithm for drugs prescription

\section{Contra-indication Algorithm for drugs prescription}

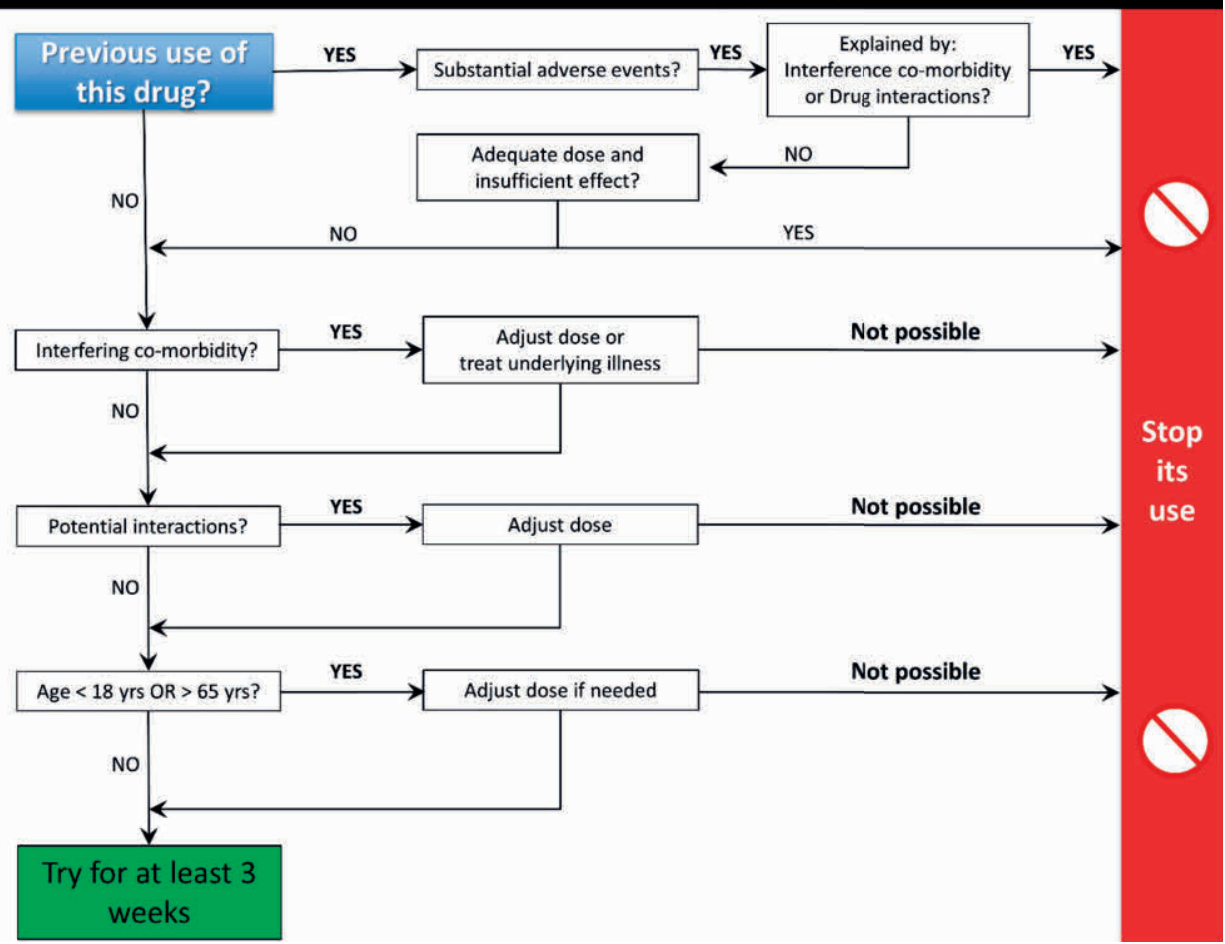

Legend to figure 3: For every drug considered, it is advisable to go through these steps to make a deliberate decision. Be aware of comorbidity such as kidney and liver impairment or cardiac disease. Yrs: years.

\section{Discussion and future perspectives}

In general the treatment of chronic neuropathic pain is complicated and multidimensional. The mechanisms underlying its occurrence and chronification, as well as the inter-individual variability, remain poorly understood. As a consequence, symptomatic and unspecific treatments are frequently the only available therapeutic options. Indeed, all the clinical trials carried out in the last 20 years provided similar results, accounting for $50 \%$ of pain relief in $50 \%$ of patients at best. ${ }^{12,14}$ Efficacious and tailored treatments for neuropathic pain are the ultimate target both for patients and scientists. The discovery of gain-of-function $\mathrm{Na}_{\mathrm{v}} 1.7$, $\mathrm{Na}_{v} 1.8$ and $\mathrm{Na}_{v} 1.9$ mutations in painful peripheral neuropathy has expanded the spectrum of painful sodium channelopathies. ${ }^{6,}{ }^{34}$ It provides a better understanding of the pathogenetic mechanisms and may provide targets for potential treatment with the expectation of fewer side-effects. ${ }^{105-107}$ Genetics may also play a role in drugs respons. For some drugs, pharmacogenetics can predict the efficacy and toxicity of treatment at individual level. ${ }^{108-110}$ As pain is a complex symptom, in which not only physical factors but also psychological, neurophysiological, socio-economic and cultural aspects may influence the experience and maintaining of pain, a multidisciplinary approach in line with the biopsychosocial model is required in optimizing treatment for the individual patient (Figure 2). ${ }^{41}$ Psychological 
techniques may be helpful, not just when pharmacological therapy is ineffective, but as an adjunct to medication or as a first-line therapy if the patient prefers. Moreover, chronic pain often has coexisting symptoms, such as depression, anxiety and sleep deprivation, and focusing on relief of these symptoms may be crucial for patients. 


\section{References}

1. England JD, Asbury AK. Peripheral neuropathy. Lancet. 2004;363(9427):2151-61.

2. Lauria G, Merkies IS, Faber CG. Small fibre neuropathy. Curr Opin Neurol. 2012;25(5):542-9.

3. Hoeijmakers JG, Faber CG, Lauria G, Merkies IS, Waxman SG. Small-fibre neuropathies--advances in diagnosis, pathophysiology and management. Nat Rev Neurol. 2012;8(7):369-79.

4. Tesfaye S, Boulton AJ, Dyck PJ, et al. Diabetic neuropathies: update on definitions, diagnostic criteria, estimation of severity, and treatments. Diabetes Care. 2010;33(10):2285-93.

5. Peters MJ, Bakkers M, Merkies IS, Hoeijmakers JG, van Raak EP, Faber CG. Incidence and prevalence of small-fiber neuropathy: a survey in the Netherlands. Neurology. 2013;81(15):1356-60.

6. Hoeijmakers JG, Faber CG, Merkies IS, Waxman SG. Painful peripheral neuropathy and sodium channel mutations. Neurosci Lett. 2015;596:51-9.

7. Bakkers M, Faber CG, Hoeijmakers JG, Lauria G, Merkies IS. Small fibers, large impact: quality of life in small-fiber neuropathy. Muscle Nerve. 2014;49(3):329-36.

8. Poliakov I, Toth C. The impact of pain in patients with polyneuropathy. Eur J Pain. 2011;15(10):1015-22.

9. Lindh J, Tondel M, Persson B, Vrethem M. Health-related quality of life in patients with cryptogenic polyneuropathy compared with the general population. Disabil Rehabil. 2011;33(7):617-23.

10. Schaefer C, Mann R, Sadosky A, et al. Health status, function, productivity, and costs among individuals with idiopathic painful peripheral neuropathy with small fiber involvement in the United States: results from a retrospective chart review and cross-sectional survey. J Med Econ. 2014;17(6):394-407.

11. Hovaguimian A, Gibbons $\mathrm{CH}$. Diagnosis and treatment of pain in small-fiber neuropathy. Curr Pain Headache Rep. 2011;15(3):193-200.

12. Attal N, Cruccu G, Baron R, et al. EFNS guidelines on the pharmacological treatment of neuropathic pain: 2010 revision. Eur J Neurol. 2010;17(9):1113-e88.

13. Haanpaa M, Attal N, Backonja M, et al. NeuPSIG guidelines on neuropathic pain assessment. Pain. 2011;152(1):14-27.

14. Finnerup NB, Attal N, Haroutounian S, et al. Pharmacotherapy for neuropathic pain in adults: a systematic review and meta-analysis. Lancet Neurol. 2015.

15. Dworkin $\mathrm{RH}, \mathrm{O}^{\prime}$ Connor AB, Backonja M, et al. Pharmacologic management of neuropathic pain: evidencebased recommendations. Pain. 2007;132(3):237-51.

16. Saarto T, Wiffen PJ. Antidepressants for neuropathic pain. Cochrane Database Syst Rev. 2007(4):CD005454.

17. Goodyear-Smith F, Halliwell J. Anticonvulsants for neuropathic pain: gaps in the evidence. Clin J Pain. 2009;25(6):528-36.

18. Eisenberg E, McNicol E, Carr DB. Opioids for neuropathic pain. Cochrane Database Syst Rev. 2006(3):CD006146.

19. Treede RD, Jensen TS, Campbell JN, et al. Neuropathic pain: redefinition and a grading system for clinical and research purposes. Neurology. 2008;70(18):1630-5.

20. Farrar JT, Young JP, Jr., LaMoreaux L, Werth JL, Poole RM. Clinical importance of changes in chronic pain intensity measured on an 11-point numerical pain rating scale. Pain. 2001;94(2):149-58.

21. Dworkin RH, Turk DC, Wyrwich KW, et al. Interpreting the clinical importance of treatment outcomes in chronic pain clinical trials: IMMPACT recommendations. J Pain. 2008;9(2):105-21.

22. Forouzanfar $\mathrm{T}$, Weber WE, Kemler M, van Kleef $M$. What is a meaningful pain reduction in patients with complex regional pain syndrome type 1? Clin J Pain. 2003;19(5):281-5.

23. Galer BS, Jensen MP. Development and preliminary validation of a pain measure specific to neuropathic pain: the Neuropathic Pain Scale. Neurology. 1997;48(2):332-8.

24. Dubin AE, Patapoutian A. Nociceptors: the sensors of the pain pathway. J Clin Invest. 2010;120(11):376072.

25. Lauria G, Merkies ISJ, Waxman SG, Faber CG. Epidermal Nerve Fibers. In: Aminoff MJ, Daroff RB, editors. Encyclopedia of the Neurological Sciences. 2nd ed. ed. Oxford: Academic Press; 2014. p. 76-9.

26. Woolf CJ, Ma Q. Nociceptors--noxious stimulus detectors. Neuron. 2007;55(3):353-64.

27. Holzer P, Maggi CA. Dissociation of dorsal root ganglion neurons into afferent and efferent-like neurons. Neuroscience. 1998;86(2):389-98. 
28. Lee $\mathrm{Y}$, Lee $\mathrm{CH}$, Oh U. Painful channels in sensory neurons. Mol Cells. 2005;20(3):315-24.

29. Aurilio C, Pota V, Pace MC, Passavanti MB, Barbarisi M. Ionic channels and neuropathic pain: physiopathology and applications. J Cell Physiol. 2008;215(1):8-14.

30. Waxman SG, Zamponi GW. Regulating excitability of peripheral afferents: emerging ion channel targets. Nat Neurosci. 2014;17(2):153-63.

31. Faber CG, Hoeijmakers JG, Ahn HS, et al. Gain of function Nav1.7 mutations in idiopathic small fiber neuropathy. Ann Neurol. 2012;71(1):26-39.

32. Faber CG, Lauria G, Merkies IS, et al. Gain-of-function Nav1.8 mutations in painful neuropathy. Proc Natl Acad Sci U S A. 2012;109(47):19444-9.

33. Huang J, Han C, Estacion M, et al. Gain-of-function mutations in sodium channel Na(v)1.9 in painful neuropathy. Brain. 2014;137(Pt 6):1627-42.

34. Brouwer BA, Merkies IS, Gerrits MM, Waxman SG, Hoeijmakers JG, Faber CG. Painful neuropathies: the emerging role of sodium channelopathies. J Peripher Nerv Syst. 2014;19(2):53-65.

35. Baron R. Peripheral neuropathic pain: from mechanisms to symptoms. Clin J Pain. 2000;16(2 Suppl):S1220.

36. Gilron I, Watson CP, Cahill CM, Moulin DE. Neuropathic pain: a practical guide for the clinician. CMAJ. 2006;175(3):265-75.

37. Porreca F, Ossipov MH, Gebhart GF. Chronic pain and medullary descending facilitation. Trends Neurosci. 2002;25(6):319-25.

38. Suzuki R, Rygh LJ, Dickenson AH. Bad news from the brain: descending 5-HT pathways that control spinal pain processing. Trends Pharmacol Sci. 2004;25(12):613-7.

39. Vanegas H, Schaible HG. Descending control of persistent pain: inhibitory or facilitatory? Brain Res Brain Res Rev. 2004;46(3):295-309.

40. Ossipov MH, Dussor GO, Porreca F. Central modulation of pain. J Clin Invest. 2010;120(11):3779-87.

41. Abdulla A, Adams N, Bone M, et al. Guidance on the management of pain in older people. Age Ageing. 2013;42 Suppl 1:i1-57.

42. Fine PG. Treatment guidelines for the pharmacological management of pain in older persons. Pain Med. 2012;13 Suppl 2:S57-66.

43. Nnoaham KE, Kumbang J. Transcutaneous electrical nerve stimulation (TENS) for chronic pain. Cochrane Database Syst Rev. 2008(3):CD003222.

44. Webb HE, Lascelles RG. Treatment of facial and head pain associated with depression. Lancet. 1962;1(7225):355-6.

45. Crisp AH, Hays $\mathrm{P}$, Carter A. Three amine-oxidase inhibitor drugs in the treatment of depression; relative value and toxic effects. Lancet. 1961;1(7167):17-8.

46. Straker M. Imipramine (tofranil): a safe, effective antidepressant drug in private practice. Can Med Assoc J. 1959;80(7):546-9.

47. Pancrazio JJ, Kamatchi GL, Roscoe AK, Lynch C, 3rd. Inhibition of neuronal Na+ channels by antidepressant drugs. J Pharmacol Exp Ther. 1998;284(1):208-14.

48. Wang GK, Russell C, Wang SY. State-dependent block of voltage-gated Na+ channels by amitriptyline via the local anesthetic receptor and its implication for neuropathic pain. Pain. 2004;110(1-2):166-74.

49. Nyback HV, Walters JR, Aghajanian GK, Roth RH. Tricyclic antidepressants: effects on the firing rate of brain noradrenergic neurons. Eur J Pharmacol. 1975;32(02):302-12.

50. Taylor JE, Richelson E. High affinity binding of tricyclic antidepressants to histamine H1-receptors: fact and artifact. Eur J Pharmacol. 1980;67(1):41-6.

51. Richelson E. Tricyclic antidepressants and histamine H1 receptors. Mayo Clin Proc. 1979;54(10):669-74.

52. Weinstock M, Cohen D. Tricyclic antidepressant drugs as antagonists of muscarinic receptors in sympathetic ganglia. Eur J Pharmacol. 1976;40(2):321-8.

53. Bohman B, Halaris A, Karbowski M. Effects of tricyclic antidepressants on muscarinic cholinergic receptor binding in mouse brain. Life Sci. 1981;29(8):833-41.

54. Gurgel JA, Lima-Junior RC, Rabelo CO, Pessoa BB, Brito GA, Ribeiro RA. Amitriptyline, clomipramine, and maprotiline attenuate the inflammatory response by inhibiting neutrophil migration and mast cell degranulation. Rev Bras Psiquiatr. 2013;35(4):387-92. 
55. Munzer A, Sack U, Mergl R, et al. Impact of antidepressants on cytokine production of depressed patients in vitro. Toxins (Basel). 2013;5(11):2227-40.

56. Bohn LM, Xu F, Gainetdinov RR, Caron MG. Potentiated opioid analgesia in norepinephrine transporter knock-out mice. J Neurosci. 2000;20(24):9040-5.

57. Watson CP, Vernich L, Chipman M, Reed K. Nortriptyline versus amitriptyline in postherpetic neuralgia: a randomized trial. Neurology. 1998;51(4):1166-71.

58. Kishore-Kumar R, Max MB, Schafer SC, et al. Desipramine relieves postherpetic neuralgia. Clin Pharmacol Ther. 1990;47(3):305-12.

59. Blier P, Briley M. The noradrenergic symptom cluster: clinical expression and neuropharmacology. Neuropsychiatr Dis Treat. 2011;7(Suppl 1):15-20.

60. Dang $\mathrm{YH}$, Xing $\mathrm{B}$, Zhao $\mathrm{Y}$, et al. The role of dopamine receptors in ventrolateral orbital cortex-evoked antinociception in a rat formalin test model. Eur J Pharmacol. 2011;657(1-3):97-103.

61. Stahl SM, Grady MM, Moret C, Briley M. SNRIs: their pharmacology, clinical efficacy, and tolerability in comparison with other classes of antidepressants. CNS Spectr. 2005;10(9):732-47.

62. American Geriatrics Society Panel on the Pharmacological Management of Persistent Pain in Older $P$. Pharmacological management of persistent pain in older persons. Pain Med. 2009;10(6):1062-83.

63. Bryans JS, Wustrow DJ. 3-substituted GABA analogs with central nervous system activity: a review. Med Res Rev. 1999;19(2):149-77.

64. Taylor CP, Garrido R. Immunostaining of rat brain, spinal cord, sensory neurons and skeletal muscle for calcium channel alpha2-delta (alpha2-delta) type 1 protein. Neuroscience. 2008;155(2):510-21.

65. Micheva KD, Taylor CP, Smith SJ. Pregabalin reduces the release of synaptic vesicles from cultured hippocampal neurons. Mol Pharmacol. 2006;70(2):467-76.

66. Joshi I, Taylor CP. Pregabalin action at a model synapse: binding to presynaptic calcium channel alpha2delta subunit reduces neurotransmission in mice. Eur J Pharmacol. 2006;553(1-3):82-8.

67. Fehrenbacher JC, Taylor CP, Vasko MR. Pregabalin and gabapentin reduce release of substance P and CGRP from rat spinal tissues only after inflammation or activation of protein kinase C. Pain. 2003;105(12):133-41.

68. Taylor CP, Angelotti T, Fauman E. Pharmacology and mechanism of action of pregabalin: the calcium channel alpha2-delta (alpha2-delta) subunit as a target for antiepileptic drug discovery. Epilepsy Res. 2007;73(2):137-50.

69. Roth T, van Seventer R, Murphy TK. The effect of pregabalin on pain-related sleep interference in diabetic peripheral neuropathy or postherpetic neuralgia: a review of nine clinical trials. Curr Med Res Opin. 2010;26(10):2411-9.

70. Hanlon JT, Aspinall SL, Semla TP, et al. Consensus guidelines for oral dosing of primarily renally cleared medications in older adults. J Am Geriatr Soc. 2009;57(2):335-40.

71. Pickering G. Antiepileptics for post-herpetic neuralgia in the elderly: current and future prospects. Drugs Aging. 2014;31(9):653-60.

72. Labianca R, Sarzi-Puttini P, Zuccaro SM, Cherubino P, Vellucci R, Fornasari D. Adverse effects associated with non-opioid and opioid treatment in patients with chronic pain. Clin Drug Investig. 2012;32 Suppl 1:53-63.

73. Moore RA, McQuay HJ. Prevalence of opioid adverse events in chronic non-malignant pain: systematic review of randomised trials of oral opioids. Arthritis Res Ther. 2005;7(5):R1046-51.

74. Noble M, Treadwell JR, Tregear SJ, et al. Long-term opioid management for chronic noncancer pain. Cochrane Database Syst Rev. 2010(1):CD006605.

75. Zochodne DW, Max MB. An old acquaintance: opioids in neuropathic pain. Neurology. 2003;60(6):8945 .

76. Dietis N, Rowbotham DJ, Lambert DG. Opioid receptor subtypes: fact or artifact? Br J Anaesth. 2011;107(1):8-18.

77. Satoh M, Minami M. Molecular pharmacology of the opioid receptors. Pharmacol Ther. 1995;68(3):34364.

78. Brady AE, Limbird LE. G protein-coupled receptor interacting proteins: emerging roles in localization and signal transduction. Cell Signal. 2002;14(4):297-309. 
79. Jordan BA, Devi LA. G-protein-coupled receptor heterodimerization modulates receptor function. Nature. 1999;399(6737):697-700.

80. Trescot AM, Datta S, Lee M, Hansen H. Opioid pharmacology. Pain Physician. 2008;11(2 Suppl):S133-53.

81. Christie MJ. Cellular neuroadaptations to chronic opioids: tolerance, withdrawal and addiction. $\mathrm{Br} J$ Pharmacol. 2008;154(2):384-96.

82. Bailey CP, Connor M. Opioids: cellular mechanisms of tolerance and physical dependence. Curr Opin Pharmacol. 2005;5(1):60-8.

83. Smith MT. Differences between and combinations of opioids re-visited. Curr Opin Anaesthesiol. 2008;21(5):596-601.

84. Kuo A, Wyse BD, Meutermans W, Smith MT. In vivo profiling of seven common opioids for antinociception, constipation and respiratory depression: no two opioids have the same profile. $\mathrm{Br} J$ Pharmacol. 2015;172(2):532-48.

85. Volkow ND, Frieden TR, Hyde PS, Cha SS. Medication-assisted therapies--tackling the opioid-overdose epidemic. N Engl J Med. 2014;370(22):2063-6.

86. Chou R, Turner JA, Devine EB, et al. The effectiveness and risks of long-term opioid therapy for chronic pain: a systematic review for a National Institutes of Health Pathways to Prevention Workshop. Ann Intern Med. 2015;162(4):276-86.

87. Pergolizzi J, Boger RH, Budd K, et al. Opioids and the management of chronic severe pain in the elderly: consensus statement of an International Expert Panel with focus on the six clinically most often used World Health Organization Step III opioids (buprenorphine, fentanyl, hydromorphone, methadone, morphine, oxycodone). Pain Pract. 2008;8(4):287-313.

88. Chou R, Weimer MB, Dana T. Methadone overdose and cardiac arrhythmia potential: findings from a review of the evidence for an American Pain Society and College on Problems of Drug Dependence clinical practice guideline. J Pain. 2014;15(4):338-65.

89. Mercadante S, Ferrera P, Villari P, Casuccio A. Opioid escalation in patients with cancer pain: the effect of age. J Pain Symptom Manage. 2006;32(5):413-9.

90. Papaleontiou M, Henderson CR, Jr., Turner BJ, et al. Outcomes associated with opioid use in the treatment of chronic noncancer pain in older adults: a systematic review and meta-analysis. J Am Geriatr Soc. 2010;58(7):1353-69.

91. Reid MC, Eccleston C, Pillemer K. Management of chronic pain in older adults. BMJ. 2015;350:h532.

92. Vadivelu N, Hines RL. Management of chronic pain in the elderly: focus on transdermal buprenorphine. Clin Interv Aging. 2008;3(3):421-30.

93. Dahan A, Yassen A, Romberg R, et al. Buprenorphine induces ceiling in respiratory depression but not in analgesia. Br J Anaesth. 2006;96(5):627-32.

94. Solomon DH, Rassen JA, Glynn RJ, Lee J, Levin R, Schneeweiss S. The comparative safety of analgesics in older adults with arthritis. Arch Intern Med. 2010;170(22):1968-76.

95. Baron R, Mayoral V, Leijon G, Binder A, Steigerwald I, Serpell M. 5\% lidocaine medicated plaster versus pregabalin in post-herpetic neuralgia and diabetic polyneuropathy: an open-label, non-inferiority twostage RCT study. Curr Med Res Opin. 2009;25(7):1663-76.

96. Davies PS, Galer BS. Review of lidocaine patch $5 \%$ studies in the treatment of postherpetic neuralgia. Drugs. 2004;64(9):937-47.

97. Rowbotham MC, Davies PS, Verkempinck C, Galer BS. Lidocaine patch: double-blind controlled study of a new treatment method for post-herpetic neuralgia. Pain. 1996;65(1):39-44.

98. Wasner G, Kleinert A, Binder A, Schattschneider J, Baron R. Postherpetic neuralgia: topical lidocaine is effective in nociceptor-deprived skin. J Neurol. 2005;252(6):677-86.

99. Casale R, Mattia C. Building a diagnostic algorithm on localized neuropathic pain (LNP) and targeted topical treatment: focus on 5\% lidocaine-medicated plaster. Ther Clin Risk Manag. 2014;10:259-68.

100. Mick G, Correa-Illanes G. Topical pain management with the $5 \%$ lidocaine medicated plaster--a review. Curr Med Res Opin. 2012;28(6):937-51.

101. Sluka KA, Walsh D. Transcutaneous electrical nerve stimulation: basic science mechanisms and clinical effectiveness. J Pain. 2003;4(3):109-21.

102. Weiner DK, Rudy TE, Glick RM, et al. Efficacy of percutaneous electrical nerve stimulation for the treatment of chronic low back pain in older adults. J Am Geriatr Soc. 2003;51(5):599-608. 
103. Reisner L. Pharmacological management of persistent pain in older persons. J Pain. 2011;12(3 Suppl 1):S21-9.

104. Cherny NI. The treatment of neuropathic pain: from hubris to humility. Pain. 2007;132(3):225-6.

105. Dib-Hajj SD, Waxman SG. Translational pain research: Lessons from genetics and genomics. Sci Transl Med. 2014;6(249):249sr4.

106. Waxman SG, Merkies IS, Gerrits MM, et al. Sodium channel genes in pain-related disorders: phenotypegenotype associations and recommendations for clinical use. Lancet Neurology. 2014:In Press.

107. Dib-Hajj SD, Binshtok AM, Cummins TR, Jarvis MF, Samad T, Zimmermann K. Voltage-gated sodium channels in pain states: role in pathophysiology and targets for treatment. Brain Res Rev. 2009;60(1):6583.

108. Kirchheiner J, Brosen K, Dahl ML, et al. CYP2D6 and CYP2C19 genotype-based dose recommendations for antidepressants: a first step towards subpopulation-specific dosages. Acta Psychiatr Scand. 2001;104(3):173-92.

109. Stamer UM, Zhang L, Book M, Lehmann LE, Stuber F, Musshoff F. CYP2D6 genotype dependent oxycodone metabolism in postoperative patients. PLoS One. 2013;8(3):e60239.

110. Gan SH, Ismail R, Wan Adnan WA, Zulmi W. Impact of CYP2D6 genetic polymorphism on tramadol pharmacokinetics and pharmacodynamics. Mol Diagn Ther. 2007;11(3):171-81. 



\section{CHAPTER 5 \\ EFFICACY, SAFETY, AND TOLERABILITY OF LACOSAMIDE IN PATIENTS WITH GAIN-OF-FUNCTION NAv1.7 MUTATIONS RELATED SMALL FIBER NEUROPATHY study protocol of a randomized controlled trial The LENSS study}

Bianca T.A. de Greef ${ }^{1}, M D$, Ingemar S.J. Merkies ${ }^{1,2}, M D$, PhD, Margot Geerts ${ }^{1}$, MSc, Catharina G. Faber ${ }^{1}$, MD, PhD, Janneke G.J. Hoeijmakers ${ }^{1}$, MD, PhD.

${ }^{1}$ Department of Neurology, School of Mental Health and Neuroscience, Maastricht University Medical Center, Maastricht, The Netherlands.

${ }^{2}$ Department of Neurology, St. Elisabeth Hospital, Willemstad, Curaçao.

The study was supported by a grant of the Prinses Beatrix Spierfonds

(W.OR12-01). 


\section{Abstract}

Background: Small fiber neuropathy generally leads to considerable pain and autonomic symptoms. Gain-of-function mutations in the SCN9A-gene, which codes for the Nav1.7 voltagegated sodium channel, have been reported in small fiber neuropathy, suggesting an underlying genetic basis in a subset of patients. Currently available sodium channel blockers lack selectivity, leading to cardiac and central nervous system side effects. Lacosamide is an anticonvulsant, which blocks $\mathrm{Na}_{\vee} 1.3, \mathrm{Na}_{v} 1.7$, and $\mathrm{Na}_{v} 1.8$, and stabilizes channels in the slowinactivation state. Since multiple $\mathrm{Na}_{\mathrm{v}} 1.7$ mutations in small fiber neuropathy showed impaired slow-inactivation, lacosamide might be effective.

Methods/Design: The lacosamide-Efficacy-' $N$ '-Safety in Small fiber neuropathy (LENSS) study is a randomized, double-blind, placebo-controlled, crossover trial in patients with SCN9Aassociated small fiber neuropathy, with the primary objective to evaluate the efficacy of lacosamide versus placebo. Eligible patients (the aim is to recruit 25) fulfilling the inclusion and exclusion criteria will be randomized to receive lacosamide (200 mg BID) or placebo during the first double-blinded treatment period ( 8 weeks), which is preceded by a titration period ( 3 weeks). The first treatment period will be followed by a tapering period ( 2 weeks). After a 2week washout period, patients will crossover to the alternate arm for the second period consisting of an equal titration phase, treatment period, and tapering period. The primary efficacy endpoint will be the proportion of patients demonstrating a 1-point average pain score reduction compared to baseline using the Pain Intensity Numerical Rating Scale. We assume a response rate of approximately $60 \%$ based on the criteria composed by the Initiative on Methods, Measurement, and Pain Assessment in Clinical Trials (IMMPACT) group for measurement of pain. Patients withdrawing from the study will be considered as nonresponders. Secondary outcomes will include changes in maximum pain score, the Small Fiber Neuropathy-Symptoms Inventory Questionnaire, sleep quality and quality of life assessment, patients' global impression of change, and safety and tolerability measurements. Sensitivity analysis will include assessing the proportion of patients having $\geq 2$ points average pain improvement compared to baseline Pain Intensity Numerical Rating Scale scores.

Discussion: This is the first study that will be evaluating the efficacy, safety, and tolerability of lacosamide in patients with SCN9A-associated small fiber neuropathy versus placebo. The findings may increase the knowledge on lacosamide as a potential treatment option in patients with painful neuropathies, considering the central role of $\mathrm{Na}_{v} 1.7$ in pain. 


\section{Background}

Neuropathic pain is described as 'pain caused by a lesion or disease of the somatosensory system. ${ }^{1}$ The prevalence of neuropathic pain in the general population is around $7 \%$ to $10 \% .{ }^{2}$,

${ }^{3}$ Neuropathic pain is one of the main symptoms of small fiber neuropathy (SFN), a condition that affects the thinly myelinated A $\delta$-fibers and the unmyelinated C-fibers. Pain in SFN is mostly described as a stitching, burning sensation, usually occurring in a length-dependent pattern, starting in the feet and hands. ${ }^{4}$ Body pain is a major contributor to the reduction of quality of life in patients with SFN. ${ }^{5}$ In addition to the neuropathic pain, patients with SFN may suffer from autonomic symptoms. ${ }^{6,7}$

Voltage-gated sodium channels have been described to play an important role in neuropathic pain. ${ }^{8}$ In approximately $15 \%$ of patients with SFN, gain-of-function mutations in the SCN9A-, SCN10A- and SCN11A-gene have been reported. ${ }^{9-12}$ The SCN9A-gene codes for the voltagegated sodium channel $\mathrm{Na}_{\mathrm{v}} 1.7$, which is predominantly expressed in the small nociceptive and autonomic neurons. In addition to being associated with SFN, gain-of-function mutations in the SCN9A-gene have been described in the following human pain disorders: inherited erythromelalgia (IEM) and paroxysmal extreme pain disorder (PEPD). ${ }^{13}$, 14 Gain-of-function mutations of the SCN9A-gene were found in $28 \%$ of patients with SFN proven by skin-biopsy. ${ }^{9}$ In a larger cohort ( $n=393$ ), the prevalence of SCN9A-gene mutations in patients diagnosed with SFN based on an abnormal skin biopsy and/or abnormal temperature threshold testing was approximately $9 \% .{ }^{12}$ Therefore, Nav1.7 appears to be an appropriate target for treatment of different human neuropathic pain conditions, including SCN9A-associated SFN.

Current treatments for pain in patients with SFN are far from satisfactory. ${ }^{15}$ Less than $50 \%$ of the patients achieve a pain reduction of $50 \% .{ }^{16,17}$ This is possibly due to drugs acting on target sites for which no strong evidence of pathogenicity exists. In addition, commercially available sodium channel blockers are not selective for $\mathrm{Na}_{v} 1.7$, thereby frequently causing intolerable side effects involving the heart and central nervous system.

Lacosamide is a functionalized amino acid molecule that selectively enhances the slow inactivation of voltage-gated sodium channels and interacts with the collapsin-response mediator protein-2. ${ }^{18}$ Lacosamide differs from other sodium channel blockers because of its unique mechanism of action. It inhibits the currents of hyperexcitable neurons of the voltagegated sodium channels $\mathrm{Na}_{v} 1.3, \mathrm{Na}_{v} 1.7$, and $\mathrm{Na}_{v} 1.8$ by targeting the slow-inactivation state and sparing channels with normal activity. ${ }^{19,} 20$ In patients with SCN9A-associated SFN, multiple mutations in the SCN9A-gene have shown an impaired slow-inactivation, ${ }^{9}$ which might potentially be considered a target mechanism of action of lacosamide. Therefore, a positive effect on pain reduction in these patients might be expected.

To date, no studies with lacosamide have been performed in patients with SFN. Some evidence exists of lacosamide reducing neuropathic pain and being well tolerated in patients with a painful diabetic neuropathy. ${ }^{21,22}$ The same results were seen in one study with patients with fibromyalgia. ${ }^{23}$ However, no robust underlying mechanism has been presented in these studies. 


\section{Methods/Design}

\section{Objective}

The primary objective of this study is to determine the efficacy and safety of lacosamide versus placebo in patients with SCN9A-associated SFN.

\section{Study design}

The Lacosamide-Efficacy-'N'-Safety in SFN (LENSS) study is a randomized, placebo-controlled, double blind, crossover-design study (figure 1). The study consists of 2 periods. Before the first period, the screening and baseline measurements takes place. Subjects fulfilling the inclusion and exclusion criteria are subsequently randomized to receive lacosamide or placebo.

Figure 1 Schematic diagram of study

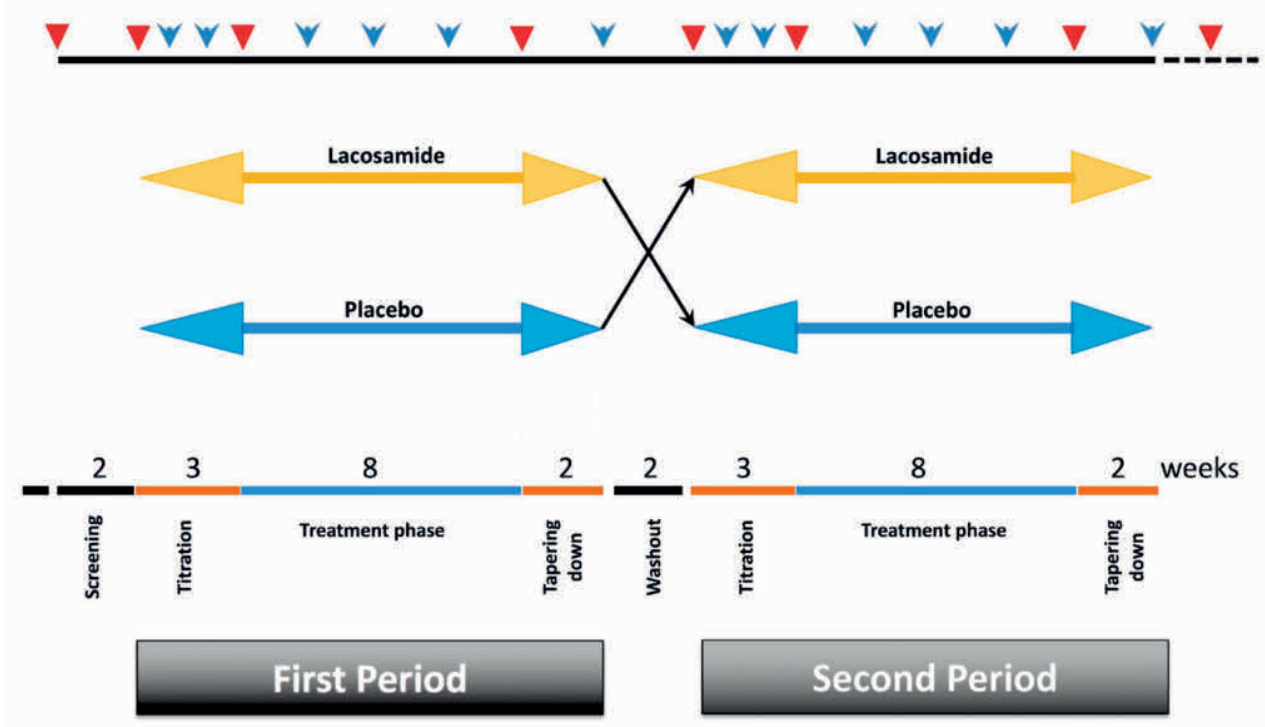

\section{Visits $\mathbb{V}$ Telephone call}

The first period starts with the first titration period of 3 weeks, in which study medication (lacosamide or equivalent placebo) will be gradually increased. Subsequently, patients enter the first treatment period of 8 weeks. This period is followed by a 2-week tapering period. After a 2-week washout period, the second period, which is executed in the same manner as the first period, begins. Subjects cross over to the alternate arm and undergo the second 3-week titration period, followed by the second treatment period ( 8 weeks) and a tapering period ( 2 weeks). In both treatment periods, subjects receive lacosamide $200 \mathrm{mg}$ BID or placebo. Patients are examined at the study outpatient site at the entry and at the end of both treatment periods (maximum of eight site visits). In addition, subjects are contacted and interviewed in a standardized manner by phone every 2 weeks to determine clinical condition and well-being, and collect data on safety and side effects. A follow-up visit is performed approximately 4 weeks after the last dose of study medication. 
The use of drugs such as lamotrigine, carbamazapine, oxcarbazapine, mexiletine, amitriptyline, topical analgesics (e.g., lidocaine patches, capsaicin patches and oral/injectable corticosteroids) that act on sodium channels is not allowed during the study period. Participants using these drugs require a washout period of at least 5 half-lives ( 90 days for capsaicin patches, which have the longest elimination period of the prohibited medications) prior to the screening visit. Other pain medications can be continued provided the dose and frequency of dosing have been stable over the previous 30 days prior to screening and remains unchanged during the study period. Additional medication is recorded.

\section{Study medication}

Each treatment phase is preceded by a titration phase. The dose of lacosamide is increased weakly, starting with $50 \mathrm{mg}$ BID in the first week, followed by $100 \mathrm{mg}$ BID in the second week, concluding with $150 \mathrm{mg}$ BID in the third week. After these 3 weeks, the treatment phase begins for 8 weeks. Based on previous studies and on the dose-related side effects, a dose of $200 \mathrm{mg}$ BID (or equivalent placebo) has been chosen as maintenance dose. ${ }^{24}$ The subjects start with the maintenance dose (200mg BID) at the first day of the treatment phase, therefore this dose is not included in the titration phase. After the treatment phase, the tapering phase begins, with study medication (lacosamide or placebo) dosage being reduced at once to $100 \mathrm{mg}$ BID in the first week of the tapering period and then to $50 \mathrm{mg}$ BID in the second week of the tapering period.

A convenient treatment period of 8 weeks was chosen based on literature findings and assuming that a positive effect of lacosamide should be seen within this period, thereby limiting the burden for patients. ${ }^{23}$

\section{Participants}

A total of 25 subjects with genetically proven SCN9A-associated SFN are recruited into the trial. SCN9A-mutations classified as certainly, probably, or potentially pathogenic are eligible for inclusion. ${ }^{25}$ Subjects are recruited at the Maastricht University Medical Center+ (Maastricht UMC+), the Netherlands.

Informed consent is obtained from all participants, before any of the study procedures (e.g. questionnaires or neurological examination) is performed.

\section{Inclusion criteria}

Subjects must fulfill the following inclusion criteria to be eligible:

1. Male and/or female subjects between 18 and 80 years.

2. Presence of a clinical diagnosis of Small Fiber Neuropathy (SFN), with at least 2 of the following clinical symptoms not otherwise explained:

- Burning feet.

- Allodynia.

- Diminished pain and/or temperature sensation.

- Dry eyes or mouth.

- Orthostatic dizziness. 
- Bowel disturbances (constipation, diarrhea, gastroparesis).

- Urinary disturbances.

- Sweat changes (hyperhidrosis/hypohidrosis).

- Visual accommodation problems and/or blurred vision.

- Hot flashes/palpitations.

- Impotence, diminished ejaculation or lubrication.

3. In addition to the clinical diagnosis of SFN, presence of confirmed abnormality on intraepidermal nerve fiber density evaluation (IENFD) and/or Quantitative Sensory Testing (QST) ${ }^{6,7}$ and a mutation in the SCN9A gene, confirmed by sequencing. Where possible, in vitro confirmation of the functionality of the mutation should have been performed and documented as has been demonstrated previously. 6,9

4. Presence of pain due to SFN for at least 3 months prior to screening and an average selfreported pain score of at least 3 during this time.

5. If on analgesic medication, subject must have a stable analgesic medication regimen for a minimum of 30 days before the start of the study and should continue with the same unchanged regimen throughout the study.

6. Evidence of a personally signed and dated informed consent document indicating that the subject (or a legal representative) has been informed of all pertinent aspects of the study.

7. Subjects who are willing and able to comply with scheduled visits, treatment plan, laboratory tests, and other study procedures.

\section{Exclusion criteria:}

Subjects presenting with any of the following cannot be included in the study:

1. Subjects with predominantly signs of large nerve fiber involvement (muscle weakness, loss of vibration sense, hyporeflexia/areflexia), or clinically significant abnormal nerve conduction studies (NCS).

2. History or presence of illnesses known to cause SFN (excluding diabetes mellitus), including liver, kidney, or thyroid dysfunction, monoclonal gammopathy, connective tissue disorders, sarcoidosis, Sjögren syndrome, amyloidosis, Fabry disease, celiac disease, HIV and neurotoxic drugs (e.g., chemotherapy).

3. Subjects with other severe pain conditions, which may impair the self-assessment of pain due to SFN.

4. Any condition possibly affecting drug intake and absorption (e.g., difficulty in swallowing, gastrectomy and /or bowel resection).

5. History of known alcohol, analgesic or illicit drug abuse within 12 months of screening.

6. Subjects taking medications with potential effect on sodium channels function, e.g., lamotrigine, carbamazapine, oxcarbazapine, mexiletine, amitriptyline, topical analgesics e.g., lidocaine patches, capsaicin patches and oral/injectable corticosteroids. These medications are prohibited until the end of the study period and require a washout period of at least 5 half-lives ( 90 days for capsaicin patches, which is the longest elimination period of the prohibited medications) prior to the screening visit. 
7. 12-lead ECG demonstrating QTCF (Fridericia's correction) $>450$ or a QRS interval $>120$ msec at screening. If QTcF exceeds $450 \mathrm{msec}$, or QRS exceeds $120 \mathrm{msec}$, the ECG should be repeated 2 more times and the average of the three QTCF values should be used to determine the subject's eligibility.

8. Severe renal impairment (creatinine clearance $\leq 30 \mathrm{~mL} / \mathrm{min}$ ).

9. Treatment with an investigational drug within 30 days (or as determined by the local requirement, whichever is longer) or 5 half-lives preceding the first dose of study medication.

10. Participation in other studies during the period of current study participation, or has planned surgery during the course of the study.

11. Pregnant females; breastfeeding females; females of childbearing potential not using effective and medically reliable contraception or not agreeing to continue effective contraception for at least 28 days after the last dose of investigational product.

12. Other clinically significant or unstable, or severe acute or chronic medical or psychiatric/psychological condition or laboratory abnormality that may increase the risk associated with study participation or investigational product administration or may interfere with the interpretation of study results and, in the judgment of the Investigator, would make the subject inappropriate for entry into this study.

13. In the case of incidental findings the patient and his/her treating physician will be informed and asked to undertake action if necessary. If a patient does not want to be informed about possible incidental findings, nor wants his treating physician to be informed, he or she cannot participate in this study.

\section{Randomization}

After the screening period, patients return to our center. To ensure that eligible subjects are compliant, it will be checked that at least 5 of the last 7 days of the pain diary are filled in. This is important because the pain diary of the screening period is used as the baseline measurement of the primary outcome. Randomization is performed by using ALEA data management. This software is provided by the Trans European Network for Clinical Trials Services (http://www.tenalea.com/). The randomization is computer-controlled based on the electronic case report form that is used. A blinded message is send to the investigator and an unblinded message is send to the pharmacy. Patients are stratified based on the type of SCN9Avariant (1. genetic variant and 2. genetically and functionally confirmed) and on the clinical diagnosis of SFN (1. abnormal skin biopsy, 2. abnormal temperature threshold testing, and 3. abnormal skin biopsy and abnormal temperature threshold).

\section{Blinding}

The study is subject- and investigator-blinded until the end of the study. Blinding codes are only broken in emergency situations for reasons of subject safety.

Lacosamide and matching placebo is provided as $50 \mathrm{mg}$ tablets for oral administration. Tablets are provided in containers. Rescue medication (acetaminophen) is provided in its approved 
marketed product dress. All medication dispensed to subjects are to be returned to the investigator and double-checked by monitor to assure study compliance.

\section{Compliance}

The following compliance calculation are applied:

$$
\begin{aligned}
\% \text { Compliance }= & \text { number of tablets taken } / \text { number of } \\
& \text { tablets expected to have taken } \times 100 .
\end{aligned}
$$

Subjects are coded as being a non-compliant if the percentage compliance according to the above formula is less than $80 \%$ or greater than $120 \%$ study drug compliance.

\section{Efficacy measurements}

The daily Pain Intensity Numerical Rating Scale (PI-NRS) consists of an 11-point numerical scale ranging from 0 to 10, were 0 represents no pain and 10 the worst pain possible. The subjects are asked to complete the PI-NRS twice daily, in the morning and evening, preferably at fixed time points. In addition, the Daily Sleep Interference Scale (DSIS) is completed every day on awakening in the morning. The DSIS consists of an 11-point numerical scale ranging from 0 (pain does not interfere with sleep) to 10 (pain completely interferes with sleep) and is used to determine sleep quality. At each assessment, the following additional questionnaires are completed: the Neuropathic Pain Scale (NPS), Small Fiber Neuropathy-Symptom Inventory Questionnaire (SFN-SIQ), Patients' Global Impression of Change (PGIC), and the generic shortform SF-36 health survey (SF-36).

\section{Outcome measurements}

The chosen outcomes are largely based on the international criteria advised by the IMMPACT group for measurement of pain. ${ }^{26}$

\section{Primary outcome}

The primary efficacy endpoint is defined as the proportion of patients demonstrating a 1-point average pain score reduction compared to baseline using the PI-NRS. A 1-point change on the $\mathrm{PI-NRS}$ is considered the minimum clinically important difference (MCID), according to unified rule of $1 / 2 \times$ standard deviation (SD) and recommendations given by the IMMPACT group. ${ }^{26,27}$

\section{Secondary outcome}

Secondary outcomes include changes seen in the maximum pain score on the PI-NRS, the NPS, DSIS, PGIC, SFN-SIQ, SF-36, adverse events, laboratory safety tests (e.g. hematology, clinical chemistry), blood pressure (BP), pulse rate (PR), and electrocardiogram (ECG).

Sensitivity analyses include assessing the proportion of patients having $\geq 2$ points average pain improvement compared to baseline PI-NRS scores. 


\section{Data management}

An electronic case report file (eCRF) is used for each patient to collect all data. To host the eCRF, MACRO electronic data capture is used, powered by InferMed Ltd, London. It has been designed to support compliance with the requirements of relevant regulatory bodies including ICH Good Clinical Practice (www.infermed.com). Assessments start at the screening visit. In addition, assessments at site visits and by phone are performed according to the scheme presented in figure 1, and include a standardized interview to determine patient's clinical condition and well-being, assessment of various questionnaires, determining compliance, laboratory assessment, and at predefined moments performing ECG. During each contact (visit or by phone), adverse events and concomitant medication are discussed. At each visit, the diary and residual medications are collected. An overview of the assessments at visits and telephone calls are summarized in table 1.

Privacy of the patients is guaranteed; stored data and materials are only identifiable to the person by a sequential assigned subject number. The handling of personal data complies with the Dutch Personal Data Protection Act (De Wet Bescherming Persoonsgegevens, WBP). The figure for the study protocol is shown in supporting information 1.

\section{Safety reporting}

Adverse events are recorded and monitored. The principal investigator is to be informed immediately in case of any serious adverse event (SAE). Every SAE is reported to the Ethics Committee. Suspected unexpected serious adverse reactions (SUSAR) are also reported. And all SUSARs are expedited to the competent authorities in other Member States, according to the requirements of the Member States.

\section{Statistical analysis}

Sample size

A 1-point change on the average PI-NRS compared to baseline is considered as the MCID. ${ }^{26,27}$ We assume a response rate of approximately $20 \%$ in the placebo-treated group, based on a meta-analysis of the placebo effect in pain studies in which the effect varied from $7-37 \%$ with a $50 \%$ pain reduction in $16 \%$. In the lacosamide-treated group, we assume a response rate of approximately $60 \%$ based on the IMMPACT criteria in which the clinical relevant pain reduction may be less than 50\%. Fixing a two-sided alpha at 5\%, a sample size of 22 patients is required per treatment group to show efficacy with $80 \%$ power between the 2 groups (chi-square test). Assuming a dropout rate of approximately $10 \%$ (two to three patients), a total of 25 subjects will be needed per treatment group (in a parallel study). Since the number of patients with SCN9A-associated SFN is limited, a crossover design was chosen to fulfill sample size requirements with the inclusion of 25 subjects.

\section{Type of analysis}

The analyses are performed on the intention-to-treat (ITT) population, defined as all patients who received at least one dose of randomized study medication and had at least one postbaseline assessment. Patients withdrawing from the study are considered as non-responders. 
The comparison of the proportion of patients in both groups (lacosamide vs. placebo) reaching the predefined cut-off is estimated using Kaplan-Meijer serial time series graphs with a logrank test.

For secondary efficacy endpoints, the treatment differences for change from baseline in selected outcome measures, according to the pre-defined inquiries, are analyzed using nonparametric tests. Statistical tests used depend on the type of data. Analyses of safety parameters are performed on the safety set (SS), which includes all randomized patients who took at least 1 dose of trial medication. Individual missing data are assigned using a last observation carried forward approach. Other missing-data treatment methods are performed (for example single and multiple imputation), to test which of these methods is the best based on sensitivity analyses.

\section{Discussion}

In this study, the efficacy, safety, and tolerability of lacosamide in patients with pain due to SCN9A-associated SFN is studied. Despite earlier studies performed with lacosamide in painful conditions, no study to date has been done in patients with SCN9A-associated SFN. This is interesting because most of them harbor an electrophysiological mechanism of pain induction through impaired slow-inactivation of the voltage-gated sodium channel Nav1.7, ${ }^{28}$ which might be a potential target for lacosamide, taking into account its unique mechanism of targeting the slow-inactivation. ${ }^{19}$ Therefore, a positive effect on pain reduction in these patients might be expected.

With lacosamide, we hope to find a new treatment option for the excruciating pain often reported by patients with SFN. This is the first pilot study that aims to show the efficacy, tolerability, and safety of lacosamide in this specific cohort of patients with SCN9A-associated SFN.

If lacosamide proves to be effective in SFN patients with a Nav1.7 mutation, this might be a viable option for patients with painful neuropathies or with neuropathic pain in general, considering the central role of $\mathrm{Na}_{v} 1.7$ in pain. The first results of the study are expected mid 2017.

\section{Trial status}

Participant recruitment for this trial is ongoing. Recruitment began in November 2014 and is expected to end mid-2016. 


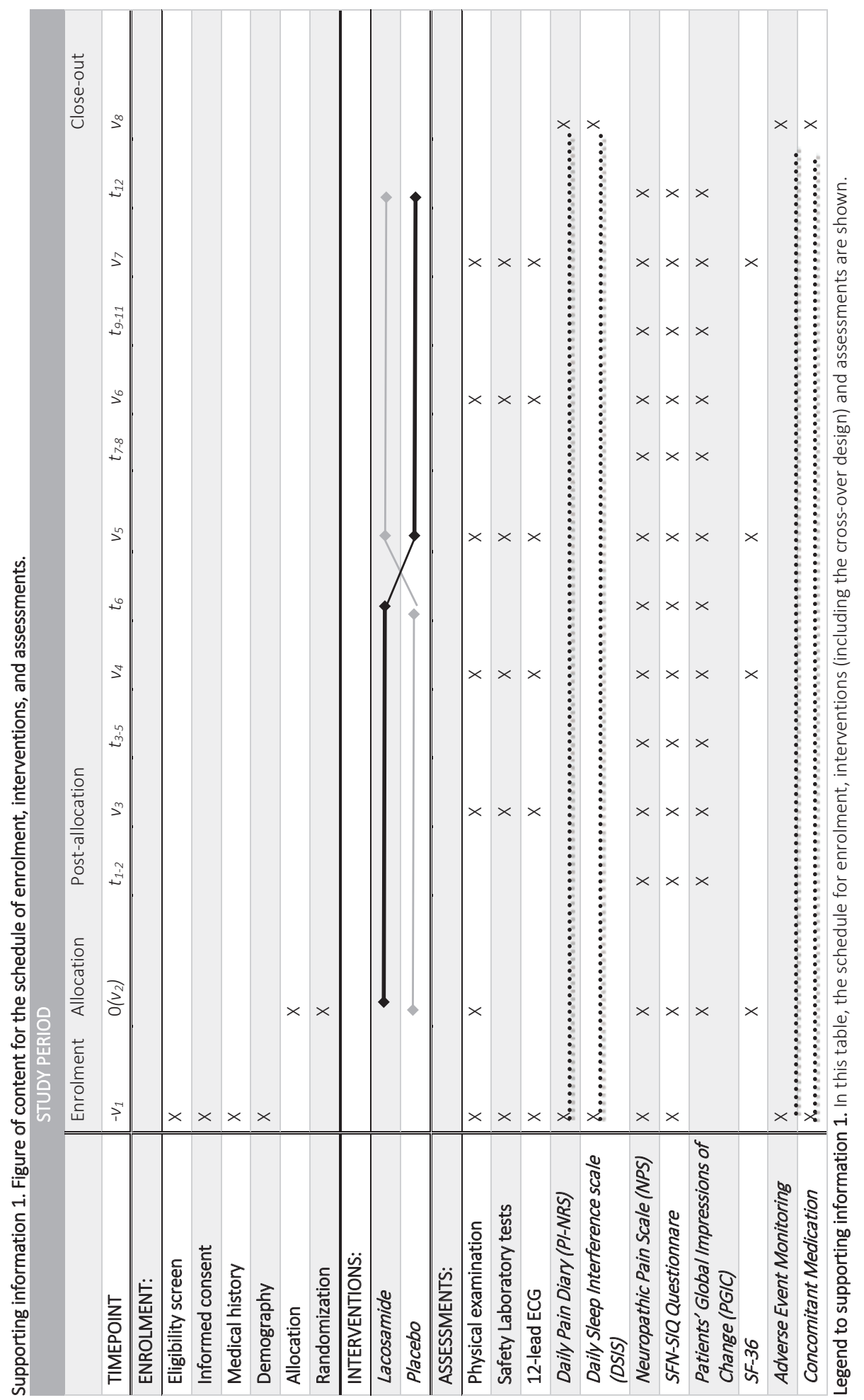



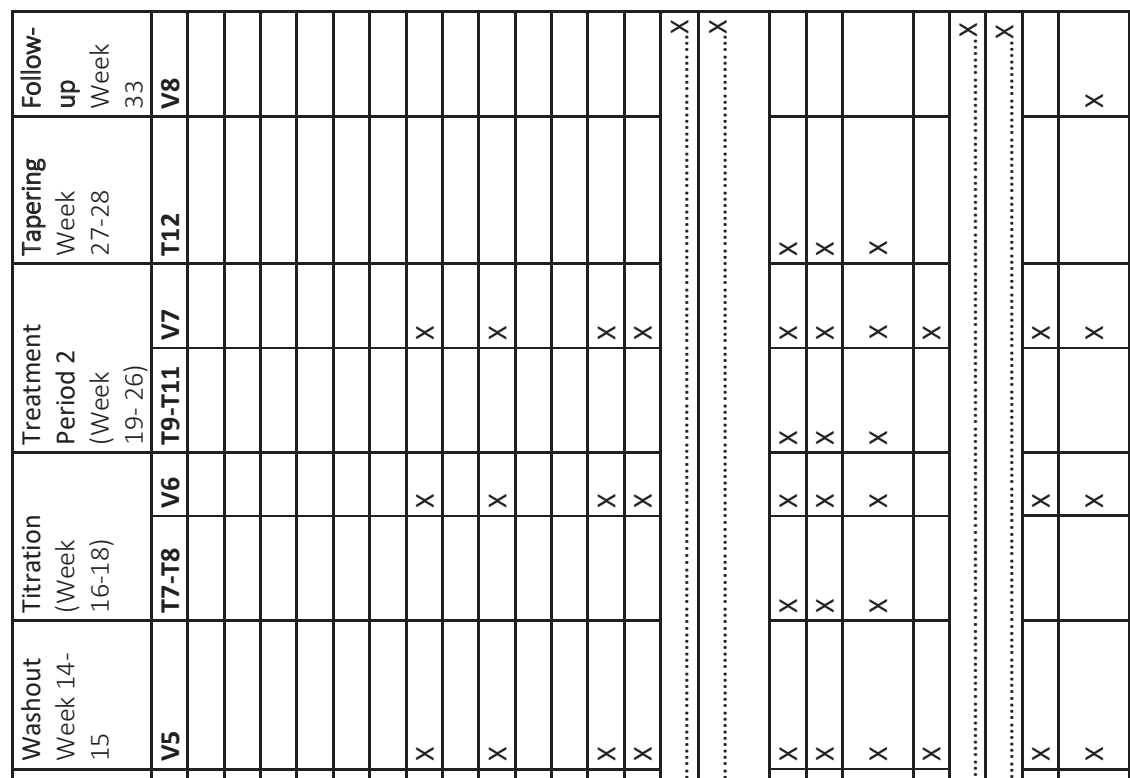

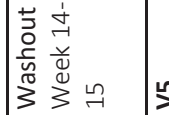

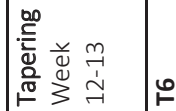
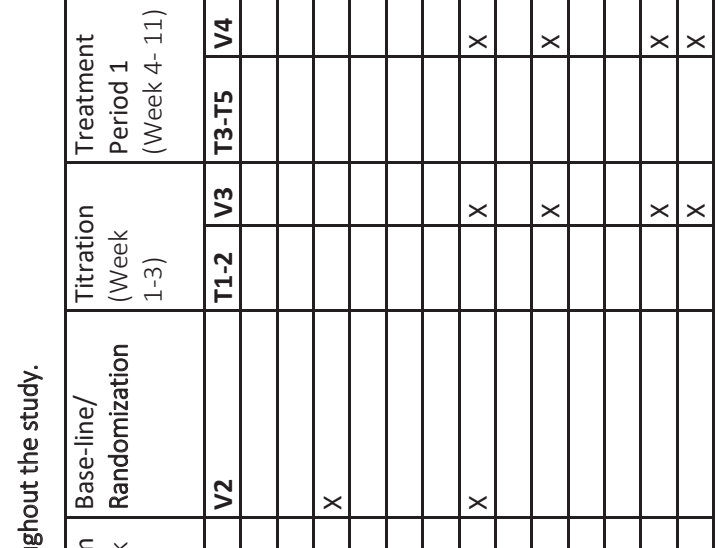

\section{$\times \times x$}
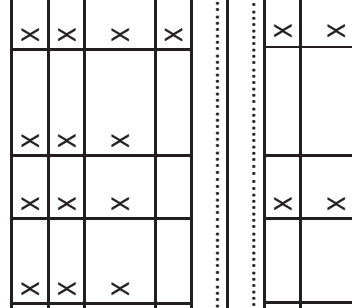

$\times \times \times$ $\times$

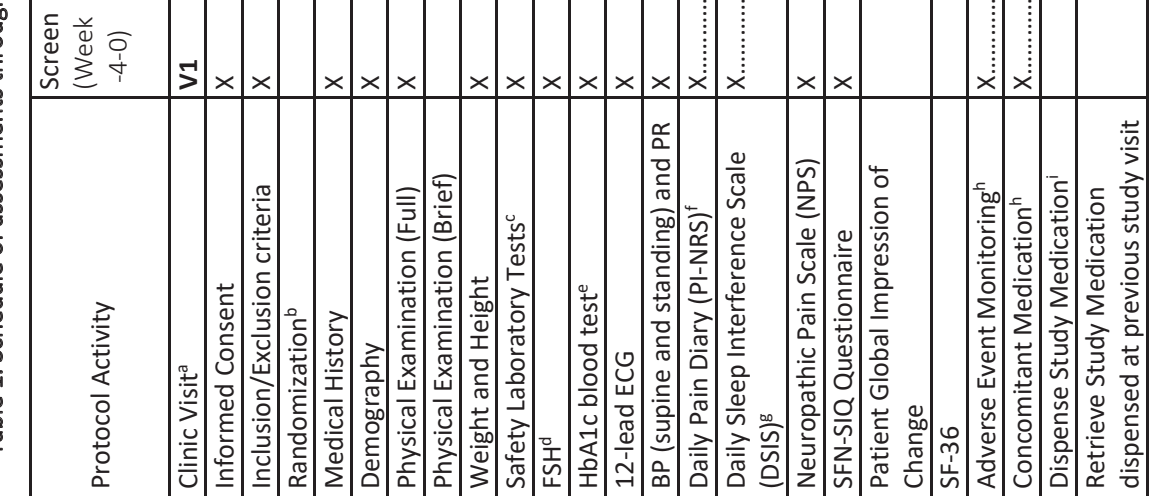



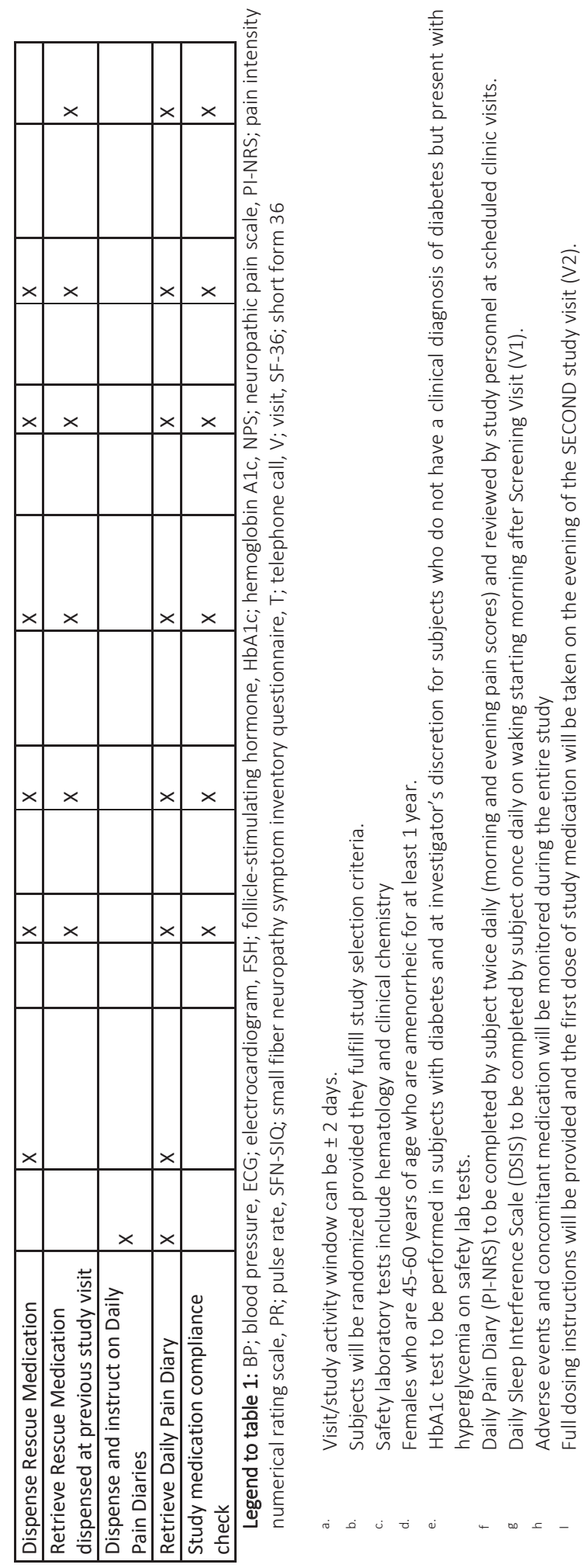

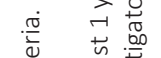 \\ 离}

ᄃ

艺

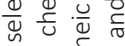

즐 $\overline{\frac{0}{E}}$

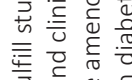

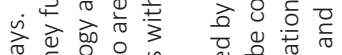

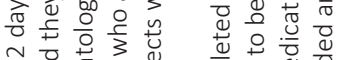

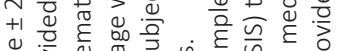

ه

饮

3 \&

它

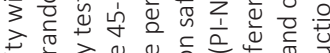

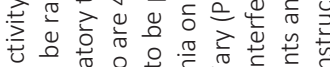

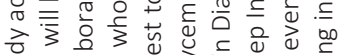

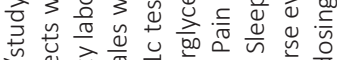

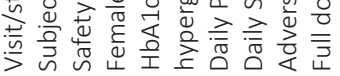




\section{References}

1. Jensen TS, Baron R, Haanpaa M, et al. A new definition of neuropathic pain. Pain. 2011;152(10):2204-5.

2. Bouhassira D, Lanteri-Minet M, Attal N, Laurent B, Touboul C. Prevalence of chronic pain with neuropathic characteristics in the general population. Pain. 2008;136(3):380-7.

3. de Moraes Vieira EB, Garcia JB, da Silva AA, Mualem Araujo RL, Jansen RC. Prevalence, characteristics, and factors associated with chronic pain with and without neuropathic characteristics in Sao Luis, Brazil. J Pain Symptom Manage. 2012;44(2):239-51.

4. Gorson KC, Ropper AH. Idiopathic distal small fiber neuropathy. Acta Neurol Scand. 1995;92(5):376-82.

5. Bakkers M, Faber CG, Hoeijmakers JG, Lauria G, Merkies IS. Small fibers, large impact: quality of life in small-fiber neuropathy. Muscle Nerve. 2014;49(3):329-36.

6. Hoeijmakers JG, Faber CG, Lauria G, Merkies IS, Waxman SG. Small-fibre neuropathies-advances in diagnosis, pathophysiology and management. Nat Rev Neurol. 2012;8(7):369-79.

7. Lauria G, Merkies IS, Faber CG. Small fibre neuropathy. Curr Opin Neurol. 2012;25(5):542-9.

8. Dib-Hajj SD, Cummins TR, Black JA, Waxman SG. Sodium channels in normal and pathological pain. Annu Rev Neurosci. 2010;33:325-47.

9. Faber CG, Hoeijmakers JG, Ahn HS, et al. Gain of function Nav1.7 mutations in idiopathic small fiber neuropathy. Ann Neurol. 2012;71(1):26-39.

10. Faber CG, Lauria G, Merkies IS, et al. Gain-of-function Nav1.8 mutations in painful neuropathy. Proc NatI Acad Sci U S A. 2012;109(47):19444-9.

11. Huang J, Han C, Estacion M, et al. Gain-of-function mutations in sodium channel Na(v)1.9 in painful neuropathy. Brain. 2014;137(Pt 6):1627-42.

12. Brouwer BA, Merkies IS, Gerrits MM, Waxman SG, Hoeijmakers JG, Faber CG. Painful neuropathies: the emerging role of sodium channelopathies. J Peripher Nerv Syst. 2014;19(2):53-65.

13. Yang Y, Wang Y, Li S, et al. Mutations in SCN9A, encoding a sodium channel alpha subunit, in patients with primary erythermalgia. J Med Genet. 2004;41(3):171-4.

14. Fertleman CR, Baker MD, Parker KA, et al. SCN9A mutations in paroxysmal extreme pain disorder: allelic variants underlie distinct channel defects and phenotypes. Neuron. 2006;52(5):767-74.

15. Themistocleous AC, Ramirez JD, Serra J, Bennett DL. The clinical approach to small fibre neuropathy and painful channelopathy. Pract Neurol. 2014;14(6):368-79.

16. Finnerup NB, Attal N, Haroutounian S, et al. Pharmacotherapy for neuropathic pain in adults: a systematic review and meta-analysis. Lancet Neurol. 2015;14(2):162-73.

17. Attal N, Cruccu G, Baron R, et al. EFNS guidelines on the pharmacological treatment of neuropathic pain: 2010 revision. Eur J Neurol. 2010;17(9):1113-e88.

18. Beyreuther BK, Freitag J, Heers C, Krebsfanger N, Scharfenecker U, Stohr T. Lacosamide: a review of preclinical properties. CNS Drug Rev. 2007;13(1):21-42.

19. Errington AC, Stohr T, Heers C, Lees G. The investigational anticonvulsant lacosamide selectively enhances slow inactivation of voltage-gated sodium channels. Mol Pharmacol. 2008;73(1):157-69.

20. Amir R, Argoff CE, Bennett GJ, et al. The role of sodium channels in chronic inflammatory and neuropathic pain. J Pain. 2006;7(5 Suppl 3):S1-29.

21. Ziegler D, Hidvegi T, Gurieva I, et al. Efficacy and safety of lacosamide in painful diabetic neuropathy. Diabetes Care. 2010;33(4):839-41.

22. Wymer JP, Simpson J, Sen D, Bongardt S, Lacosamide SPSG. Efficacy and safety of lacosamide in diabetic neuropathic pain: an 18-week double-blind placebo-controlled trial of fixed-dose regimens. Clin J Pain. 2009;25(5):376-85.

23. Hearn L, Derry S, Moore RA. Lacosamide for neuropathic pain and fibromyalgia in adults. Cochrane Database Syst Rev. 2012;2:CD009318.

24. Zaccara G, Perucca P, Loiacono G, Giovannelli F, Verrotti A. The adverse event profile of lacosamide: a systematic review and meta-analysis of randomized controlled trials. Epilepsia. 2013;54(1):66-74.

25. Waxman SG, Merkies IS, Gerrits MM, et al. Sodium channel genes in pain-related disorders: phenotypegenotype associations and recommendations for clinical use. Lancet Neurol. 2014;13(11):1152-60.

26. Dworkin RH, Turk DC, Wyrwich KW, et al. Interpreting the clinical importance of treatment outcomes in chronic pain clinical trials: IMMPACT recommendations. J Pain. 2008;9(2):105-21. 
27. Sloan J, Symonds T, Vargas-Chanes D, Fridley B. Practical guidelines for assessing the clinical significance of health-related quality of life changes within clinical trials. Drug Inform J. 2003;37:23-31.

28. Dib-Hajj SD, Cummins TR, Black JA, Waxman SG. From genes to pain: Na v 1.7 and human pain disorders. Trends Neurosci. 2007;30(11):555-63. 



\section{CHAPTER 6}

LACOSAMIDE IN PATIENTS WITH NAv1.7 MUTATIONSRELATED SMALL FIBER NEUROPATHY: a randomized controlled trial

Bianca T.A. de Greef ${ }^{1}, M D$, Janneke G.J. Hoeijmakers ${ }^{1}, M D$, Margot Geerts ${ }^{1}$, MSC, Mike Oakes², Tim J.E. Church ${ }^{3}$, Stephen G. Waxman ${ }^{4,5}, M D$, Sulayman D. Dib-Hajj ${ }^{4,5}$, PhD, Catharina G. Faber ${ }^{1}$, MD, Ingemar S.J. Merkies ${ }^{1,6}$, MD.

${ }^{1}$ Department of Neurology, School of Mental Health and Neuroscience, Maastricht University Medical Center+, Maastricht, The Netherlands.

${ }^{2}$ ParamStat Limited, University of Sussex, Fairlight, East Sussex, United Kingdom.

${ }^{3}$ Torch Consultants Ltd, Eastbourne, East Sussex, United Kingdom. ${ }^{4}$ Department of Neurology, Yale University School of Medicine, New Haven, Connecticut, United States of America.

${ }^{5}$ Center for Neuroscience and Regeneration Research, Veterans Affairs Medical Center, West Haven, Connecticut, United States of America. ${ }^{6}$ Department of Neurology, St. Elisabeth Hospital, Willemstad, Curaçao.

The study was supported by a grant of the Prinses Beatrix Spierfonds (W.OR12-01). 


\section{Abstract}

Background: Symptomatic treatment of neuropathic pain in small fiber neuropathy (SFN) is often disappointing. The finding of voltage-gated sodium channel mutations in SFN, with mutations in SCN9A, encoding for Nav1.7, being most frequently reported, suggest a specific target for therapy. The anticonvulsant lacosamide acts on Nav1.3, Nav1.7, and Nav1.8. The aim of this study was to evaluate the efficacy, safety, and tolerability of lacosamide as a potential treatment for pain in Nav1.7-related SFN.

Methods: The LENSS study was a randomized, placebo-controlled, double-blind, crossoverdesign study. Subjects were recruited in the Netherlands between November 2014 and July 2016. Patients with $\mathrm{Na}_{\mathrm{v}}$ 1.7-related SFN were randomized to start with lacosamide followed by placebo or vice versa. In both eight-week treatment phases, patients received 200mg BID, preceded by a titration period, and ended by a tapering period. The primary outcome was efficacy, defined as the proportion of patients with 1-point average pain score reduction compared to baseline using the Pain Intensity Numerical Rating Scale. The trial is registered with ClinicalTrials.gov, number NCT01911975.

Findings: Twenty-four subjects received lacosamide, and 23 received placebo. In $58.3 \%$ of patients receiving lacosamide, mean average pain decreased by at least 1 point, compared to $21.7 \%$ in the placebo group (sensitivity analyses, OR 5.65 (95\% Cl: 1.83;17.41); $p=0.0045$ ). In the lacosamide group, $33.3 \%$ reported that their general condition improved versus $4.3 \%$ in the placebo group ( $p$-value 0.0156). Additionally, a significant decrease in daily sleep interference, and in surface pain intensity was demonstrated. No significant changes in quality of life or autonomic symptoms were found. Lacosamide was well-tolerated and safe in use.

Interpretation: This study shows that lacosamide has a significant effect on pain, general wellbeing, and sleep quality. Lacosamide was well-tolerated and safe, suggesting that it can be used for pain treatment in Nav1.7-related SFN. 


\section{Introduction}

Small fiber neuropathy (SFN) is a peripheral neuropathy of the thinly myelinated A $\delta$-fibers and unmyelinated C-fibers, and is associated with multiple underlying conditions. ${ }^{1-3}$ Patients suffer from excruciating pain and autonomic symptoms, leading to a significant negative impact on quality of life. ${ }^{4}$

In cases where an underlying condition is present, initial treatment usually focuses on this, but additional symptomatic therapy is generally needed. First-line treatment of neuropathic pain consists of tricyclic antidepressants, serotonin-noradrenaline reuptake inhibitors, pregabalin and gabapentin..$^{5-7}$ However, the efficacy of these drugs is often unsatisfactory. ${ }^{5,} 6$ Therefore new treatment options are of great importance.

Voltage-gated sodium channels (VGSC; $\mathrm{Na}_{\mathrm{v}}$ ) underlie the initiation and propagation of action potentials in excitable membranes. Animal studies have shown that $\mathrm{Na}_{\mathrm{v}} \mathrm{s}$ that are expressed in peripheral sensory neurons play important roles in neuropathic and inflammatory pain. ${ }^{8}$ $\mathrm{Na}_{v} 1.7, \mathrm{Na}_{v} 1.8$ and Nav1.9, encoded by the genes SCN9A, SCN10A, and SCN11A, respectively, are preferentially expressed in dorsal root ganglion (DRG) neurons and their peripheral axons. Genetic and functional studies have shown that gain-of-function mutations in these genes cause human pain disorders. ${ }^{9}$ Gain-of-function mutations in Navs have been reported in around $15 \%$ of patients with SFN, ${ }^{3,10}$ with SCN9A mutations being the most frequent. Taken together, inhibition of Navs is expected to be therapeutically beneficial for pain patients. ${ }^{8}$

Lacosamide is a functionalized amino acid which was thought to bind to the slow-inactivated state of Navs. ${ }^{11-16}$ Recent data suggests that lacosamide binds to fast-inactivated Nav1.7 with slower kinetics than classical sodium channel blockers. ${ }^{17}$ Since pain in SFN is produced by inappropriate firing of DRG neurons, ${ }^{3,10}$ the $\mathrm{Na}_{\mathrm{v}}$ channels in these neurons would be expected to be in at least a partially inactivated state, so that lacosamide would be expected to bind with and inhibit these channels, thus attenuating the firing of DRG neurons. In addition, lacosamide has also been shown to modulate $\mathrm{Na}_{v} 1.7$ via regulation of collapsing response mediator protein 2 (CRMP2), ${ }^{18}$ which acts on multiple pathways involved in pain. ${ }^{19}$ The multi-modal action of lacosamide suggests that it might be effective in treating patients with Nav1.7-related SFN.

To date, no studies with lacosamide in patients with SFN have been published. In studies with lacosamide in painful diabetic neuropathy a reduction in neuropathic pain was found, and the drug was well tolerated, ${ }^{20-23}$ but the small number of patients in these cohorts, and the small numbers of patients and events for most outcomes led to the conclusion that lacosamide is not useful in treating neuropathic pain. The aim of our study was to evaluate the effect on pain, safety, and tolerability of lacosamide in painful peripheral neuropathy, with a specific focus on a well-defined group of patients with Nav1.7-related SFN.

\section{Methods}

\section{Study design and participants}

The Lacosamide-Efficacy-'N'-Safety in SFN (LENSS) study was a randomized, placebocontrolled, double-blind, crossover-design study. A detailed description of the study design was published previously; ${ }^{24}$ a summary is given below. 
All subjects were recruited at the Maastricht University Medical Center+ (Maastricht UMC+), the Netherlands, between November 2014 and July 2016, and data collection continued until May 2017. Patients were eligible if they had been diagnosed with pure SFN in combination with an SCN9A-variant. According to the international guidelines, the diagnosis of pure SFN was based on typical clinical symptoms in combination with a diminished intraepidermal nerve fiber density in skin biopsy and/or abnormal temperature threshold testing (TTT) without signs of large fiber involvement. ${ }^{1,2}$ Patients with a history of associated conditions of SFN (except diabetes mellitus) were excluded for this study. Variants of the SCN9A-gene were classified according to the Practice Guidelines for the Evaluation of Pathogenicity and the Reporting of Sequence Variants in clinical Molecular Genetics. ${ }^{25}$ SFN patients with an SCN9A-variant that was classified as class 3,4 , or 5 (respectively variants of uncertain pathogenicity, variants likely to be pathogenic, and clearly pathogenic variants) were included. ${ }^{25}$ Where possible, in vitro confirmation of the functional effect of the mutation was performed and documented. ${ }^{10,14} \mathrm{All}$ participants signed an informed consent form before entering the study. A detailed description of the inclusion and exclusion criteria was published elsewhere. ${ }^{24}$

The study was conducted in accordance with the Declaration of Helsinki and International Conference on Harmonization Good Clinical Practice Guidelines. The institutional Medical Ethics Committee approved the study protocol. The trial was registered under http://www.clinicaltrials.gov/, NCT01911975, as well as EudraCT, number 2013-001511-70.

\section{Randomization and masking}

From subjects who fulfilled the inclusion- and exclusion criteria, baseline measurements were recorded. Randomization was performed by computer software called ALEA. Patients were stratified based on the type of the SCN9A-variant (genetically confirmed variant or genetically and functionally confirmed variant) and on the clinical diagnosis of SFN (abnormal skin biopsy, abnormal TTT, and abnormal skin biopsy in combination with an abnormal TTT). Patients were randomized into one of the two treatment arms, starting with lacosamide followed by placebo or starting with placebo followed by lacosamide. Because of the crossover-design, patients completed two identical study periods, but in different arms. For subjects and investigators, the order in which patients received lacosamide and placebo, was blinded. Lacosamide and matching placebo were provided as $50 \mathrm{mg}$ capsules for oral administration. The blinding codes were not broken during the entire study. Compliance and the use of rescue medication (acetaminophen) were recorded. 
Figure 1. Schematic diagram of study.

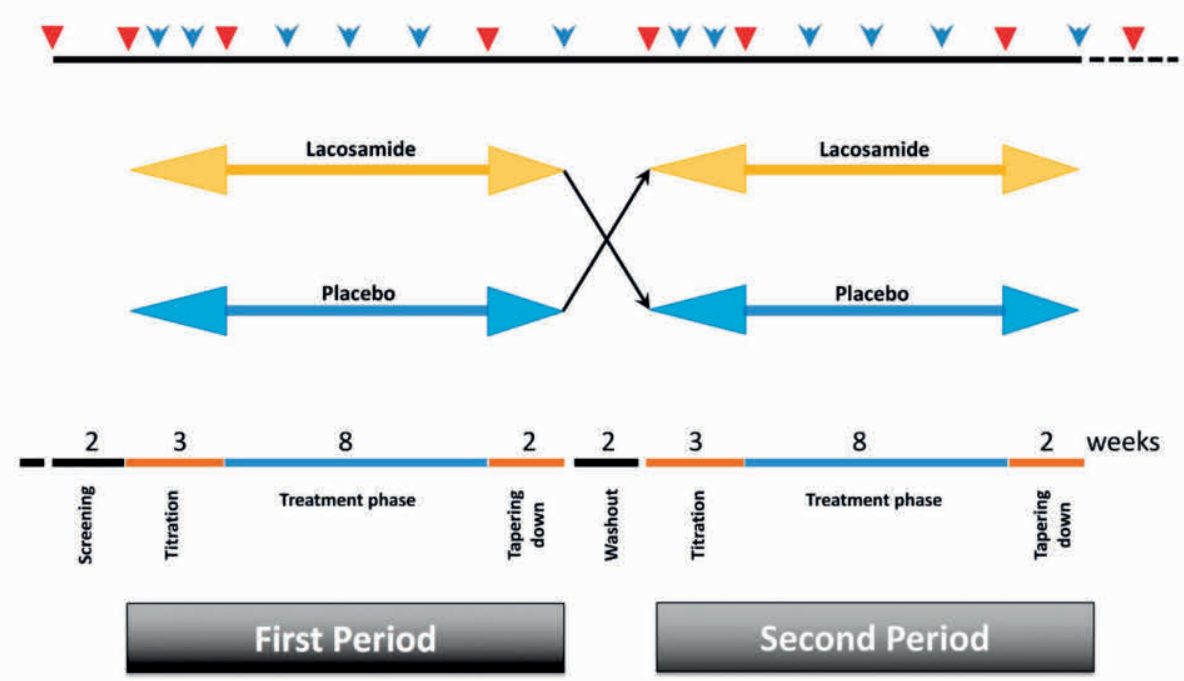

$\nabla$ Visits $W$ Telephone call

Legend to figure 1: This is the schematic design of the study. After the screening, eligible patients were randomized. After that, the titration period of 3 weeks was followed by a treatment period of 8 weeks and ended by a tapering period of 2 weeks. After a washout period of at least 2 weeks, the same study periods took place with the different treatment. In addition to the visits at every new study period, there were regular telephone calls and patients filled in a daily pain diary from the first day of the study until the end.

\section{Procedures}

Figure 1 provides the study algorithm..$^{24}$ In essence, each study part consisted of a titration period of three weeks, followed by a treatment period of eight weeks, and a tapering period of two weeks. After a washout period of at least two weeks, the same schedule was repeated for the other arm. Four weeks after the last tapering period the study ended. During the threeweek titration period, patients received an increasing dose of lacosamide or placebo, starting with 50mg BID in the first week, 100mg BID in the second week, and 150mg BID in the third week. Doses of 200mg BID were then administered for eight weeks. This part of the trial concluded with a two-week tapering period, in which patients received 100mg BID in the 12th week and 50mg BID in the 13th week. At the beginning of each period (for example the titration period or treatment period), patients visited our center. The unused study medication of the previous period was returned and the study medication for the next period was provided. Additionally, questionnaires were taken, blood tests and an electrocardiogram (ECG) were performed. In between the visits, there were standardized check-up telephone calls scheduled. 


\section{Outcome}

The daily pain intensity numerical rating scale (PI-NRS) was used as the primary outcome measure according to the provided guidelines in painful neuropathic studies. ${ }^{28}$ The PI-NRS consists of an 11-point numerical scale ranging from 0 to 10, where 0 represents no pain and 10 the worst pain possible. Subjects were asked to complete the PI-NRS twice daily, in the morning and evening at fixed time points. In addition to the PI-NRS, the daily sleep interference scale (DSIS) was completed every day on awakening. The DSIS consists of an 11-point numerical scale ranging from 0 (pain does not interfere with sleep) to 10 (pain completely interferes with sleep). Additional questionnaires were completed at each visit that included the neuropathic pain scale (NPS), small fiber neuropathy symptom inventory questionnaire (SFN-SIQ), patients' global impression of change (PGIC), and the generic short-form SF-36 health survey (SF-36). The primary efficacy outcome was at least a 1-point improvement (thus, reduction in score) on the PI-NRS compared to baseline, which is considered the minimum clinically important difference (MCID), according to unified rule of $1 / 2 \times$ standard deviation (SD) and the guidelines. ${ }^{28}$ Secondary outcomes were the proportion of patients having $\geq 2$ points average pain improvement compared to their baseline PI-NRS scores, changes in the mean and maximum pain score on the PI-NRS, the NPS, DSIS, PGIC, SFN-SIQ, SF-36, adverse events, laboratory safety tests, blood pressure, pulse rate, and ECG. Sensitivity analyses included the 1-point and 2-point improvement from a less restricted baseline.

\section{Statistical analyses}

The sample size of 25 subjects was calculated with a response rate of $20 \%$ in the placebo- group and $60 \%$ in the lacosamide-group, a two-sided alpha of 5\%, and an $80 \%$ power between the two groups (chi-square test), including the assumption of a dropout rate of $10 \%$. An independent statistician was consulted and analyzed the results after making some adjustments to the previously published statistical protocol. ${ }^{24}$

The Full Analysis Set (FAS) consisted of all subjects who were randomized to receive study medication, regardless of whether or not they subsequently completed the study or deviated from the protocol. However, at least one measurement after taking the study medication should have been recorded. Subjects were analyzed for efficacy according to randomized treatment. The FAS was used for all analyses of efficacy endpoints.

For all questionnaires, the difference between the baseline and treatment period was analyzed. To determine the baseline of period 1, the last 14 days prior to randomization were taken. The interval for determining the period 2 baseline was the last 7 days of the washout period prior to commencing titration of the period 2 study medication. The comparator interval for the endpoint was the last 28 days of the respective treatment maintenance period.

For the primary efficacy endpoint (PI-NRS), each subject produced a baseline mean pain average and an on-treatment mean pain average. The average of non-missing day pain and night pain scores was derived. This was termed pain average. For example, if a night pain score was missing then the pain average equaled the day pain score. The difference between the average pain at baseline and after treatment was computed for each subject for each period. If for a given subject the change in mean pain average from on-treatment to period baseline was $\leq-1$, then the subject was defined as a responder for that period. Any subject with missing 
change was defined as a non-responder for that period conditional upon that subject having commenced study treatment for that period. Otherwise their responder status was set to missing. In one of the secondary efficacy endpoints, a responder was defined as a subject whose pain was reduced by 2 or more points. Other secondary endpoints, the mean day and night pain, the maximum day and night pain and the maximum average pain were analyzed, using these as a continuous variable. In the sensitivity analyses the 1-point and 2-point improvement were analyzed with a less restricted baseline too include more information in the analyses.

Period 1 baseline was only calculated if the subject has recorded a pain score for at least 10 days of the 14 day baseline period. Period 2 baseline was only calculated if the subject has recorded a pain score for at least 5 days of the 7 day baseline period. A weekly pain score was only calculated if the subject has recorded a pain score for at least 4 days for that week. If the subject failed to meet these criteria the pain score was set to missing. Averages and maxima were calculated over available data. No data was imputed for missing observations.

The DSIS outcome was derived for PI-NRS, where the changes from baseline were analyzed as a continuous variable without dichotomization. The measurements at baseline and the last 28 days of the maintenance treatment period were compared.

For the other non-diary efficacy endpoints: NPS, PGIC, SFN-SIQ, and the SF-36, the period baselines were those assessed before the titration period of period 1 and 2 . The comparator assessment was taken at the end of the 8-week maintenance course of treatment. Changes from period baseline were derived. The 10 NPS subscales were calculated separately. For the PGIC, for each period a subject was coded to 'responder' if their response was either, "minimally improved", "much improved", or "very much improved". Missing values were coded to 'non-responders'. The SFN-SIQ sumscore was calculated. For the SF-36, absolute scores and changes from baseline for the different dimensions were analyzed.

The Safety Set (SAF) included all subjects in the FAS who received at least one dose of comparative study medication and had one measurement after taking medication. Subjects were analyzed according to treatment received. The SAF was used for all analyses of safety endpoints.

The binary data for whether or not a subject was a responder was analyzed using Generalized Estimating Equations (GEE) with treatment, period, period baseline, subject baseline, the stratification factors and interaction between treatment and period in the model. Subject was a random factor. The formal test of the primary hypothesis was conducted at the two-sided $5 \%$ level of significance. For continuous outcome variables, a mixed effect model was used to investigate the treatment effect upon the change in scores between baseline and after treatment, fitting treatment, period, interaction between treatment and period, subject baseline, period baseline, and the stratification factors as fixed effects. Subject was fitted as a random effect. Least squares (LS) means for the change from baseline with standard errors were calculated for each treatment, and the LS mean difference between the treatment groups was presented together with the $95 \% \mathrm{Cl}$. The PGIC was analyzed with a McNemar's test instead of the planned repeated measures analyses, because with the stricter definition, the placebo response was too sparse. All analyses and summaries were produced using SAS ${ }^{\circledR}$ version 9.2 (or higher). There was no imputation of missing data. 


\section{Role of the funding source}

The Prinses Beatrix Spierfonds funded the study (W.OR12-01). The foundation had no role in the study design, data collection, data analysis, data interpretation, or writing of the report. The corresponding author had full access to all data of the study and had final responsibility for the decision to submit for publication.

\section{Results}

Twenty nine patients were screened for the study between November 2014 and July 2016 (figure 2). Four of these patients were excluded, because of prohibited co-medication $(n=2)$, ECG abnormalities $(n=1)$, and non-compliance of scheduled appointments $(n=1)$. A total of 25 patients were randomized, with one patient dropping out directly after randomization but before treatment due to an accidental fall. This patient was excluded from further analyses because no post-baseline measurements were recorded. An additional patient dropped out during the washout period after the first treatment period, due to conflicting personal commitments, not related to the study medication. This patient was included in the analyses for the first period. Thus, 24 patients received lacosamide and 23 patients received placebo.

Figure 2. Trial profile.

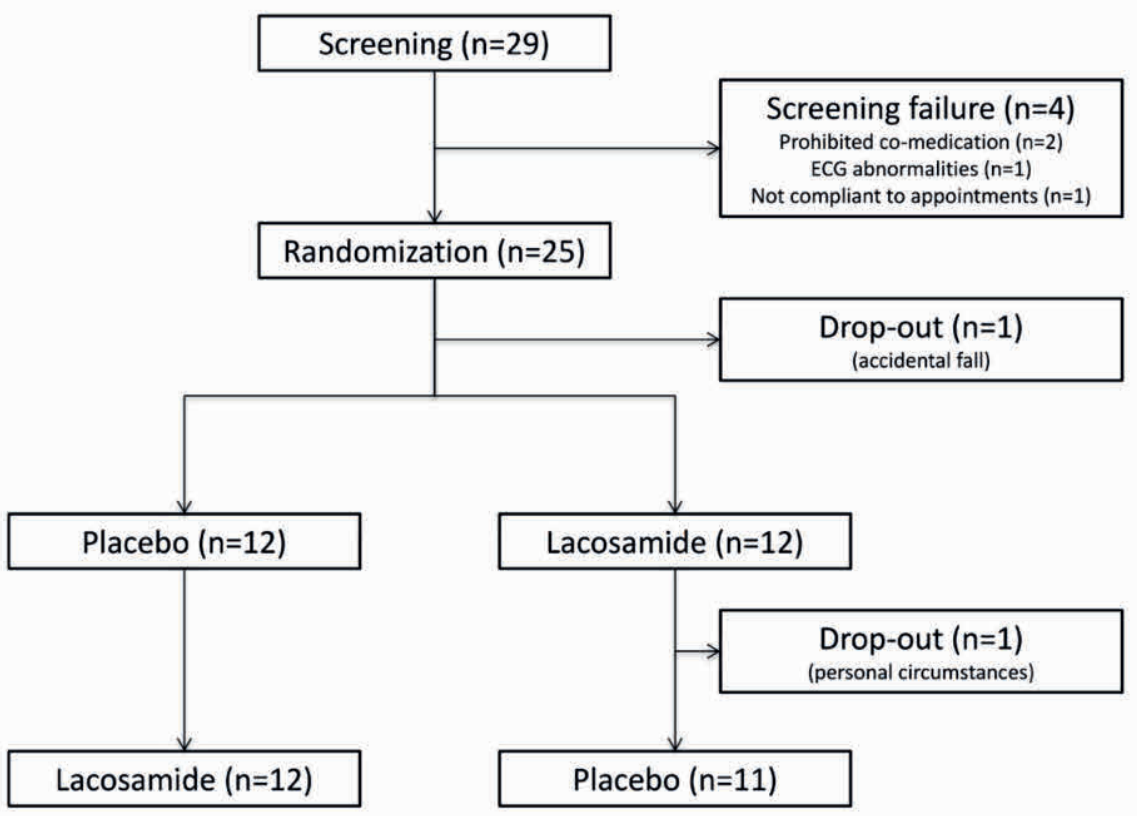

Legend to figure 2: In total 29 patients were screened for the study. Four were excluded, because of using medication that acts on sodium channels $(n=2)$, because of ECG abnormalities $(n=1)$, and non-compliance of appointments $(n=1)$. In total 25 patients were randomized, of which one patient dropped out directly after randomization due to an accidental fall. The patient was excluded from further analyses because no post-baseline measurements were recorded. An additional patient dropped out during the washout period after the first treatment period, due to personal circumstances, not related to the study medication. This patient was included in the analyses for the first period. In total 24 patients received lacosamide and 23 patients received placebo. 
Baseline characteristics are shown in table 1. Because of the trial design, the analyses of the primary and secondary outcomes were based on the whole group $(n=24)$. Therefore, differences between the groups based on baseline characteristics were not analyzed.

Figure 3 shows the average pain scores for each individual before and after treatment for the lacosamide and the placebo period. Figures $3 \mathrm{~A}$ and $3 \mathrm{~B}$ show that average pain decreased more during the lacosamide period compared to the placebo period. The individual change in average pain scores before and after treatment for the two periods shows a larger significant decrease in patients using lacosamide compared to placebo. Figure 4 shows the weekly mean average pain for both groups in both treatment periods. The mean average pain of the patients that were using lacosamide was lower compared to the scores of the patients that used placebo during that time, which was the case in both treatment periods.

Figure 3. Average pain before and after treatment.
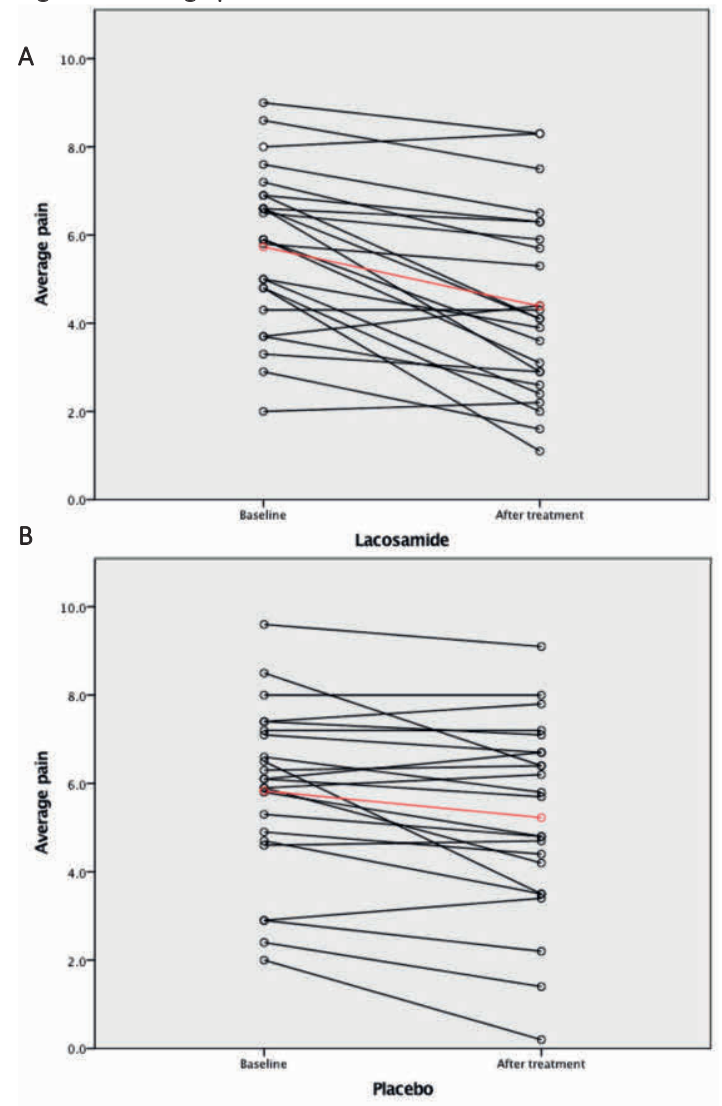

Legend to figure 3:

A: Change in average pain scores and in pain scores for each individual patient with the use of lacosamide.

$B$ : Change in average pain scores and in pain scores for each individual patient with the use of placebo.

In figure $3 \mathrm{~A}$ and $3 \mathrm{~B}$ the average pain scores are shown before and after treatment for respectively lacosamide and placebo (in red lines). The mean change of the average pain is larger for the lacosamide period compared to the placebo period. Also the change per subject before and after treatment is shown. More subjects have a decline, or a larger decline, during the use of lacosamide compared to placebo. 
Table 1. Baseline characteristics.

\begin{tabular}{|c|c|c|c|}
\hline & Lacosamide : Placebo $(n=12)$ & $\begin{array}{l}\text { Placebo : Lacosamide } \\
(n=12)\end{array}$ & Total $(n=24)$ \\
\hline \multicolumn{4}{|l|}{ Age (years) } \\
\hline Mean (SD) & $48.3(14.87)$ & $59.8(12.92)$ & $54(14.84)$ \\
\hline Median (range) & $50.5(24-70)$ & $61.5(27-78)$ & $57.5(24-78)$ \\
\hline \multicolumn{4}{|l|}{ Sex } \\
\hline Male & $7(58.3 \%)$ & $3(25.0 \%)$ & $10(41.7 \%)$ \\
\hline Female & $5(41.7 \%)$ & $9(75.0 \%)$ & $14(58.3 \%)$ \\
\hline \multicolumn{4}{|l|}{ Race } \\
\hline Caucasian & $11(91.7 \%)$ & $9(75.0 \%)$ & $20(83.3 \%)$ \\
\hline Turkish & 0 & $1(8.3 \%)$ & $1(4.2 \%)$ \\
\hline South-American & 0 & $1(8.3 \%)$ & $1(4.2 \%)$ \\
\hline African & $1(8.3 \%)$ & 0 & $1(4.2 \%)$ \\
\hline Asian & 0 & $1(8.3 \%)$ & $1(4.2 \%)$ \\
\hline \multicolumn{4}{|l|}{ Diagnosis } \\
\hline Abnormal TाT & $12(100 \%)$ & $7(58.3 \%)$ & $19(79.2 \%)$ \\
\hline Abnormal TाT and skin biopsy & 0 & $4(33.3 \%)$ & $4(16.7 \%)$ \\
\hline Abnormal skin biopsy & 0 & $1(8.3 \%)$ & $1(4.2 \%)$ \\
\hline \multicolumn{4}{|l|}{ SCN9A-variant } \\
\hline Only genetically confirmed & $6(50.0 \%)$ & $9(75.0 \%)$ & 15 (62.5\%) \\
\hline $\begin{array}{l}\text { Functionally and genetically } \\
\text { confirmed }\end{array}$ & $6(50.0 \%)$ & $3(25.0 \%)$ & $9(37.5 \%)$ \\
\hline \multicolumn{4}{|l|}{ PI-NRS, median (range) } \\
\hline Mean day pain & $6.4(4-9)$ & $6.6(4-8)$ & $6.5(4-9)$ \\
\hline Mean night pain & $5.7(1-9)$ & $5.5(1-8)$ & $5.6(1-9)$ \\
\hline Mean average pain & $6.2(3-9)$ & $6.1(2-8)$ & $6.1(2-9)$ \\
\hline Max day pain & $7.6(6-9)$ & $7.4(5-10)$ & $7.5(5-10)$ \\
\hline Max night pain & $6.7(1-10)$ & $7.0(1-9)$ & $6.8(1-10)$ \\
\hline DSIS & $4.8(0-10)$ & $5.9(5-8)$ & $5.6(0-10)$ \\
\hline SFN-SIQ & $34.5(24-43)$ & $28.0(18-45)$ & $31.5(18-45)$ \\
\hline \multicolumn{4}{|l|}{ NPS } \\
\hline Intense & $6.5(3-9)$ & $7.0(5-8)$ & $7.0(3-9)$ \\
\hline Sharp & $7.5(0-10)$ & $7.5(0-9)$ & $7.5(0-10)$ \\
\hline Hot & $7.5(0-10)$ & $7.0(0-10)$ & $7.0(0-10)$ \\
\hline Dull & $5.5(0-9)$ & $7.0(0-9)$ & $6.0(0-9)$ \\
\hline Cold & $3.0(0-10)$ & $3.5(0-10)$ & $3.0(0-10)$ \\
\hline Sensitive & $6.0(0-9)$ & $6.0(0-10)$ & $6.0(0-10)$ \\
\hline Itchy & $4.5(0-8)$ & $2.5(0-8)$ & $3.5(0-8)$ \\
\hline Unpleasant & $8.0(4-10)$ & $7.0(4-8)$ & $7.0(4-10)$ \\
\hline Intense deep & $7.0(5-10)$ & $7.0(0-10)$ & $7.0(0-10)$ \\
\hline Intense surface & $7.0(2-9)$ & $6.0(5-9)$ & $6.5(2-9)$ \\
\hline \multicolumn{4}{|l|}{ SF-36 } \\
\hline Physical Functioning & $30.6(10-67)$ & $37.5(28-90)$ & $33.3(10-90)$ \\
\hline Role-Physical & $12.5(0-75)$ & $18.8(0-100)$ & $12.5(0-100)$ \\
\hline Bodily Pain & $20.5(0-61)$ & $31.0(0-61)$ & $31.0(0-61)$ \\
\hline Social Functioning & $62.5(0-100)$ & $75.0(25-100)$ & $62.5(0-100)$ \\
\hline Mental Health & $65.0(10-100)$ & $80.0(25-95)$ & $65.0(10-100)$ \\
\hline Role-Emotional & $70.8(8-100)$ & $75.0(17-100)$ & $75.0(8-100)$ \\
\hline Vitality & $37.5(0-75)$ & $50.0(6-69)$ & $40.6(0-75)$ \\
\hline General Health & $42.5(10-60)$ & $35(20-82)$ & $37.5(10-82)$ \\
\hline
\end{tabular}


Figure 4 . Weekly mean acverage pain during both treatment periods.

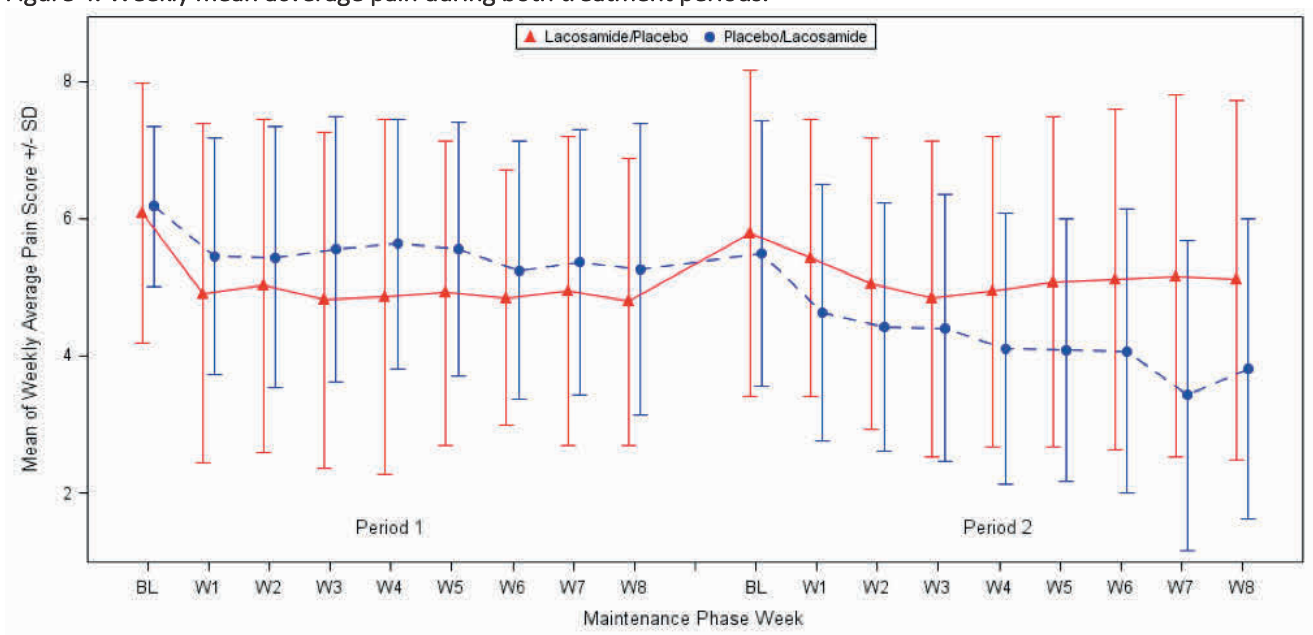

Legend to figure 4: The weekly mean average pain is shown for both groups in both treatment periods. The mean average pain of the patients that were using lacosamide was lower compared to the scores of the patients that used placebo during that time, which was the case in both treatment periods. BL: baseline, SD: standard deviation, W: week number.

Table 2. Primary outcome.

\begin{tabular}{|c|c|c|c|c|c|c|}
\hline & \multicolumn{3}{|c|}{ Full analyses set } & \multicolumn{3}{|c|}{ Sensitivity analyses set } \\
\hline & $\begin{array}{l}\text { Lacosamide vs } \\
\text { placebo }\end{array}$ & p-value & OR $(95 \% \mathrm{Cl})$ & $\begin{array}{l}\text { Lacosamide vs } \\
\text { placebo }\end{array}$ & $p$-value & OR $(95 \% \mathrm{Cl})$ \\
\hline $\begin{array}{l}\geq 1 \text {-point decrease in } \\
\text { average pain }\end{array}$ & $50.0 \%$ vs $21.7 \%$ & $0.0213^{*}$ & $4.45(1.38 ; 14.36)$ & $58.3 \%$ vs $21.7 \%$ & $0.0045^{*}$ & $5.65(1.83 ; 17.41)$ \\
\hline $\begin{array}{l}\geq 2 \text {-point decrease in } \\
\text { average pain }\end{array}$ & $25.0 \%$ vs $8.7 \%$ & 0.0637 & $7.94(1.20 ; 52.79)$ & $33.3 \%$ vs $8.7 \%$ & $0.0244 *$ & $10.58(1.63 ; 68.63)$ \\
\hline
\end{tabular}

The proportion of responders for lacosamide and placebo was calculated from these data, and as the primary outcome shown in table 2 . There was a significant effect of lacosamide on average pain compared to placebo. In the full analyses set there was a significant effect of lacosamide in $a \geq 1$-point decrease of the mean average pain $(50.0 \%$ responder with lacosamide versus $21.7 \%$ placebo) with a p-value of 0.0231 and odds ratio (OR) of 4.45 (95\% $\mathrm{Cl} 1.38 ; 14.36$ ) and a trend towards an effect on a $\geq 2$-point decrease of the average pain with a p-value of 0.0637 ( $25 \%$ responder with lacosamide versus $8.7 \%$ responder with placebo). In the sensitivity analyses both effects were significant; for $\geq 1$-point decrease $58.3 \%$ responded with lacosamide versus $21.7 \%$ with placebo ( $p$-value 0.0045 , OR $5.65(1.83 ; 17.41)$ ) and for $\geq 2$ point decrease $33.3 \%$ responded with lacosamide versus $8.7 \%$ with placebo (p-value 0.0244 , OR $10.58(1.63 ; 68.63))$. Additionally, in the lacosamide period 10 out of 24 patients $(41.67 \%)$ had a $30 \%$ reduction of the average pain from baseline, compared to 3 out of 23 patients $(13.04 \%)$ in the placebo period. In total 4 out of 24 patients $(16.67 \%)$ had a $50 \%$ reduction of the average pain, compared to 1 out of 23 patients (4.35\%) in the placebo group. 


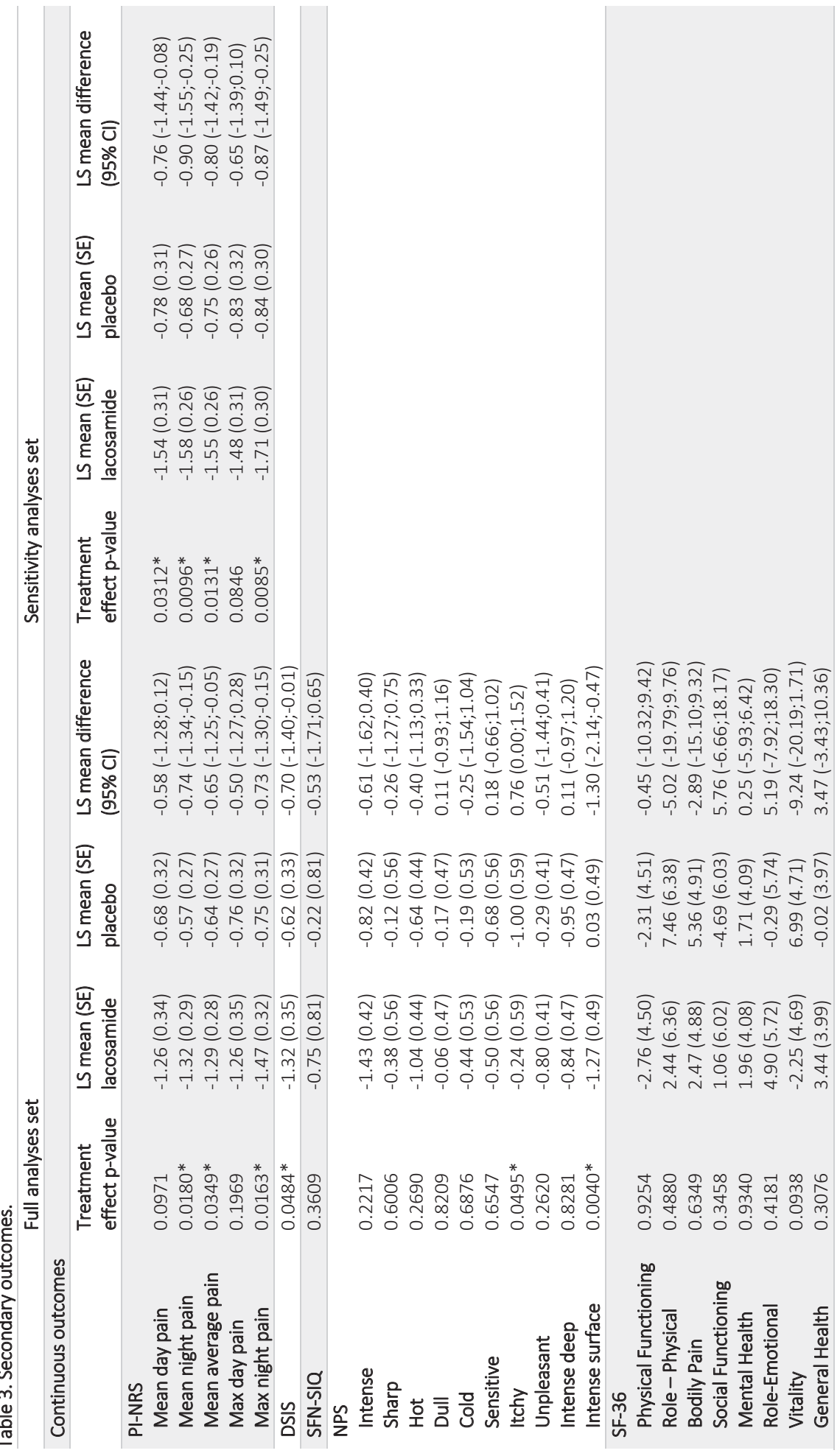




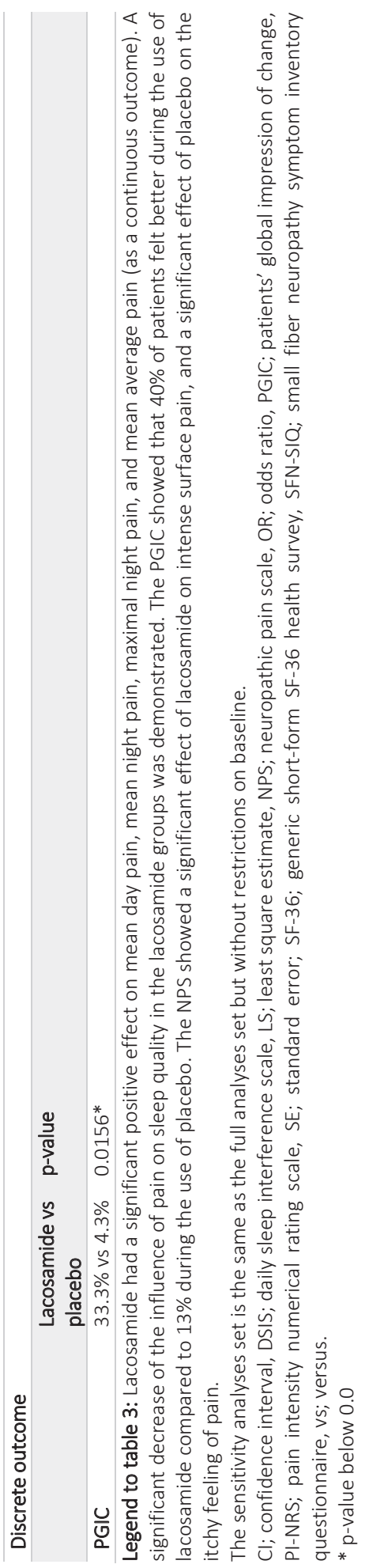


A pathogenic gain-of-function mutation was found in 13 out of the 24 patients, while the other patients carried a variant that was not yet functionally confirmed. In the lacosamide period 6 out of the 13 patients with a gain-of-function mutation (46.2\%) had a $\geq 1$-point decrease of the mean average pain and 4 patients $(30.8 \%)$ had $a \geq 2$-point decrease of the average pain (compared to 8 out of 11 (72.7\%) and 4 out of 11 (36.4\%) respectively for the patients with the other variants). In the placebo period, 3 out of 13 patients with a gain-of-function mutation (23.1\%) had $a \geq 1$-point decrease and 1 out of 13 (7.7\%) had $a \geq 2$-point decrease of the mean average (compared to 2 out of $10(20.0 \%)$ and 1 out of $10(10.0 \%)$ respectively for the patients with the other variants).

The secondary outcomes, table 3, showed similar results for the sensitivity analyses for the mean day pain, the mean night pain, the maximal night pain, and the mean average pain (as a continuous outcome). Only the maximal day pain showed no significant difference between lacosamide and placebo. There was also a significant decrease of the influence of pain on sleep quality, with a median value of the DSIS of 5.3 for the lacosamide period and a 5.7 for the placebo period (least square (LS) mean of -1.32 for lacosamide compared to LS mean of -0.62 for placebo, with a LS mean difference of -0.70). Also, the PGIC showed significant differences between the two groups, $33.3 \%$ of patients felt better during the use of lacosamide compared to $4.3 \%$ during the use of placebo ( $p$-value of 0.0156). The NPS showed a significant effect of lacosamide on the intense surface pain (item 10b) (LS mean of -1.27 for lacosamide compared to LS mean of 0.03 for placebo, with a LS mean difference of -0.70) but there was also a significant effect of placebo on the itchy feeling of pain (LS mean of - 0.24 for lacosamide compared to LS mean of -1.00 for placebo, with a LS mean difference of -0.76) compared to lacosamide. No significant differences were found for the SFN-SIQ sumscore and the SF-36.

Regarding safety, in total six serious adverse events (SAE) were reported (which were classified as serious because they required hospitalization), of which two occurred in the lacosamide period and four in the placebo period. The six SAE's were diplopia, vomiting, chest pain, conversion disorder, dyspnea, and a bladder operation (which was requested by the patient because of complaints present prior to the start of the study). The adverse events that occurred in at least $5 \%$ in one of the two treatment groups are presented in table 4 . The most frequent $A E s$ in the lacosamide period were dizziness, headache, and nausea, which were comparable to the most frequent AEs in the placebo period.

During the study, eight of the 24 patients changed neuropathic pain medication, as shown in table 5. Three patients changed medication during the placebo period. One patient decreased the medication during the lacosamide period, because of side effects, and increased them again during the placebo period, because of the return of pain. This patient was a responder during the lacosamide period, but not during the placebo period. One patient started medication during the lacosamide period and also during the placebo period, but was a nonresponder in both periods. The other three patients started or increased their medication in the lacosamide period, 2 of them were responders for this period. 
Table 4: Adverse events

\begin{tabular}{|c|c|c|c|c|c|c|c|c|c|c|}
\hline \multicolumn{7}{|c|}{ Lacosamide $(n=24)$} & \multicolumn{4}{|c|}{ Placebo $(n=23)$} \\
\hline \multicolumn{7}{|c|}{ Total } & \multicolumn{4}{|l|}{ Total } \\
\hline \multicolumn{7}{|c|}{$\begin{array}{l}\text { Patients with at21(87.5\%) } \\
\text { least one adverse } \\
\text { event }\end{array}$} & \multicolumn{4}{|l|}{$19(82.6 \%)$} \\
\hline \multicolumn{11}{|l|}{$\begin{array}{l}\text { All serious adverse } \\
\text { events }\end{array}$} \\
\hline Diplopia & \multicolumn{6}{|c|}{$1(4.2 \%)$} & \multicolumn{4}{|l|}{0} \\
\hline Vomiting & \multicolumn{6}{|c|}{$1(4.2 \%)$} & \multicolumn{4}{|l|}{0} \\
\hline Chest pain & \multicolumn{6}{|l|}{0} & \multicolumn{4}{|l|}{$1(4.3 \%)$} \\
\hline $\begin{array}{l}\text { Conversion } \\
\text { disorder }\end{array}$ & \multicolumn{6}{|l|}{0} & \multicolumn{4}{|l|}{$1(4.3 \%)$} \\
\hline Dyspnea & \multicolumn{6}{|l|}{0} & \multicolumn{4}{|l|}{$1(4.3 \%)$} \\
\hline Bladder operation & \multicolumn{6}{|c|}{ n 0} & \multicolumn{4}{|l|}{$1(4.3 \%)$} \\
\hline $\begin{array}{l}\text { Most commor } \\
\text { adverse events* }\end{array}$ & nTot & & Mil & ild & Moderate & Severe & Total & Mild & Moderate & Severe \\
\hline Dizziness & & $(41.7 \%)$ & 6 & $(25.0 \%)$ & $4(16.7 \%)$ & 0 & $4(17.4 \%)$ & $1(4.3 \%)$ & $3(13.0 \%)$ & 0 \\
\hline Nausea & 6 & $(25.0 \%)$ & 3 & $(12.5 \%)$ & $3(12.5 \%)$ & 0 & $4(17.4 \%)$ & $2(8.7 \%)$ & $2(8.7 \%)$ & 0 \\
\hline Headache & & $(25.0 \%)$ & 4 & $(16.7 \%)$ & $2(8.3 \%)$ & 0 & $4(17.4 \%)$ & $2(8.7 \%)$ & $2(8.7 \%)$ & 0 \\
\hline Fatigue & 5 & $(20.8 \%)$ & 2 & $(8.3 \%)$ & $3(12.5 \%)$ & 0 & 0 & 0 & 0 & 0 \\
\hline Tremor & 5 & $(20.8 \%)$ & 3 & $(12.5 \%)$ & $2(8.3 \%)$ & 0 & 0 & 0 & 0 & 0 \\
\hline Somnolence & 4 & $(16.7 \%)$ & 1 & $(4.2 \%)$ & $3(12.5 \%)$ & 0 & 0 & 0 & 0 & 0 \\
\hline $\begin{array}{l}\text { Epigastric } \\
\text { discomfort }\end{array}$ & 4 & $(16.7 \%)$ & 3 & $(12.5 \%)$ & $1(4.2 \%)$ & 0 & $1(4.3 \%)$ & 0 & $1(4.3 \%)$ & 0 \\
\hline $\begin{array}{l}\text { Memory } \\
\text { impairment }\end{array}$ & 3 & $(12.5 \%)$ & 0 & & $3(12.5 \%)$ & 0 & 0 & 0 & 0 & 0 \\
\hline Pruritus & 3 & $(12.5 \%)$ & 3 & $(12.5 \%)$ & 0 & 0 & $1(4.3 \%)$ & 0 & $1(4.3 \%)$ & 0 \\
\hline Vomiting & 2 & $(8.3 \%)$ & 1 & $(4.2 \%)$ & 0 & $1(4.2 \%)$ & 0 & 0 & 0 & 0 \\
\hline Balance disorder & 2 & $(8.3 \%)$ & 0 & & $2(8.3 \%)$ & 0 & $1(4.3 \%)$ & 0 & $1(4.3 \%)$ & 0 \\
\hline Constipation & 2 & $(8.3 \%)$ & 0 & & $2(8.3 \%)$ & 0 & 0 & 0 & 0 & 0 \\
\hline Flushing & 2 & $(8.3 \%)$ & 0 & & $2(8.3 \%)$ & 0 & 0 & 0 & 0 & 0 \\
\hline $\begin{array}{l}\text { Disturbance in } \\
\text { attention }\end{array}$ & 2 & (8.3\%) & 1 & $(4.2 \%)$ & 1 (4.2\%) & 0 & 0 & 0 & 0 & 0 \\
\hline Feeling drunk & 2 & $(8.3 \%)$ & 1 & $(4.2 \%)$ & 1 (4.2\%) & 0 & $1(4.3 \%)$ & 0 & $1(4.3 \%)$ & 0 \\
\hline Rash & 2 & $(8.3 \%)$ & 1 & $(4.2 \%)$ & 1 (4.2\%) & 0 & $1(4.3 \%)$ & $1(4.3 \%)$ & 0 & 0 \\
\hline Vision blurred & 2 & $(8.3 \%)$ & 1 & $(4.2 \%)$ & 1 (4.2\%) & 0 & 0 & 0 & 0 & 0 \\
\hline Dyskinesia & 2 & $(8.3 \%)$ & 2 & $(8.3 \%)$ & 0 & 0 & 0 & 0 & 0 & 0 \\
\hline Diarrhoea & 1 & $(4.2 \%)$ & 0 & & 1 (4.2\%) & 0 & $2(8.7 \%)$ & $2(8.7 \%)$ & 0 & 0 \\
\hline Influenza & 1 & $(4.2 \%)$ & 0 & & 1 (4.2\%) & 0 & $3(13.0 \%)$ & $2(8.7 \%)$ & $1(4.3 \%)$ & 0 \\
\hline Back pain & 1 & $(4.2 \%)$ & 1 & $(4.2 \%)$ & 0 & 0 & $2(8.7 \%)$ & $1(4.3 \%)$ & $1(4.3 \%)$ & 0 \\
\hline Dyspnoea & 1 & $(4.2 \%)$ & 1 & $(4.2 \%)$ & 0 & 0 & $3(13.0 \%)$ & 0 & $3(13.0 \%)$ & 0 \\
\hline Parasthesia & 0 & & 0 & & 0 & 0 & $3(13.0 \%)$ & $2(8.7 \%)$ & $1(4.3 \%)$ & 0 \\
\hline $\begin{array}{l}\text { Upper respiratory } \\
\text { tract infection }\end{array}$ & 0 & & 0 & & 0 & 0 & $2(8.7 \%)$ & 0 & $2(8.7 \%)$ & 0 \\
\hline $\begin{array}{l}\text { Viral upper } \\
\text { respiratory tract } \\
\text { infection }\end{array}$ & 0 & & 0 & & 0 & 0 & $2(8.7 \%)$ & 0 & $2(8.7 \%)$ & 0 \\
\hline Visual impairment & 0 & & 0 & & 0 & 0 & $2(8.7 \%)$ & $2(8.7 \%)$ & 0 & 0 \\
\hline
\end{tabular}

Legend to table $4:{ }^{*}$ Only those reported by at least $5 \%$ of participants in one of the groups are shown. 


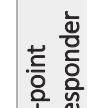

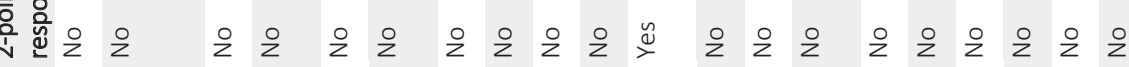

들 흥

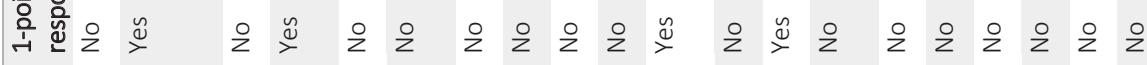

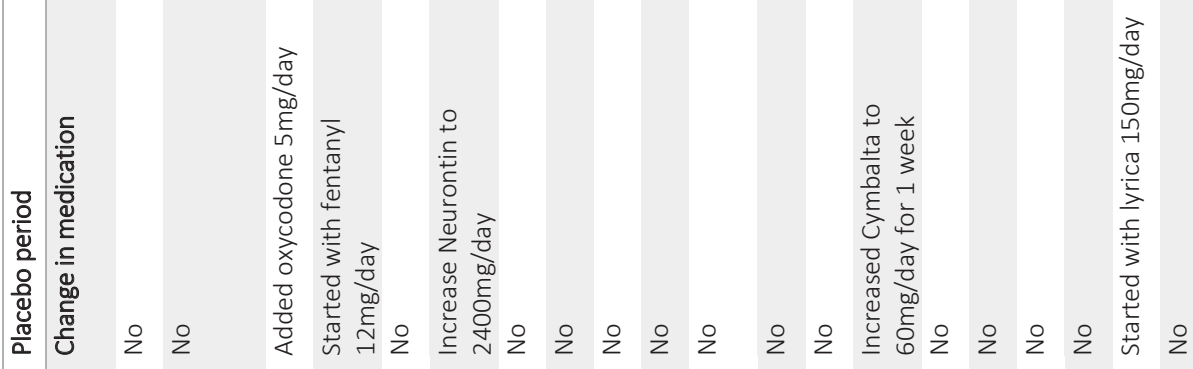

:

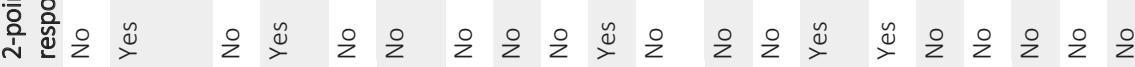

능 흥

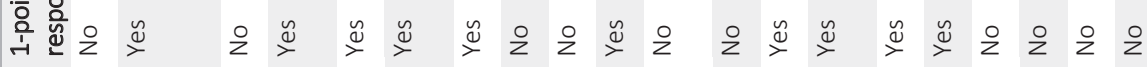

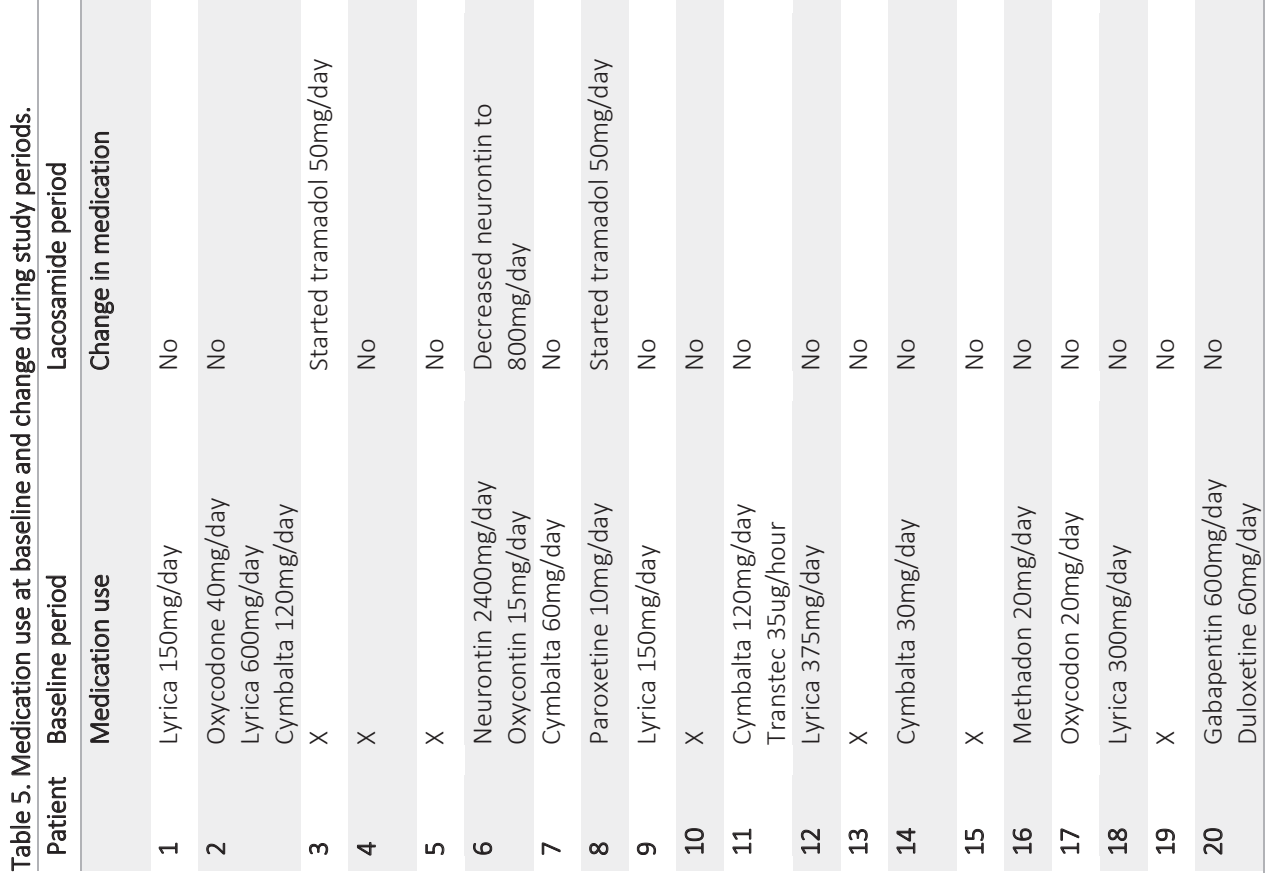




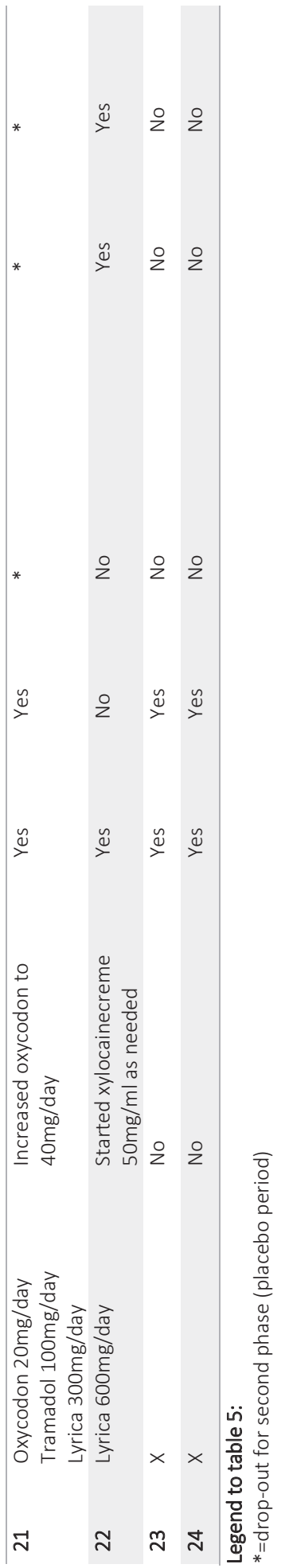




\section{Discussion}

This is the first study that investigated the efficacy of lacosamide in patients with SFN. The results show that lacosamide significantly decreased pain and had a positive effect on sleep quality compared to placebo in patients with Nav1.7-related SFN. Specifically, the surface pain intensity (item 10b of the NPS) was positively influenced. In addition, more than $33.3 \%$ of patients felt better (as reflected by the PGIC questionnaire) when using lacosamide. Compared with placebo, lacosamide appeared to be safe to use and well-tolerated in this cohort of patients with SFN.

The results are similar or even more positive compared to studies investigating the effect of lacosamide on neuropathic pain in painful diabetic neuropathy. ${ }^{20-23}$ In contrast to those studies, however, the crossover design used in our study was chosen to provide reliable results despite small patient numbers. A recent study showed an effect of another $\mathrm{Na}_{v}$ blocker, BIIB0074 on the pain attacks in patients with trigeminal neuralgia. ${ }^{29}$

Lacosamide appears to be as effective as currently available neuropathic pain treatment, with a response rate of $50-60 \%$, which is at least comparable to the $50 \%$ of patients that have a reduction in pain intensity when treated with currently available therapeutics. ${ }^{6,7}$ The factors underlying the variance in response to lacosamide are not known, but the variability in response possibly could be due to the different gene variants or epigenetic differences between patients. In this study, lacosamide showed a significant effect on the intensity of surface pain (item 10b on the NPS), which might suggest that lacosamide reduces the allodynic symptoms. At the moment, no accurate objective tools are available to test allodynia in the clinic; however this would be of interest to test in future trials with lacosamide.

Our study did not show an effect of lacosamide on quality of life. The treatment period of eight weeks was long enough to observe differences in pain intensity, but the duration of pain reduction might have been too short to result in a positive effect on quality of life. Another explanation for the absence of a significant change in quality of life could be that, in addition to neuropathic pain, other factors such as autonomic dysfunction might influence the quality of life of these patients.

$\mathrm{Na}_{\mathrm{v}} 1.7$ is expressed in both DRG neurons and sympathetic ganglion neurons, which explains the combination of neuropathic pain and dysautonomia in most patients with Nav1.7mutations. ${ }^{14}$ Based on this, lacosamide also might be expected to have a positive effect on autonomic complaints. However, it is known that mutated sodium channels can have a different effect on excitability, depending on the cell background, with some mutations having dramatically different effects on excitability of peripheral sensory versus sympathetic ganglion neurons. ${ }^{30,31}$ The effect of lacosamide on $\mathrm{Na}_{\mathrm{v}} 1.7$ within different subtypes of neurons, and its effect on excitability in different cell types of neurons, have not thus far been studied.

In this study, we did not see any changes in the SFN-SIQ, a questionnaire that also includes autonomic functions. A confounding factor could be the side effects that lacosamide can cause (like dizziness, dry eyes, or intestinal problems). It is not clear if these side effects are the result of central autonomic dysregulation, or due to a direct effect of lacosamide on the peripheral sympathetic neurons. 
In the placebo-group a significant positive effect on the itchy feeling of pain was demonstrated. This is in line with previous research that showed a substantial placebo-effect on itch in various dermatological conditions. ${ }^{32}$

The attenuation of pain that we observed is consistent with the mechanism of action of lacosamide. Lacosamide is thought to bind to preferentially to $\mathrm{Na}_{v}$ channels in the inactivated state. ${ }^{16,17}$ Our previous studies have demonstrated spontaneous firing in DRG neurons expressing SFN-related Nav1.7 mutations. ${ }^{15,33,34}$ As a result of spontaneous activity in these neurons, which appears to contribute to pain, lacosamide would be expected to have a preferential effect on DRG neurons in SFN. As with lacosamide and other sodium channel blockers (e.g. phenytoin and carbamazepine) in epilepsy, the mechanistic bases for nonresponsiveness of some patients are not fully understood.

The strength of the crossover-design in our study was that fewer patients were required to obtain reliable results than in a parallel design, because each patient served as his/her own matched control. The crossover-design is justifiable because lacosamide was not being evaluated as a cure or a disease modifying agent, but only a therapy for alleviating pain symptoms. It has been shown earlier that this design is useful for screening compounds for efficacy in proof-of-concept studies with neuropathic pain. ${ }^{35}$ The dosage used in this study (200mg BID) was based on previous studies. ${ }^{36,37}$ At this dosage, a significant effect was reached. In practice, for patients who did not respond on $200 \mathrm{mg}$ BID, an increase of dosage to $300 \mathrm{mg}$ BID might be considered, although the expected incidence of side effects increases with higher doses. Conversely, the dosage of lacosamide can be lowered to $100 \mathrm{mg}$ or $150 \mathrm{mg}$ BID when patients experience bothersome side effects.

This study has some potential limitations. First, as a result of the chosen study design a carryover effect could have occurred. This might confound direct treatment effects, because these effects cannot be estimated separately. This is minimized, however, because we implemented a washout period that was longer than the advised five (or more) half-life time lengths of the drug concentration in the blood (half-life of approximately 13 hours). In the mixed effects model analyses, no significant interaction was found between the treatment effect and the period effect, suggesting that there was no carry-over effect. This is confirmed by data in figure 4, which show that the average pain scores return to the baseline in the washout period after the lacosamide arm. Thus, although the design is potentially open to carry-over effects, we found no evidence for such effects.

Second, the cohort that was been investigated was relatively small and limited to patients carrying specific Nav1.7 variants. SFN is rare and an SCN9A-variant can be found in around 9\%. ${ }^{38}$ We chose this well-defined cohort, because our aim was to demonstrate proof of concept, which can be used for future studies involving larger groups of patients diagnosed with SFN. Since VGSCs also play a role in pathological neuropathic pain states even in the absence of mutations, ${ }^{8}$ a positive effect of lacosamide on pain in non-VGSC-mutation-related SFN is expected. After this study was started, the SFN-specific Rasch-built overall disability scale (SFNRODS) was developed. ${ }^{39}$ Besides the effect on neuropathic pain, this outcome measure can be of great value in future SFN studies to investigate the effect of lacosamide and other treatments on daily activity. ${ }^{39}$ 
Third, the study was powered to find a difference between $60 \%$ response rate in the treatment period and $20 \%$ in the placebo period. However, the observed proportions were $58.3 \%$ and $21.7 \%$, which was a little lower than expected. The results of this proof-of-concept study support further studies on lacosamide in patients with SFN.

Fourth, during this study, patients were allowed to continue using their current medications, when the dosage was stable for 30 days prior to screening and they did not inhibit sodium channels. Our data show that lacosamide can be prescribed as an effective add-on therapy. However, the quantities and types of concomitant medications differed between patients. Although we attempted to keep the use of concomitant medication as constant as possible, change was unavoidable in some cases, for example when patients suffered from side effects or severe pain. Therefore, no statements about interactions between lacosamide and other neuropathic painkillers can be made. In epilepsy it is known that lacosamide is more effective as a first add-on drug compared to a later add-on treatment. ${ }^{40}$ This might suggest that the effect of lacosamide might be even greater as a monotherapy or a first add-on treatment.

Finally, multiple Nav1.7-variants were included in this study. Almost one-half of the patients with a pathogenic gain-of-function mutation were responders, which is comparable to the overall effect. Further research will be needed to see whether patients with some specific variants are to be more likely to respond to lacosamide compared to other variants. This could lead to more insight into why some patients derive benefit from lacosamide and some do not, and could lead to patient-specific treatments in the future.

In conclusion, this study provides evidence indicating that, in some patients with SFN, lacosamide can attenuate neuropathic pain. Specifically, our results show that lacosamide is well-tolerated and safe, and can reduce neuropathic pain in Nav1.7-related SFN. 


\section{References}

1. Hoeijmakers JG, Faber CG, Lauria G, Merkies IS, Waxman SG. Small-fibre neuropathies-advances in diagnosis, pathophysiology and management. Nature reviews Neurology 2012; 8(7): 369-79.

2. Cazzato D, Lauria G. Small fibre neuropathy. Current opinion in neurology 2017; 30(5): 490-9.

3. de Greef BTA, Hoeijmakers JGJ, Gorissen-Brouwers CML, Geerts M, Faber CG, Merkies ISJ. Associated conditions in small fiber neuropathy - A large cohort study and review of the literature. European journal of neurology: the official journal of the European Federation of Neurological Societies 2017; 25(2): 34855.

4. Bakkers M, Faber CG, Hoeijmakers JG, Lauria G, Merkies IS. Small fibers, large impact: quality of life in small-fiber neuropathy. Muscle \& nerve 2014; 49(3): 329-36.

5. Brouwer BA, de Greef BT, Hoeijmakers JG, et al. Neuropathic Pain due to Small Fiber Neuropathy in Aging: Current Management and Future Prospects. Drugs \& aging 2015; 32(8): 611-21.

6. Finnerup NB, Attal N, Haroutounian S, et al. Pharmacotherapy for neuropathic pain in adults: a systematic review and meta-analysis. Lancet neurology 2015; 14(2): 162-73.

7. Attal N, Cruccu G, Baron R, et al. EFNS guidelines on the pharmacological treatment of neuropathic pain: 2010 revision. European journal of neurology : the official journal of the European Federation of Neurological Societies 2010; 17(9): 1113-e88.

8. Dib-Hajj SD, Cummins TR, Black JA, Waxman SG. Sodium channels in normal and pathological pain. Annu Rev Neurosci 2010; 33: 325-47.

9. Dib-Hajj SD, Geha P, Waxman SG. Sodium channels in pain disorders: pathophysiology and prospects for treatment. Pain 2017; 158 Suppl 1: S97-S107.

10. Brouwer BA, Merkies IS, Gerrits MM, Waxman SG, Hoeijmakers JG, Faber CG. Painful neuropathies: the emerging role of sodium channelopathies. Journal of the peripheral nervous system : JPNS 2014; 19(2): 53-65.

11. Beyreuther BK, Freitag J, Heers C, Krebsfanger N, Scharfenecker U, Stohr T. Lacosamide: a review of preclinical properties. CNS drug reviews 2007; 13(1): 21-42.

12. Errington AC, Stohr T, Heers C, Lees G. The investigational anticonvulsant lacosamide selectively enhances slow inactivation of voltage-gated sodium channels. Molecular pharmacology 2008; 73(1): 157-69.

13. Amir R, Argoff CE, Bennett GJ, et al. The role of sodium channels in chronic inflammatory and neuropathic pain. The journal of pain : official journal of the American Pain Society 2006; 7(5 Suppl 3): S1-29.

14. Faber CG, Hoeijmakers JG, Ahn HS, et al. Gain of function Nav1.7 mutations in idiopathic small fiber neuropathy. Annals of neurology 2012; 71(1): 26-39.

15. Han C, Hoeijmakers JG, Ahn HS, et al. Nav1.7-related small fiber neuropathy: Impaired slow-inactivation and DRG neuron hyperexcitability. Neurology 2012; 78(21): 1635-43.

16. Rogawski MA, Tofighy A, White HS, Matagne A, Wolff C. Current understanding of the mechanism of action of the antiepileptic drug lacosamide. Epilepsy research 2015; 110: 189-205.

17. Jo S, Bean BP. Lacosamide Inhibition of Nav1.7 Voltage-Gated Sodium Channels: Slow Binding to FastInactivated States. Molecular pharmacology 2017; 91(4): 277-86.

18. Dustrude ET, Moutal A, Yang X, Wang Y, Khanna M, Khanna R. Hierarchical CRMP2 posttranslational modifications control NaV1.7 function. Proceedings of the National Academy of Sciences of the United States of America 2016; 113(52): E8443-E52.

19. Moutal A, Yang X, Li W, et al. CRISPR/Cas9 editing of Nf1 gene identifies CRMP2 as a therapeutic target in neurofibromatosis type 1-related pain that is reversed by (S)-Lacosamide. Pain 2017; 158(12): 230119.

20. Ziegler D, Hidvegi T, Gurieva I, et al. Efficacy and safety of lacosamide in painful diabetic neuropathy. Diabetes care 2010; 33(4): 839-41.

21. Wymer JP, Simpson J, Sen D, Bongardt S, Lacosamide SPSG. Efficacy and safety of lacosamide in diabetic neuropathic pain: an 18-week double-blind placebo-controlled trial of fixed-dose regimens. The Clinical journal of pain 2009; 25(5): 376-85. 


\section{Chapter 6}

22. Shaibani A, Fares S, Selam JL, et al. Lacosamide in painful diabetic neuropathy: an 18-week double-blind placebo-controlled trial. The journal of pain : official journal of the American Pain Society 2009; 10(8): 818-28.

23. Rauck RL, Shaibani A, Biton V, Simpson J, Koch B. Lacosamide in painful diabetic peripheral neuropathy: a phase 2 double-blind placebo-controlled study. The Clinical journal of pain 2007; 23(2): 150-8.

24. de Greef BT, Merkies IS, Geerts M, Faber CG, Hoeijmakers JG. Efficacy, safety, and tolerability of lacosamide in patients with gain-of-function Nav1.7 mutation-related small fiber neuropathy: study protocol of a randomized controlled trial-the LENSS study. Trials 2016; 17(1): 306.

25. Yarnitsky D, Sprecher E. Thermal testing: normative data and repeatability for various test algorithms. Journal of the neurological sciences 1994; 125(1): 39-45.

26. Bakkers M, Faber CG, Reulen JP, Hoeijmakers JG, Vanhoutte EK, Merkies IS. Optimizing temperature threshold testing in small-fiber neuropathy. Muscle \& nerve 2015; 51(6): 870-6.

27. Wallis Y, Payne S, McAnulty C, et al. Practical Guidelines for the Evaluation of Pathogenicity and the Reporting of Sequence Variants in Clinical Molecular Genetics. Association for Clinical Genetic Science (ACGS) 2013: 1-16.

28. Dworkin RH, Turk DC, Wyrwich KW, et al. Interpreting the clinical importance of treatment outcomes in chronic pain clinical trials: IMMPACT recommendations. The journal of pain : official journal of the American Pain Society 2008; 9(2): 105-21.

29. Zakrzewska JM, Palmer J, Morisset V, et al. Safety and efficacy of a Nav1.7 selective sodium channel blocker in patients with trigeminal neuralgia: a double-blind, placebo-controlled, randomised withdrawal phase 2a trial. Lancet neurology 2017; 16(4): 291-300.

30. Han C, Hoeijmakers JG, Liu S, et al. Functional profiles of SCN9A variants in dorsal root ganglion neurons and superior cervical ganglion neurons correlate with autonomic symptoms in small fibre neuropathy. Brain 2012.

31. Rush AM, Dib-Hajj SD, Liu S, Cummins TR, Black JA, Waxman SG. A single sodium channel mutation produces hyper- or hypoexcitability in different types of neurons. Proceedings of the National Academy of Sciences of the United States of America 2006; 103(21): 8245-50.

32. van Laarhoven AIM, van der Sman-Mauriks IM, Donders ART, Pronk MC, van de Kerkhof PCM, Evers AWM. Placebo effects on itch: a meta-analysis of clinical trials of patients with dermatological conditions. The Journal of investigative dermatology 2015; 135(5): 1234-43.

33. Faber CG, Hoeijmakers JG, Ahn HS, et al. Gain of function Nanu1.7 mutations in idiopathic small fiber neuropathy. Annals of neurology 2012; 71(1): 26-39.

34. Estacion M, Han C, Choi JS, et al. Intra- and interfamily phenotypic diversity in pain syndromes associated with a gain-of-function variant of NaV1.7. Molecular pain 2011; 7: 92.

35. Ho TW, Backonja M, Ma J, Leibensperger H, Froman S, Polydefkis M. Efficient assessment of neuropathic pain drugs in patients with small fiber sensory neuropathies. Pain 2009; 141(1-2): 19-24.

36. Zaccara G, Perucca P, Loiacono G, Giovannelli F, Verrotti A. The adverse event profile of lacosamide: a systematic review and meta-analysis of randomized controlled trials. Epilepsia 2013; 54(1): 66-74.

37. Hearn L, Derry S, Moore RA. Lacosamide for neuropathic pain and fibromyalgia in adults. The Cochrane database of systematic reviews 2012; 2: CD009318.

38. de Greef BTA, Hoeijmakers JGJ, Gorissen-Brouwers CML, Geerts M, Faber CG, Merkies ISJ. Associated conditions in small fiber neuropathy - a large cohort study and review of the literature. European journal of neurology : the official journal of the European Federation of Neurological Societies 2018; 25(2): 34855.

39. Brouwer BA, Bakkers M, Hoeijmakers JG, Faber CG, Merkies IS. Improving assessment in small fiber neuropathy. Journal of the peripheral nervous system : JPNS 2015; 20(3): 333-40.

40. Zadeh WW, Escartin A, Byrnes W, et al. Efficacy and safety of lacosamide as first add-on or later adjunctive treatment for uncontrolled partial-onset seizures: A multicentre open-label trial. Seizure 2015; 31: 72-9. 




\section{CHAPTER 7} INTRAVENOUS IMMUNOGLOBULIN THERAPY FOR SMALL FIBER NEUROPATHY study protocol for a randomized controlled trial

Bianca T.A. de Greef ${ }^{1}, M D$, Margot Geerts ${ }^{1}, M S c$, Janneke G.J. Hoeijmakers ${ }^{1}$, MD, PhD, Catharina G. Faber ${ }^{1}, M D$, PhD, Ingemar S.J. Merkies ${ }^{1,2}, M D, P h D$.

\footnotetext{
${ }^{1}$ Department of Neurology, School of Mental Health and Neuroscience, Maastricht University Medical Center, Maastricht, The Netherlands. ${ }^{2}$ Department of Neurology, St. Elisabeth Hospital, Willemstad, Curaçao.
}

The study was supported by the Grifols Investigator-Sponsored Research (ISR) Program.

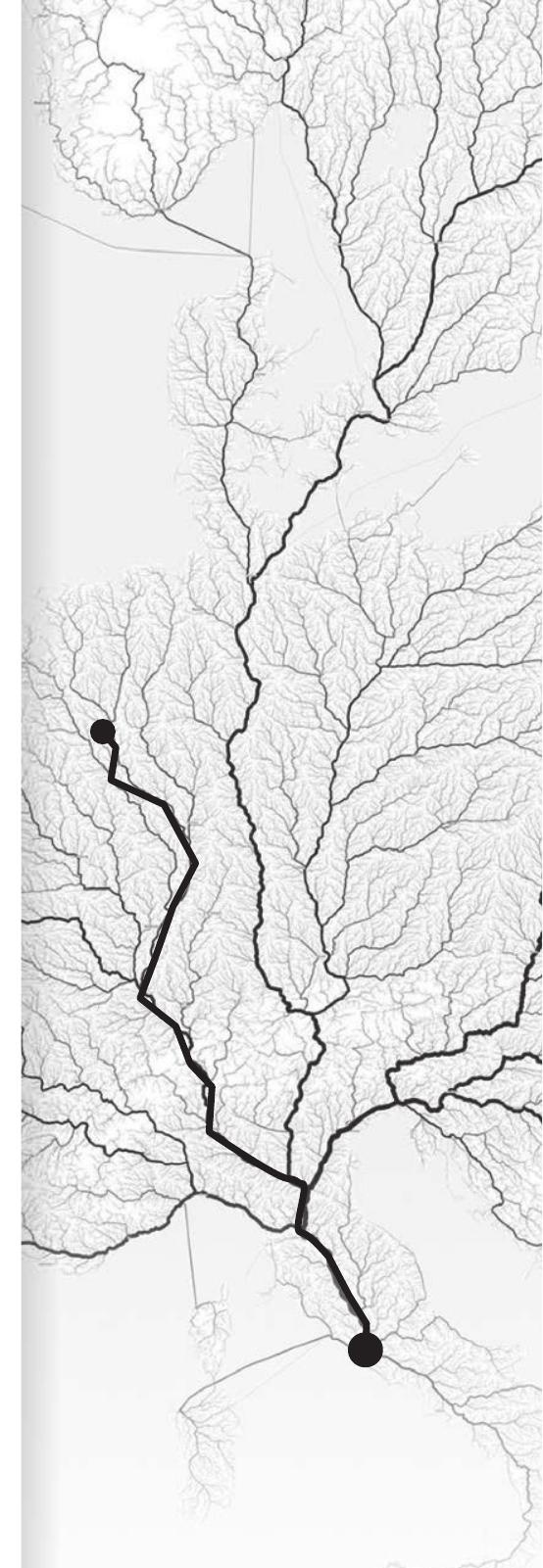

Trials. 2016;17(1):330; 


\section{Abstract}

Background: Small fiber neuropathy is the most common cause of neuropathic pain in peripheral neuropathies, with a minimum prevalence of 53/100,000. Patients experience excruciating pain and currently anti-neuropathic and other pain drugs do not relieve the pain substantially. Several open-labeled studies have suggested an immunological basis in small fiber neuropathy and have reported efficacy of treatment with intravenous immunoglobulin. Therefore, immunological mechanisms conceivably may play a role in small fiber neuropathy. To date no randomized controlled study with intravenous immunoglobulin in patients with small fiber neuropathy has been performed.

Methods/Design: This study is a randomized, double-blind, placebo-controlled clinical trial in patients with idiopathic small fiber neuropathy. The primary objective is to investigate the efficacy of intravenous immunoglobulin versus placebo on pain alleviation. A 1-point change on the PI-NRS compared to baseline is considered the minimum clinically important difference. In the IVIg-treated group we assume a response rate of approximately $60 \%$ based on the criteria composed by the IMMPACT group for measurement of pain. Based on this, a total sample size of 60 patients is needed. Eligible patients fulfilling the inclusion/exclusion criteria will be randomized to receive either intravenous immunoglobulin or placebo ( $0.9 \%$ saline). The treatment regimen will start with a loading dose of $2 \mathrm{~g} / \mathrm{kg}$ body weight over 2-4 consecutive days, followed by a maintenance dose of $1 \mathrm{~g} / \mathrm{kg}$ body weight over $1-2$ consecutive days given 3 times at 3 weeks interval. The primary endpoint is the comparison of the percentage of responder subjects between the two treatment groups from the first randomization during 12 weeks treatment. A responder is defined as $\geq 1$-point Pain Intensity Numerical Rating Scale improvement on the mean weekly peak pain relative to baseline. The secondary outcomes are pain intensity, pain qualities, other small fiber neuropathy-related complaints, daily and social functioning, as well as quality of life. In addition, safety assessments will be performed like adverse events, vital signs and laboratory values outside the normal range. Responders during the 12 weeks treatment period will be followed during a 3-month extension phase.

Discussion: This is the first randomized, double-blind, placebo-controlled clinical trial with intravenous immunoglobulin in patients with idiopathic small fiber neuropathy. Positive findings will result in a new treatment option for small fiber neuropathy and support an immunological role in this condition. 


\section{Background}

Small fiber neuropathy (SFN) is a disorder of the thinly myelinated A $\delta$-fibers and the unmyelinated C-fibers, with a minimum prevalence of 53/100,000. ${ }^{1}$ Patients suffer from neuropathic pain, usually following a length-depending pattern. ${ }^{2}$ Besides, they report autonomic symptoms, like palpitations, gastrointestinal disturbances, and orthostatic dizziness. ${ }^{3,4}$ SFN interferes with daily functioning and may lead to a decrement in quality of life expectations. ${ }^{5}$ The diagnosis is based on SFN related symptoms, without signs of large-fiber involvement, in combination with an abnormal intra-epidermal nerve fiber density (IENFD) in skin biopsy and/or an abnormal temperature threshold levels in quantitative sensory testing. ${ }^{3,}$ ${ }^{4}$ Despite intensive search for underlying causes such as diabetes mellitus, impaired glucose tolerance, Fabry's disease, hereditary disorders, celiac disease, sarcoidosis, HIV and other systemic illnesses which may be potentially treatable, ${ }^{3,4}$ the proportion of patients with idiopathic SFN (I-SFN) remains substantial, ranging in different series from $24 \%$ up to $93 \%$. ${ }^{1,6-8}$ It is conceivable that immunological mechanisms may play a role in patients with I-SFN, since several immune-mediated diseases, such as sarcoidosis, Sjogren's disease and systemic lupus erythematosus are associated with SFN.-11 Auto-antibodies have also been reported in patients with SFN. ${ }^{12-14}$ Moreover, inflammatory changes in nerves have been found. ${ }^{15,16}$ Elevated pro-inflammatory cytokines have been suggested to be involved in the pathophysiology of pain in SFN. ${ }^{17}$ In other immune-mediated neuropathies, such as chronic inflammatory demyelinating polyneuropathy, treatment with intravenous immunoglobulin (IVIg) has proven to be efficacious. ${ }^{18,} 19$ Moreover, some immunomodulation therapies have shown efficacy in some open-labelled case studies in patients with SFN with chronic pain. ${ }^{20-24}$ Similar findings have been reported in erythromelalgia, a condition that is associated with SFN. ${ }^{25}, 26$ Pain reduction with IVIg treatment has been summarized recently. ${ }^{23}$

IVIg is a blood product with high doses of pooled IgG molecules, which are derived from thousands of donors. IgG antibodies are the primary mediators of protective humoral immunity against pathogens, but can also be pathogenic. ${ }^{27} \mathrm{IVIg}$ may be used either to boost the patients' immunological capabilities or, conversely, to blunt an immune response directed toward the patients' own tissues. ${ }^{28}$ This dual IVIg-mediated effect on the immune system makes IVIg suitable for the treatment of several different diseases. When administered in high concentrations, IVIg has anti-inflammatory properties. How this anti-inflammatory effect is mediated has not been fully elucidated yet. Several mechanisms have been proposed, including toxin inactivation, stimulation of the leukocyte and serum bactericidal action, modulation of cytokine effect, and the modulation of the complement system. ${ }^{28}$

In SFN, current neuropathic pain treatment options are generally insufficient to relief the pain substantially. ${ }^{29,30}$ Therefore, a better treatment is warranted. IVIg appears to be a potential therapeutic option for pain alleviation in SFN. The aim of the current pilot study is to investigate the efficacy and safety of IVIg in patients with I-SFN in a randomized, double-blind, placebocontrolled, clinical trial. 


\section{Methods/Design}

\section{Objectives}

The primary objective of the study is to evaluate the efficacy of IVIg treatment compared to placebo in patients with skin biopsy proven I-SFN on pain alleviation.

Secondary objectives are to assess the effect of IVIg on pain intensity, pain qualities, and other small fiber neuropathy-related complaints, daily and social functioning, as well as quality of life. In addition, safety features of IVIg therapy in SFN will be evaluated.

\section{Study design}

The study has a randomized, double-blind, parallel group, placebo-controlled prospective design, shown in Figure 1. This design has been partly applied and published previously. ${ }^{18,31}$ This design has been partly applied and published previously in the ICE-trial, in which the effect of IVIg for the treatment of chronic inflammatory demyelinating polyradiculopathy has been studied. ${ }^{18}$ In that study a screening period up to 10 days was chosen, thereafter patients were divided to one of the two parallel groups with IVIg or placebo. Patients received a baselineloading dose of $2 \mathrm{~g} / \mathrm{kg}$ over 2-4 days, followed by a maintenance infusion of $1 \mathrm{~g} / \mathrm{kg}$ over $1-2$ days every 3 weeks. For the current trial this part of the study design has been adopted.

In brief, after a screening period of $\leq 10$ days, eligible subjects are randomized to receive either IVIg at a uploading dose of $2 \mathrm{~g} / \mathrm{kg}$ body weight (bw) ideally over 2-4 (consecutive) days or matching placebo. Thereafter, a study drug infusion is administered every 3 weeks at a dose of $1 \mathrm{~g} / \mathrm{kg}$ bw, given over 1-2 (consecutive) days for a total of 3 additional infusions following baseline. Subjects' pain is measured using Pain Intensity Numerical Rating Scale (PI-NRS) at baseline and at each study visit scheduled every 3 weeks for 12 weeks. Pain is also assessed twice a day (daytime and nocturnal pain, through PI-NRS) on two days per week (Monday and Friday). A responder is defined as $\geq 1$-point improvement on the mean weakly peak pain using the PI-NRS relative to baseline. Patients who showed an improvement and completed the 12 weeks of study treatment will be followed during a 3-month extension phase to determine the long-term effect on pain alleviation of therapy received.

The study is placebo-controlled, because previously in analgesic trials a placebo effect of 7$37 \%$ has been shown. ${ }^{32}$ To make sure IVIg has a factual effect on pain reduction, a placebocontrolled design is necessary to exclude the placebo-effect of this treatment on the patients. In addition, patients are allowed to use pain medication that not has been changed in the 30 days prior to randomization. As a result, in case the patient receives a placebo, the treatment does not differ from the situation before participating the study. 
Figure 1. Schematic diagram representing overall study design and study visits.
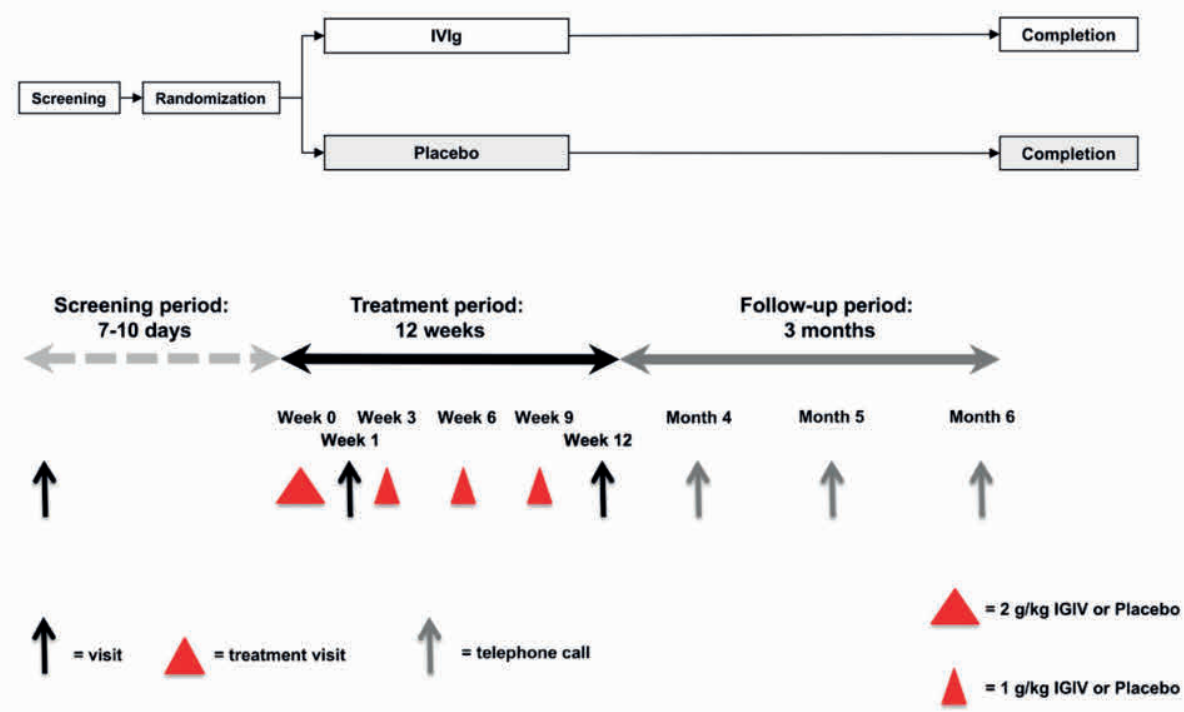

Legend to Figure 1: IVIg = intravenous immunoglobulin, red triangles represent the treatment visits. The first treatment visit is spread out over 2-4 consecutive days, treatment visit 2-4 will consist of 1-2 consecutive days.

\section{Setting and duration}

The study is conducted at the department of Neurology of the Maastricht University Medical Center+ (Maastricht UMC+), Maastricht, the Netherlands. For logistic reasons, all subjects are residents of the Netherlands. The duration of the study is 6 months per subject. Examination will be performed by neuromuscular experts and/or highly trained fellows in neurology. We are aiming to conduct the study in a 2-year period.

\section{Participants}

A total of 60 patients, 30 per treatment arm, will be included in the study. These are patients with newly or previously diagnosed skin-biopsy proven idiopathic (predominantly) SFN. Subjects are recruited at the Maastricht UMC+, the Netherlands. Informed consent will be obtained from all participants, before study start.

\section{Inclusion criteria}

Subjects must meet all of the following inclusion criteria to be eligible for enrollment into the study:

18 years or older.

2. Skin-biopsy proven idiopathic SFN or idiopathic painful neuropathy with predominantly SFN pattern.

3. Pain intensity rated $\geq 5$ on the PI-NRS (maximum pain) or on the neuropathic pain scale (NPS), ${ }^{33,}{ }^{34}$ question number 1 for at least 12 weeks before the study as 
declared by each patient to the best of their knowledge; if available, medical records of each patient will be consulted on the reported pain intensity.

4. Each subject will receive an information leaflet and an informed consent form. Subjects must give written informed consent prior to study entry.

5. Eligible patients must be willing to complete all study-related activities and examination required by the protocol.

Exclusion criteria:

Subjects presenting with any of the following will not be included in the study:

1. Predominant clinical picture of large nerve fiber involvement (i.e., weakness, loss of vibration sense, hypo-/areflexia).

2. Treatment with IVIg or any other immunomodulatory/immunosuppressive agents (e.g., steroids) within the last 12 weeks prior to the date of informed consent.

3. An underlying cause of SFN (diabetes, SCN9A/SCN10A/SCN11A mutations, hypothyroidism, renal failure, vitamin B12 deficiency, monoclonal gammopathy, alcohol abuse (more than $5 \mathrm{IU} /$ day), malignancies, drugs that cause neuropathy (e.g. chemotherapy, amiodarone, propafenone)).

4. History of anaphylaxis or severe systemic response to immunoglobulin or with a blood product.

5. Cardiac insufficiency (NYHA III/IV), cardiomyopathy, significant cardiac dysrhythmia requiring treatment, unstable or advanced ischemic heart disease, or history of congestive heart failure, severe hypertension (diastolic blood pressure $>120 \mathrm{mmHg}$ or systolic $>170 \mathrm{mmHg}$ ).

6. Known hyperviscosity, history of renal insufficiency or high serum creatinine levels $(\mathrm{MDRD}<30)$, selective IgA deficiency, or hypercoagulable state.

7. Conditions whose symptoms and effects could alter protein catabolism and/or IgG utilization (e.g. protein-losing enteropathies, nephrotic syndrome).

8. Females who are pregnant, breast-feeding, or, if of childbearing potential, unwilling to practice adequate contraception throughout the study.

9. Mentally challenged adult subjects unable to give independent informed consent.

10. Patients using pain medication that has changed in the 30 days prior to randomization. Unchanged pain medication is allowed, provided dosages stay equal during the study.

\section{Study medication}

Gamunex@ $10 \%, 100 \mathrm{mg} / \mathrm{ml}$, solution for infusion is a Human normal immunoglobulin that is currently available commercially in a number of countries for the treatment of primary immunodeficiency, idiopathic thrombocytopenic purpura, and chronic inflammatory demyelinating polyneuropathy as well as other indications in some countries. Placebo is supplied as $0.9 \%$ saline.

The dose of IVIg chosen for this study has been considered to be potentially the most effective in other immune-mediated polyneuropathies, specifically $2.0 \mathrm{~g} / \mathrm{kg}$ of IVIg as loading dose followed by $1 \mathrm{~g} / \mathrm{kg}$ bw for maintenance at intervals of 3 weeks. ${ }^{18}$ 
The maximum dose is $80 \mathrm{~g}$ IVIg per infusion day, even for subjects whose body weight exceed $80 \mathrm{~kg}$. Maximum dose is $160 \mathrm{~g}$ IVIg for a $2 \mathrm{~g} / \mathrm{kg}$ bw application and $80 \mathrm{~g}$ for $1 \mathrm{~g} / \mathrm{kg} / \mathrm{bw}$ application.

The calculated dose is administered over a 2-4 days period at baseline, dividing the total dose equally among the amount of infusion days. The infusion will be prepared on the day of infusion and administered on that same day. The 3 additional infusions, given at subsequent study visits, are each administered as a single infusion on 1 day but may be given over 2 consecutive days for reasons of tolerability.

On the first two days of the treatment (day 1 and day 2), the initial infusion rate will be 0.05 $\mathrm{mL} / \mathrm{kg} /$ hour for the first $20 \mathrm{~min}$. If there is no evidence of a hypersensitivity reaction, the infusion rate will be increased to $1.0 \mathrm{~mL} / \mathrm{kg} /$ hour for the next $20 \mathrm{~min}$. After that, the infusion rate will be increased to $3.0 \mathrm{~mL} / \mathrm{kg} /$ hour. If this is tolerated well, the infusion rate will start at $1 \mathrm{~mL} / \mathrm{kg} /$ hour for additional treatments and will be increased to $3 \mathrm{~mL} / \mathrm{kg} /$ hour and 5 $\mathrm{mL} / \mathrm{kg} /$ hour over 20 minutes up to a maximum allowable rate of $7 \mathrm{~mL} / \mathrm{kg} /$ hour. This infusion scheme is according to the protocol of the hospital. Each infusion will take approximately 3-4 h. Vital signs will be documented during the infusion. The subject will be monitored during the infusion for any adverse events.

\section{Compliance}

Volume of the study drug administered will be documented in the medical record and the electronic case report file (eCRF). When less than $100 \%$ of the calculated study drug volume is given, the reasons for deviation will be recorded in medical record and eCRF.

\section{Randomization and blinding}

All eligible subjects participating in the study will receive a subject number consecutively beginning with the abbreviation of the study (IVIG) followed by $01,02,03$, etc. A computer will randomize the subjects to one of the two treatment groups. An automatic message with this allocation will be send to the unblinded pharmacist and will be kept confidential.

The study will be subject- and investigator blinded during the treatment periods, from visit 2 until the end of the study. Blinding codes will only be broken in emergency situations for reasons of subject safety.

Blinding of different study groups will be guaranteed by ensuring all subjects receiving the same total volume per kg body weight of trial medication with no visible difference in the external aspect between IVIg and placebo, by using nontransparent infusion lines and bags. An unblinded pharmacist or designee will prepare study medication. This individual, responsible for dispensing the drug, will also be responsible for the blinding procedure.

\section{Outcome measurements}

\section{Primary outcome}

The primary outcome measure will be based on pain assessment, since pain is considered the most important feature of SFN. ${ }^{2-4,35,36}$ Pain intensity will be evaluated using the 11-point Pain Intensity Numeric Rating Scale (PI-NRS; 0: no pain to 10: worst imaginable pain). ${ }^{33,} 37$ In 
particular, a difference in mean weakly peak pain intensity will be considered as the primary outcome parameter. A responder is defined as $\geq 1$-point improvement on the PI-NRS during 12 weeks treatment relative to baseline. The rationale for choosing the primary outcome measure was based on recommendations regarding the clinical importance of treatment outcomes in chronic pain clinical trials as postulated by the IMMPACT (Initiative on Methods, Measurements and Pain Assessment in Clinical Trials) study group. ${ }^{38,39}$

\section{Secondary outcomes}

Secondary outcome measures include changes in daily pain intensity, nocturnal pain intensity, and the average of these two obtained from the PI-NRS, change in Patients' Global Impression of Change (PGIC), ${ }^{38,} 39$ the Rash-transformed 13 items SFN-Symptoms Inventory Questionnaire (RT-SFN-SIQ), ${ }^{40}$ the amount of pain medication, the use of non-medical rescue activities, the amount of pain relief (using a 5-point Likert-scale), the NPS, ${ }^{34}$ Daily Sleep Interference Scale (DSIS), the Short Form 36 Health Survey (SF-36), ${ }^{41,}{ }^{42}$ and the Rasch-built Overall Disability Outcome Scale (SFN-RODS). ${ }^{40}$

Safety evaluation features will include the following additional tests: adverse events, laboratory test (e.g. hematology, clinical chemistry, as shown in table 2), and vital signs.

\section{Data management}

An eCRF is used for each patient to collect all data. To host the eCRF, MACRO electronic data capture is used, powered by InferMed Ltd, London. It has been designed to support compliance with the requirements of relevant regulatory bodies including ICH Good Clinical Practice (www.infermed.com). Assessments start at the screening visit and are subsequently performed according to the scheme presented in Figure 1, Table 1 and Table 2, and include a standardized interview to determine patient's clinical condition and well-being, assessment of various questionnaires, and laboratory assessment. During each visit, adverse events and concomitant medication are discussed. At each visit, the diary and residual medications are collected.

Privacy of the patients is guaranteed; stored data and materials are only identifiable to the person by a sequential assigned subject number. The handling of personal data complies with the Dutch Personal Data Protection Act (De Wet Bescherming Persoonsgegevens, WBP). The figure for this study protocol is shown in supporting information 1.

\section{Adverse events}

Adverse events will be recorded and monitored. The principal investigator will be informed immediately in case of any serious adverse event (SAE) is occurring. Every SAE will be reported to the Ethics Committee. 
Supporting information 1. Figure of content for the schedule of enrolment, interventions, and assessments. STUDY PERIOD

\begin{tabular}{|c|c|c|c|c|c|c|c|c|}
\hline \multirow[b]{2}{*}{ TIMEPOINT** } & \multirow{2}{*}{$\begin{array}{l}\text { Enrolment } \\
-t_{1}\end{array}$} & \multirow{2}{*}{$\begin{array}{l}\text { Allocation } \\
0\end{array}$} & \multicolumn{4}{|c|}{ Post-allocation } & \multirow{2}{*}{$\begin{array}{l}\text { End of } \\
\text { treatment } \\
v_{7}\end{array}$} & \multirow{2}{*}{$\begin{array}{l}\text { Follow-up } \\
v_{8-10}\end{array}$} \\
\hline & & & $v_{1}$ & $v_{2}$ & $v_{3}$ & $V_{4-6}$ & & \\
\hline \multicolumn{9}{|l|}{ ENROLMENT: } \\
\hline Eligibility screen & $x$ & & & & & & & \\
\hline Informed consent & $x$ & & & & & & & \\
\hline Medical history & $x$ & & & & & & & \\
\hline Physical examination & $x$ & & & & & & & \\
\hline $\begin{array}{l}\text { Nerve conduction } \\
\text { studies }\end{array}$ & $x$ & & & & & & & \\
\hline Skin biopsy and QST & $x$ & & & & & & & \\
\hline Allocation & & $x$ & & & & & & \\
\hline \multicolumn{9}{|l|}{ INTERVENTIONS: } \\
\hline $\begin{array}{l}\text { Intravenous } \\
\text { Immunoglobulin }\end{array}$ & & & $\hookleftarrow$ & & & & & \\
\hline \multicolumn{9}{|l|}{ Placebo } \\
\hline \multicolumn{9}{|l|}{ ASSESSMENTS: } \\
\hline $\begin{array}{l}\text { Laboratory } \\
\text { assessments }\end{array}$ & $x$ & & $x$ & $x$ & $x$ & $x$ & $x$ & \\
\hline PI-NRS & $x$ & & & & & $x$ & $x$ & $x$ \\
\hline$P G / C$ & & & & & & $x$ & $x$ & $x$ \\
\hline SFN-SIQ & $x$ & & & & & $x$ & $x$ & $x$ \\
\hline NPS & $x$ & & & & & $x$ & $x$ & $x$ \\
\hline SFN-RODS & $x$ & & & & & $x$ & $x$ & $x$ \\
\hline Pain relief & & & & & & $x$ & $x$ & $x$ \\
\hline Sleep quality & $x$ & & & & & $x$ & $x$ & $x$ \\
\hline$S F-36$ & $x$ & & & & & $x$ & $x$ & $x$ \\
\hline $\begin{array}{l}\text { Study medication } \\
\text { infusion }\end{array}$ & & & $x$ & & & $x$ & & \\
\hline Vita/signs & & & $x$ & & & $x$ & $x$ & \\
\hline $\begin{array}{l}\text { Concomitant } \\
\text { medication }\end{array}$ & $x$ & $x$ & $x$ & $x$ & $x$ & $x$ & $x$ & $x$ \\
\hline Adverse events & $x$ & $x$ & $x$ & $x$ & $x$ & $x$ & $X$ & $x$ \\
\hline
\end{tabular}

Legend to supporting information 1: In this table, the schedule for enrolment, interventions and assessments are shown.

$\mathrm{v} 1$ = Week 0 baseline / day 1

$\mathrm{v} 2=$ Completion of baseline infusion

$\mathrm{v} 3=3-6$ days after completion of baseline infusion

$\mathrm{v} 4$ = week 3 (second treatment)

$\mathrm{v} 5=$ week 6 (third treatment)

$v 6=$ week 9 (fourth treatment)

$\mathrm{v} 7=$ week 12 (end of treatment)

v8 = month 4 (follow-up)

$\mathrm{v} 9=$ month 5 (follow-up)

$\mathrm{v} 10=$ month 6 (follow-up) 
Table 1. Study flow chart (except laboratory assessments)

\begin{tabular}{|c|c|c|c|c|c|c|c|}
\hline & Screening & Treatment & phase & & & End of & Follow- \\
\hline $\begin{array}{l}\text { Assessment/ } \\
\text { Evaluation }\end{array}$ & $\begin{array}{l}\text { - } 10 \text { days } \\
\text { (Day }-10 \\
\text { to Day 0) }\end{array}$ & $\begin{array}{l}\text { Week } 0 \\
\text { Baseline/ } \\
\text { Day } 1\end{array}$ & $\begin{array}{l}\text { Completion } \\
\text { of baseline } \\
\text { infusion } \\
\text { (Day } 2,3 \text { or } \\
4)^{3}\end{array}$ & $\begin{array}{l}\text { 3-6 Days } \\
\text { after } \\
\text { completion } \\
\text { of baseline } \\
\text { infusion }^{4}\end{array}$ & $\begin{array}{l}\text { Week } \\
3,6,9 \\
( \pm 3 \\
\text { days })\end{array}$ & $\begin{array}{l}\text { Week } \\
12 \\
( \pm 3 \\
\text { days) }\end{array}$ & $\begin{array}{l}\text { Month 4, } \\
5,6\end{array}$ \\
\hline
\end{tabular}

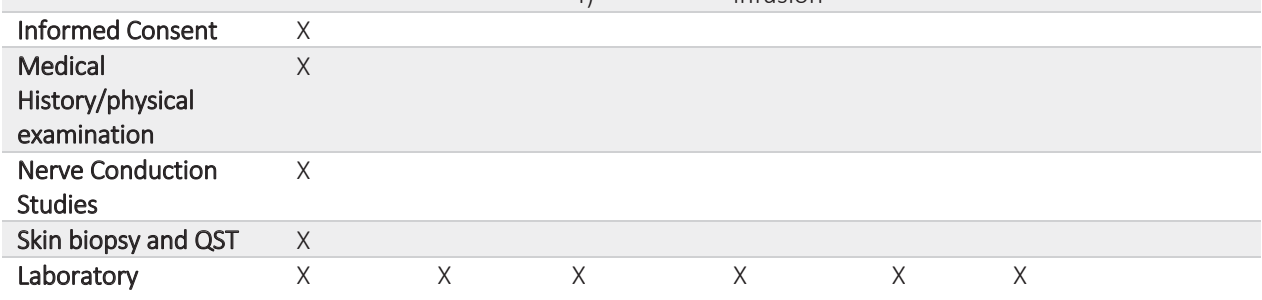

Assessments

(see Table 2)

\begin{tabular}{|c|c|c|c|c|c|c|c|}
\hline PI-NRS & $x$ & & & & $x$ & $x$ & $x$ \\
\hline PGIC & & & & & $x$ & $x$ & $x$ \\
\hline SFN-SIQ & $x$ & & & & $x$ & $x$ & $x$ \\
\hline NPS & $x$ & & & & $x$ & $x$ & $x$ \\
\hline SFN-RODS & $x$ & & & & $x$ & $x$ & $x$ \\
\hline Pain relief & & & & & $x$ & $x$ & $x$ \\
\hline Sleep quality & $x$ & & & & $x$ & $x$ & $x$ \\
\hline SF-36 & $x$ & & & & $x$ & $x$ & $x$ \\
\hline $\begin{array}{l}\text { Study Medication } \\
\text { Infusion }^{1}\end{array}$ & & $x$ & & & $x$ & & \\
\hline Vital Signs $^{2}$ & & $x$ & & & $x$ & $x$ & \\
\hline $\begin{array}{l}\text { Concomitant } \\
\text { Medication }\end{array}$ & $x$ & $x$ & $x$ & $x$ & $x$ & $x$ & $x$ \\
\hline Adverse Events & $x$ & $x$ & $x$ & $x$ & $x$ & $x$ & $x$ \\
\hline
\end{tabular}

Legend to table 1:

1. Medications given over 2 consecutive days at baseline and over 1 day every 3 weeks thereafter. Treatment is allowed to be prolonged up to 4 or 2 days respectively for reasons of tolerability.

2. Vital signs (blood pressure and heart rate) to be taken right before infusion, 30 minutes after starting infusion, and immediately after infusion completed.

3. Visit to be conducted after completion of entire baseline infusion (Day 2, 3, or 4 depending on duration of baseline infusion).

4. Visit to be conducted 3-6 days after completion of the baseline infusion, not 3-5 days after baseline/Day 1 infusion began.

5. The follow-up period will be performed by standardized telephone call interviews.

QST = quantitative sensory testing, PI-NRS = pain intensity numerical rating scale, PGIC = patients' global impression of change, RT-SFN-SIQ = Rasch-transformed small fiber neuropathy symptoms inventory questionnaire, NPS = neuropathic pain scale, SFN-RODS = small fiber neuropathy Rasch-built overall disability outcome scale, SF-36 = short form 36 health survey.

\section{Statistical analysis}

\section{Sample size}

One point change on the PI-NRS compared to baseline is considered as the minimum clinically important difference (MCID), according to unified rule of $1 / 2 \times S D$ and recommendations given by the IMMPACT group. ${ }^{38,43}$ In the placebo group we assume a response rate of approximately $25 \%$ in the placebo treated group, based on a meta-analysis of the placebo effect in pain 
studies in which the effect varied from $7-37 \%$, and where $16 \%$ of the patients had a pain reduction of $50 \% .{ }^{32}$ In the IVIg treated group we assume a response rate of approximately $60 \%$ based on the IMMPACT criteria. $^{38}$

Table 2. Study flow chart - laboratory assessments

Screening Treatment phase

\begin{tabular}{|c|c|c|c|c|c|c|c|}
\hline & & & & & & eatment & $u^{5}$ \\
\hline Lab assessment & $\begin{array}{l}\text { - } 10 \text { days } \\
\text { (Day -10 } \\
\text { to Day 0) }\end{array}$ & $\begin{array}{l}\text { Week } 0 \\
\text { Baseline/ } \\
\text { Day } 1\end{array}$ & $\begin{array}{l}\text { Completion } \\
\text { of baseline } \\
\text { infusion } \\
\text { (Day } 2 \text { or } 3 \\
\text { or 4) }\end{array}$ & $\begin{array}{l}\text { 3-6 Days } \\
\text { after } \\
\text { completion } \\
\text { of baseline } \\
\text { infusion }\end{array}$ & $\begin{array}{l}\text { Week } \\
3,6,9 \\
( \pm 3 \\
\text { days) }\end{array}$ & $\begin{array}{l}\text { Week } \\
12( \pm 3 \\
\text { days) }\end{array}$ & $\begin{array}{l}\text { Month } \\
4,5,6\end{array}$ \\
\hline
\end{tabular}

\begin{tabular}{lll}
\hline Immunofixation & $X$ \\
\hline $\begin{array}{l}\text { Pregnancy Test (Serum } \\
\beta \text { HCG) }\end{array}$ & $X$ \\
\hline
\end{tabular}

$\mathrm{TSH}^{1} /$ regular T4 $\quad X$

Fasting blood glucose, $X$

vitamin $\mathrm{B} 12^{2}$

Serum Retain ${ }^{3}$

Urinalysis

\begin{tabular}{|c|c|c|c|c|c|c|}
\hline $\operatorname{lgG4}$ & & $x$ & $x^{4}$ & $x$ & $x$ & $x$ \\
\hline Hematology/CBC & $x$ & $x$ & & $x$ & $x$ & $x$ \\
\hline
\end{tabular}

(hematocrit, hemoglobin, WBC, RBC,

platelets)

Creatinine, Blood urea

nitrogen

$\begin{array}{lccccc}\text { AST/ALT, LDH, } & X & X^{4} & X & X \\ \text { potassium, bilirubin, CK } & X & X^{4} & X & X\end{array}$

Legend to table 2:

1. TSH to be conducted at screening if results not available since SFN diagnosis. Regular T4 automatically run by LabCorp if TSH determined to be above the upper limits of normal.

2. To be conducted at screening if results not available since SFN diagnosis.

3. 2 aliquots required at screening (one for viral retain and one for possible future antibody testing); 1 aliquot required at both Week 12 (for possible future antibody testing).

4. Samples to be obtained immediately after completion of entire baseline infusion. If the entire baseline infusion is completed in 2 days, then samples are to be collected post-infusion on Day 2. If the entire baseline infusion is completed in 3 or 4 days, then samples are to be collected postinfusion on Day 3 or 4 respectively.

5. The follow-up period will be performed by standardized telephone call interviews.

Fixing a one-sided alpha at 5\%, a sample size of 24 patients per treatment group would be required to show efficacy with $80 \%$ power and an effect size of $60 \%$ between the two groups (Chi-squared test). Accounting for a dropout rate of approximately $20 \%$ (six patients), a total of 30 subjects per treatment group will be included in this study.

\section{Type of analysis}

The primary efficacy comparison is the comparison of the proportion of responders in the perprotocol-population where a responder is defined as $\geq 1$ point improvement in the mean weekly peak pain measured with the PI-NRS (maximum pain) during the 12 weeks treatment 
period after first study drug infusion compared to baseline, using Kaplan-Meier curves (log rank test). The following sensitivity analyses will be performed. The primary efficacy analysis will be repeated in the per-protocol population using a more strict definition of a responder: a 'responder of $\geq 2$ points' is defined as $\geq 2$ points improvement in the PI-NRS at the last evaluation following the first study drug infusion during the blinded 12 weeks treatment period compared to baseline.

In the intention to treat (ITT) population the following additional sensitivity analyses will be performed: Any subject who drops out with at least the week 6 PI-NRS assessment with their last mean weakly peak pain on the PI-NRS will be carried forward. A subject dropping out before the week 6 PI-NRS assessment or any subject with no baseline PI-NRS will be counted as non-responder independent of the last PI-NRS. Furthermore, in the ITT population the following sensitivity analyses will be performed. The analysis will be repeated using a more strict definition of a responder: a 'responder of $\geq 2$ points' is defined as $\geq 2$ points improvement in the PI-NRS at the last evaluation following the first study drug infusion during the blinded 12 weeks treatment period compared to baseline. Subjects with no baseline or no post baseline PI-NRS assessment will be counted as non-responder in this analysis.

When there are missing values, we will use multiple imputation based on a regression method, using SPSS (IBM Corp. Released 2015. IBM SPSS Statistics for Macintosh, Version 22.0. Armonk, NY: IBM Corp) or Stata (StataCorp. 2013. Stata Statistical Software: Release 13. College Station, TX: StataCorp LP).

The differences between the per-protocol-analyses and the ITT-analyses will give a good impression of the bias that might occur in the study. Comparing these two methods, we can make a clear picture of the two populations and can investigate the true effect of IVIg in the most reliable way.

The secondary efficacy variables will be tested for treatment group differences by analyses of covariance (ANCOVAs) with baseline measurement as covariate and the difference of the last post-baseline measurement in the treatment period relative to baseline as an independent variable (treatment group as fixed factor). In case no post-baseline measurement is documented, the baseline measurement will be used as the last post-baseline measurement. This analysis is an endpoint analysis using the 'last observation carried forward' (LOCF) approach.

\section{Discussion}

In this study, the efficacy and safety of IVIg is evaluated in patients with skin-biopsy proven idiopathic SFN. This will be the first randomized, placebo-controlled, double-blind clinical trial with IVIg versus placebo in patients with SFN.

In previous case studies with patients diagnosed with SFN and an underlying autoimmune disease (such as sarcoidosis, Sjögren's syndrome and celiac disease), IVIg has shown to be effective on chronic pain. ${ }^{20,21,24}$ Besides, in chronic refractory pain in general, pain reduction after IVIg treatment has been described, ${ }^{23}$ suggesting immunological mechanisms may play a role in the development or maintenance of pain, even if no clear immunological disorders are present. 
One of the limitations of the study is that the specific mechanism of action of IVIg is not known, making it hard to predict which patients will have benefit of the treatment. A second limitation might be that the treatment period of three months is too short to obtain effect. Third, patients will be kept stable on their current pain treatment, which could be of influence. However, stopping current pain medication would be ethically difficult.

In SFN, a better treatment is warranted, since currently available (neuropathic) pain medication does not relief pain substantially and often have a lot of side effects. ${ }^{44}$ For IVIg both a complementary and diminishing acting on the immune system have been described. ${ }^{45}$ In SFN, probably an activated immune system is causing inflammatory responses to the small nerve fibers, which can be diminished by IVIg.

Positive findings of IVIg treatment in SFN will result in a new treatment option and may support an immunological role in this condition.

\section{Trial status}

Participant recruitment will start at the half of 2016. 


\section{References}

1. Peters MJ, Bakkers M, Merkies IS, Hoeijmakers JG, van Raak EP, Faber CG. Incidence and prevalence of small-fiber neuropathy: a survey in the Netherlands. Neurology. 2013;81(15):1356-60.

2. Gorson KC, Ropper AH. Idiopathic distal small fiber neuropathy. Acta Neurol Scand. 1995;92(5):376-82.

3. Hoeijmakers JG, Faber CG, Lauria G, Merkies IS, Waxman SG. Small-fibre neuropathies-advances in diagnosis, pathophysiology and management. Nat Rev Neurol. 2012;8(7):369-79.

4. Lauria G, Merkies IS, Faber CG. Small fibre neuropathy. Curr Opin Neurol. 2012;25(5):542-9.

5. Bakkers M, Faber CG, Hoeijmakers JG, Lauria G, Merkies IS. Small fibers, large impact: quality of life in small-fiber neuropathy. Muscle Nerve. 2014;49(3):329-36.

6. Devigili G, Tugnoli V, Penza P, et al. The diagnostic criteria for small fibre neuropathy: from symptoms to neuropathology. Brain. 2008;131(Pt 7):1912-25.

7. Bednarik J, VIckova-Moravcova E, Bursova S, Belobradkova J, Dusek L, Sommer C. Etiology of small-fiber neuropathy. J Peripher Nerv Syst. 2009;14(3):177-83.

8. Hoitsma E, Marziniak M, Faber CG, et al. Small fibre neuropathy in sarcoidosis. Lancet. 2002;359(9323):2085-6.

9. Bakkers M, Merkies IS, Lauria G, et al. Intraepidermal nerve fiber density and its application in sarcoidosis. Neurology. 2009;73(14):1142-8.

10. Goransson LG, Herigstad A, Tjensvoll AB, Harboe E, Mellgren SI, Omdal R. Peripheral neuropathy in primary sjogren syndrome: a population-based study. Arch Neurol. 2006;63(11):1612-5.

11. Goransson LG, Brun JG, Harboe E, Mellgren SI, Omdal R. Intraepidermal nerve fiber densities in chronic inflammatory autoimmune diseases. Arch Neurol. 2006;63(10):1410-3.

12. Chamberlain JL, Pittock SJ, Oprescu AM, et al. Peripherin-lgG association with neurologic and endocrine autoimmunity. J Autoimmun. 2010;34(4):469-77.

13. Ferrari S, Morbin M, Nobile-Orazio E, et al. Antisulfatide polyneuropathy: antibody-mediated complement attack on peripheral myelin. Acta Neuropathol. 1998;96(6):569-74.

14. Dabby R, Weimer LH, Hays AP, Olarte M, Latov N. Antisulfatide antibodies in neuropathy: clinical and electrophysiologic correlates. Neurology. 2000;54(7):1448-52.

15. Zafrir B, Zimmerman M, Fellig Y, Naparstek Y, Reichman N, Flatau E. Small fiber neuropathy due to isolated vasculitis of the peripheral nervous system. Isr Med Assoc J. 2004;6(3):183-4.

16. Kelkar P, McDermott WR, Parry GJ. Sensory-predominant, painful, idiopathic neuropathy: inflammatory changes in sural nerves. Muscle Nerve. 2002;26(3):413-6.

17. Uceyler N, Kafke W, Riediger N, et al. Elevated proinflammatory cytokine expression in affected skin in small fiber neuropathy. Neurology. 2010;74(22):1806-13.

18. Hughes RA, Donofrio P, Bril V, et al. Intravenous immune globulin (10\% caprylate-chromatography purified) for the treatment of chronic inflammatory demyelinating polyradiculoneuropathy (ICE study): a randomised placebo-controlled trial. Lancet Neurol. 2008;7(2):136-44.

19. European Federation of Neurological S, Peripheral Nerve S, van Schaik IN, et al. European Federation of Neurological Societies/Peripheral Nerve Society guideline on management of multifocal motor neuropathy. Eur J Neurol. 2006;13(8):802-8.

20. Parambil JG, Tavee JO, Zhou L, Pearson KS, Culver DA. Efficacy of intravenous immunoglobulin for small fiber neuropathy associated with sarcoidosis. Respir Med. 2011;105(1):101-5.

21. Wakasugi D, Kato T, Gono T, et al. Extreme efficacy of intravenous immunoglobulin therapy for severe burning pain in a patient with small fiber neuropathy associated with primary Sjogren's syndrome. Mod Rheumatol. 2009;19(4):437-40.

22. Dabby R, Gilad R, Sadeh M, Lampl Y, Watemberg N. Acute steroid responsive small-fiber sensory neuropathy: a new entity? J Peripher Nerv Syst. 2006;11(1):47-52.

23. Goebel A. Immunoglobulin responsive chronic pain. J Clin Immunol. 2010;30 Suppl 1:S103-8.

24. Souayah N, Chin RL, Brannagan TH, et al. Effect of intravenous immunoglobulin on cerebellar ataxia and neuropathic pain associated with celiac disease. Eur J Neurol. 2008;15(12):1300-3.

25. Jackson AL, Oates JA. A patient with adult erythermalgia: evidence suggesting an autoimmune etiology. Am J Med Sci. 2008;335(4):320-2. 
26. Moody S, Pacheco S, Butler IJ, Koenig MK. Secondary erythromelalgia successfully treated with intravenous immunoglobulin. J Child Neurol. 2012;27(7):922-3.

27. Nimmerjahn F, Ravetch JV. The antiinflammatory activity of IgG: the intravenous IgG paradox. J Exp Med. 2007;204(1):11-5.

28. Berlot G, Rossini P, Turchet F. Biology of immunoglobulins. Trans/ Med UniSa. 2015;11:24-7.

29. Finnerup NB, Attal N, Haroutounian S, et al. Pharmacotherapy for neuropathic pain in adults: a systematic review and meta-analysis. Lancet Neurol. 2015;14(2):162-73.

30. Brouwer BA, de Greef BT, Hoeijmakers JG, et al. Neuropathic Pain due to Small Fiber Neuropathy in Aging: Current Management and Future Prospects. Drugs Aging. 2015;32(8):611-21.

31. Deng C, Hanna K, Bril V, et al. Challenges of clinical trial design when there is lack of clinical equipoise: use of a response-conditional crossover design. J Neurol. 2012;259(2):348-52.

32. McQuay H, Carroll D, Moore A. Variation in the placebo effect in randomised controlled trials of analgesics: all is as blind as it seems. Pain. 1996;64(2):331-5.

33. Jensen MP, McFarland CA. Increasing the reliability and validity of pain intensity measurement in chronic pain patients. Pain. 1993;55(2):195-203.

34. Galer BS, Jensen MP. Development and preliminary validation of a pain measure specific to neuropathic pain: the Neuropathic Pain Scale. Neurology. 1997;48(2):332-8.

35. Stewart JD, Low PA, Fealey RD. Distal small fiber neuropathy: results of tests of sweating and autonomic cardiovascular reflexes. Muscle Nerve. 1992;15(6):661-5.

36. Merkies IS, Lauria G. 131st ENMC International workshop: Selection of Outcome Measures for Peripheral Neuropathy Clinical Trials 10-12 December 2004, Naarden, The Netherlands. Neuromuscul Disord. 2006;16(2):149-56.

37. Farrar JT, Young JP, Jr., LaMoreaux L, Werth JL, Poole RM. Clinical importance of changes in chronic pain intensity measured on an 11-point numerical pain rating scale. Pain. 2001;94(2):149-58.

38. Dworkin RH, Turk DC, Wyrwich KW, et al. Interpreting the clinical importance of treatment outcomes in chronic pain clinical trials: IMMPACT recommendations. J Pain. 2008;9(2):105-21.

39. Farrar JT. What is clinically meaningful: outcome measures in pain clinical trials. Clin J Pain. 2000;16(2 Suppl):S106-12.

40. Brouwer BA, Bakkers M, Hoeijmakers JG, Faber CG, Merkies IS. Improving assessment in small fiber neuropathy. J Peripher Nerv Syst. 2015;20(3):333-40.

41. Aaronson NK. Quality of life: what is it? How should it be measured? Oncology (Williston Park). 1988;2(5):69-76, 64.

42. Aaronson NK, Muller M, Cohen PD, et al. Translation, validation, and norming of the Dutch language version of the SF-36 Health Survey in community and chronic disease populations. J Clin Epidemiol. 1998;51(11):1055-68.

43. Sloan J, Symonds T, Vargas-Chanes D, Fridley B. Practical Guidelines for Assessing the Clinical Significance of Health-Related Quality of Life Changes within Clinical Trials. Therapeutic Innovation \& Regulatory Science. 2003;37(1):23-31.

44. Themistocleous AC, Ramirez JD, Serra J, Bennett DL. The clinical approach to small fibre neuropathy and painful channelopathy. Pract Neurol. 2014.

45. Durandy A, Kaveri SV, Kuijpers TW, et al. Intravenous immunoglobulins--understanding properties and mechanisms. Clin Exp Immunol. 2009;158 Suppl 1:2-13. 





\section{CHAPTER 8 SUMMARY, GENERAL DISCUSSION, AND FUTURE PERSPECTIVES}

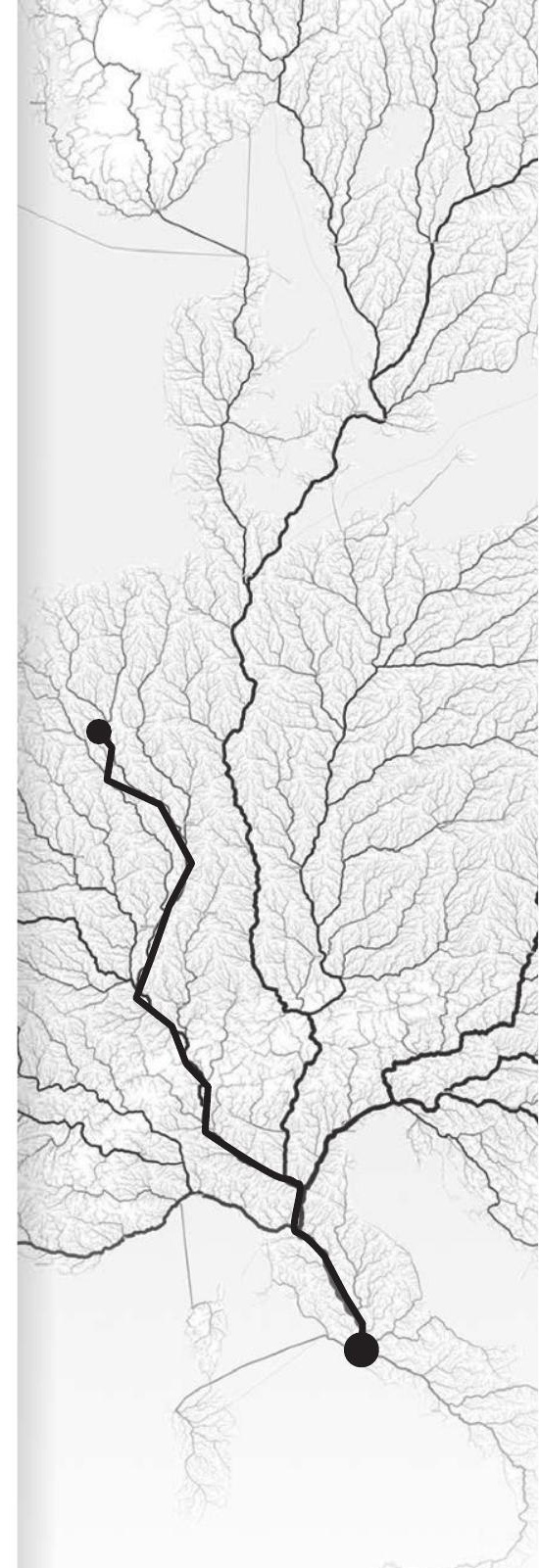


Neuropathic pain in patients with small fiber neuropathy (SFN) is difficult to control. To provide more specific treatments, with higher efficacy and fewer side effects, more knowledge is needed regarding the underlying pathophysiological mechanisms and conditions related to SFN. This thesis provides insight in the incidence of underlying SFN conditions in a large cohort of patients and presents data on potential mechanisms related to SFN, which is reflected in some studies investigating possible targeted therapeutic approaches in this debilitating condition. In the following, a summary of the chapters in this thesis will be provided, followed by future perspectives highlighting some caveats and unsolved needs in SFN.

\section{Summary and general discussion.}

Chapter 1 is an introduction in which general information about SFN is presented. The anatomy and function of the peripheral nerves is briefly described. Subsequently, the symptoms and diagnosis of SFN are clarified. In literature, various diseases have been suggested being related to SFN. These conditions and, specifically, the role of voltage-gated sodium channels are discussed. Finally, the current approach, from diagnostic to therapeutic management of neuropathic pain is addressed. The aims and outline of the thesis are presented in this chapter as well.

\section{Associated conditions in SFN and pathophysiological mechanisms}

SFN is a condition that reflects the complaints related to small nerve fiber damage. It is a "horrible condition that drives some patients crazy due to the excruciating continuously ongoing pain", as pointed out by a patient and agreed upon by many others suffering from SFN. Key questions are why specifically these nerve fibers get damaged and what the possible underlying pathophysiological mechanism would be. Various articles have been written regarding the possible underlying causes potentially related to SFN. Numerous diseases have been mentioned to be causal to SFN, however, most of these being based on cohort studies or case studies without providing any pathophysiologic evidence to develop SFN. For most of the diseases mentioned in literature potential treatments are available, justifying the need to test patients with SFN for the presence of such potentially related conditions. However, extensive diagnostic testing in SFN is not always the solution, and physicians should examine the burden to patients and related costs on the one hand, versus the benefits of an elaborative diagnostic approach on the other hand.

Chapter 2 illustrates elegantly the disadvantages of standard execution of additional tests having little if any benefit at all. Fabry disease is a metabolic disease that results in an accumulation of globotriaosylceramide (lyso-GB3) in different cell types, including the heart, kidneys, skin, and also neurons. ${ }^{1,2}$ Some patients with Fabry disease suffer from burning or shooting pains in hands and feet. Therefore, it was thought that SFN could be the first symptom of Fabry disease as has been previously reported. ${ }^{1-5}$ In a large cohort of patients $(n=725)$ with pure SFN, we investigated the presence of Fabry disease and found no patients with this concomitant illness. ${ }^{6}$ This finding suggests that pure SFN is unlikely to be the first expression of Fabry disease in adult patients, which contradicted literature on the presence of Fabry in 
pure SFN. ${ }^{7,8}$ Screening for Fabry disease in patients with SFN leads to high health care costs and may even provide confusing test results within a patient when one of the diagnostic tests turn out to be inconclusive, while the others are negative. Hence, we conclude that in patients with pure SFN, without other signs or symptoms of Fabry disease (like cardiac involvement, kidney involvement, or skin abnormalities), the screening for Fabry disease can be left out. However, this should always be chosen with great care, since this illness is treatable. It is suggested to re-evaluate those patients with additional involvement of other organs during evaluation over time and reconsider this testing if needed.

Patients that were referred to our center with the suspicion of SFN, have not only been tested for Fabry disease, but also for many other potentially related conditions based on literature review as presented in Table 1.8-18

The absence of Fabry disease in our cohort of patients with SFN triggered the thought of investigating the prevalence of other conditions too, which is presented in Chapter 3. In the SFN cohort ( $n=921)$, the most prevalent conditions were: autoimmune diseases (including abnormal immunological laboratory findings) in $19 \%$ of the patients, sodium channel gene variants (including variants with uncertain clinical significance, possibly pathogenic, probably pathogenic or pathogen variants) $)^{19}$ in $16.7 \%$, diabetes mellitus in $7.7 \%$, impaired glucose tolerance in 9.7\%, and vitamin B12 deficiencies in 4.7\%. All of these conditions were more prevalent than reported in the general Dutch population. Besides, even though some patients already had a known condition related to SFN before screening, additional underlying conditions related to SFN were found in $26.7 \%$ of these patients. ${ }^{20}$

These findings are considered the first step in investigating the relationship between SFN and most prevalent underlying conditions found. More research is suggested to investigate and provide knowledge on the pathophysiology and mechanisms behind this relationship. This might eventually lead to more targeted treatments, as are discussed in chapters 5-7. Even though there are a lot of conditions present in patients with SFN, in the cohort of the study no underlying condition could be found in $53 \%$ of the patients, which is congruent with reported literature. ${ }^{14,21-23}$ The findings also tell us that even though someone may have an illness that might contribute to SFN (e.g. diabetes mellitus) one should still examine the patient for other additional conditions that may co-contribute to its existence. 
Table 1. Underlying conditions of SFN mentioned in literature.

\begin{tabular}{|c|c|c|}
\hline $\begin{array}{l}\text { Immune-mediated } \\
\text { Sarcoidosis } \\
\text { Sjögren syndrome } \\
\text { Celiac disease } \\
\text { Inflammatory bowel disease } \\
\text { Monoclonal gammopathies } \\
\text { Systemic lupus erythematosus } \\
\text { Paraneoplastic neuropathy } \\
\text { Rheumatoid or psoriatic arthritis } \\
\text { (Primary) Amyloidosis } \\
\text { Chronic inflammatory } \\
\text { demyelinating } \\
\text { polyradiculoneuropathy (CIDP) } \\
\text { Vasculitis } \\
\text { Guillain-Barré syndrome } \\
\text { Autoimmune autonomic } \\
\text { ganglionopathy } \\
\text { Scleroderma } \\
\text { Behcet disease } \\
\text { Churg-Strauss syndrome } \\
\text { Anti-sulfatide antibodies } \\
\text { Anti-trisulfated heparin } \\
\text { disaccharide antibodies }\end{array}$ & $\begin{array}{l}\text { Infectious } \\
\text { Human immunodeficiency virus } \\
\text { (HIV) } \\
\text { Hepatitis B/C } \\
\text { Leprosy } \\
\text { Lyme disease } \\
\text { Epstein-Barr virus } \\
\text { Influenza } \\
\text { Critical illness or severe sepsis } \\
\text { Herpes simplex infection } \\
\text { Mycoplasma pneumonia } \\
\text { Rubella } \\
\text { Antecedent viral infection } \\
\text { Syphilis } \\
\text { Rabies vaccination } \\
\text { Varicella } \\
\text { Diphtheria } \\
\text { Chagas disease } \\
\text { Botulism }\end{array}$ & $\begin{array}{l}\text { Hereditary } \\
\text { Sodium channel gene mutations } \\
\text { Primary erythermalgia } \\
\text { Fabry disease } \\
\text { Haemochromatosis } \\
\text { Familial amyloidosis } \\
\text { Hereditary sensory autonomic } \\
\text { neuropathies } \\
\text { Autosomal recessive hereditary } \\
\text { neuropathy } \\
\text { Pompe disease } \\
\text { Ross syndrome } \\
\text { Tangier disease } \\
\text { Friedreich ataxia } \\
\text { Cerebrotendinous } \\
\text { xanthomatosis } \\
\text { Familial burning feet syndrome } \\
\text { Spinocerebellar Ataxia } 3 \\
\text { Charcot-Marie-Tooth } \\
\text { Mitochondrial disease } \\
\text { Acute intermittent porphyria } \\
\text { Generalized anhidrosis }\end{array}$ \\
\hline
\end{tabular}

Legend to table 1 . This tables summarizes all the different conditions that are mentioned in the literature to be associated with SFN. 
For some of the above-mentioned conditions, data have been provided regarding a pathophysiological mechanism leading to small nerve fibers damage. Some of these conditions are briefly discussed in the following:

- Diabetes mellitus (DM) is one of the best-known underlying diseases of painful neuropathies. It is believed that hyperglycemia-mediated superoxide overproduction may lead to micro vascular complications via various pathways. ${ }^{24}$ But also other mechanisms of action are described, like an increase in inflammatory markers in the dorsal root ganglia (DRG). ${ }^{25}$ However, even though these mechanisms might explain how the small nerve fibers are damaged, it still leaves us with some questions. Part of the patients with diabetes mellitus will develop a painful neuropathy as a complication of the disease, while others develop a non-painful neuropathy, and another subset does not develop a neuropathy at all. Moreover, next to neuropathic pain, also nociceptive pain occurs in DM. ${ }^{26}$ Nociceptive pain is a result of injury of tissues, for example because of ischemia damaging the blood vessels and tissues. Which factors contribute to the susceptibility for developing a painful neuropathy are largely unknown. This also illustrates that a condition may be related to SFN, but may not directly cause SFN. ${ }^{27}$

- Sodium channels play an important role in neuropathic pain. The SCN9A-, SCN10A-, and SCN11A-gene are encoding for $\mathrm{Na}_{\vee} 1.7, \mathrm{Na}_{\vee} 1.8$, and $\mathrm{Na}_{\vee} 1.9$ respectively, which are preferentially expressed in the peripheral nerves and the DRG neurons. Gain-of-function mutations in these genes are found in around $15 \%$ of the patients with SFN ${ }^{20,28}$ and can cause increased firing frequency and spontaneous firing of the neurons of the DRG. ${ }^{29-34}$ These changes may lead to a decreased neurite length, but no DRG neuron death occurs. ${ }^{29}$

Even though the screening of underlying conditions in patients with SFN is very comprehensive, in half of the patients, no conditions can be found and these patients are still idiopathic after an extensive diagnostic work up..$^{20-22}$ This might suggest that there are still unknown internal/external mechanisms that cause damage to the small nerve fibers, such as other gene mutations leading to hyperexcitable neurons or intracellular deficits leading to a disturbed axonal transport.

\section{Treatment of neuropathic pain in SFN}

About $5-10 \%$ of the general population is suffering from neuropathic pain, ${ }^{35}$ which is caused by a disease or lesion that affects the somatosensory nervous system. ${ }^{36}$ Patients with SFN are suffering from excruciating neuropathic pain, having a negative impact on their quality of life. ${ }^{37}$ Therefore adequate treatment is desirable. There are different types of drugs that are used to reduce the symptoms of SFN, i.e. anticonvulsants, antidepressants, opioids, and topical agents. In chapter 4, the different therapeutic possibilities are mentioned with their known pathophysiological aspects, side effects and precautions. Especially in the elderly, a large proportion of patients with SFN (19\% begins at the age of 65 years or older), the treatment is more challenging because of frequent comorbidity and the use of co-medication. ${ }^{38}$ Therefore, other first-line treatments or another regimen of use of neuropathic agents might be considered compared to younger patients. 
Even though several drugs are available for the treatment of neuropathic pain, and practical treatment algorithms are available, still only $50 \%$ of the patients have demonstrated a $50 \%$ reduction of their pain experience, often with disturbing side effects. ${ }^{38,39}$ One of the crucial things is that all these medications are not very specific and are only used to reduce the symptoms, but not heal the patients or the small nerve fibers' damage. Therefore, we are in desperate need for new and more targeted treatment options.

Lacosamide is an anticonvulsant that selectively acts on the sodium channel $\mathrm{Na}_{v} 1.3, \mathrm{Na}_{\mathrm{v}} 1.7$, and $\mathrm{Na}_{\mathrm{v}} 1.8$. Next to this selectivity in sodium channels, lacosamide spares the channels with a normal activity and only inhibits the currents of hyperexcitable neurons. Thereby, it binds to the channels with a slow- or fast-inactivated state. ${ }^{40-46}$ Lacosamide has not been tested before in patients with SFN. In studies with painful diabetic neuropathy however, a reduction in neuropathic pain was found, although not robust. ${ }^{47-50}$ In chapter 5 , the rationale and the design of the Lacosamide-Efficacy-' $N^{\prime}$-Safety in SFN (LENSS-study) is explained in detail.

The LENSS-study was a randomized, double-blinded, placebo-controlled crossover trial. The primary objective of this study was to evaluate the efficacy of lacosamide versus placebo in subjects with SCN9A-associated SFN. The primary efficacy endpoint was defined as at least a 1-point decrease on the daily pain intensity numerical rating scale (PI-NRS) and the secondary efficacy endpoint at least a 2-point decrease. These efficacy outcomes were chosen as such based on the IMMPACT recommendations. ${ }^{51}$ Other secondary objectives were the evaluation of the safety and tolerability of lacosamide, and the effect of lacosamide versus placebo on autonomic symptoms, daily sleep interference, and quality of life.

To assure that the study results could be interpreted with sufficient power and because SCN9Aassociated SFN is relatively rare, a crossover trial design was chosen. Another advantage of the crossover design was that the influence of confounders (e.g. age, gender distribution) could be reduced, since every patient will be his/her own control, an extremely important entity in a heterogeneous condition like SFN. Patients were given a dose of 200mg BID of lacosamide (and placebo in the other treatment period). This dose was selected based on previous studies, where it was shown that $200 \mathrm{mg}$ BID was effective and the side effects were acceptable, in contrast to a dose of $100 \mathrm{mg}$ BID which had few side effects but was less effective and $300 \mathrm{mg}$ BID which was effective however caused a lot of side effects. ${ }^{52}$ The treatment period for both lacosamide and placebo had duration of eight weeks. This was chosen because of the knowledge that the analgesic effect of the pain medication may take several weeks to occur. ${ }^{53}$

In Chapter 6 the results of the LENSS-study are described. ${ }^{54}$ In total 24 patients received lacosamide and 23 of them placebo. In 58.3\% the average pain decreased with at least 1 point on the PI-NRS during the lacosamide period, compared to $21.7 \%$ during the placebo period ( $p$ value $=0.0045$, with an odds ratio of 5.65 and a 95\% confidence interval of 1.83-17.41). A decrease of at least 2 point on the PI-NRS was found in 33.3\% in the lacosamide period and in $8.7 \%$ in the placebo period ( $p$-value $=0.0244$, with an odds ratio of 10.58 and a $95 \%$ confidence interval of 1.63-68.63). Additionally, in the lacosamide group, 33.3\% reported that their general condition improved, versus $4.3 \%$ in the placebo group ( $p$-value $=0.0156$ ), captured with the Patients' Global Impression of Change (PGIC) questionnaire. Other secondary 
outcomes showed that there was a significant positive effect on the daily sleep interference and there was a significant decrease in surface pain. In contrast, there was no significant improvement on quality of life or autonomic symptoms. The most common side effects of lacosamide were dizziness (41.7\%), nausea (25.0\%), and headache (25.0\%), which is in agreement with the known adverse event profile reported, although these were addressed as being mild. ${ }^{52}$ However, these complaints were also the most frequent adverse event during the placebo period (17.4\% for all three complaints). Furthermore lacosamide was safe to use. The results of this study are in line with the clinical experience that the current treatment possibilities cause a $50 \%$ reduction of the complaints in $50 \%$ of the patients. ${ }^{39,55}$ Based on the theoretical background of the working mechanism of lacosamide on this specific group of patients, a larger effect could be expected. Even though the effect was similar than in other drugs, in our study patients were allowed to continue most of their pain medication, and therefore the treatment effect may even be bigger in drug-naïve patients. Whether lacosamide is also beneficial in SFN patients without SCN9A mutations, remains to be investigated.

One can also question if the right outcome measure has been used to investigate the efficacy of the medicine. For this study, the primary efficacy endpoint was at least 1-point decrease on the PI-NRS, based on guidelines for painful neuropathic studies. ${ }^{51}$ There are a lot of different outcome measures regarding measuring the effect on pain, the 1-point or 2-point decrease on the PI-NRS can be used, but also a $30 \%$ or $50 \%$ reduction from baseline on the PI-NRS is mentioned. ${ }^{51}$ Perhaps we should not look at these numbers since these are simple ordinal metrics with no numerical value, but we have to start listening to our patients and take their response's addressing voices into account. A patient score going from 8 to 7 , does not per se mean anything, since the patient may still feel terrible. Or what if a patient's pain goes from 6 to 5 , but they feel much better? Therefore, we should focus more on patients' response questionnaires like the Patients' Global Impression of Change (PGIC) addressing the clinical meaningfulness of their personal experience rather than looking at these insignificant numbers or multidimensional scales. ${ }^{56} 57$

In the LENSS study, no significant effect of lacosamide on the autonomic symptoms was found. An explanation could be that the side effects that are caused by using lacosamide mask the effect of lacosamide on the autonomic symptoms, because they are comparable; for example, dizziness is an autonomic symptom, but also a side effect of lacosamide. So the questionnaire to register autonomic symptoms might be influenced by the presence of similar side effects. The influence of small fiber neuropathy on the quality of life of these patients has been investigated earlier. ${ }^{37}$ The biggest declines were found in the domains of physical role of functioning and body pain. ${ }^{37}$ By decreasing the intensity of pain in these patients with lacosamide, it could be expected that the quality of life would increase because the role of body pain would decrease. However, in this study this was not found, not even in the pain domain, which could be explained by a study period that was too short ( 8 weeks) to notice a significant reduction in quality of life.

To conclude, the study showed that lacosamide is an effective, safe and tolerable treatment for SCN9A-associated SFN. However, the study has to be confirmed in a larger cohort and in patients without an SCN9A-variant before proposing the therapeutic use of this drug. 
The LENSS-study is an example of a study that investigates a drug that is more targeted than other current available treatment possibilities for SFN. However, a targeted approach is only possible when the target is known. As mentioned earlier, in a large proportion of patients with SFN no underlying conditions have been found. However, the question is what to do if there is no defined underlying condition? In patients with SFN, a role of the immune system is suggested in those with associated diseases, such as sarcoidosis, Sjogren disease, and celiac disease. ${ }^{23,58,59}$ Also the presence of inflammatory changes, ${ }^{60}$ autoantibodies, ${ }^{61,62}$ and elevated cytokines ${ }^{63}$ provide some support for the hypotheses that in SFN the immune system plays an important role, even in absence of immune-mediated diseases. Without knowing the specific disturbance in the immune system, there are treatment possibilities based on this hypothesis. Based on literature review, some open-labelled studies in patients with painful neuropathies treated with intravenous immunoglobulin (IVIg) have shown substantial relief, justifying the exploration of IVIg as a new treatment modality in SFN in a more extensive manner. ${ }^{64,65}$

Chapter 7 describes a randomized, double-blinded, placebo-controlled, parallel study evaluating the efficacy and safety of IVIg in patients with predominant SFN complaints. ${ }^{66}$ The study design has been adopted from the landmark paper of IVIg in the treatment of patients with chronic inflammatory demyelinating polyradiculoneuropathy (ICE trial), ${ }^{67}$ starting with a loading dose of IVIg of $2 \mathrm{~g} / \mathrm{kg}$ body weight given over 2-5 days. After that, patients will be receiving a maintenance dose of $1 \mathrm{~g} / \mathrm{kg}$ body weight IVIg every three weeks for three months, with an extension period after the randomization period of three months to determine the long-term effect of IVIg on pain. This is the first randomized clinical trial that will be investigating the efficacy, safety, and tolerability of IVIg in patients with idiopathic SFN. Patients randomized to placebo, will get the same treatment regimen. The study is currently running and aims to include 60 patients. The primary outcome will be a 1-point decrease change in the PI-NRS from baseline. Secondary outcomes will be 2-point decrease change in the PI-NRS from baseline, the influence of IVIg on autonomic symptoms, daily sleep interference, and quality of life. Because all of these outcome measures are based on questionnaires, also an objective outcome measure has been included, namely the cornea confocal microscopy. ${ }^{68}$ This is a technique that can detect nerve fiber loss but also nerve fiber regeneration, investigated thoroughly in patients with diabetes mellitus. ${ }^{69,70}$ In this sub-study, only patients with an abnormal skin biopsy and no underlying conditions (idiopathic SFN) will be examined. If IVIg is proven to be effective, more insight could be obtained to examine the underlying pathophysiology in patients with idiopathic SFN. 


\section{Future perspectives}

In this thesis, more insight is provided regarding the underlying conditions that are prevalent in patients with SFN. In addition, new treatments are investigated, not only to give more possibilities for patients to reduce their complaints, but also to gain more insight into the pathophysiology of SFN. So all studies that are described in this thesis contribute to the knowledge on SFN, but also generate more research questions, which can be investigated in the future.

\section{Diagnostics and clinical outcome measures}

The complaints of SFN are mostly subjective feelings, which are difficult to measure objectively. At the moment, skin biopsy and temperature threshold testing are used to confirm the diagnosis of SFN. ${ }^{9,18}$ However, the intensity of pain, different pain sensations, quality of life, and autonomic symptoms should all be evaluated by questionnaires because of the lack of an objective measurement. This could lead to biased results, as mentioned above in the LENSS study, where the influence of lacosamide on autonomic symptoms might be influenced by the occurrence of side effects, which are not differentiated through the questionnaire. Future studies should aim to develop a tool that can measure the autonomic function.

In addition to objectifying more symptoms of SFN, it would be very worthwhile to have a diagnostic tool, which can be used in clinical trials.

Skin biopsy is used at the moment as the golden standard to diagnose SFN, together with the temperature threshold testing. However, the sensitivity of the skin biopsy is moderate. When the intraepidermal nerve fiber density (IENFD) is normal in patients with possible SFN, it could suggest that there is no SFN, but it is also possible that there is a pre-degenerative functional impairment of the small nerve fibers, which cannot be detected with the current skin biopsy method. It is known that the IENFD decreases with increasing age ${ }^{71}$ and the IENFD is stable within a 3-week period and for right and left side. ${ }^{72}$ The decreasing IENFD in aging might be due to the aging of the central nervous system. ${ }^{73}$

A small study investigated the longitudinal trend of the IENFD in patients with idiopathic SFN $(n=25)$, found no different degree of decrease in IENFD compared to patients with SFN and diabetes mellitus or glucose intolerance. ${ }^{74}$ It would be of interest to compare the decrease in IENFD in patients with (complaints of) SFN and healthy subjects. Besides, the proximal/distal IENFD ratio can give more insight and be of value for diagnosing SFN. ${ }^{75}$ Currently, the distal IENFD is used for diagnosing SFN. The ratio between the proximal and distal IENFD is investigated sparsely. One study showed that there was a greater reduction in the IENFD of the distal leg compared with the thigh, resulting in an elevated proximal/distal IENFD ratio, compared to healthy controls. ${ }^{76,77}$ The use of the longitudinal course of the distal IENFD and/or the use of the proximal/distal IENFD ratio, in addition to the current one-time distal IENFD might be an enrichment for the diagnostic workup for SFN.

Skin biopsy is an invasive, time-consuming and expensive method for diagnosing SFN. In the Bowman's membrane of the cornea, the nerve endings of the unmyelinated C-fibers from the trigeminal nerve can be seen. ${ }^{78}$ Corneal confocal microscopy (CCM) is a non-invasive method that detects these nerve fibers and nerve fiber loss in the cornea, with a high repeatability. ${ }^{79}$ 
This method has been primarily applied in patients with diabetes mellitus. ${ }^{80}$ In two small studies, a decrease in the corneal nerve fiber density was found in patients with SFN. ${ }^{69,81}$ Subsequently, it was also shown that CCM was not only useful to prove nerve fiber loss, but also nerve fiber regeneration after pancreas and kidney transplantation in patients with diabetes mellitus. ${ }^{70}$ Therefore, CCM might be useful as a diagnostic tool to diagnose (nonlength-dependent) SFN, and perhaps also as an objective outcome measure in clinical trials. Because of this, the CCM was included in the IVIG in SFN study.

All of the above-mentioned methods are based on the peripheral mechanisms that are known in SFN. However, this focus should be widened to also understand other potential pathophysiological mechanisms of pain in these patients like the (central) processing of pain stimuli. This entity is thought to be very complex, including different regions of the brain, like the cortex, subcortical structures and the midbrain. ${ }^{82}$ In addition, chronic pain may lead to structural changes in the brain. ${ }^{83}$ The pattern of these changes may differ among different pain syndromes and may be reversible. ${ }^{84}$ Functional imaging of the brain has shown specific brain activity patterns in patients with pain. ${ }^{85,86}$ To date, there is no objective tool to measure pain, but only questionnaires are available like the neuropathic pain scale (NPS), Pain Intensity Numeric Rating scale (PI-NRS), or the Visual Analogue Pain Scale (VAS). Functional MRI (fMRI) data can provide more insight into the specific pathways of neuropathic pain in SFN. Additionally, the fMRI can possibly be used in the future as a biomarker for evaluation in clinical trials. This technique may also elucidate differences that might reflect the heterogeneity of SFN, as has been demonstrated in patients with migraine. ${ }^{87}$

The finding of new biomarkers could be very helpful in conditions like SFN. ${ }^{88}$ With the finding and presence of biomarkers, patients can be stratified in different groups, new treatment targets arise, and more personalized treatments can be given. ${ }^{89}$ Besides, specific biomarkers can create an opportunity to grade disease severity, which is not possible at current stage.

In the literature some biomarkers are linked to neuropathic pain. Post-transcriptional regulator molecules, microRNAs, are reported to be dysregulated in patients with pain. ${ }^{90}$ MicroRNAs are crucial micro-modulators of normal cellular homeostasis, and dysregulation has been associated with different conditions such as cancer, ${ }^{91}$ cardiovascular diseases, ${ }^{92}$ and neurodegenerative disorders. ${ }^{93}$ In animal pain models, microRNA modulation is present in different levels, like the sciatic nerve, DRG, spinal dorsal horn and the brain. ${ }^{90}$ Additionally, it has been found that microRNAs control sodium channel expression. ${ }^{94}$ Besides the finding that microRNAs have a potential of being a specific biomarker for neuropathic pain, it could possibly also create new therapeutic possibilities, as shown in animal models. ${ }^{95,96}$ Because microRNAs are present in all biofluids, it can be searched for in patients with SFN in the blood or in the cerebrospinal fluid as is done in other pain conditions. ${ }^{97,98}$

Also cytokine-related biomarkers have been found in neuropathic pain, for example anti-tumor necrosis factor (TNF)- $\alpha$. Upregulated TNF- $\alpha$ is believed to play a role in the development, facilitation, and maintenance of neuropathic pain. ${ }^{99-103}$ Thereby, it is shown that agents that antagonize TNF- $\alpha$ can reduce pain-behavior in animal models. ${ }^{104,105}$

A totally different biomarker that is mentioned in literature, is objectifying the hyperexcitability of the small nerve fibers, for example with microneurography. The finding that in patients with neuropathic pain due to peripheral neuropathy a large proportion of the nociceptors had a 
significant ongoing activity, led to the hypothesis that microneurography could be a biomarker for pain. ${ }^{106}$ Microneurography can record the peripheral C-nociceptors in humans and aminals, ${ }^{107}$ which make it an interesting method to be used in clinical trials.

A targeted approach can be used to search for the above-mentioned biomarkers in SFN. An untargeted approach can also be considered, although this has some advantages and disadvantages. This cohort of patients is probably very heterogeneous, which might make it very difficult to find a specific biomarker, compared with subgroups (for example idiopathic SFN patients with abnormal skin biopsy). However, this group is very suitable because of the large sample size for modern statistical techniques, like machine learning with which biomarkers can be identified out of large datasets. ${ }^{108,109}$

To find these biomarkers, different methods are described, for example metabolomics or proteomics. Metabolomics is the profiling of metabolites, with nuclear magnetic resonance spectroscopy, $^{110}$ mass spectrometry, ${ }^{111}$ gas chromatography, ${ }^{112}$ or liquid chromatography. ${ }^{113,114}$ The analysis can be targeted (quantitative analyses of a substrate or product metabolites of a target protein), untargeted (overview of whole-cell metabolic patterns), or metabolic profiling can be performed (quantitative analyses of a set of predefined metabolites). Proteomics is the quantitative analyses of the composition of proteins in a cell, tissue, or organism.

A recent study investigated metabolomics and proteomics in sciatic nerves in diabetic and healthy control rats. Alterations in the metabolic lipids were found, which were more present distal than proximal. In addition, increased proteins were found in the sural nerve and not more proximal. ${ }^{115}$ These findings gave more insight in the consequences of diabetes mellitus and the influence on the nerve fibers. This is one example of how metabolomics or proteomics can provide more insights in underlying pathophysiological mechanisms, but may also reveal specific biomarkers.

In many diseases, the correlation between subjective and objective measures is weak. ${ }^{116}$ Thereby, subjective measurements are highly variable and therefore only really useful when the effect of an intervention is large. The invention of objective tools to measure the function of the nerve fibers or autonomic symptoms or the discovery of biomarkers is therefore an important step. However, we should also focus on the opinion of the patients and listen to what they have to say. What does improvement of a biomarker following treatment mean if the patient is still having the same complaints? Do we conclude that our treatment is effective or not? Therefore, we should, besides objective measurements, include the opinion of the patient (like the PGIC). Or maybe the disability and functionality of patients should be taken more into consideration, with for example the small fiber neuropathy Rasch-built overall disability (SFN-RODS) as an option. ${ }^{117}$ Moreover, the opinion of the patient should also be used in designing studies, making decisions, and evaluating treatments. With this we can shift our focus from statistical significance to clinical relevance. ${ }^{118}$ Shared-decision making is defined as an approach where patients and clinicians share the best available evidence in order to make a decision, where patients are supported to consider different options and point out their preference. ${ }^{119,120}$

Lately, shared-decision making is more and more used in clinical practice. However, it has been known for a long time that patients prefer to have experts perform the problem-solving tasks, 
but wish to take an active role in decision making. ${ }^{121}$ Shared-decision making was first proven to be effective in serious or life-threatening conditions, when different therapies exist with different benefits and risks. ${ }^{122,123}$ Shared decision-making is also useful in situations where outcomes are uncertain. For neuropathic pain, current treatment possibilities are not satisfactory at the moment, as discussed earlier. Therefore, when patients with SFN start using one of these therapies, the result is uncertain (trial and error approach). It is shown that the implementation of shared-decision making in pain management will increase the satisfaction of patients. ${ }^{124,125}$ Because pain is a multidimensional entity, shared-decision making could lead to a more bearable experience of their complaints.

In studies, quantitative data is often used without the presence of qualitative data. Quantitative data consists of close-ended information, such as rating scales and other questionnaires. On the other hand, qualitative data consists of open-ended information that is gathered for example by interviews and focus groups. The addition of qualitative data can be used to elaborate, clarify, or build on findings from other methods, but also for looking at a research question from different angels, for example from a patients perspective or other caregivers. With this we can evaluate why patients think their quality of life is diminished, or which other things they experience because of SFN. Or focus groups with clinical experts from different disciplines can be organized, to develop new ideas, insights or theories. So for some research questions a single research method might not be enough. ${ }^{126}$ Mixed methods analyses are used to combine these two types of data by triangulation. ${ }^{127}$ The combination provides strengths that can neutralize the weaknesses of both quantitative (weak knowledge of context) and qualitative (biased interpretations) research.

Mixed methods analyses and shared-decision making are two examples in which patients and physicians are 'forced' to talk and listen to each other. However, also the communication between patients themselves should be stimulated. Patient can give advice or share experiences with each other. It would be beneficial to create a platform in which patients can be in contact with each other, but also caregivers and physicians should be a part of this. Working together can on the one hand improve the patient care, but on the other hand also gain new ideas or insights. In epilepsy, for example, it is shown that an online platform benefits in finding other patients experiencing the same symptoms and learning more about the symptoms and treatments. ${ }^{128}$

In line with this, one could also think about making a mobile application wherein patients can monitor their complaints, for example with questionnaires or diaries.

\section{Associated conditions and pathophysiology}

To confirm if some underlying conditions, which are found in patients with SFN, are really a cause of the disease, more studies should be conducted. In diabetes mellitus, a lot of animal studies are already performed. ${ }^{129-131}$ This should also be executed (more) for other conditions like vitamin B12 deficiencies and autoimmune disorders. When knowing the exact underlying pathophysiology of these conditions, this could lead to possible treatment options. The advantage of interfering with these pathways with for example targeted drugs, is that the disease could possibly be solved and the nerve fibers can be regenerated, instead of symptom reduction as we do with our current practice. 
When potential underlying mechanisms are hypothesized, animal models can give evidence for this. For example, mouse models can be used, in which some mice are exposed to the hypothesized underlying mechanism, and the others don't. After that, differences can be visualized, like pain, anxiety, and distress. ${ }^{132}$ It would also be interesting to investigate if all animals exposed to that mechanism develop the same complaints. Animal models can also be used to see the effect of different levels of biomarkers, again to prove their causality. ${ }^{133}$ In models for sodium channel gene mutations, often zebra fish are being used. ${ }^{134}$ In these, transfected lines can be created, with the mutation of interest, and compared to the wild types. On the one hand, these animal models can be used to search and prove underlying mechanisms. On the other hand, they are of importance for testing different treatment possibilities.

The finding of mutations in the sodium channels $\mathrm{Na}_{v} 1.7,{ }^{32} \mathrm{Na}_{v} 1.8,{ }^{33}$ and $\mathrm{Na}_{v} 1.9,{ }^{34}$ was a large breakthrough in SFN, and has led to more insight in the pathophysiology, and to new treatment possibilities, for example with pharmacogenomics. ${ }^{135}$ In addition, this has led to the idea that maybe other sodium channels or other mechanisms might also be responsible for neuropathic pain in SFN. In DRG, sodium channels $\mathrm{Na}_{v} 1.3$ and $\mathrm{Na}_{v} 1.6$ are also present and seem to have a role in pain as well. ${ }^{28,136-140}$

However, sodium channels are working together with other channels and have some corresponding characteristics. Potassium and calcium channelopathies have also been associated with pain. ${ }^{141}$

To investigate which other gene mutations are present in patients with chronic neuropathic pain, next generation sequencing (NGS) like whole exome sequencing (WES) or whole genome sequencing (WGS) can be used as an untargeted approach, while the analysis of candidate genes can be a useful targeted method. The PROPANE study group aimed to identify why patients with a common associated condition can have different phenotypes, for example a painful or painless neuropathy in patients with DM. The findings of this study will be published soon, hopefully providing us more insights into the genetic background. ${ }^{34,142}$ The advantage of WES analyses is that not only preselected variants can be found, so it is an example of an unbiased molecular-genetic approach. ${ }^{143}$ With this, new insights can be gained and a possible explanation for the $50 \%$ of idiopathic patients can be found. However, WES analyses also have disadvantages. With this technique, various variants will be found in even only one person. When searching for common variants in a cohort, even more different results will arise. For this, again machine learning or clustered data analyses can solve this, to search for correlations even between different variants in relation to patient's personal determinants like age, gender, educational level, habits, occupation, etc.

Although sodium channel gene mutations have been proven to be responsible for the clinical picture in a proportion of patients suffering from SFN, it is remarkable that there is a marked clinical heterogeneity between these patients, even when the same mutation is found. ${ }^{144}$ Furthermore, in some patients a trigger (like a viral infection, trauma, operation, severe exercise, pregnancy of vaccination) precedes the clinical symptoms. Since all these factors demand a lot of energy of the body, dysfunction of mitochondria might be an explanation. In case the energy supply or reserves are not sufficient, this may lead to nerve damage. Both in the central and in the peripheral nervous system neurons have a high-energy demand, which 
is reflected by the high number of mitochondria in these cells. ${ }^{145}$ Especially unmyelinated neurons and the nerve endings contain mitochondria. ${ }^{146,147}$ Dysfunctional mitochondria or a disturbed migration of healthy mitochondria to the nerve endings can result in a disturbance of different steps in the oxidative phosphorylation. Peripheral neuropathic pain has been shown to be a result of ATP-depletion, an elevation of free radicals or inadequate calcium buffering in the cell. ${ }^{146}$ When the ATP-production is too low this might lead to a dysfunctional $\mathrm{Na}^{+} / \mathrm{K}^{+}$-pump, leading to abnormal firing of the neurons. ${ }^{147} \mathrm{~A}$ combination of a high sodium influx in sodium channel gene mutations and dysfunctioning mitochondria, will lead to a reverse-mode $\mathrm{Na}^{+} / \mathrm{Ca}^{2+}$ exchange because of the increased intracellular sodium level, resulting in import of calcium into the cell, rising to toxic levels and causing cell death. ${ }^{148-150}$

But also defects in the mitochondrial dynamics might contribute to the origin of SFN. Since most patients show a length-dependent pattern, disturbances in the axonal transport or mitochondrial fusion or fission could be responsible for the nerve endings damage. ${ }^{150-152}$ Already, in other hereditary neuropathies of the Charcot-Marie-Tooth spectrum these mechanisms have been shown to be pathogenic. ${ }^{151}$ Both DNA-analysis of mtDNA or nuclear DNA responsible for the mitochondrial dynamics genes might be of interest in SFN.

Also epigenetic mechanisms might play a role in the pathophysiology of SFN. ${ }^{153}$ These mechanisms can enhance or suppress gene expressions, without altering the primary DNA sequence. ${ }^{154}$ This may explain why some people are carrying for example an SCN9A-gene mutation, without having complaints, while a different person with the same variant does have complaints of SFN. It may also provide the explanation for the development of SFN symptoms later in life in patients carrying a sodium channel gene mutation. Epigenetics may therefore be an important link between acquired and hereditary causes.

\section{Treatment}

There is high demand for new treatment possibilities. The current available medications are not effective in all patients and have side effects that can be very bothersome.

At this time, more targeted treatments are being investigated. Lacosamide is a sodium channel blocker that is selectively blocking sodium channels $\mathrm{Na}_{v} 1.3, \mathrm{Na}_{v} 1.7$, and $\mathrm{Na}_{v} 1.8 .{ }^{42}$ At present, sodium channel blockers with a high selectivity for $\mathrm{Na}_{v} 1.7$ are being investigated. Such a selective sodium channel blocker was studied in trigeminal neuralgia. ${ }^{155}$ Even though this was a Nav1.7-selective and state-dependent sodium channel blocker, the response in pain reduction was again similar as the current medications, a 50\% reduction in paroxysms in $60 \%$ of the patients with the use of the selective sodium channel blocker, compared to $21 \%$ in the placebo group. In addition to the comparable pain effect, additionally side effects occurred similar to the side effect profile of current available medications, e.g. headache and dizziness. So it might be a utopia to expect that a selective and targeted approach always will lead to better efficacy and fewer side effects. This might be explained by the idea that some underlying conditions of SFN are not causative alone, and thereby other pathways play a role at the same time. A more recent study investigated a different $\mathrm{Na}_{v} 1.7$ blocker in a randomized, placebocontrolled, double-blinded study. ${ }^{156}$ However, this agent showed no statistically significant decrease in the average pain score. Besides, the effect was even lower than seen in pregabalin study. The past years, a lot of patents are treated with sodium channel blockers. ${ }^{157}$ The future 
will show if this is the right direction and the solution for patients with SFN. One could also speculate whether studies combining different agents could provide via different action mechanisms more relief to the experience of pain.

Until now, it is still unclear why some patients respond to treatment and others don't. For this, it would be very useful to have some patient-specific factors known that influence the drug response. A recent study started to search for associations between underlying conditions and the response on neuropathic pain medication. They found that diabetes mellitus had an impact on the effect of anticonvulsants and the duration of pain had an impact on the effect of antidepressants on neuropathic pain. ${ }^{158}$

The genetic and functional findings in SFN may lead to the development of new targeted treatments. This can also be supported by pharmacogenomics. As mentioned earlier, not all patients with SFN respond to the current available treatments in the same way and even the side effects differ between patients. Pharmacogenomics may be an additional tool to predict the variability in treatment efficacy and side effects. ${ }^{159} \mathrm{~A}$ few experiments already showed that with pharmacogenomics, it could be predicted if the hyperexcitability of nerve fibers due to a specific SCN9A mutation is reduced by a specific treatment, or not. ${ }^{160,161}$ With these results, eventually prediction models can be developed to be used in daily clinical practice. In the long term, this may lead to higher satisfaction of the patients and lower health care costs. However, when it is predicted that a specific treatment should work in specific patients, naturally this should still be proven in practice, as for example is done in patients with erythromelalgia. ${ }^{162}$

Targeting the sodium channels may be of interest in patients having mutated channels (about $15 \%$ of the patients), though other patients may also benefit from sodium channel blockers. In over $50 \%$ of the SFN patients no underlying condition can be found. However, for new treatment possibilities for these idiopathic patients, we should think about possibilities that are beyond the current knowledge of the pathophysiology. One of these new ideas is the use of intravenous immunoglobulins in SFN. The results of the IVIg in SFN study will become available in 2019. If positive, a lot of new research questions will arise, to figure out how this treatment works in these patients, which patients would benefit, and what treatment regime should be used and for how long. To ensure health insurance coverage and registration of IVIg as a treatment option for patient with SFN, clear evidence of the efficacy should be available, and probably future confirmation studies should also investigate the cost-effectiveness of this treatment. In extension to this study, the benefit of other immunomodulating therapies in SFN may also be hypothesized

Corticosteroids are working via various mechanisms, for example inhibition of the T-celldependent immunity and interfering with cytokines of which TNF- $\alpha$ is an example. ${ }^{163}$ As mentioned earlier, there are suggestions that TNF- $\alpha$ is a biomarker in neuropathic pain, so corticosteroids might be effective. An example from current practice is the use of prednisone in patients with post-herpetic pain, ${ }^{164}$ as well as reduction of the pain resulting from a vasculitic neuropathy in HIV. ${ }^{165}$ There are also studies that investigate the role of biologicals as an alternative for chemical substances in chronic pain. Monoclonal antibodies (mAbs) are very specific and have a high affinity. ${ }^{166}$ However, the mAbs should attack the right targets to be effective. There are mAbs that inhibit TNF- $\alpha$, interleukin-1 or interleukin-6, in immunemediated conditions as rheumatoid arthritis. Therefore, it should be investigated if these are 
still effective in diminishing non-inflammatory pain. ${ }^{167}$ Biologicals can provide more specific and therefore safer alternatives in the future, though the high costs of these therapies are a limit to wide-spread use.

To take it one step further, maybe not only chemical or biological agents should be investigated more in the future, but it would be of interest to look more in depth into interventional methods, or combinations of these. Spinal cord stimulation could lead to a reduction of pain in chronic pain patients, based on the gate control theory and general principles of segmental pain inhibition. ${ }^{168-170}$ Or, should we even move more upwards, to the brain, for new interventions? It is hypothesized that abnormal synchronization between brain networks in chronic pain can be disrupted by deep brain stimulation DBS. ${ }^{171}$ Finally, repetitive transcranial magnetic stimulation is a noninvasive neuromodulation technique, which can possibly improve the efficacy of conventional medical treatments in chronic pain patients. ${ }^{172}$

Besides trying to treat SFN or diminish the symptoms, attention should be given to the consequences of the symptoms on patients' wellbeing. As described earlier, patients with SFN have a decreased quality of life, ${ }^{37}$ but also affective disorders like anxiety or depression have a high prevalence. ${ }^{173}$ High levels of depression and anxiety may worsen pain and pain-related disability. ${ }^{174}$ Therefore, trials regarding the effect of interventions focused on mood disorders or coping with pain are of great interest. Mindfulness therapy has been described to improve pain, as well as depression symptoms and quality of life. ${ }^{175}$ Furthermore, several trials have been performed with graded exposure or graded activity therapy in chronic pain, for example in chronic back pain. ${ }^{176,177}$ There is some evidence that both of them may be effective, however, these therapies are not tested yet in patients with SFN.

The oldest known non-pharmacological method for relieving pain is music. ${ }^{178}$ Pain can be diminished by passive music listening, called music-induced analgesia. Thereby, music can also diminish stress, depression and distress. ${ }^{179}$ Even a $70 \%$ greater probability of reporting a pain decrease of at least $50 \%$ and a reduction in opioid medication as a result of music listening is reported. ${ }^{179}$ In addition, changes on functional MRI are found. ${ }^{178}$

In patients with chronic neuropathic spinal cord injury pain, it is found that multidisciplinary cognitive behavioral programs improved pain intensity, pain-related disability, anxiety and participation. ${ }^{180}$ So finally, why use only one method, when combining therapeutic strategies (figure 1) might be even better? ${ }^{181}$ 
Figure 1. Multimodal treatment possibilies and shared-decision making.

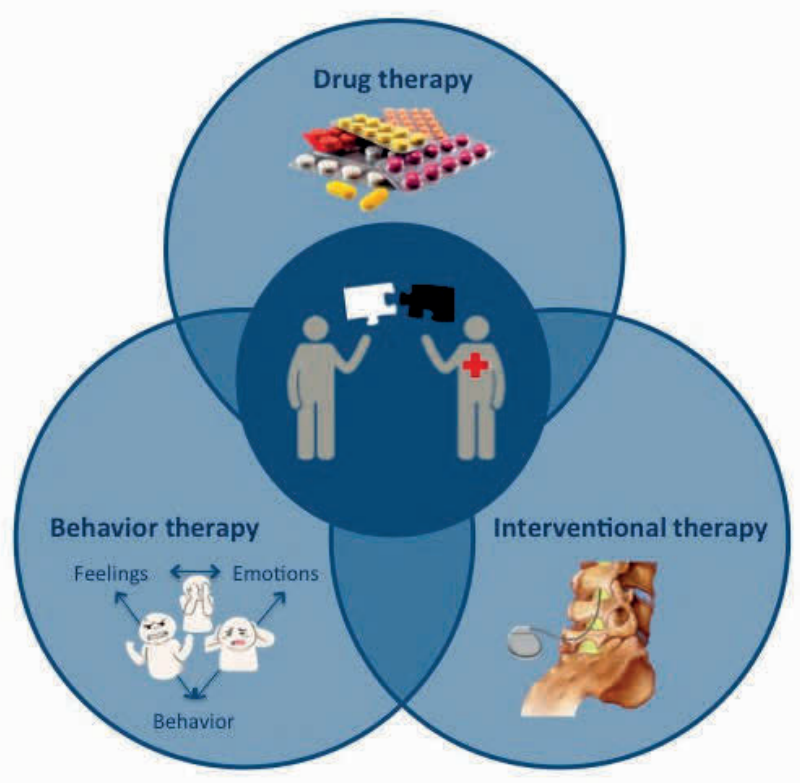

Legend to figure 1. This figure represents the mulitmodal treatment possibilities and shared-decision making in SFN. 


\section{Conclusions}

SFN is a condition resulting in a heterogeneous cohort of patients. Not only the complaints can differ between patients, there is also a variety of underlying conditions that can possibly cause damage to the small nerve fibers. However, in a substantial part of the patients no underlying potential cause can be demonstrated. The knowledge that some conditions are more prevalent in patients with SFN compared to healthy subjects, like diabetes mellitus (including impaired glucose tolerance), autoimmune diseases (including abnormal immunological laboratory findings), sodium channel gene mutations, and vitamin B12 deficiencies, could lead to more specific research in the future. Unraveling the exact pathophysiological pathways behind these conditions leading to SFN perhaps may lead to better treatment options. As an example, the finding of sodium channel gene mutations, led to a more selective treatment with lacosamide, which can be used possibly in the future as a treatment option for a broader group of patients with SFN after confirmative studies have been performed. More specific treatments might result in better pain relief with fewer side effects. However, new insights may also lead to the finding that SFN might not be caused by one mechanism on its own, but it is a more complex process. In all cases, other multimodal new therapeutic strategies should be considered in the approach of SFN, as it is a debilitating disorder.

As already mentioned in the introduction of this thesis, our aim is to work from the perspective of the patients, searching for associated conditions and biomarkers, revealing the pathophysiological mechanisms behind this, which may lead to new treatment possibilities; the entire process should be evaluated with the patients, and this cycle can then be repeated. From bench to bedside and back again: translational research is of great importance to finally rule out SFN. 


\section{References}

1. Biegstraaten M, Linthorst GE, van Schaik IN, Hollak CE. Fabry disease: a rare cause of neuropathic pain. Current pain and headache reports 2013; 17(10): 365.

2. El-Abassi R, Singhal D, England JD. Fabry's disease. Journal of the neurological sciences 2014; 344(1-2): 519.

3. Bertelsen AK, Tondel C, Krohn J, et al. Small fibre neuropathy in Fabry disease. Journal of neurology 2013; 260(3): 917-9.

4. Biegstraaten M, Binder A, Maag R, Hollak CE, Baron R, van Schaik IN. The relation between small nerve fibre function, age, disease severity and pain in Fabry disease. European journal of pain 2011; 15(8): 8229.

5. Biegstraaten M, Hollak CE, Bakkers M, Faber CG, Aerts JM, van Schaik IN. Small fiber neuropathy in Fabry disease. Molecular genetics and metabolism 2012; 106(2): 135-41.

6. de Greef BT, Hoeijmakers JG, Wolters EE, et al. No Fabry Disease in Patients Presenting with Isolated Small Fiber Neuropathy. PloS one 2016; 11(2): e0148316.

7. Tanislav C, Kaps M, Rolfs A, et al. Frequency of Fabry disease in patients with small-fibre neuropathy of unknown aetiology: a pilot study. European journal of neurology : the official journal of the European Federation of Neurological Societies 2011; 18(4): 631-6.

8. Samuelsson K, Kostulas K, Vrethem M, Rolfs A, Press R. Idiopathic small fiber neuropathy: phenotype, etiologies, and the search for fabry disease. Journal of clinical neurology 2014; 10(2): 108-18.

9. Hoeijmakers JG, Faber CG, Lauria G, Merkies IS, Waxman SG. Small-fibre neuropathies-advances in diagnosis, pathophysiology and management. Nature reviews Neurology 2012; 8(7): 369-79.

10. Terkelsen AJ, Karlsson P, Lauria G, Freeman R, Finnerup NB, Jensen TS. The diagnostic challenge of small fibre neuropathy: clinical presentations, evaluations, and causes. Lancet neurology 2017; 16(11): 93444.

11. Farhad K, Traub R, Ruzhansky KM, Brannagan TH, 3rd. Causes of neuropathy in patients referred as "idiopathic neuropathy". Muscle \& nerve 2016; 53(6): 856-61.

12. Themistocleous AC, Ramirez JD, Serra J, Bennett DL. The clinical approach to small fibre neuropathy and painful channelopathy. Practical neurology 2014; 14(6): 368-79.

13. Gibbons CH. Small fiber neuropathies. Continuum (Minneap Minn) 2014; 20(5 Peripheral Nervous System Disorders): 1398-412.

14. Bednarik J, Vlckova-Moravcova E, Bursova S, Belobradkova J, Dusek L, Sommer C. Etiology of small-fiber neuropathy. Journal of the peripheral nervous system : JPNS 2009; 14(3): 177-83.

15. Lauria G. Small fibre neuropathies. Current opinion in neurology 2005; 18(5): 591-7.

16. Hoitsma E, Reulen JP, de Baets M, Drent M, Spaans F, Faber CG. Small fiber neuropathy: a common and important clinical disorder. Journal of the neurological sciences 2004; 227(1): 119-30.

17. Lacomis D. Small-fiber neuropathy. Muscle \& nerve 2002; 26(2): 173-88.

18. Lauria G, Merkies IS, Faber CG. Small fibre neuropathy. Current opinion in neurology 2012; 25(5): 542-9.

19. Waxman SG, Merkies IS, Gerrits MM, et al. Sodium channel genes in pain-related disorders: phenotypegenotype associations and recommendations for clinical use. Lancet neurology 2014; 13(11): 1152-60.

20. de Greef BTA, Hoeijmakers JGJ, Gorissen-Brouwers CML, Geerts M, Faber CG, Merkies ISJ. Associated conditions in small fiber neuropathy - A large cohort study and review of the literature. European journal of neurology : the official journal of the European Federation of Neurological Societies 2017; 25(2): 34855.

21. Peters MJ, Bakkers M, Merkies IS, Hoeijmakers JG, van Raak EP, Faber CG. Incidence and prevalence of small-fiber neuropathy: a survey in the Netherlands. Neurology 2013; 81(15): 1356-60.

22. Devigili G, Tugnoli V, Penza P, et al. The diagnostic criteria for small fibre neuropathy: from symptoms to neuropathology. Brain 2008; 131(Pt 7): 1912-25.

23. Hoitsma E, Marziniak M, Faber CG, et al. Small fibre neuropathy in sarcoidosis. Lancet 2002; 359(9323): 2085-6.

24. Feldman EL. Oxidative stress and diabetic neuropathy: a new understanding of an old problem. The Journal of clinical investigation 2003; 111(4): 431-3. 


\section{Chapter 8}

25. Galloway C, Chattopadhyay M. Increases in inflammatory mediators in DRG implicate in the pathogenesis of painful neuropathy in Type 2 diabetes. Cytokine 2013; 63(1): 1-5.

26. Aslam A, Singh J, Rajbhandari S. Pathogenesis of painful diabetic neuropathy. Pain Res Treat 2014; 2014: 412041.

27. Hoeijmakers JG, Faber CG, Merkies IS, Waxman SG. Channelopathies, painful neuropathy, and diabetes: which way does the causal arrow point? Trends Mol Med 2014; 20(10): 544-50.

28. Dib-Hajj SD, Cummins TR, Black JA, Waxman SG. Sodium channels in normal and pathological pain. Annu Rev Neurosci 2010; 33: 325-47.

29. Persson AK, Liu S, Faber CG, Merkies IS, Black JA, Waxman SG. Neuropathy-associated Nav1.7 variant I228M impairs integrity of dorsal root ganglion neuron axons. Annals of neurology 2013; 73(1): $140-5$.

30. Huang J, Yang Y, Zhao P, et al. Small-fiber neuropathy Nav1.8 mutation shifts activation to hyperpolarized potentials and increases excitability of dorsal root ganglion neurons. The Journal of neuroscience : the official journal of the Society for Neuroscience 2013; 33(35): 14087-97.

31. Han C, Hoeijmakers JG, Liu S, et al. Functional profiles of SCN9A variants in dorsal root ganglion neurons and superior cervical ganglion neurons correlate with autonomic symptoms in small fibre neuropathy. Brain 2012.

32. Faber CG, Hoeijmakers JG, Ahn HS, et al. Gain of function Nav1.7 mutations in idiopathic small fiber neuropathy. Annals of neurology 2012; 71(1): 26-39.

33. Faber CG, Lauria G, Merkies IS, et al. Gain-of-function Nav1.8 mutations in painful neuropathy. Proceedings of the National Academy of Sciences of the United States of America 2012; 109(47): 194449.

34. Huang J, Han C, Estacion M, et al. Gain-of-function mutations in sodium channel Na(v)1.9 in painful neuropathy. Brain 2014; 137(Pt 6): 1627-42.

35. van Hecke O, Austin SK, Khan RA, Smith BH, Torrance N. Neuropathic pain in the general population: a systematic review of epidemiological studies. Pain 2014; 155(4): 654-62.

36. Treede RD, Jensen TS, Campbell JN, et al. Neuropathic pain: redefinition and a grading system for clinical and research purposes. Neurology 2008; 70(18): 1630-5.

37. Bakkers M, Faber CG, Hoeijmakers JG, Lauria G, Merkies IS. Small fibers, large impact: quality of life in small-fiber neuropathy. Muscle \& nerve 2014; 49(3): 329-36.

38. Brouwer BA, de Greef BT, Hoeijmakers JG, et al. Neuropathic Pain due to Small Fiber Neuropathy in Aging: Current Management and Future Prospects. Drugs \& aging 2015; 32(8): 611-21.

39. Finnerup NB, Attal N, Haroutounian S, et al. Pharmacotherapy for neuropathic pain in adults: a systematic review and meta-analysis. Lancet neurology 2015; 14(2): 162-73.

40. Amir R, Argoff CE, Bennett GJ, et al. The role of sodium channels in chronic inflammatory and neuropathic pain. The journal of pain : official journal of the American Pain Society 2006; 7(5 Suppl 3): S1-29.

41. Beyreuther BK, Freitag J, Heers C, Krebsfanger N, Scharfenecker U, Stohr T. Lacosamide: a review of preclinical properties. CNS drug reviews 2007; 13(1): 21-42.

42. Errington AC, Stohr T, Heers C, Lees G. The investigational anticonvulsant lacosamide selectively enhances slow inactivation of voltage-gated sodium channels. Molecular pharmacology 2008; 73(1): 157-69.

43. Faber CG, Hoeijmakers JG, Ahn HS, et al. Gain of function Nanu1.7 mutations in idiopathic small fiber neuropathy. Annals of neurology 2012; 71(1): 26-39.

44. Han C, Hoeijmakers JG, Ahn HS, et al. Nav1.7-related small fiber neuropathy: Impaired slow-inactivation and DRG neuron hyperexcitability. Neurology 2012; 78(21): 1635-43.

45. Rogawski MA, Tofighy A, White HS, Matagne A, Wolff C. Current understanding of the mechanism of action of the antiepileptic drug lacosamide. Epilepsy research 2015; 110: 189-205.

46. Jo S, Bean BP. Lacosamide Inhibition of Nav1.7 Voltage-Gated Sodium Channels: Slow Binding to FastInactivated States. Molecular pharmacology 2017; 91(4): 277-86.

47. Rauck RL, Shaibani A, Biton V, Simpson J, Koch B. Lacosamide in painful diabetic peripheral neuropathy: a phase 2 double-blind placebo-controlled study. The Clinical journal of pain 2007; 23(2): 150-8.

48. Shaibani A, Fares S, Selam JL, et al. Lacosamide in painful diabetic neuropathy: an 18-week double-blind placebo-controlled trial. The journal of pain : official journal of the American Pain Society 2009; 10(8): 818-28. 
49. Wymer JP, Simpson J, Sen D, Bongardt S, Lacosamide SPSG. Efficacy and safety of lacosamide in diabetic neuropathic pain: an 18-week double-blind placebo-controlled trial of fixed-dose regimens. The Clinical journal of pain 2009; 25(5): 376-85.

50. Ziegler D, Hidvegi T, Gurieva I, et al. Efficacy and safety of lacosamide in painful diabetic neuropathy. Diabetes care 2010; 33(4): 839-41.

51. Dworkin RH, Turk DC, Wyrwich KW, et al. Interpreting the clinical importance of treatment outcomes in chronic pain clinical trials: IMMPACT recommendations. The journal of pain : official journal of the American Pain Society 2008; 9(2): 105-21.

52. Zaccara G, Perucca P, Loiacono G, Giovannelli F, Verrotti A. The adverse event profile of lacosamide: a systematic review and meta-analysis of randomized controlled trials. Epilepsia 2013; 54(1): 66-74.

53. Park HJ, Moon DE. Pharmacologic management of chronic pain. Korean J Pain 2010; 23(2): 99-108.

54. de Greef BT, Merkies IS, Geerts M, Faber CG, Hoeijmakers JG. Efficacy, safety, and tolerability of lacosamide in patients with gain-of-function Nav1.7 mutation-related small fiber neuropathy: study protocol of a randomized controlled trial-the LENSS study. Trials 2016; 17(1): 306.

55. Attal N, Cruccu G, Baron R, et al. EFNS guidelines on the pharmacological treatment of neuropathic pain: 2010 revision. European journal of neurology : the official journal of the European Federation of Neurological Societies 2010; 17(9): 1113-e88.

56. Younger J, McCue R, Mackey S. Pain outcomes: a brief review of instruments and techniques. Current pain and headache reports 2009; 13(1): 39-43.

57. Todd $\mathrm{KH}$. Clinical versus statistical significance in the assessment of pain relief. Annals of emergency medicine 1996; 27(4): 439-41.

58. Goransson LG, Herigstad A, Tjensvoll AB, Harboe E, Mellgren SI, Omdal R. Peripheral neuropathy in primary sjogren syndrome: a population-based study. Archives of neurology 2006; 63(11): 1612-5.

59. Brannagan TH, 3rd, Hays AP, Chin SS, et al. Small-fiber neuropathy/neuronopathy associated with celiac disease: skin biopsy findings. Archives of neurology 2005; 62(10): 1574-8.

60. Kelkar P, McDermott WR, Parry GJ. Sensory-predominant, painful, idiopathic neuropathy: inflammatory changes in sural nerves. Muscle \& nerve 2002; 26(3): 413-6.

61. Chamberlain JL, Pittock SJ, Oprescu AM, et al. Peripherin-lgG association with neurologic and endocrine autoimmunity. Journal of autoimmunity 2010; 34(4): 469-77.

62. Ferrari S, Morbin M, Nobile-Orazio E, et al. Antisulfatide polyneuropathy: antibody-mediated complement attack on peripheral myelin. Acta Neuropathol 1998; 96(6): 569-74.

63. Uceyler N, Kafke W, Riediger N, et al. Elevated proinflammatory cytokine expression in affected skin in small fiber neuropathy. Neurology 2010; 74(22): 1806-13.

64. Wakasugi D, Kato T, Gono T, et al. Extreme efficacy of intravenous immunoglobulin therapy for severe burning pain in a patient with small fiber neuropathy associated with primary Sjogren's syndrome. Mod Rheumatol 2009; 19(4): 437-40.

65. Goebel A. Immunoglobulin responsive chronic pain. J Clin Immunol 2010; 30 Suppl 1: S103-8.

66. de Greef BT, Geerts M, Hoeijmakers JG, Faber CG, Merkies IS. Intravenous immunoglobulin therapy for small fiber neuropathy: study protocol for a randomized controlled trial. Trials 2016; 17(1): 330.

67. Hughes RA, Donofrio P, Bril V, et al. Intravenous immune globulin (10\% caprylate-chromatography purified) for the treatment of chronic inflammatory demyelinating polyradiculoneuropathy (ICE study): a randomised placebo-controlled trial. Lancet neurology 2008; 7(2): 136-44.

68. Alam U, Jeziorska M, Petropoulos IN, et al. Diagnostic utility of corneal confocal microscopy and intraepidermal nerve fibre density in diabetic neuropathy. PloS one 2017; 12(7): e0180175.

69. Tavakoli M, Marshall A, Pitceathly R, et al. Corneal confocal microscopy: a novel means to detect nerve fibre damage in idiopathic small fibre neuropathy. Experimental neurology 2010; 223(1): 245-50.

70. Tavakoli M, Mitu-Pretorian M, Petropoulos IN, et al. Corneal confocal microscopy detects early nerve regeneration in diabetic neuropathy after simultaneous pancreas and kidney transplantation. Diabetes 2013; 62(1): 254-60.

71. Lauria G, Bakkers M, Schmitz C, et al. Intraepidermal nerve fiber density at the distal leg: a worldwide normative reference study. Journal of the peripheral nervous system : JPNS 2010; 15(3): 202-7.

72. Lauria G, Dacci $P$, Lombardi $R$, et al. Side and time variability of intraepidermal nerve fiber density. Neurology 2015; 84(23): 2368-71. 
73. Martina IS, van Koningsveld R, Schmitz PI, van der Meche FG, van Doorn PA. Measuring vibration threshold with a graduated tuning fork in normal aging and in patients with polyneuropathy. European Inflammatory Neuropathy Cause and Treatment (INCAT) group. Journal of neurology, neurosurgery, and psychiatry 1998; 65(5): 743-7.

74. Khoshnoodi MA, Truelove S, Burakgazi A, Hoke A, Mammen AL, Polydefkis M. Longitudinal Assessment of Small Fiber Neuropathy: Evidence of a Non-Length-Dependent Distal Axonopathy. JAMA Neurol 2016; 73(6): 684-90.

75. Provitera V, Gibbons CH, Wendelschafer-Crabb G, et al. The role of skin biopsy in differentiating smallfiber neuropathy from ganglionopathy. European journal of neurology : the official journal of the European Federation of Neurological Societies 2018; 25(6): 848-53.

76. McArthur JC, Stocks EA, Hauer P, Cornblath DR, Griffin JW. Epidermal nerve fiber density: normative reference range and diagnostic efficiency. Archives of neurology 1998; 55(12): 1513-20.

77. Umapathi T, Tan WL, Tan NC, Chan YH. Determinants of epidermal nerve fiber density in normal individuals. Muscle \& nerve 2006; 33(6): 742-6.

78. Tavakoli M, Hossain P, Malik RA. Clinical applications of corneal confocal microscopy. Clinical ophthalmology 2008; 2(2): 435-45.

79. Petropoulos IN, Manzoor T, Morgan P, et al. Repeatability of in vivo corneal confocal microscopy to quantify corneal nerve morphology. Cornea 2013; 32(5): e83-9.

80. Tavakoli M, Marshall A, Thompson L, et al. Corneal confocal microscopy: a novel noninvasive means to diagnose neuropathy in patients with Fabry disease. Muscle \& nerve 2009; 40(6): 976-84.

81. Gemignani F, Ferrari G, Vitetta F, Giovanelli M, Macaluso C, Marbini A. Non-length-dependent small fibre neuropathy. Confocal microscopy study of the corneal innervation. Journal of neurology, neurosurgery, and psychiatry 2010; 81(7): 731-3.

82. Apkarian AV, Bushnell MC, Treede RD, Zubieta JK. Human brain mechanisms of pain perception and regulation in health and disease. European journal of pain 2005; 9(4): 463-84.

83. Borsook D, Erpelding N, Becerra L. Losses and gains: chronic pain and altered brain morphology. Expert review of neurotherapeutics 2013; 13(11): 1221-34.

84. Seminowicz DA, Wideman TH, Naso L, et al. Effective treatment of chronic low back pain in humans reverses abnormal brain anatomy and function. The Journal of neuroscience : the official journal of the Society for Neuroscience 2011; 31(20): 7540-50.

85. Zhang SS, Wu W, Liu ZP, Huang GZ, Guo SG, Yang JM. Altered regional homogeneity in experimentally induced low back pain: a resting-state fMRI study. Journal of neuroengineering and rehabilitation 2014; 11: 115

86. Wang P, Du H, Chen N, et al. Regional homogeneity abnormalities in patients with tensiontype headache: a resting-state fMRI study. Neuroscience bulletin 2014.

87. Maleki N, Linnman C, Brawn J, Burstein R, Becerra L, Borsook D. Her versus his migraine: multiple sex differences in brain function and structure. Brain 2012; 135(Pt 8): 2546-59.

88. Smith SM, Dworkin RH, Turk DC, et al. The Potential Role of Sensory Testing, Skin Biopsy, and Functional Brain Imaging as Biomarkers in Chronic Pain Clinical Trials: IMMPACT Considerations. The journal of pain : official journal of the American Pain Society 2017; 18(7): 757-77.

89. Nicholson JK, Lindon JC. Systems biology: Metabonomics. Nature 2008; 455(7216): 1054-6.

90. Andersen HH, Duroux M, Gazerani P. MicroRNAs as modulators and biomarkers of inflammatory and neuropathic pain conditions. Neurobiology of disease 2014; 71: 159-68.

91. Calin GA, Croce CM. MicroRNA-cancer connection: the beginning of a new tale. Cancer research 2006; 66(15): 7390-4.

92. Vickers KC, Rye KA, Tabet F. MicroRNAs in the onset and development of cardiovascular disease. Clin Sci (Lond) 2014; 126(3): 183-94.

93. Abe M, Bonini NM. MicroRNAs and neurodegeneration: role and impact. Trends Cell Bio/ 2013; 23(1): 306.

94. Zhao J, Lee MC, Momin A, et al. Small RNAs control sodium channel expression, nociceptor excitability, and pain thresholds. The Journal of neuroscience : the official journal of the Society for Neuroscience 2010; 30(32): 10860-71. 
95. Chattopadhyay M, Zhou Z, Hao S, Mata M, Fink DJ. Reduction of voltage gated sodium channel protein in DRG by vector mediated miRNA reduces pain in rats with painful diabetic neuropathy. Molecular pain 2012; 8: 17.

96. Willemen HL, Huo XJ, Mao-Ying QL, Zijlstra J, Heijnen CJ, Kavelaars A. MicroRNA-124 as a novel treatment for persistent hyperalgesia. J Neuroinflammation 2012; 9: 143.

97. Orlova IA, Alexander GM, Qureshi RA, et al. MicroRNA modulation in complex regional pain syndrome. Journal of translational medicine 2011; 9: 195.

98. Bjersing JL, Lundborg C, Bokarewa MI, Mannerkorpi K. Profile of cerebrospinal microRNAs in fibromyalgia. PloS one 2013; 8(10): e78762.

99. Myers RR, Campana WM, Shubayev VI. The role of neuroinflammation in neuropathic pain: mechanisms and therapeutic targets. Drug discovery today 2006; 11(1-2): 8-20.

100. Zeng XY, Zhang Q, Wang J, Yu J, Han SP, Wang JY. Distinct role of tumor necrosis factor receptor subtypes 1 and 2 in the red nucleus in the development of neuropathic pain. Neurosci Lett 2014; 569: 43-8.

101. Xu J, E X, Liu H, et al. Tumor necrosis factor-alpha is a potential diagnostic biomarker for chronic neuropathic pain after spinal cord injury. Neurosci Lett 2015; 595: 30-4.

102. Empl M, Renaud S, Erne B, et al. TNF-alpha expression in painful and nonpainful neuropathies. Neurology 2001; 56(10): 1371-7.

103. Leung L, Cahill CM. TNF-alpha and neuropathic pain--a review. J Neuroinflammation 2010; 7: 27.

104. Lindenlaub T, Teuteberg P, Hartung T, Sommer C. Effects of neutralizing antibodies to TNF-alpha on painrelated behavior and nerve regeneration in mice with chronic constriction injury. Brain research 2000; 866(1-2): 15-22.

105. Sommer C, Lindenlaub T, Teuteberg P, Schafers M, Hartung T, Toyka KV. Anti-TNF-neutralizing antibodies reduce pain-related behavior in two different mouse models of painful mononeuropathy. Brain research 2001; 913(1): 86-9.

106. Serra J. Microneurography: towards a biomarker of spontaneous pain. Pain 2012; 153(10): $1989-90$.

107. Serra J, Bostock H, Sola R, et al. Microneurographic identification of spontaneous activity in C-nociceptors in neuropathic pain states in humans and rats. Pain 2012; 153(1): 42-55.

108. Swan AL, Mobasheri A, Allaway D, Liddell S, Bacardit J. Application of machine learning to proteomics data: classification and biomarker identification in postgenomics biology. OMICS 2013; 17(12): 595-610.

109. Lin E, Lane HY. Machine learning and systems genomics approaches for multi-omics data. Biomark Res 2017; 5: 2.

110. Brindle KM. Imaging metabolism with hyperpolarized (13)C-labeled cell substrates. J Am Chem Soc 2015; 137(20): 6418-27.

111. Gowda GA, Djukovic D. Overview of mass spectrometry-based metabolomics: opportunities and challenges. Methods Mol Biol 2014; 1198: 3-12.

112. Fiehn O. Metabolomics by Gas Chromatography-Mass Spectrometry: Combined Targeted and Untargeted Profiling. Curr Protoc Mol Biol 2016; 114: 304 1- 42.

113. Gika HG, Theodoridis GA, Plumb RS, Wilson ID. Current practice of liquid chromatography-mass spectrometry in metabolomics and metabonomics. J Pharm Biomed Anal 2014; 87: 12-25.

114. Clish CB. Metabolomics: an emerging but powerful tool for precision medicine. Cold Spring Harb Mol Case Stud 2015; 1(1): a000588.

115. Freeman OJ, Unwin RD, Dowsey AW, et al. Metabolic Dysfunction Is Restricted to the Sciatic Nerve in Experimental Diabetic Neuropathy. Diabetes 2016; 65(1): 228-38.

116. Zhang J, Yu C, Holgate ST, Reiss TF. Variability and lack of predictive ability of asthma end-points in clinical trials. The European respiratory journal 2002; 20(5): 1102-9.

117. Brouwer BA, Bakkers M, Hoeijmakers JG, Faber CG, Merkies IS. Improving assessment in small fiber neuropathy. Journal of the peripheral nervous system : JPNS 2015; 20(3): 333-40.

118. Vanhoutte EK, Faber CG, Merkies IS. [Statistical significance or clinical relevance?]. Nederlands tijdschrift voor geneeskunde 2010; 154: A2516.

119. Elwyn G, Frosch D, Thomson R, et al. Shared decision making: a model for clinical practice. J Gen Intern Med 2012; 27(10): 1361-7.

120. Elwyn G, Laitner S, Coulter A, Walker E, Watson P, Thomson R. Implementing shared decision making in the NHS. Bmj 2010; 341: c5146. 
121. Deber RB. Physicians in health care management: 8. The patient-physician partnership: decision making, problem solving and the desire to participate. CMAJ : Canadian Medical Association journal = journal de I'Association medicale canadienne 1994; 151(4): 423-7.

122. Frosch DL, Kaplan RM. Shared decision making in clinical medicine: past research and future directions. Am J Prev Med 1999; 17(4): 285-94.

123. Levine MN, Gafni A, Markham B, MacFarlane D. A bedside decision instrument to elicit a patient's preference concerning adjuvant chemotherapy for breast cancer. Annals of internal medicine 1992; 117(1): 53-8.

124. Spies CD, Schulz CM, Weiss-Gerlach E, et al. Preferences for shared decision making in chronic pain patients compared with patients during a premedication visit. Acta anaesthesiologica Scandinavica 2006; 50(8): 1019-26.

125. Flierler WJ, Nubling M, Kasper J, Heidegger T. Implementation of shared decision making in anaesthesia and its influence on patient satisfaction. Anaesthesia 2013; 68(7): 713-22.

126. van Griensven H, Moore AP, Hall V. Mixed methods research - the best of both worlds? Man Ther 2014; 19(5): 367-71.

127. Ostlund U, Kidd L, Wengstrom Y, Rowa-Dewar N. Combining qualitative and quantitative research within mixed method research designs: a methodological review. Int J Nurs Stud 2011; 48(3): 369-83.

128. Wicks P, Keininger DL, Massagli MP, et al. Perceived benefits of sharing health data between people with epilepsy on an online platform. Epilepsy \& behavior : E\&B 2012; 23(1): 16-23.

129. Cheng HT, Dauch JR, Hayes JM, Yanik BM, Feldman EL. Nerve growth factor/p38 signaling increases intraepidermal nerve fiber densities in painful neuropathy of type 2 diabetes. Neurobiology of disease 2012; 45(1): 280-7.

130. Dauch JR, Yanik BM, Hsieh W, Oh SS, Cheng HT. Neuron-astrocyte signaling network in spinal cord dorsal horn mediates painful neuropathy of type 2 diabetes. Glia 2012; 60(9): 1301-15.

131. Jack MM, Ryals JM, Wright DE. Characterisation of glyoxalase I in a streptozocin-induced mouse model of diabetes with painful and insensate neuropathy. Diabetologia 2011; 54(8): 2174-82.

132. Gregory NS, Harris AL, Robinson CR, Dougherty PM, Fuchs PN, Sluka KA. An overview of animal models of pain: disease models and outcome measures. The journal of pain : official journal of the American Pain Society 2013 ; 14(11): 1255-69.

133. James EL, Parkinson EK. Serum metabolomics in animal models and human disease. Curr Opin Clin Nutr Metab Care 2015; 18(5): 478-83.

134. Curtright A, Rosser M, Goh S, et al. Modeling nociception in zebrafish: a way forward for unbiased analgesic discovery. PloS one 2015; 10(1): e0116766.

135. Yang Y, Mis MA, Estacion M, Dib-Hajj SD, Waxman SG. NaV1.7 as a Pharmacogenomic Target for Pain: Moving Toward Precision Medicine. Trends Pharmacol Sci 2018; 39(3): 258-75.

136. Lampert A, Hains BC, Waxman SG. Upregulation of persistent and ramp sodium current in dorsal horn neurons after spinal cord injury. Exp Brain Res 2006; 174(4): 660-6.

137. Hains BC, Saab CY, Klein JP, Craner MJ, Waxman SG. Altered sodium channel expression in second-order spinal sensory neurons contributes to pain after peripheral nerve injury. The Journal of neuroscience : the official journal of the Society for Neuroscience 2004; 24(20): 4832-9.

138. Gasser A, Ho TS, Cheng X, et al. An ankyrinG-binding motif is necessary and sufficient for targeting Nav1.6 sodium channels to axon initial segments and nodes of Ranvier. The Journal of neuroscience : the official journal of the Society for Neuroscience 2012; 32(21): 7232-43.

139. Klein AH, Vyshnevska A, Hartke TV, et al. Sodium Channel Nav1.8 Underlies TTX-Resistant Axonal Action Potential Conduction in Somatosensory C-Fibers of Distal Cutaneous Nerves. The Journal of neuroscience : the official journal of the Society for Neuroscience 2017; 37(20): 5204-14.

140. Chen L, Huang J, Zhao P, et al. Conditional knockout of NaV1.6 in adult mice ameliorates neuropathic pain. Scientific reports 2018; 8(1): 3845.

141. Cregg R, Momin A, Rugiero F, Wood JN, Zhao J. Pain channelopathies. The Journal of physiology 2010; 588(Pt 11): 1897-904.

142. Lauria G, Ziegler D, Malik R, et al. The role of sodium channels in painful diabetic and idiopathic neuropathy. Current diabetes reports 2014; 14(10): 538. 
143. Wang D, Kim H, Wang XM, Dionne R. Genomic methods for clinical and translational pain research. Methods Mol Biol 2012; 851: 9-46.

144. Estacion M, Han C, Choi JS, et al. Intra- and interfamily phenotypic diversity in pain syndromes associated with a gain-of-function variant of NaV1.7. Molecular pain 2011; 7: 92.

145. Carelli V, Chan DC. Mitochondrial DNA: impacting central and peripheral nervous systems. Neuron 2014; 84(6): 1126-42.

146. Flatters SJ. The contribution of mitochondria to sensory processing and pain. Prog Mol Biol Trans/ Sci 2015; 131: 119-46.

147. Bennett GJ, Doyle T, Salvemini D. Mitotoxicity in distal symmetrical sensory peripheral neuropathies. Nature reviews Neurology 2014; 10(6): 326-36.

148. Persson AK, Kim I, Zhao P, Estacion M, Black JA, Waxman SG. Sodium channels contribute to degeneration of dorsal root ganglion neurites induced by mitochondrial dysfunction in an in vitro model of axonal injury. The Journal of neuroscience : the official journal of the Society for Neuroscience 2013; 33(49): 19250-61.

149. Estacion M, Vohra BP, Liu S, et al. Ca2+ toxicity due to reverse $\mathrm{Na}+\mathrm{Ca} 2+$ exchange contributes to degeneration of neurites of DRG neurons induced by a neuropathy-associated Nav1.7 mutation. Journal of neurophysiology 2015; 114(3): 1554-64.

150. Persson AK, Hoeijmakers JGJ, Estacion M, Black JA, Waxman SG. Sodium Channels, Mitochondria, and Axonal Degeneration in Peripheral Neuropathy. Trends Mol Med 2016; 22(5): 377-90.

151. Baloh RH. Mitochondrial dynamics and peripheral neuropathy. The Neuroscientist : a review journal bringing neurobiology, neurology and psychiatry 2008; 14(1): 12-8.

152. Pareyson D, Saveri P, Sagnelli A, Piscosquito G. Mitochondrial dynamics and inherited peripheral nerve diseases. Neurosci Lett 2015; 596: 66-77.

153. Liang L, Lutz BM, Bekker A, Tao YX. Epigenetic regulation of chronic pain. Epigenomics 2015; 7(2): 23545.

154. Descalzi G, Ikegami D, Ushijima T, Nestler EJ, Zachariou V, Narita M. Epigenetic mechanisms of chronic pain. Trends Neurosci 2015; 38(4): 237-46.

155. Zakrzewska JM, Palmer J, Morisset V, et al. Safety and efficacy of a Nav1.7 selective sodium channel blocker in patients with trigeminal neuralgia: a double-blind, placebo-controlled, randomised withdrawal phase 2a trial. Lancet neurology 2017; 16(4): 291-300.

156. Donnell AM, Collins S, Ali Z, et al. Efficacy of the Nav1.7 Blocker Pf-05089771 in A Randomised, PlaceboControlled, Double-Blind Clinical Study in Subjects with Painful Diabetic Peripheral Neuropathy. Pain 2018.

157. Zuliani V, Rapalli A, Patel MK, Rivara M. Sodium channel blockers: a patent review (2010 - 2014). Expert Opin Ther Pat 2015; 25(3): 279-90.

158. Sindrup SH, Holbech J, Demant D, Finnerup NB, Bach FW, Jensen TS. Impact of etiology and duration of pain on pharmacological treatment effects in painful polyneuropathy. European journal of pain 2017; 21(8): 1443-50.

159. Ko TM, Wong CS, Wu JY, Chen YT. Pharmacogenomics for personalized pain medicine. Acta Anaesthesiol Taiwan 2016; 54(1): 24-30.

160. Yang Y, Dib-Hajj SD, Zhang J, et al. Structural modelling and mutant cycle analysis predict pharmacoresponsiveness of a $\mathrm{Na}(\mathrm{V}) 1.7$ mutant channel. Nat Commun 2012; 3: 1186.

161. Yang Y, Adi T, Effraim PR, Chen L, Dib-Hajj SD, Waxman SG. Reverse pharmacogenomics: carbamazepine normalizes activation and attenuates thermal hyperexcitability of sensory neurons due to Nav 1.7 mutation I234T. British journal of pharmacology 2018; 175(12): 2261-71.

162. Geha P, Yang Y, Estacion M, et al. Pharmacotherapy for Pain in a Family With Inherited Erythromelalgia Guided by Genomic Analysis and Functional Profiling. JAMA Neurol 2016; 73(6): 659-67.

163. Hughes RA, Mehndiratta MM. Corticosteroids for chronic inflammatory demyelinating polyradiculoneuropathy. The Cochrane database of systematic reviews 2012; (8): CD002062.

164. Han Y, Zhang J, Chen N, He L, Zhou M, Zhu C. Corticosteroids for preventing postherpetic neuralgia. The Cochrane database of systematic reviews 2013; (3): CD005582.

165. Bradley WG, Verma A. Painful vasculitic neuropathy in HIV-1 infection: relief of pain with prednisone therapy. Neurology 1996; 47(6): 1446-51. 
166. Chessell IP, Dudley A, Billinton A. Biologics: the next generation of analgesic drugs? Drug discovery today 2012; 17(15-16): 875-9.

167. Bannwarth B, Kostine M. Biologics in the treatment of chronic pain: a new era of therapy? Clin Pharmacol Ther 2015; 97(2): 122-4.

168. Slangen R, Schaper NC, Faber CG, et al. Spinal cord stimulation and pain relief in painful diabetic peripheral neuropathy: a prospective two-center randomized controlled trial. Diabetes care 2014; 37(11): 3016-24.

169. Biurrun Manresa JA, Sorensen J, Andersen OK, Arendt-Nielsen L, Gerdle B. Dynamic Changes in Nociception and Pain Perception After Spinal Cord Stimulation in Chronic Neuropathic Pain Patients. The Clinical journal of pain 2015; 31(12): 1046-53.

170. Melzack R, Wall PD. Pain mechanisms: a new theory. Science 1965; 150(3699): 971-9.

171. Shirvalkar P, Veuthey TL, Dawes HE, Chang EF. Closed-Loop Deep Brain Stimulation for Refractory Chronic Pain. Front Comput Neurosci 2018; 12: 18.

172. Goudra B, Shah D, Balu G, et al. Repetitive Transcranial Magnetic Stimulation in Chronic Pain: A Metaanalysis. Anesth Essays Res 2017; 11(3): 751-7.

173. Velly AM, Mohit S. Epidemiology of pain and relation to psychiatric disorders. Prog Neuropsychopharmacol Biol Psychiatry 2017.

174. Lerman SF, Rudich Z, Brill S, Shalev H, Shahar G. Longitudinal associations between depression, anxiety, pain, and pain-related disability in chronic pain patients. Psychosom Med 2015; 77(3): 333-41.

175. Hilton L, Hempel S, Ewing BA, et al. Mindfulness Meditation for Chronic Pain: Systematic Review and Meta-analysis. Ann Behav Med 2017; 51(2): 199-213.

176. Macedo LG, Smeets RJ, Maher CG, Latimer J, McAuley JH. Graded activity and graded exposure for persistent nonspecific low back pain: a systematic review. Phys Ther 2010; 90(6): 860-79.

177. Lopez-de-Uralde-Villanueva I, Munoz-Garcia D, Gil-Martinez A, et al. A Systematic Review and MetaAnalysis on the Effectiveness of Graded Activity and Graded Exposure for Chronic Nonspecific Low Back Pain. Pain medicine 2016; 17(1): 172-88.

178. Dobek CE, Beynon ME, Bosma RL, Stroman PW. Music modulation of pain perception and pain-related activity in the brain, brain stem, and spinal cord: a functional magnetic resonance imaging study. The journal of pain : official journal of the American Pain Society 2014; 15(10): 1057-68.

179. Cepeda MS, Carr DB, Lau J, Alvarez H. Music for pain relief. The Cochrane database of systematic reviews 2006; (2): CD004843.

180. Heutink M, Post MW, Luthart $P$, et al. Long-term outcomes of a multidisciplinary cognitive behavioural programme for coping with chronic neuropathic spinal cord injury pain. J Rehabil Med 2014; 46(6): 5405.

181. Bulaj G. Combining non-pharmacological treatments with pharmacotherapies for neurological disorders: a unique interface of the brain, drug-device, and intellectual property. Front Neurol 2014; 5: 126. 



Dunnevezelneuropathie (DVN) is een aandoening waarbij pijn op de voorgrond staat. Dit is het gevolg van een beschadiging van de aller dunste zenuwvezels (dun-gemyeliniseerde $A \delta$-vezels en ongemyeliniseerde C-vezels), die normaal gesproken voor de registratie van pijn en temperatuur zorgen. Bij DVN ervaren patiënten neuropathische pijn, die meestal in de voeten begint. Daarnaast kan DVN ook autonome klachten veroorzaken, zoals duizeligheid, droge ogen, maag- en darmklachten en hartkloppingen. De combinatie van deze klachten leidt vaak tot een sterke verminderde kwaliteit van leven.

De diagnose DVN wordt gesteld op basis van typische klachten, in combinatie met een verlaagde intra-epidermale zenuwvezeldichtheid in het huidbiopt en/of een afwijkend temperatuurdrempelonderzoek. De behandeling is meestal symptomatisch, waarbij het vaak lastig is de neuropathische pijn onder controle te krijgen. Om meer specifieke behandelingen aan te kunnen bieden, met een hogere werkzaamheid en minder bijwerkingen, is meer kennis nodig omtrent de onderliggende pathofysiologische mechanismen en aandoeningen die geassocieerd zijn met DVN. Dit proefschrift geeft inzicht in de incidentie van onderliggende aandoeningen bij DVN in een grote groep patiënten met daarbij de mogelijke onderliggende mechanismen. Op basis hiervan zijn twee studies opgezet om een meer gerichte behandeling voor deze invaliderende aandoening te onderzoeken.

Hoofdstuk 1 is een introductie waarin algemene informatie over DVN wordt gegeven. De anatomie en functie van de perifere zenuwen wordt kort beschreven. Vervolgens worden de symptomen en de diagnose van DVN uitgelegd, zoals ook kort hierboven besproken is. In de literatuur worden verschillende aandoeningen in verband gebracht met DVN. Deze aandoeningen en in het bijzonder de rol van spanningsafhankelijke natriumkanalen worden besproken. Ten slotte wordt de huidige aanpak beschreven van diagnose tot de behandeling van neuropathische pijn.

\section{Geassocieerde aandoeningen bij DVN en pathofysiologische mechanismen}

DVN is een aandoening waarbij klachten ontstaan door beschadiging van de dunne zenuwvezels. Een patiënt beschreef het als: "vreselijke aandoening die sommige patiënten gek maakt vanwege de ondraaglijke, voortdurend aanhoudende pijn", waar vele anderen die lijden aan DVN zich in herkennen. De vraag is waarom specifiek deze dunne zenuwvezels beschadigd raken en wat het mogelijke onderliggende pathofysiologische mechanisme zou kunnen zijn. Er zijn diverse artikelen geschreven over onderliggende aandoeningen die gerelateerd zouden kunnen zijn aan DVN. Verschillende ziekten zijn genoemd als oorzaak van DVN, maar dit is meestal gebaseerd op kleine cohortstudies of casestudies zonder dat pathofysiologisch bewijs is geleverd over hoe dit leidt tot DVN. Voor een aantal aandoeningen die in de literatuur worden genoemd, zijn mogelijke behandelingen beschikbaar, wat het rechtvaardigt om patiënten met DVN op de aanwezigheid van deze aandoeningen te testen. Voor diagnostische testen moeten de lasten voor de patiënten en de bijbehorende kosten afwegen tegen de voordelen van een uitgebreide diagnostische aanpak.

Hoofdstuk 2 toont de nadelen van het standaard uitvoeren van aanvullende testen die weinig of geen toegevoegde waarde hebben. De ziekte van Fabry is een metabole ziekte die resulteert 
in een opeenstapeling van globotriaosylceramide (lyso-GB3) in verschillende cellen, waaronder cellen van het hart, de nieren, de huid en ook de zenuwen. Sommige patiënten met de ziekte van Fabry lijden aan brandende of schietende pijn in handen en voeten. In de literatuur wordt beschreven dat DVN een eerste symptoom van de ziekte van Fabry kan zijn. Aangezien de aandoening behandelbaar is, zou testen voor deze aandoening van belang kunnen zijn. In een groot cohort van patiënten $(n=725)$ met pure DVN (zonder beschadiging van de dikke zenuwvezels), hebben we bij niemand de ziekte van Fabry aan kunnen tonen. Deze bevinding suggereert dat pure DVN waarschijnlijk niet de eerste uiting van de ziekte van Fabry bij volwassen patiënten is, in tegenstelling tot wat er eerder in de literatuur werd vermeld. Screening op de ziekte van Fabry bij patiënten met DVN leidt tot hoge kosten voor de gezondheidszorg en kan zelfs verwarrende testresultaten opleveren bij een patiënt, wanneer bijvoorbeeld één van de diagnostische testen een twijfelachtige uitslag geeft en de rest goed is. Daarom concluderen we dat bij patiënten met pure DVN, zonder andere tekenen of symptomen van de ziekte van Fabry (zoals betrokkenheid van het hart, nieren of huidafwijkingen), de screening op de ziekte van Fabry kan worden weggelaten. Dit moet echter altijd met de grootste zorg worden besloten, aangezien het een behandelbare ziekte betreft. Het voorstel is om de patiënten die in de loop der tijd betrokkenheid van andere organen ontwikkelen opnieuw te evalueren en eventueel dan alsnog te testen.

Patiënten die naar ons centrum worden verwezen met het vermoeden van DVN, worden niet alleen getest op de ziekte van Fabry, maar ook op vele andere potentieel gerelateerde aandoeningen op basis van literatuuronderzoek (hoofdstuk 3). In het DVN-cohort ( $n=921$ ) waren de meest voorkomende aandoeningen: auto-immuunziekten (inclusief afwijkende immunologische laboratoriumuitslagen) bij 19\% van de patiënten, natriumkanaalmutaties (inclusief varianten met onzekere klinische betekenis, mogelijk pathogene, waarschijnlijk pathogene of pathogene varianten) bij 16,7\%, diabetes mellitus bij 7,7\%, gestoorde glucosetolerantie bij 9,7\% en vitamine B12-tekort bij 4,7\%. Al deze aandoeningen kwamen meer voor dan beschreven in de algemene Nederlandse bevolking. Hoewel bij sommige patiënten al voorafgaand aan de screening een aandoening aanwezig was die gerelateerd is aan DVN, werd alsnog bij $26,7 \%$ van deze patiënten een andere onderliggende aandoening aangetroffen.

Bovenstaande bevindingen zijn de eerste stap in het onderzoek naar de relatie tussen DVN en de meest voorkomende onderliggende aandoeningen. Meer onderzoek is nodig om kennis te verkrijgen over de mogelijke onderliggende pathofysiologische mechanismen. Dit kan uiteindelijk leiden tot meer gerichtere behandelingen, zoals besproken in hoofdstuk 5-7. Hoewel verschillende aandoeningen bij patiënten met DVN voorkomen, kon in het cohort van de studie bij 53\% van de patiënten geen onderliggende aandoening worden gevonden, wat overeenkomt met eerder gerapporteerde studies. De bevindingen van de studie laten ook zien dat, hoewel iemand misschien een ziekte heeft die kan bijdragen aan DVN (bijv. diabetes mellitus), een patiënt nog steeds moet worden onderzocht op andere onderliggende aandoeningen. 
Voor sommige van de bovengenoemde aandoeningen is al wat bekend over het pathofysiologisch mechanisme dat leidt tot beschadiging van dunne zenuwvezels.

- Diabetes mellitus (DM) is een van de bekendste onderliggende aandoeningen bij pijnlijke neuropathieën. Er wordt verondersteld dat hyperglycemie-gemedieerde superoxide-overproductie op verschillende manieren kan leiden tot microvasculaire complicaties. Maar ook andere werkingsmechanismen worden beschreven, zoals een toename van inflammatoire markers in de dorsale ganglia (DRG). Hoewel deze mechanismen kunnen verklaren hoe de dunne zenuwvezels beschadigd raken, het laat nog steeds enkele vragen onbeantwoord. Slechts een deel van de patiënten met DM ontwikkelt een pijnlijke neuropathie als een complicatie van de ziekte, terwijl anderen een niet-pijnlijke neuropathie ontwikkelen, en een ander deel helemaal geen neuropathie ontwikkelt. Bovendien treedt, naast neuropathische pijn, ook nociceptieve pijn op bij DM. Nociceptieve pijn is een gevolg van een beschadiging van weefsels, bijvoorbeeld vanwege een verminderde doorbloeding die de bloedvaten en weefsels beschadigt. Welke factoren zorgen voor de ontwikkeling van een pijnlijke neuropathie zijn grotendeels onbekend. Dit laat ook zien dat een aandoening mogelijk gerelateerd is aan DVN, maar dat het DVN mogelijk niet direct veroorzaakt.

- Natriumkanalen spelen een belangrijke rol bij neuropathische pijn. Het SCN9A-, SCN10A- en SCN11A-gen coderen respectievelijk voor de natriumkanalen Nav1.7, $\mathrm{Na}_{v} 1.8$ en Nav1.9, die voornamelijk tot uiting komen in de perifere zenuwen en de dorsale ganglioncellen. Gain-of-function-mutaties in deze genen werden gevonden bij ongeveer $15 \%$ in een DVN cohort en kunnen leiden tot een verhoogde frequentie van vuren en spontaan afvuren van de neuronen van de DRG. Deze veranderingen kunnen leiden tot een afname van de lengte van de zenuwen.

Hoewel de screening naar onderliggende aandoeningen bij patiënten met DVN zeer uitgebreid is, wordt bij de helft van de patiënten geen onderliggende aandoening gevonden. Bij deze patiënten is de oorzaak ondanks uitgebreid diagnostisch onderzoek nog steeds onbekend, wat idiopathische DVN genoemd wordt. Waarschijnlijk spelen bij deze groep patiënten voor nu nog onbekende interne en/of externe mechanismen een rol bij het ontstaan van schade aan de dunne zenuwvezels. Hierbij kan gedacht worden aan mutaties in andere genen of verstoringen in het axonaal transport.

\section{Behandeling van neuropathische pijn bij DVN}

Ongeveer 5-10\% van de algemene bevolking lijdt aan neuropathische pijn, die wordt veroorzaakt door een ziekte of beschadiging die het somatosensorische zenuwstelsel aantast. Patiënten met DVN lijden aan ondraaglijke neuropathische pijn, welke een negatieve invloed heeft op hun kwaliteit van leven. Daarom is een betere behandeling erg gewenst. Er zijn verschillende soorten medicijnen die worden gebruikt om de symptomen van DVN te verminderen, waaronder anticonvulsiva, antidepressiva, opiö̈den en lokale behandelingen. In hoofdstuk 4 worden de verschillende behandelingsmogelijkheden benoemd met hun bekende werkingsmechanismen, bijwerkingen en voorzorgsmaatregelen. Bij 19\% van de patiënten met DVN beginnen de klachten op een leeftijd van 65 jaar of ouder. Vooral bij ouderen is de 
behandeling van DVN uitdagender vanwege vaker voorkomende comorbiditeit en het gebruik van co-medicatie.

Hoewel verschillende medicijnen beschikbaar zijn voor de behandeling van neuropathische pijn heeft slechts $50 \%$ van de patiënten een pijnreductie van $50 \%$, waarbij daarnaast vaak vervelende bijwerkingen aanwezig zijn. Een van de redenen voor deze teleurstellende resultaten is dat de huidige medicijnen niet erg specifiek zijn en alleen worden gebruikt om de symptomen te verminderen, maar niet om de patiënten of de beschadiging van de dunne zenuwvezels te genezen. Daarom is er dringend behoefte aan nieuwe en meer gerichte behandelingsmogelijkheden.

Lacosamide is een medicijn dat wordt gebruikt bij de behandeling van epilepsie. Lacosamide werkt specifiek op het natriumkanaal $\mathrm{Na}_{v} 1.3, \mathrm{Na}_{v} 1.7$ en $\mathrm{Na}_{v} 1.8$. Naast de werking op deze specifieke natriumkanalen, bespaart lacosamide de kanalen met een normale activiteit en remt het alleen de overactieve zenuwen. Het bindt aan de kanalen met een langzame of snelgeïnactiveerde toestand. Lacosamide is nog niet eerder getest bij patiënten met DVN. In studies met pijnlijke diabetische neuropathie werd een vermindering van neuropathische pijn gevonden, hoewel deze resultaten niet heel overtuigend waren. In hoofdstuk 5, wordt de motivering en het ontwerp van de Lacosamide-Efficacy-' ${ }^{\prime}$-Safety in SFN (LENSS-studie) in detail uitgelegd.

De LENSS-studie was een gerandomiseerde, dubbel-geblindeerde, placebo-gecontroleerde cross-over studie. Het primaire doel van deze studie was om de werkzaamheid van lacosamide versus placebo te evalueren bij patiënten met SCN9A-geassocieerde DVN. Het primaire eindpunt om de werkzaamheid te testen, werd gedefinieerd als een daling van ten minste één punt op de numerieke beoordelingsschaal voor de dagelijkse pijnintensiteit (PI-NRS) ten opzichte van baseline. Het secundaire eindpunt om de werkzaamheid van lacosamide te testen, was een afname van ten minste 2 punten. Deze uitkomstmaten voor de werkzaamheid werden als zodanig gekozen op basis van de IMMPACT-aanbevelingen. Andere secundaire doelstellingen waren de beoordeling van de veiligheid en verdraagbaarheid van lacosamide en het effect van lacosamide versus placebo op autonome klachten, dagelijkse invloed van pijn op het slapen en de kwaliteit van leven.

Omdat SCN9A-geassocieerde DVN zeldzaam is, werd gekozen voor een cross-over design. Een ander voordeel van het cross-over design was dat de invloed van andere bijdragende factoren (bijvoorbeeld leeftijd en geslacht) kon worden verminderd, omdat elke patiënt zijn/haar eigen controle was. Dit is belangrijk omdat DVN een heterogene aandoening is. In de studie kregen patiënten tweemaal daags een dosering van $200 \mathrm{mg}$ lacosamide (en placebo in de andere behandelingsperiode). Deze dosering werd gekozen op basis van eerdere onderzoeken, waarbij werd aangetoond dat tweemaal daags $200 \mathrm{mg}$ lacosamide effectief was en de bijwerkingen aanvaardbaar waren. Daarentegen bleek dat een dosering van $100 \mathrm{mg}$ tweemaal daags minder effectief te zijn met weinig bijwerkingen en dat een dosering van $300 \mathrm{mg}$ tweemaal daags effectief was maar veel bijwerkingen veroorzaakte. De behandelingsperiode voor zowel lacosamide als placebo was acht weken. Dit werd gekozen vanwege het feit dat het pijnstillende effect van de medicatie enkele weken kan duren. 
In Hoofdstuk 6 worden de resultaten van de LENSS-studie beschreven. In totaal kregen 24 patiënten lacosamide en 23 van hen placebo. Bij 58,3\% nam de gemiddelde pijn af met tenminste 1 punt op de PI-NRS tijdens de lacosamide-periode, vergeleken met 21,7\% tijdens de placebo-periode. Een afname van de gemiddelde pijn van ten minste 2 punten op de PI-NRS werd gevonden bij 33,3\% van de patiënten in de lacosamide-periode en bij 8,7\% in de placeboperiode. Bovendien rapporteerde $33,3 \%$ in de lacosamidegroep dat hun algemene toestand verbeterde, versus 4,3\% in de placebogroep, gemeten met de Patients' Global Impression of Change (PGIC). Andere secundaire uitkomsten toonden aan dat er een significant positief effect was van lacosamide op de dagelijkse invloed van pijn op slaap en dat er een aanzienlijke afname van de oppervlakkige pijn was. Er was geen significante verbetering van de kwaliteit van leven of autonome symptomen. De meest voorkomende bijwerkingen van lacosamide waren duizeligheid $(41,7 \%)$, misselijkheid $(25,0 \%)$ en hoofdpijn $(25,0 \%)$, wat overeenkomt met de bekende gerapporteerde bijwerkingen van het medicijn; deze bijwerkingen werden als mild beschouwd. Deze bijwerkingen waren ook de meest frequente tijdens de placebo-periode (17,4\% voor alle drie de klachten). Bovendien was lacosamide veilig om te gebruiken.

De resultaten van deze studie zijn in overeenstemming met de klinische ervaring dat de huidige behandelingsmogelijkheden een 50\% vermindering van de klachten geven bij 50\% van de patiënten. Een groter effect werd verwacht, op basis van de theoretische achtergrond van het werkingsmechanisme van lacosamide op deze specifieke groep van patiënten. In onze studie konden patiënten voor het grootste deel hun eigen pijnmedicatie blijven gebruiken. Daarom zou het behandelingseffect van lacosamide misschien zelfs groter kunnen zijn bij patiënten die (nog) geen medicatie gebruiken. Of lacosamide ook effectief is bij DVN-patiënten zonder SCN9A-mutaties moet nog worden onderzocht.

Een vraag is of de juiste uitkomstmaat is gebruikt om de werkzaamheid van het medicijn te onderzoeken. Voor deze studie was het primaire eindpunt om de werkzaamheid te meten ten minste 1 punt afname van de gemiddelde pijn op de PI-NRS, gebaseerd op richtlijnen voor studies naar pijnlijke neuropathieën. Er zijn veel verschillende uitkomstmaten voor het meten van het effect op pijn, de 1-punts of 2-punts afname van pijn op de PI-NRS kan worden gebruikt, maar ook een vermindering van 30\% of 50\% ten opzichte van de baseline op de PI-NRS wordt vermeld. Deze schalen hebben als nadeel dat het ordinale maten zijn; de getallen die worden gegeven hebben dus geen numerieke waarde. Dat maakt rekenen met dergelijke getallen niet goed mogelijk. Bovendien weten we niet goed wat een klinisch relevant verschil is. Wanneer een pijnscore van een patiënt van een 8 naar een 7 gaat, betekent dat op zichzelf niets, omdat de patiënt zich nog steeds verschrikkelijk kan voelen. Of wat als de pijn van patiënten van 6 naar 5 gaat, maar ze voelen zich veel beter? Daarom moeten we ons meer richten op de klinische betekenis van de persoonlijk ervaring van patiënten, zoals gemeten met de PGIC, in plaats van onbelangrijke getallen of multidimensionele vragenlijsten te gebruiken.

In de LENSS-studie werd geen significant effect van lacosamide op de autonome symptomen gevonden. Een verklaring zou kunnen zijn dat de bijwerkingen die worden veroorzaakt door het gebruik van lacosamide het effect van lacosamide op de autonome symptomen maskeren, omdat ze vergelijkbaar zijn. Zo is duizeligheid bijvoorbeeld een autonome klacht, maar ook een bijwerking van lacosamide. De vragenlijst om autonome symptomen te registreren kan daarmee zijn beïnvloed door de aanwezigheid van vergelijkbare bijwerkingen. 
De invloed van dunnevezelneuropathie op de kwaliteit van leven van deze patiënten is eerder onderzocht. De sterkste verminderingen van de kwaliteit werden gevonden in de domeinen van fysieke rol van functioneren en lichaamspijn. Door de pijnintensiteit met lacosamide te verlagen, zou het te verwachten zijn dat de kwaliteit van leven toeneemt omdat de invloed van lichaamspijn op de kwaliteit van leven zou afnemen. In deze studie werd dit echter niet gevonden, zelfs niet in het pijndomein. Dit kon mogelijk verklaard kon worden doordat de studieperiode van 8 weken te kort was om een significante vermindering van de kwaliteit van leven op te merken.

Tot slot toonde de studie aan dat lacosamide een effectieve, veilige en goed te verdragen behandeling is voor SCN9A-geassocieerde DVN. Het onderzoek moet echter worden bevestigd in een groter cohort en bij patiënten zonder een SCN9A-variant voordat het gebruik van dit medicijn kan worden aanbevolen als algemene behandeling bij DVN.

De LENSS-studie is een voorbeeld van een onderzoek dat een geneesmiddel onderzoekt dat specifieker gericht is dan andere momenteel beschikbare behandelingsmogelijkheden voor DVN. Een gerichte aanpak is echter alleen mogelijk als het doelwit ook bekend is. Zoals eerder vermeld, worden bij een groot deel van de patiënten met DVN geen onderliggende aandoeningen gevonden. De vraag is echter: wat wat als er geen onderliggende aandoening wordt gevonden? Bij patiënten met DVN wordt een rol van het immuunsysteem gesuggereerd bij patiënten met geassocieerde aandoeningen zoals sarcoïdose, de ziekte van Sjögren en coeliakie. Ook de aanwezigheid van inflammatoire veranderingen, auto-antilichamen, en verhoogde cytokines, bieden ondersteuning voor de hypothese dat het immuunsysteem bij DVN een belangrijke rol speelt, zelfs bij afwezigheid van immuun-gemedieerde ziekten. Een aantal open-label studies, waarbij pijnlijke neuropathieën werden behandeld met intraveneuze immunoglobulinen (IVIg), tonen een aanzienlijke verlichting van de pijn. Dit heeft geleid tot het idee om IVIg als nieuwe behandelingsmethode bij DVN verder te onderzoeken.

Hoofdstuk 7 beschrijft de opzet van een gerandomiseerde, dubbel-geblindeerde, placebogecontroleerde, parallel studie waarin de werkzaamheid en veiligheid van intraveneuze immunoglobulinen (IVIg) wordt geëvalueerd bij patiënten met DVN. Het onderzoeksdesign is hetzelfde als van een belangrijke studie van IVIg bij de behandeling van patiënten met chronische inflammatoire demyeliniserende polyradiculoneuropathie (de ICE trial). In de studie wordt gestart met een oplaaddosering van IVIg van $2 \mathrm{~g} / \mathrm{kg}$ lichaamsgewicht gedurende 2-5 aaneengesloten dagen. Daarna krijgen patiënten elke drie weken een infuus met een onderhoudsdosering van $1 \mathrm{~g} / \mathrm{kg}$ lichaamsgewicht IVIg gedurende drie maanden. Daarna worden patiënten gedurende drie maanden gevolgd om het lange-termijneffect van IVIg op pijn te bepalen. Dit is de eerste gerandomiseerde klinische studie die de werkzaamheid, veiligheid en verdraagbaarheid van IVIg bij patiënten met idiopathische DVN zal onderzoeken. Patiënten die gerandomiseerd zijn voor placebo, krijgen hetzelfde behandelingsschema. Het onderzoek loopt momenteel en heeft als doel 60 patiënten te includeren. De primaire uitkomstmaat zal een 1-puntsdaling op de PI-NRS ten opzichte van baseline zijn. Secundaire uitkomsten zijn 2-puntsdalingen op de PI-NRS ten opzichte van baseline, de invloed van IVIg op autonome symptomen, dagelijkse invloed van pijn op slaap en kwaliteit van leven. Omdat al 
deze uitkomstmaten gebaseerd zijn op vragenlijsten, is ook een objectieve uitkomstmaat meegenomen, namelijk de cornea confocale microscopie. Dit is een techniek die het verlies van dunne zenuwvezels en de regeneratie van zenuwen in het hoornvlies kan meten. Deze techniek is uitvoerig onderzocht bij patiënten met diabetes mellitus. In deze studie zullen alleen patiënten met een afwijkend huidbiopt en zonder onderliggende aandoeningen (idiopathische DVN) worden onderzocht. Als aangetoond kan worden dat IVIg effectief is bij DVN, kan mogelijk ook meer inzicht worden verkregen om de onderliggende pathofysiologie te onderzoeken bij patiënten met idiopathische DVN.

In hoofdstuk 8 worden de resultaten van dit proefschrift ter discussie gesteld en aanbevelingen gedaan voor toekomstig onderzoek. 



\section{CHAPTER 10 VALORIZATION ADDENDUM}

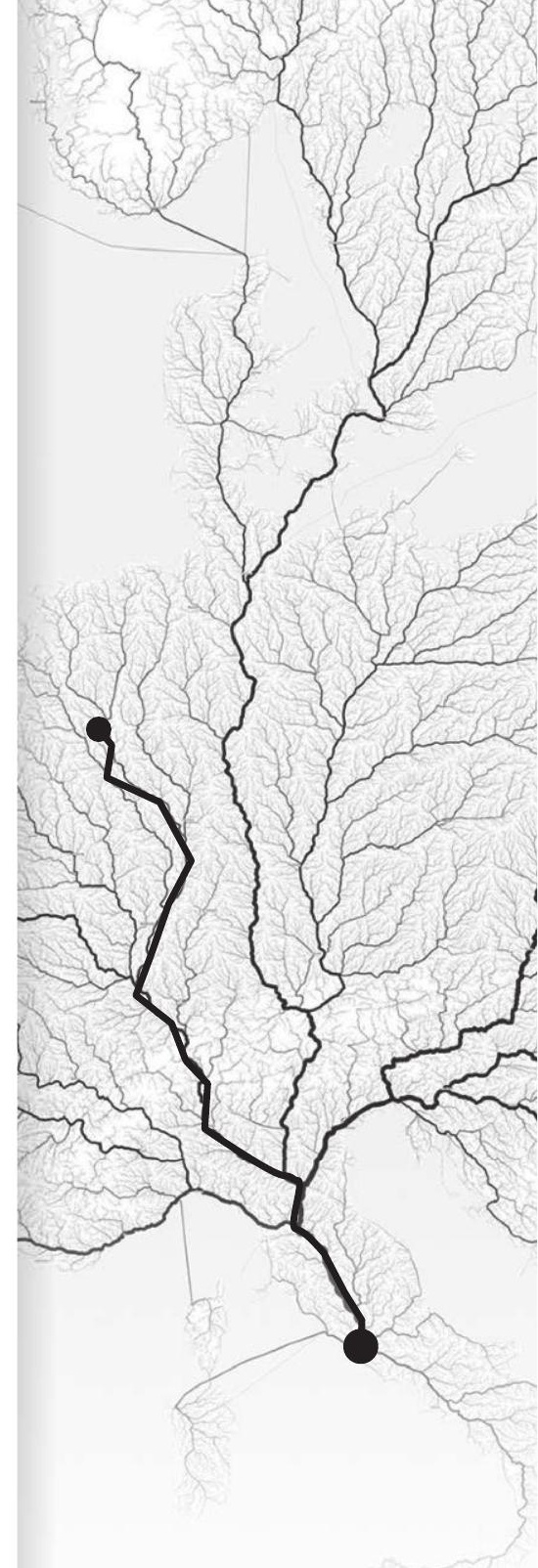



Valorization is the utilization of the scientific knowledge in practice and the act of making research results appropriate and useful in order to enhance opportunities for others to use them. ${ }^{1}$ It is a process with the aim to create societal impact in any way. This thesis provided more knowledge about the underlying conditions and possible treatments for patients with small fiber neuropathy (SFN). In this chapter I will discuss the clinical and societal relevance of these findings.

\section{Small fiber neuropathy}

Patients with SFN suffer from excruciating neuropathic pain and autonomic symptoms. The combination of complaints leads to a severe decrease in quality of life. ${ }^{2}$ Between 2006 and 2011, the overall minimum incidence was calculated to be 12 cases /100,000 inhabitants/year and the overall minimum prevalence of SFN was 53 cases $/ 100,000 .^{3}$ The last years, SFN has received more attention and recognition, possibly leading to higher incidence and prevalence numbers. Because many general practitioners and physicians still do not recognize the disorder, patients often visit multiple specialists to search for answers, and it usually takes a long time before the diagnosis is confirmed. SFN leads to substantial direct and indirect costs. ${ }^{4,5}$ For example, current available treatments only diminish the pain of $50 \%$ of the patients, with many side effects. This may lead to a long search for the right treatment per patient. Patients may be interested in the prognostic information that testing provides, even if it is not used to guide treatment. ${ }^{6}$ Establishing a diagnosis as explanation for unexplained pain may result in reassurance, acceptance, understanding, and more insight in their future perspectives. ${ }^{6}$ In contrast, not performing diagnostic testing may lead to a continued search for an explanation, with increased medical consumption, resulting in higher costs on the longer term (both medical and non-medical, e.g. absenteeism). An adequate diagnosis may also be relevant to patients in terms of self-management and positive health. ${ }^{7}$

\section{Associated conditions in SFN}

There are several studies reporting many different conditions to be associated with SFN. However, most of these studies lack evidence for the underlying pathophysiological mechanisms. The endless list of associated conditions mentioned in literature leads to a large number of diagnostic tests, often with low yield. A proper guideline is needed describing the tests that should be performed to cover the conditions that are associated with SFN. For such a guideline, knowledge about the prevalence of these diseases in SFN patients is needed. This thesis describes the negative and positive consequences of testing different conditions mentioned in literature. In some studies, it is claimed that SFN could be a first sign of Fabry disease. However, in a large cohort of patients with SFN, no patients were diagnosed with Fabry disease. The diagnostics for this condition included three different tests, which led to cases in which one of the test had a doubtful result, but the other two tests were negative. These results may lead to confusion within and between physicians, but even more to confusion and uncertainty for the patient. The costs of these diagnostic tests were high. On the other hand, Fabry disease is a treatable disease, which brings up an ethical dilemma when deciding not to test patients for this condition. As a follow-up to this study, we investigated the prevalence of other conditions based on a literature study in a large cohort of patients with SFN. With these 
results, we were able to generate recommendations for other physicians regarding additional testing in patients with SFN, like diabetes mellitus, glucose intolerance, vitamin B12 deficiency, immunological abnormalities, and sodium channel gene mutations. With this information, a physician can make a more evidence-based decision on required additional testing.

There is a growing interest in the hypothesis that early treatment might lead to less chronification of pain..$^{8,9}$ Additionally, screening might lead to early detection of an underlying condition, and the possibility to prevent further damage to the nerve fibers. If so, proper and early diagnostics are crucial. However, screening tests are only justified when benefits outweigh drawbacks. ${ }^{10}$ A physician should always make a decision based on the benefits for the patients on the one hand and the burden (physical and mental) and costs on the other hand.

New treatment possibilities for SFN

The results about the prevalence of underlying conditions in SFN also lead to new research questions. The underlying pathophysiological mechanisms are still largely unknown. Better understanding of the mechanisms may provide new targets for treatment, with a greater probability of pain reduction and less side effects, finally resulting in a better quality of life. This would also have a positive effect on reduction of health-related costs. ${ }^{4}$

Both the lacosamide (LENSS) study and the IVIg in SFN study are examples of studies that investigate the efficacy and safety of specific therapies in SFN, based on the mechanisms of action. Although already registered for the treatment of other conditions, both of these agents were never tested before in this specific group of patients.

The LENSS-study provided evidence for lacosamide being an effective treatment option for patients with SCN9A-associated SFN. Besides patients with SCN9A-associated SFN (in 8.5\% of all SFN patients), it is thought that also other patients, without a mutation, may benefit from sodium channel blockers, like lacosamide, because sodium channels play an important role in the generation and conduction of pain signals in the small nerve fibers. This hypothesis needs to be confirmed in a larger cohort of SFN patients without sodium channel gene mutation. At the moment, more selective sodium channel blockers are being tested in clinical studies.

The LENSS-study is an example of targeted treatment that is studied because of the discovery of the sodium channel gene mutations in SFN. ${ }^{11-13}$ However, in around $50 \%$ of the patients with SFN, no underlying condition can be found at screening, as presented in this thesis. In these cases, no targets for treatment are available. In the IVIg in SFN study, we treat idiopathic SFN patients with IVIg based on supposed immunological mechanism that might play a role in the development of SFN in general. In case the study proves that IVIg is effective in these patients, this may lead both to a new treatment possibility and a new mechanisms of action in SFN.

\section{Conclusion}

This thesis provides more knowledge about the underlying conditions associated with SFN. These results have led to recommendations for which underlying condition to test. This thesis also presents two treatment options with lacosamide and IVIg, also enabling us to gain further knowledge about the underlying mechanisms, and possibly leading to more targeted treatments in the near future. 


\section{References}

1. AWT. Valorisatiebeleid voor de Alfa- en Gammawetenschappen. Alfa en Gamma stralen 2007; (AWTrapport 70).

2. Bakkers M, Faber CG, Hoeijmakers JG, Lauria G, Merkies IS. Small fibers, large impact: quality of life in small-fiber neuropathy. Muscle \& nerve 2014; 49(3): 329-36.

3. Peters MJ, Bakkers M, Merkies IS, Hoeijmakers JG, van Raak EP, Faber CG. Incidence and prevalence of small-fiber neuropathy: a survey in the Netherlands. Neurology 2013; 81(15): 1356-60.

4. Schaefer C, Mann R, Sadosky A, et al. Health status, function, productivity, and costs among individuals with idiopathic painful peripheral neuropathy with small fiber involvement in the United States: results from a retrospective chart review and cross-sectional survey. J Med Econ 2014; 17(6): 394-407.

5. Schaefer C, Sadosky A, Mann R, et al. Pain severity and the economic burden of neuropathic pain in the United States: BEAT Neuropathic Pain Observational Study. ClinicoEconomics and outcomes research : CEOR 2014; 6: 483-96.

6. Asch DA, Patton JP, Hershey JC. Knowing for the sake of knowing: the value of prognostic information. Med Decis Making 1990; 10(1): 47-57.

7. Huber $M$, van Vliet $M$, Giezenberg $M$, et al. Towards a 'patient-centred' operationalisation of the new dynamic concept of health: a mixed methods study. BMJ open 2016; 6(1): e010091.

8. Pak DJ, Yong RJ, Kaye AD, Urman RD. Chronification of Pain: Mechanisms, Current Understanding, and Clinical Implications. Current pain and headache reports 2018; 22(2): 9.

9. Salvat E, Yalcin I, Muller A, Barrot M. A comparison of early and late treatments on allodynia and its chronification in experimental neuropathic pain. Molecular pain 2018; 14: 1744806917749683.

10. Wilson JM. Principles of screening for disease. Proc R Soc Med 1971; 64(12): 1255-6.

11. Faber CG, Hoeijmakers JG, Ahn HS, et al. Gain of function Nav1.7 mutations in idiopathic small fiber neuropathy. Annals of neurology 2012; 71(1): 26-39.

12. Faber CG, Lauria G, Merkies IS, et al. Gain-of-function Nav1.8 mutations in painful neuropathy. Proceedings of the National Academy of Sciences of the United States of America 2012; 109(47): 194449.

13. Huang J, Han C, Estacion M, et al. Gain-of-function mutations in sodium channel Na(v)1.9 in painful neuropathy. Brain 2014; 137(Pt 6): 1627-42. 


Zoals Johan Cruijff ooit zei: "alleen kun je niets, je moet het samen doen". Dit geldt zeker ook voor de totstandkoming van dit proefschrift. Niet alleen het onderzoeksteam en collega's hebben ervoor gezorgd dat ik sta waar ik nu sta, maar ook de dierbaren om me heen. Graag wil ik in dit hoofdstuk een aantal mensen in het bijzonder bedanken.

Allereerst gaat mijn dank uit naar het Prinses Beatrix Spierfonds en Spierziekten Nederland. Zonder de steun van het Prinses Beatrix Spierfonds had ik dit promotietraject niet kunnen doen en had de lacosamide studie niet uitgevoerd kunnen worden. Dank dat jullie, net als Spierziekten Nederland, zo voor de patiënten klaar staan en voor hun strijden om deze ziekte bekender te maken en onderzoeken te financieren. Ook jullie steun aan promovendi zelf is erg waardevol en het is erg bijzonder dat zelfs Koninklijke Hoogheid Prinses Beatrix ons persoonlijk een warm hart heeft toegedragen. Tevens gaat mijn dank uit naar de patiënten die hebben meegedaan aan de verschillende studies. Zonder jullie waren de resultaten van dit proefschrift er niet geweest. Dank voor jullie geduld, want helaas duurt onderzoek altijd net wat langer duren dan gepland. Ik hoop dat we in de toekomst nog meer vragen kunnen beantwoorden en betere behandelingsmogelijkheden hebben.

Mijn allergrootste dank gaat uit naar mijn promotieteam: prof. dr. C.G. Faber, dr. I.S.J. Merkies en dr. J.G.J. Hoeijmakers. Jullie ambities, enthousiasme en harde werken is uitzonderlijk. Bedankt voor de kansen die jullie me geven en hebben gegeven en jullie geloof in mij. Jullie zijn me altijd blijven steunen en hebben me de vrijheid gegeven om aan mezelf te werken en mijn eigen ambities te ontdekken. Zonder deze vrijheid en jullie vertrouwen had ik hier nu niet zo gestaan. Ik hoop dan ook dat ik nog lang onderdeel mag uitmaken van dit bijzondere team.

Beste Karin, jouw oneindige energie, vrolijkheid en optimisme is noemenswaardig. Daarnaast werkt het ook erg aanstekelijk. Toen ik na 3 maanden bij je binnen liep en mijn twijfels uitsprak over mijn toekomst als neuroloog, vertelde jij me dat ik op zoek moest naar hetgeen waar mijn hart lag. Een beter antwoord had je op dat moment niet kunnen geven. Ik wil je dan ook enorm bedanken voor het feit dat je me de ruimte hebt gegeven en me hebt geholpen mijn hart te volgen. Ik waardeer je openheid en de warmhartigheid die je uitstraalt naar iedereen om je heen. Ook dank voor alle borrels en heerlijke etentjes bij je thuis.

Beste Ingemar, vanaf onze eerste ontmoeting gingen onze gesprekken al snel over onderwerpen in de statistiek. Ik denk dat jij als een van de eersten doorhad dat ik erg blij werd van discussies omtrent wiskundige berekeningen. Deze passie is alleen maar sterker geworden en inmiddels denk ik dat een aardig weerwoord kan leveren in deze gesprekken. Ook heb je me een aantal levenslessen bijgebracht in de afgelopen jaren, waaraan ik mezelf zo af en toe weer even moet helpen herinneren. Ik hoop dat we onze dromen snel kunnen gaan najagen en de (onderzoeks-)wereld kunnen veroveren met onze ideeën.

Beste Janneke, wat was het een eer om jouw onderzoek te mogen voortzetten. Ik weet nog dat ik na een maand in dienst te zijn, ontzettend zenuwachtig was om bij jouw verdediging aanwezig te zijn. Dit moment zal ik niet meer vergeten. Vanaf toen wist ik dat ik een lange weg 
te gaan had, maar dat ik een ontzettend sterk en intelligent team om me heen had. Jij bent altijd een luisterend oor voor me, ook in periodes waarin ik me wat minder goed voelde. Hoewel sommigen vinden dat we samen veel te veel, te snel en van de hak op de tak springend praten, wij volgen elkaar perfect. Onze denkpatronen zijn soms angstaanjagend vergelijkbaar. Naast collega ben je ook een hele goede vriendin geworden bij wie ik mijn hart kan luchten. Ik hoop dat we nog lang samen mogen werken en we nog lang heel hard kunnen lachen om onze eigen grappen.

Dear prof. S.G. Waxman, Dr. S.D. Dib-Hajj, and your team of Yale University, thank you for all the support in our studies. Although there are many miles in between us, you always respond directly to our questions and inspire us with fantastic ideas concerning the role of sodium channels in painful neuropathies. I would also like to thank dr. G. Lauria and his team of the Carlo Besta institute in Milan for the great collaboration. I am honored to be involved in the PROPANE-study and PAIN-Net project.

Hartelijk dank aan de leden van de beoordelingscommissie, prof. dr. C.D. Dirksen, dr. M. Bakkers, prof. dr. W.H. Mess, dr. C. Verhamme en prof. dr. R.J. Vermeulen, voor jullie tijd en moeite om dit proefschrift te lezen en beoordelen.

Naast mijn promotieteam zou ik heel graag de rest van het neuromusculaire team willen bedanken voor hun eindeloze steun en hulp in de patiëntenzorg en het onderzoek.

Zonder Carla Gorissen-Brouwers zouden we nooit zoveel patiënten kunnen zien en konden we nooit al deze studies uitvoeren. Lieve Carla, als er iemand is bij wie het hart bij de patiënten ligt, ben jij het. Zowel bij dunnevezelneuropathie als myotone dystrofie zijn alle patiënten ontzettend blij met je, en terecht! Jij zal altijd alles aan de kant schuiven, inclusief jezelf, om nog ergens een patiënt tussen te plannen of te woord te staan. Maar niet alleen voor de patiënt sta je dag en nacht klaar, ook voor je collega's. Dank voor al je hulp bij het opzetten en bijhouden van de database. Maar vooral heel veel dank voor alle kopjes thee en uren die we samen kletsend hebben doorgebracht.

Na een lange zoektocht, was met name ík erg blij dat Maurice Sopacua zich bij ons team aansloot. Lieve Maurice, bedankt voor het overnemen van de PROPANE-studie en al het werk dat je hebt verricht. Dank voor het feit dat je altijd wilde inspringen als er iemand ziek was, ik met verlof ging of als we planningstechnisch niet uitkwamen. Het is bewonderenswaardig dat je alles deed zonder ook maar ooit geklaagd te hebben over de drukte.

Gedurende mijn promotietraject kwam Margot Geerts bij ons team en heeft zij me erg veel geholpen tijdens de uitvoering van de medicatiestudies. Lieve Margot, bedankt voor je hulp bij alle studies, niet alleen in het zien van de patiënten maar ook in de planning en registratie. Ik kan nog veel leren van jouw organisatievermogen. Onze sterke eigen meningen hebben de kwaliteit van het onderzoek alleen maar verbeterd. 
Natuurlijk wil ik ook alle anderen van het huidige onderzoeksteam bedanken. Mariëlle Pruppers, ik vond het een eer dat jij mijn eerste studente was, beter had ik het niet kunnen treffen en des te leuker dat je nog steeds in ons team bent. Brigitte Brouwer, dank voor je positiviteit en goede zorgen voor iedereen om je heen. Tim Draak, dank voor je rust en onze interessante brainstormen over Rasch-analyses en MCID. Isis Joosten, dank voor je enthousiasme en de inbreng van alle jonge plantjes in de kamer. Amir Far, een meer enthousiaste eerste promovendus om te begeleiden had ik me niet kunnen wensen. Karen Groot, Celine Goijen, Danielle Jeurissen-Bekkering en Romy Spee, dank voor jullie hulp bij alles en jullie gezelligheid in de kamer!

Daarnaast zou ik graag alle medewerkers van de afdeling neurologie met aan het hoofd prof. dr. R.J. van Oostenbrugge, inclusief de neurodaycare (afdeling C5), willen bedanken. Alle polimedewerkers van de neurologie, bedankt dat jullie altijd weer een kamertje vrij planden voor alle studiepatiënten. Ook dank aan het secretariaat van de neurologie, in het bijzonder Miranda Gerets, die alle telefoontjes heeft verwerkt en vragen omtrent studies bij de juiste persoon wist te krijgen. Speciaal mijn grote dank aan Charlotte van Hoegee en Edith Peeters die alle patiënten inplannen en zorgen dat alle onderzoeken gepland staan. Ook wanneer wij vragen of misschien nog één extra brief of vragenlijst bij de post kan, is dit nooit een probleem voor jullie. Ook dank aan de afdeling klinische neurofysiologie dat jullie zo flexibel zijn om alle onderzoeken op een dag te laten platsvinden. Tenslotte grote dank aan de afdeling pathologie, in het bijzonder Benoit Frere, Aline Kosten en Ilse Driesmans, voor het verwerken, kleuren en tellen van alle huidbiopten.

Daarnaast wil ik de afdeling Clinical Genomics en klinische genetica bedanken voor hun bijdrage aan de studies. Daarbij wil ik graag prof. dr. H.J.M. Smeets en dr. M.M. Gerrits in het bijzonder bedanken. Monique, bedankt dat we je op elk moment mogen lastigvallen met vragen omtrent uitslagen of over eigenschappen van een specifieke variant. Dank voor je kritische blik en bijdrage bij het schrijven van een artikel of uitvoeren van een onderzoek. En natuurlijk ook onze gezellige momenten tijdens besprekingen of congressen niet te vergeten, zoals het noodzakelijke winkeluitstapje met Rowida al Momani in Canada. Tevens wil ik ook graag Arthur van den Wijngaard en Linda Meekels bedanken voor hun bijdrage aan de diagnostische testen voor de ziekte van Fabry.

Beste collega's van de apotheek en het interne dagcentrum, dank voor al jullie inspanningen om de patiënten van de studies te voorzien van de juiste medicatie. Bedankt voor jullie acuut inspringen en geduld wanneer het nodig was. Maar bovenal dank voor de prettige samenwerking en hulp die jullie ons hebben geboden. En natuurlijk ook mijn dank aan de MIT voor de hulp bij de zoektocht naar de mooie oranje infuuslijnen.

Ook wil ik graag de collega's van het CTCM bedanken. In het bijzonder wil ik Chantalle Moors bedanken voor je oprechte interesse en hulp, Mathieu van Adrichem, voor je altijd snelle hulp bij de database en Valery Hellwig, Nadine Severins en Davina Jorissen die urenlang alle data hebben gecontroleerd, dank voor jullie bijdrage, oplettendheid en gezellige dagen. 
De afgelopen jaren voelde ik me ontzettend thuis bij de afdeling neurologie en bij het promotietraject wat ik aan het doen was. Echter kwam ik al snel tot de conclusie dat ik geen neuroloog wilde worden. Ik heb toen de vrijheid en mogelijkheid gekregen om mijn gevoel te volgen en een master in biostatistiek te gaan volgen naast mijn werk. Ik wil graag Prof. dr. C.D. Dirksen en Dr. S.M.J. van Kuijk bedanken. Beste Carmen en Sander, bedankt dat jullie mij een kans hebben gegeven om bij het KEMTA te komen werken ondanks mijn gebrek aan ervaring in de statistiek. Jullie en alle andere collega's van het KEMTA hebben ervoor gezorgd dat ik in een warm bad terecht kwam en me meteen thuis voelde. Sander, bedankt dat ik met al mijn vragen en twijfels bij je binnen kan lopen en we gesprekken kunnen hebben over onze gedeelde frustraties die de statistiek ook soms met zich meebrengt. Ik hoop nog lang met jullie te blijven werken.

De meeste uren heb ik tijdens mijn promotietraject doorgebracht op de onderzoekskamer. Lieve Debbie, Eleana, Ellen en Renske, dank voor jullie warme ontvangst en jullie hulp in de beginperiode van mijn promotietraject. Al snel bereidde het clubje zich uit, waarmee nog meer gezelligheid de kamer in kwam. Lieve Neuronols, Amir, Anne-France, Daniëlle, Danique, Eefje, Eleana, Eric, Fred, Irene, Isis, Judith, Mariëlle, Maurice, Renske, Robert-Jan, Sara, Sjors en Wouter, allen dank voor de leuke weekendjes weg, etentjes en afleiding van het werk (in positieve zin)! Ik zal de heerlijke tosti's en vervelende pomodoro's niet vergeten! Ook dank voor de interessante discussies, mede door jullie zal ik niet meer vergeten dat gapen een teken is van oververhitting van je hersenen maar je daarmee meteen kunt testen wie er van je houdt! Jullie hebben mijn promotietraject tot een onvergetelijke tijd gemaakt!

Tijdens de verdediging van mijn proefschrift zullen Jordi van Laarhoven en Luca Lammers mij bijstaan als paranimfen. Lieve Jordi, urenlang hebben wij op straat met onze fiets in ons hand gesprekken gevoerd over alles en niets. Inmiddels vinden deze gesprekken plaats als we uren in de auto zitten van het werk naar huis. Je hebt me altijd goede adviezen gegeven. En hoewel ik daar niet altijd meteen naar luisterde, bleef je me altijd steunen. Natuurlijk wist ik stiekem dat je gelijk had en luisterde ik wel degelijk! Lieve Luca, al een paar dagen na onze kennismaking gaf jij me onderdak na een heftige periode samen (de ontgroening). Het was mooi om dit samen mee te maken en hieruit is een mooie vriendschap ontstaan. Ons clubje is de jaren daarna uitgebreid tot een hechte groep vrienden. Jullie beide bezitten dezelfde eigenschappen die ik enorm bewonder, namelijk jullie rust, humor, doorzettingsvermogen, intelligentie en perfectionisme. Ik vind het een grote eer dat jullie op deze speciale dag achter me staan en ik hoop dat onze bijzondere vriendschap nog lang voort zal duren.

Lieve Mariska, Stephanie en Tessa, jullie mogen natuurlijk ook niet ontbreken! Dank voor alle heerlijke logeerpartijtjes waarbij we eindeloos spellen spelen, foute films kijken, genieten van lekker eten en elkaar bijpraten over alles wat we hebben meegemaakt. Ook al zien we elkaar niet vaak, de surprises, gedichten en met name de facebook-samenvattingen maken alles meteen weer vertrouwd. Dank voor jullie onvoorwaardelijke steun, ook in mindere tijden! 
Dit dankwoord zou niet compleet zijn zonder nog een aantal belangrijke mannen uit mijn leven te bedanken. Lieve Alain, Bas, Dennis, Joep, Jordi, Mark en Steven, dank voor alle stapavonden en borrelavondjes sinds de middelbare school! Hoeveel tijd er soms ook tussen zit, niemand van jullie zal dit ooit veroordelen. Het is altijd even gezellig, hoewel het nóg gezelliger wordt wanneer de karaoke-set aangaat! Ook al vond ik het een eer om een hele tijd als enige vrouw in jullie midden te mogen zijn, ben ik erg blij met jullie lieve vriendinnen. Lieve Anne-Marie, Maud, Sanne, Sanne en Suzan, met jullie erbij zijn de gesprekken wat vrouwvriendelijker geworden en is er alleen nog maar meer gezelligheid bijgekomen!

Lieve Kiki, dit boekje is voor jou. Er had hier een hele andere tekst moeten staan. Je was en blijft een groot voorbeeld voor me. Ik bewonderde je enthousiasme, vrolijkheid, assertiviteit, optimisme, doorzettingsvermogen en perfectionisme. Ik weet zeker dat jij net zo'n mooi boekje, maar waarschijnlijk een nog betere versie had gemaakt! Ik hoop zo dat je dit allemaal ziet en dat je trots bent. Ik zal onze reisjes, urenlange gesprekken, stapavonden en grappen echt nooit vergeten! Ik mis jou en Giuseppe nog elke dag en ik hoop, maar weet eigenlijk zeker, dat ik jullie voor altijd in mijn hart zal blijven voelen. Lieve Jos, Lian en Sjors, dit boekje is ook voor jullie. Ontzettend bedankt voor het contact en de band die we samen hebben, dit is een grote steun. Ik hoop jullie iets kleins terug te kunnen geven door jullie een onderdeel van mijn leven te maken. Ik bewonder jullie kracht en doorzettingsvermogen. Ik weet wel van wie Kiki dat had! Ik hoop dat we nog lang contact houden en jullie een beetje rust vinden.

Lieve Anne, Luca, Karen en Tomas. Roerige jaren hebben we meegemaakt maar we slaan ons samen overal doorheen. De vriendschap begon natuurlijk in Maastricht, maar verplaatste zich al snel richting Brabant (en inmiddels nog iets noordelijker). Hoe groot het gemis van Kiki en Giuseppe ook is, des te sterker zijn wij naar elkaar toegetrokken en voelen we hoeveel we voor elkaar betekenen. Dank voor alle gezellige etentjes, spelletjesavonden en dagjes/weekendjes weg. Ik hoop dat onze vriendschap nog heel lang voort mag duren.

Lieve pap en mam, zonder jullie steun en liefde was ik nooit gekomen waar ik nu ben. Jullie hebben me altijd meegegeven om te doen wat je hart je ingeeft, hoe eng of moeilijk dit soms ook is. Jullie staan altijd voor me klaar als ik weer eens een slaapplek na een feestje nodig heb, een bord eten of een oppas! Lieve Desirée en Robert, ook jullie wil ik bedanken voor jullie eindeloze steun. Ook al heb ik het jullie vroeger soms best lastig gemaakt, jullie staan altijd voor me klaar. Desirée, als ik persoonlijk advies nodig heb of een lunchgenoot of oppas zoek, weet ik dat je altijd mag bellen. Robert, als ik weer een langs de A2 sta, zijn jij en papa de eerste die ik bel om advies te vragen en daarna pas de ANWB. Het is een heel fijn maar ook bijzonder gevoel dat ik altijd op jullie kan rekenen. Lieve Niels en Salina, jullie hebben het maar getroffen met zo'n leuke partners, en wij met jullie! En hoe bijzonder dat de Roparun dit allemaal heeft veroorzaakt! Niels, jammer dat we nu niet meer kunnen winnen als we spelletjes spelen. Salina, dank voor je steun en goede invloed die je op mijn levensstijl hebt! 
Natuurlijk kan ik ook de familie Bertens niet genoeg bedanken. Lieve Monique, Wim, Matthijs, Thom en Linda, dank dat jullie mij met open armen hebben ontvangen. Ook bij jullie weet ik dat ik op iedereen kan rekenen als we hulp nodig hebben. Ook dank voor alle leuke dagjes en weekendjes weg, die voor veel ontspanning en plezier hebben gezorgd tijdens mijn promotietraject.

Lieve Nicky, wat ben jij een ongelofelijke steun voor me geweest de afgelopen jaren. Je maakt me altijd aan het lachen, ongeacht mijn humeur en altijd met dezelfde grap! Je bent de meest liefdevolle vader die ik me voor Sepp kan bedenken. 'Some heroes don't wear capes' slaat zeker op jou! Dank dat je me onvoorwaardelijk steunt, me mijn hart laat volgen en je nooit zult klagen als ik's avonds nog héél even mijn laptop pak! Ik zou nooit zonder je kunnen! Ik hoop dat we nog lang onze dromen achterna kunnen gaan, prachtige bestemmingen mogen bezoeken en genieten van ons gezin! Ik hou van je, 'to infinity and beyond'!

Lieve Sepp, kleine boef, ook al was de zwangerschap niet mals, het cliché is helemaal waar, je krijgt er zoiets moois voor terug. Door jou heb ik leren ontspannen en ben ik gaan inzien wat nu echt belangrijk is in het leven! Ik had nooit kunnen voorstellen hoeveel ik van je houd en hoe blij je me maakt. Ik hoop dat je altijd die sprankel in je ogen houdt en de wereld vol bewondering zal blijven ontdekken. Maar wil je alsjeblieft niet te snel groot worden? 




\section{CURRICULUM VITAE}

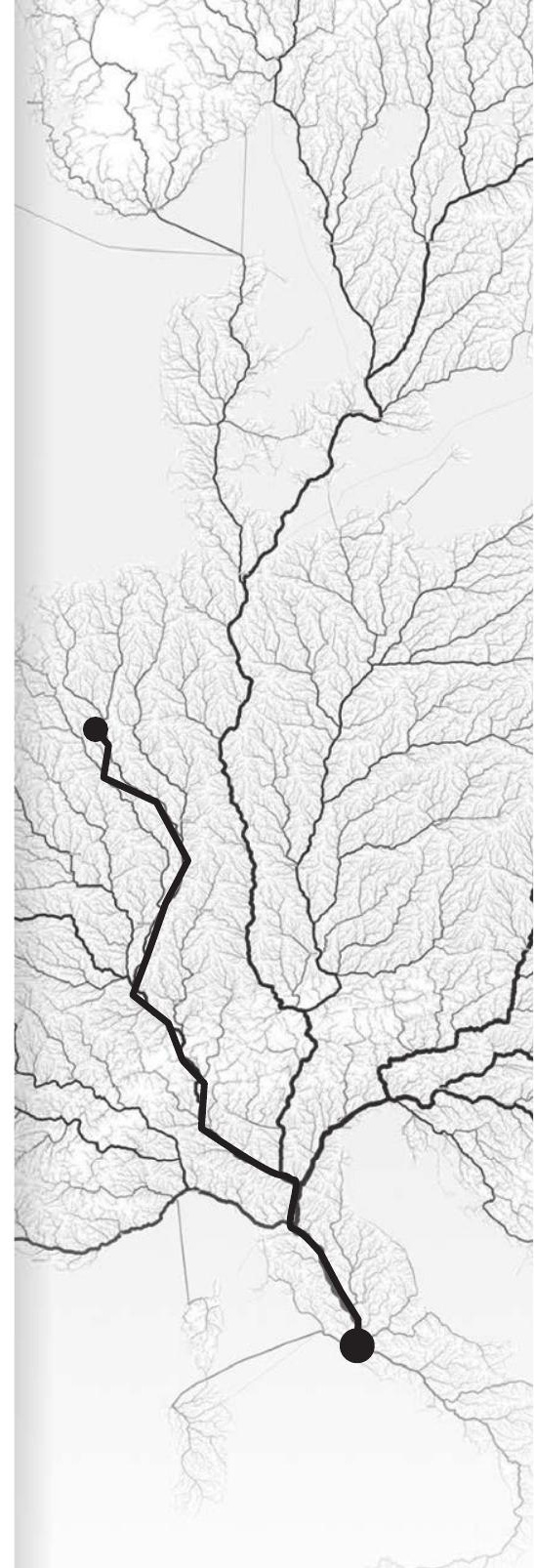





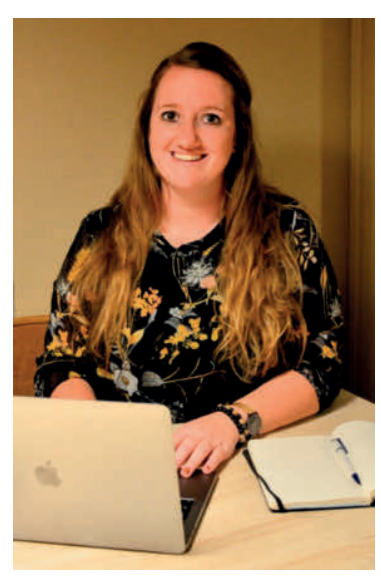

Bianca Theodora Andrea de Greef was born on the $24^{\text {th }}$ of March 1989 in Geldrop, the Netherlands. She graduated in 2007 from highschool (Gymnasium, Strabrecht College, Geldrop). In the same year she started studying Medicine at Maastricht University, where she graduated in 2013. During her studies she worked as a chairman and member of the travel committee, master committee, career day committee and cash audit committee of the study association M.S.V. Pulse and she worked as a junior triagist at the general practice center of South-East Brabant. She has also been a member of the athletes committee of the Marathon Eindhoven for many years and has volunteered in South Africa. After obtaining her medical degree, Bianca started working as a resident neurology at the Zuyderland Medical Center in Sittard (formerly Orbis Medical Center). In January 2014 she started working as a PhD student at the neurology department of the Maastricht University Medical Center+ (Maastricht UMC+). In September 2015, Bianca started a second master study in addition to her doctoral research, the master Biostatistics at the University of Hasselt, Belgium. In October 2017 she was nominated for the Pélerin Science Price from the Maastricht UMC+ for the results of the LENSS-study. Since February 2018, Bianca combined the completion of her thesis with a position as a consultant statistician at the Department of Clinical Epidemiology and Medical Technology Assessment (KEMTA) of the Maastricht UMC+.

Bianca Theodora Andrea de Greef werd geboren op 24 maart 1989 in Geldrop. In 2007 behaalde zij haar gymnasiumdiploma aan het Strabrecht College te Geldrop. In datzelfde jaar begon zij aan de studie Geneeskunde aan de Universiteit Maastricht, waar ze in 2013 afstudeerde. Tijdens haar studie is ze werkzaam geweest als voorzitter en lid van de reiscommissie, de mastercommissie, carrièredagcommissie en kascontrolecommissie van de studievereniging M.S.V. Pulse en werkte zij als junior triagist bij de huisartsenpost van ZuidOost Brabant. Tevens is ze naast haar studie jarenlang lid geweest van de atletencommissie van de Marathon Eindhoven en heeft ze vrijwilligerswerk gedaan in Zuid-Afrika. Na het behalen van haar artsexamen is Bianca als arts-assistent bij de neurologie gaan werken bij het Zuyderland Medisch Centrum te Sittard (voorheen Orbis Medisch Centrum). In januari 2014 startte ze haar promotietraject bij de afdeling neurologie van het Maastricht Universitair Medisch Centrum+ (Maastricht UMC+). In september 2015 is Bianca een tweede masterstudie gestart naast haar promotieonderzoek, de master Biostatistiek aan de Universiteit van Hasselt, België. In oktober 2017 werd ze genomineerd voor de Pélerin Wetenschapsprijs van het Maastricht UMC+ voor de resultaten van de LENSS-studie. Sinds februari 2018 combineerde Bianca de afronding van haar promotietraject met een functie als consultant statisticus bij de afdeling Klinische Epidemiologie en Medical Technology Assessment (KEMTA) van het Maastricht UMC+. 



\section{LIST OF PUBLICATIONS}

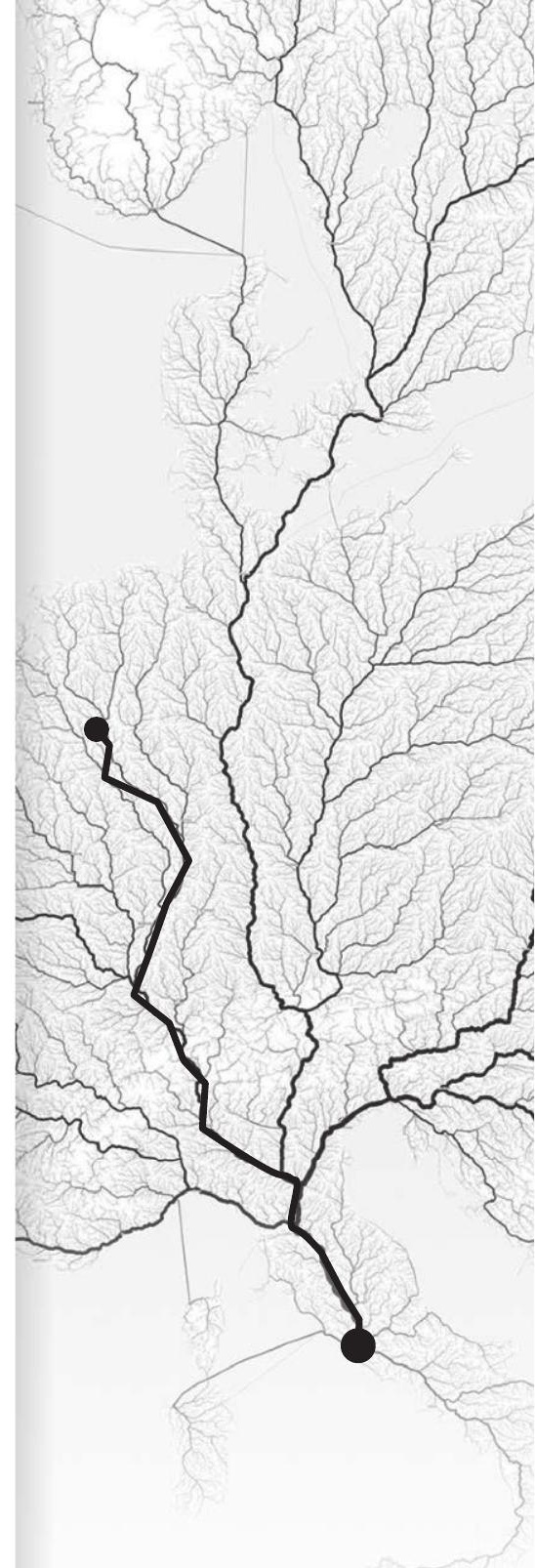



de Greef BTA, Hoeijmakers JGJ, Geerts M, Oakes M, Church TJE, Waxman SG, Dib-Hajj SD, Faber CG, Merkies ISJ. Lacosamide in patients with Nav1.7 mutations-related small fiber neuropathy: a randomized controlled trial. Brain 2019; in press.

Eijkenboom I, Sopacua M, Otten ABC, Gerrits MM, Hoeijmakers JGJ, Waxman SG, Lombardi R, Lauria G, Merkies ISJ, Smeets HJM, Faber CG, Vanoevelen JM, PROPANE Study Group. Expression of pathogenic SCN9A mutations in the zebrafish: A model to study small-fiber neuropathy. Exp Neurol. 2019;311:257-64.

Eijkenboom I, Sopacua M, Hoeijmakers JGJ, de Greef BTA, Lindsey P, Almomani R, Marchi M, Vanoevelen J, Smeets HJM, Waxman SG, Lauria G, Merkies ISJ, Faber CG, Gerrits MM. Yield of peripheral sodium channels gene screening in pure small fibre neuropathy. J Neurol Neurosurg Psychiatry 2018; in press.

de Greef BTA, Hoeijmakers JGJ, Gorissen-Brouwers CML, Geerts M, Faber CG, Merkies ISJ. Associated conditions in small fiber neuropathy - a large cohort study and review of the literature. European journal of neurology : the official journal of the European Federation of Neurological Societies 2018; 25(2): 348-55.

Claessens D, Bekelaar K, Schreuder FHBM, de Greef BTA, Vlooswijk MCG, Staals J, van Oostenbrugge RJ, Rouhl RPW. Mortality after primary intracerebral hemorrhage in relation to post-stroke seizures. Journal of neurology 2017; 264(9): 1885-91.

Kapetis D, Sassone J, Yang Y, Galbardi B, Xenakis MN, Westra RL, Szklarczyk R, Lindsey P, Faber CG, Gerrits M, Merkies IS, Dib-Hajj SD, Mantegazza M, Waxman SG, Lauria G, PROPANE Study Group. Network topology of Nav1.7 mutations in sodium channel-related painful disorders. BMC Syst Biol. 2017 Feb 24;11(1):28.

de Greef BTA, Geerts M, Hoeijmakers JGJ, Faber CG, Merkies ISJ. Intravenous immunoglobulin therapy for small fiber neuropathy: study protocol for a randomized controlled trial. Trials 2016; 17(1): 330.

de Greef BTA, Merkies ISJ, Geerts M, Faber CG, Hoeijmakers JGJ. Efficacy, safety, and tolerability of lacosamide in patients with gain-of-function Nav1.7 mutation-related small fiber neuropathy: study protocol of a randomized controlled trial-the LENSS study. Trials 2016; 17(1): 306.

de Greef BTA, Hoeijmakers JGJ, Wolters EE, Smeets HJ, van den Wijngaard A, Merkies ISJ, Faber CG, Gerrits MM. No Fabry Disease in Patients Presenting with Isolated Small Fiber Neuropathy. PloS one 2016; 11(2): e0148316. 
Brouwer BA, de Greef BTA, Hoeijmakers JGJ, Geerts M, van Kleef M, Merkies ISJ, Faber CG. Neuropathic Pain due to Small Fiber Neuropathy in Aging: Current Management and Future Prospects. Drugs \& aging 2015; 32(8): 611-21.

Han C, Yang Y, de Greef BTA, Hoeijmakers JGJ, Gerrits MM, Verhamme C, Qu J, Lauria G, Merkies ISJ, Faber CG, Dib-Hajj SD, Waxman SG. The Domain II S4-S5 Linker in Nav1.9: A Missense Mutation Enhances Activation, Impairs Fast Inactivation, and Produces Human Painful Neuropathy. Neuromolecular Med 2015; 17(2): 158-69.

de Greef BTA, Hoeijmakers JGJ, Brouwer BA, Gerrits MM, Merkies ISJ, Faber CG. Small fiber neuropathy and sodium channelopathy: unraveling a burning issue. Tijdschr Neurol Neurochir 2015;116:5-9.

de Greef BTA, Schreuder FHBM, Vlooswijk MCG, Schreuder AH, Rooyer FA, van Oostenbrugge RJ, Rouhl RPW. Early seizures after intracerebral hemorrhage predict drug-resistant epilepsy. Journal of neurology 2015; 262(3): 541-6. 

The cover of this thesis represents a map of Western Europe. The lines on this map reflect all kinds of routes that lead to Rome. "All roads lead to Rome" is an old proverb, as a metaphor for the infinite possibilities that exist to reach your goal.

This image is applicable to my thesis for different reasons. On the one hand because the roads on this map look very similar to the small nerve fibers that can be seen in a skin biopsy under a microscope. On the other hand, my dissertation describes that several disorders could lead to the development of one condition, namely small fiber neuropathy. Besides that, there are also several treatment options that can reduce the complaints associated with this condition.

In addition to the relationship with the content of my thesis, this image also represents a number of personal feelings. Personally, I have come to a point in my career, via a not entirely standard route, where I feel incredibly at home, happy, and enthusiastic. In my opinion, that is exactly what the proverb tries to say. Additionally, my partner and I have that same feeling about Italy (including Rome); ever since our first holiday together this country has felt like home and we will always keep coming back. Last but not least, there are two people who have a special place in my heart, with Italy also having a special place in their hearts.

For all this, this cover has become a small tribute to Italy, with its Rome! 